\title{
An Examination of Faying Surface Fretting in Single Lap Splices
}

By

\author{
Adam Brown, B.Eng. \\ A dissertation submitted to \\ the Faculty of Graduate Studies and Research \\ in partial fulfilment of the \\ requirements for the degree of \\ Doctor of Philosophy \\ Department of Mechanical and Aerospace Engineering \\ Ottawa-Carleton Institute of \\ Mechanical and Aerospace Engineering \\ Carleton University \\ Ottawa, Ontario
}

August 25, 2008

CAdam Brown, 2008 


$\begin{array}{ll}\begin{array}{l}\text { Library and } \\ \text { Archives Canada }\end{array} & \begin{array}{l}\text { Bibliothèque et } \\ \text { Archives Canada }\end{array} \\ \begin{array}{l}\text { Published Heritage } \\ \text { Branch }\end{array} & \begin{array}{l}\text { Direction du } \\ \text { Patrimoine de l'édition }\end{array} \\ \begin{array}{l}\text { 395 Wellington Street } \\ \text { Ottawa ON K1A 0N4 } \\ \text { Canada }\end{array} & \begin{array}{l}\text { 395, rue Wellington } \\ \text { Ottawa ON K1A 0N4 } \\ \text { Canada }\end{array}\end{array}$

Your file Votre référence ISBN: 978-0-494-43887-9 Our file Notre référence ISBN: 978-0-494-43887-9

NOTICE:

The author has granted a nonexclusive license allowing Library and Archives Canada to reproduce, publish, archive, preserve, conserve, communicate to the public by telecommunication or on the Internet, loan, distribute and sell theses worldwide, for commercial or noncommercial purposes, in microform, paper, electronic and/or any other formats.

The author retains copyright ownership and moral rights in this thesis. Neither the thesis nor substantial extracts from it may be printed or otherwise reproduced without the author's permission.
AVIS:

L'auteur a accordé une licence non exclusive permettant à la Bibliothèque et Archives Canada de reproduire, publier, archiver, sauvegarder, conserver, transmettre au public par télécommunication ou par l'Internet, prêter, distribuer et vendre des thèses partout dans le monde, à des fins commerciales ou autres, sur support microforme, papier, électronique et/ou autres formats.

L'auteur conserve la propriété du droit d'auteur et des droits moraux qui protège cette thèse. $\mathrm{Ni}$ la thèse ni des extraits substantiels de celle-ci ne doivent être imprimés ou autrement reproduits sans son autorisation.
In compliance with the Canadian Privacy Act some supporting forms may have been removed from this thesis.

While these forms may be included in the document page count, their removal does not represent any loss of content from the thesis.
Conformément à la loi canadienne sur la protection de la vie privée, quelques formulaires secondaires ont été enlevés de cette thèse.

Bien que ces formulaires aient inclus dans la pagination, il n'y aura aucun contenu manquant.

\section{Canada}




\begin{abstract}
While fretting damage in mechanically fastened joints is widely acknowledged as a common source of crack nucleation, little work is available in the open literature on the role that fretting damage plays in the fatigue life of a riveted joint. To expand on the limited knowledge available, a study was undertaken on fretting fatigue in thin-sheet riveted fuselage lap joints. In joints constructed out of $1 \mathrm{~mm}$ thick 2024-T3 aluminum sheet the rivet forming load was found to have a significant effect on the location of fretting damage and crack nucleation. This effect was observed for splices riveted with machine countersunk and with universal rivets. The shift in the location of peak fretting damage and crack nucleation with changing rivet forming loads was investigated through numerical and experimental methods.

A predictive model based on the critical plane Smith-Watson-Topper strain life equation was applied to the complex geometry of the single lap splice and was shown to be effective in predicting the fretting fatigue life as well as the location of fretting-induced crack nucleation. Basing this model on an explicit finite element simulation allowed for the inclusion of compressive residual stresses generated during rivet forming. Key to the proper functionality of the predictive model was to have a validated finite element model from which results for the stress and strain field in the loaded component could be obtained.
\end{abstract}


In addition to the predictive model, a series of splice coupon and simplified geometry fretting fatigue tests were performed. The tests showed that, at higher rivet forming loads, crack nucleation is on the faying surface away from the hole edge and that the type of surface condition is important to the fretting fatigue life of the splice. The discovery of this variation with surface treatment at high rivet forming loads is important as more research is showing the benefit of using load-controlled rivet forming and higher rivet forming loads in the manufacturing of lap splices to increase the fatigue life. 


\section{Acknowledgments}

With any piece of research comes the acknowledgement that the work is a result of contributions from many individuals who shared their knowledge, support, and time. There were many who assisted me in this work during my time at Carleton and I would like extend my gratitude.

I would first like to acknowledge the tremendous support from my supervisor, Paul Straznicky, who decided to take on hopeful, inexperienced undergrad as his graduate student. You taught me a great deal through your example and through our many discussions.

I would also like to thank and acknowledge the support staff at Carleton University who, with great patience, helped a naive student find his way through graduate school. From the MAE machine shop, Alex Proctor and Kevin Sangster provided endless advice and freedom to work in the shop. In the Structures Lab, Gary Clements and Fred Barrett were always there to provide help and I would especially like to thank Steve Truttman for his assistance and the stimulating conversation that helped the testing time pass. I must also acknowledge the wonderful work done by the Administrative staff: Marlene Groves, Nancy Powell, and Christie Egbert. You three always had answers when I needed them accompanied by warm greetings. I also cannot forget the tireless work done by Neil McFadyen who was always quick to respond to all of my computing needs. 
A special thanks goes out to the undergraduate students, Gewana Abdelmesih, Caroline $\mathrm{Li}$, and Jason Sarafian, who helped me in my work allowing me to focus on other tasks.

I must also give thanks to my fellow grad students who always kept life on and off campus entertaining.

Finally, I would like to thank my family for all of their support through my pursuit of a graduate degree. Always at the forefront of that support was my wife, Carolyn, without whom none of this would have been possible. 


\section{Table of Contents}

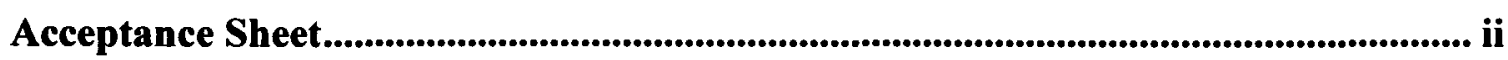

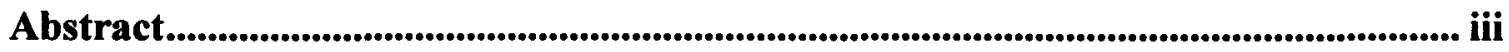

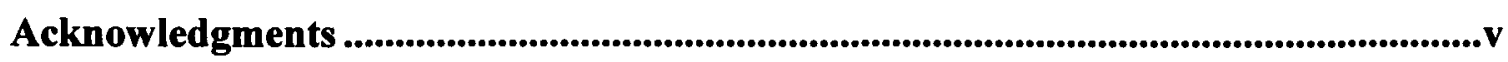

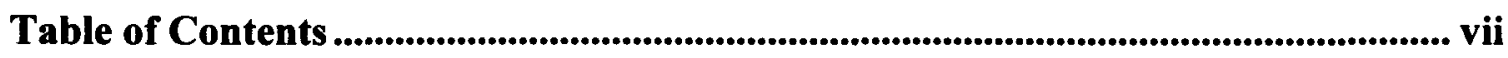

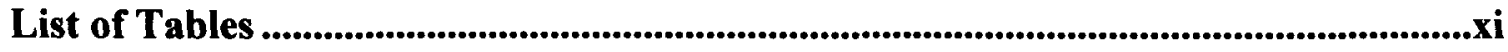

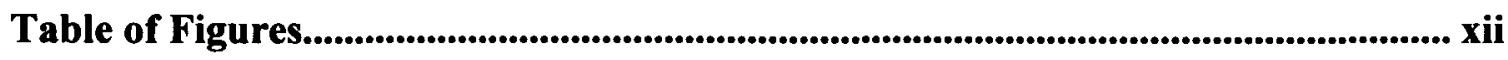

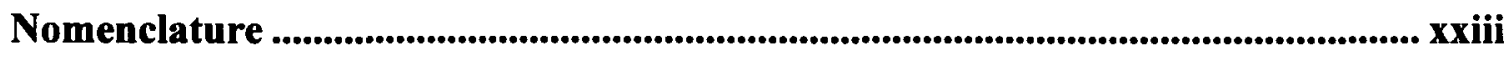

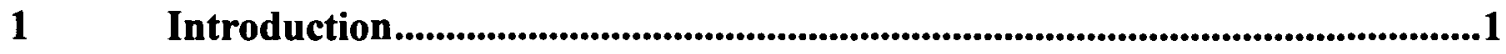

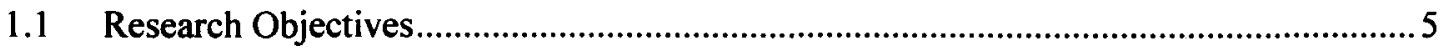

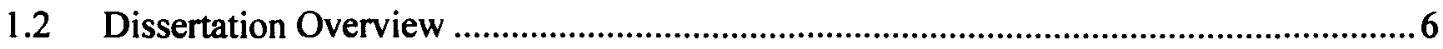

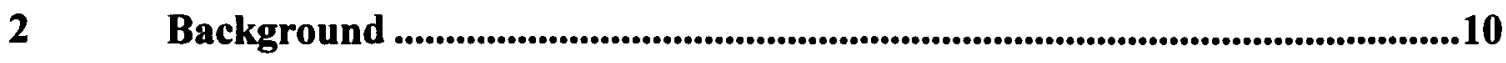

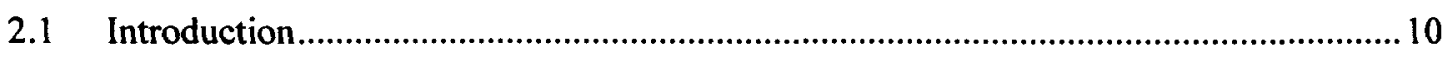

2.2 Riveted Lap Splice Construction ........................................................................ 10

2.2.1 Common Splice Designs .............................................................. 11

2.2.2 Splice Nomenclature ................................................................... 12

2.2.3 Solid Fasteners ............................................................................ 13

2.2.4 Methods of Countersinking ......................................................... 15

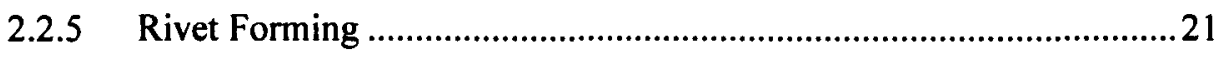

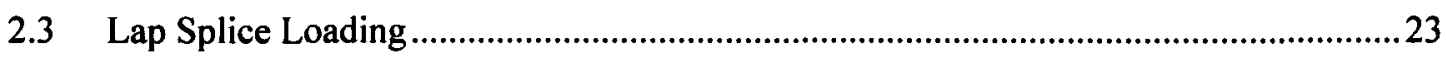

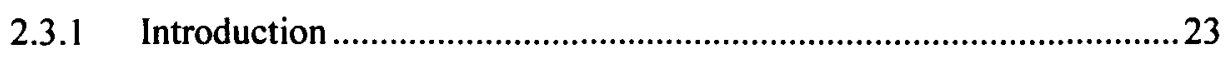

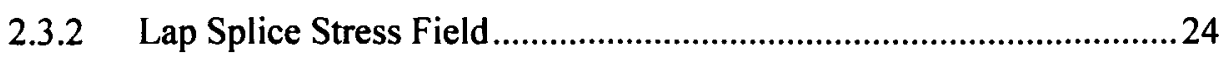




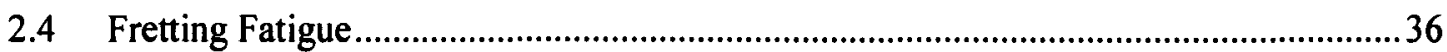

2.4.1 Predictive Life Models for Fretting..............................................42

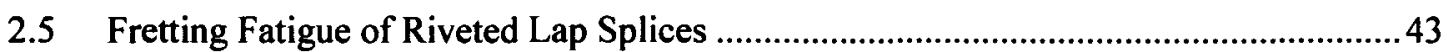

2.5.1 Finite Element Simulation of Fretting in Splices ............................. 45

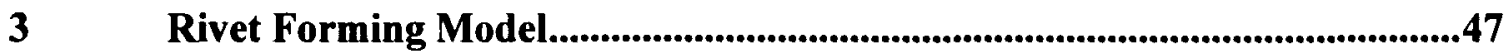

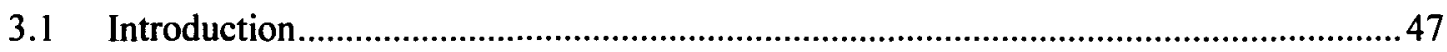

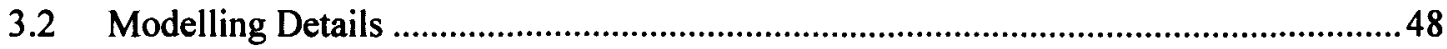

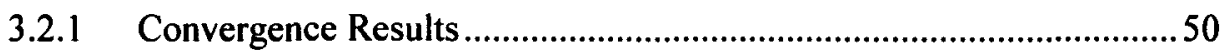

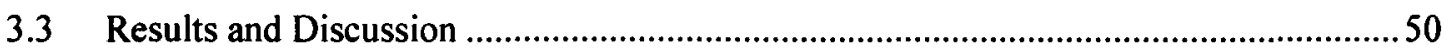

3.3.1 Residual Stress Results for Machine Countersunk Rivets ..................51

3.3.2 Residual Stress Results for Universal Rivets ..................................55

3.3.3 Sheet Clamping Results ..............................................................56

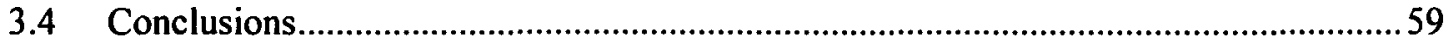

4 Simplified Fretting Contact Problem........................................................61

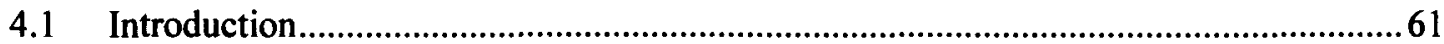

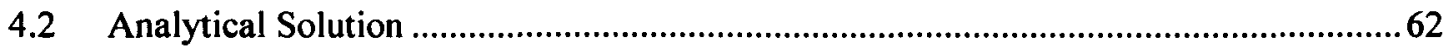

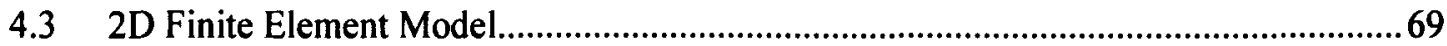

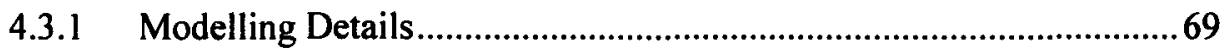

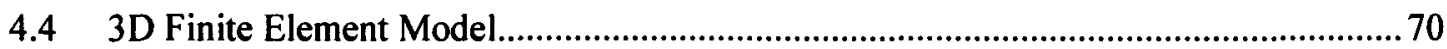

4.4.1 Sub-modelling ......................................................................... 71

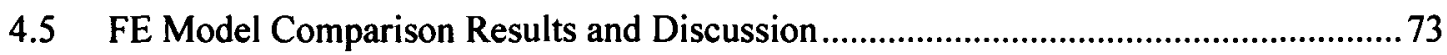

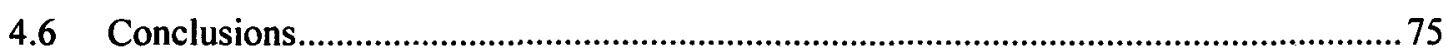

$5 \quad$ Lap Splice Finite Element Model ......................................................... 77

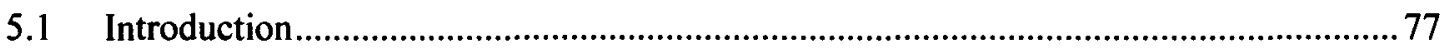

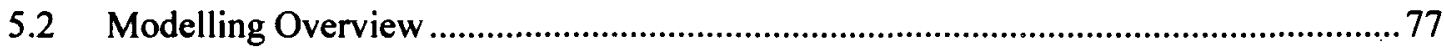

5.2.1 Modelling Details......................................................................... 77

5.2.2 Model Verification and Validation ..............................................81

6 Lap Splice Fretting Fatigue Prediction.............................................................94

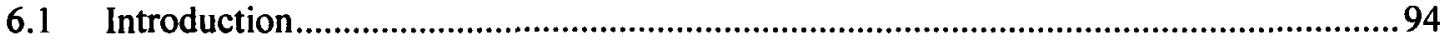

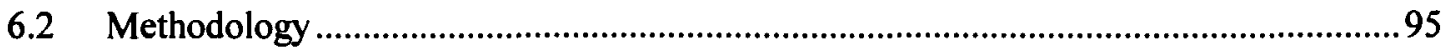

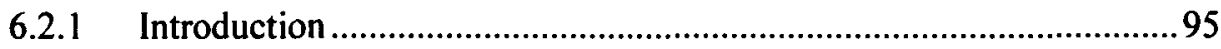




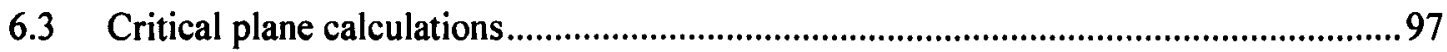

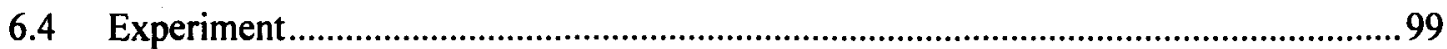

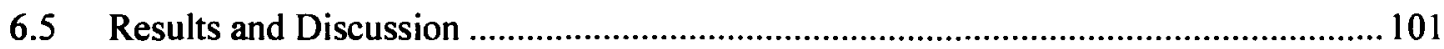

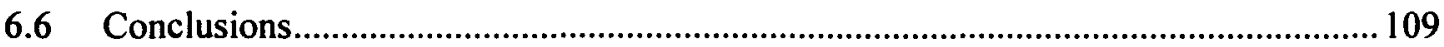

$7 \quad$ Effect of Surface Treatment on Fretting Fatigue Life...................................111

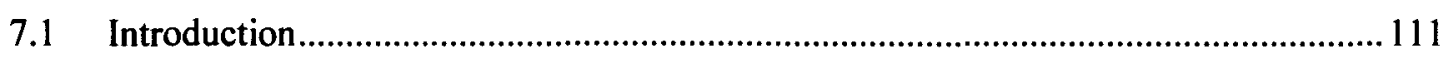

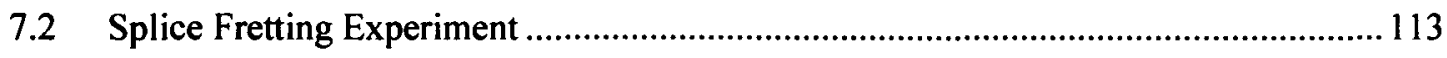

7.2.1 Experimental Set-up.................................................................113

7.2.2 Fatigue Life Results .............................................................. 113

7.2.3 Fretting Damage Results .........................................................116

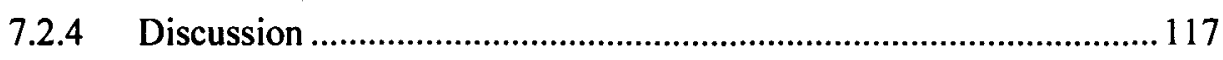

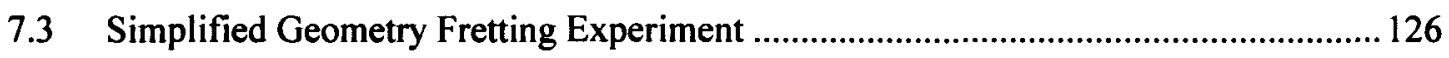

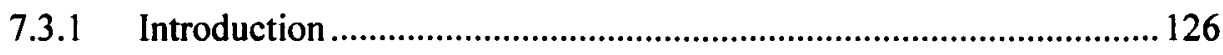

7.3.2 Design of Fretting Test Fixture .................................................... 129

7.3.3 Test Coupons.............................................................................. 134

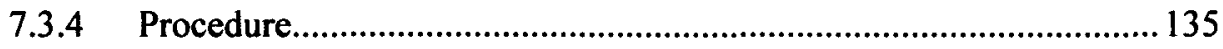

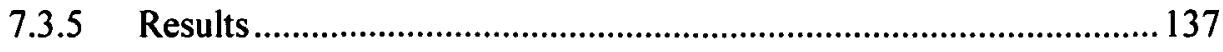

7.3.6 Discussion ................................................................................ 139

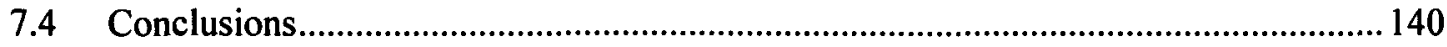

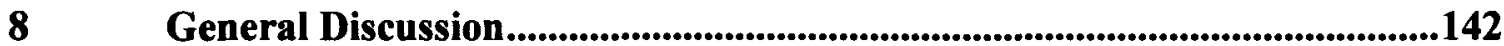

8.1 Predicting Faying Surface Fretting Fatigue in Lap Splices .................................... 142

8.1.1 Explicit Simulation of Fretting Contact ......................................... 143

8.1.2 SWT Critical Plane Predictive Method.......................................... 144

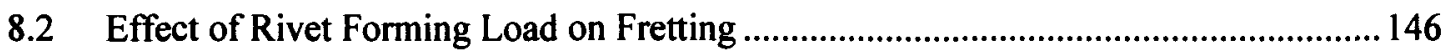

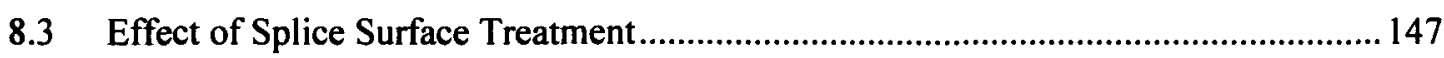

8.4 Faying Surface Fretting in Single Lap Splices..................................................... 149

9 Conclusions and Contribution Statement......................................................150

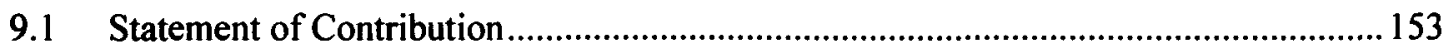


10 Future Work...................................................................................................154

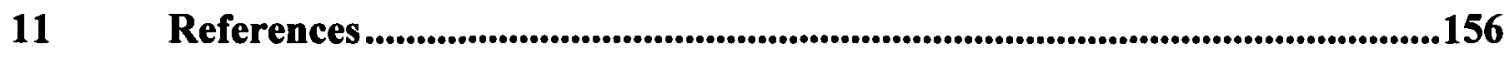

Appendix A - Splice Through-thickness Residual Stress .........................................160

Appendix B - Neutron Diffraction Measurements ............................................................169

Appendix C - Matlab Program for Critical Plane SWT Calculations ......................173

Appendix D - Fretting Fatigue Data ..................................................................176

Appendix E - Fretting Fatigue Coupon Photos ...........................................................185

Appendix F - Fretting Test Rig Design........................................................................192

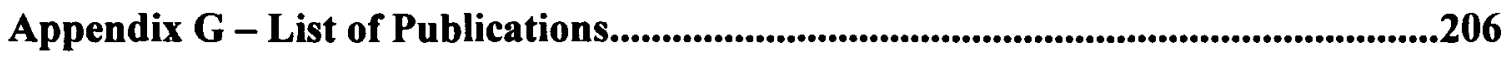




\section{LIST OF TABLES}

Table 2.1 Common material codes for aluminium alloy rivets................................................ 15

Table 3.1 Convergence results for universal rivet forming model........................................50

Table 4.1 Convergence results for 3D Mindlin sub-model analysis. $127 \mathrm{~mm}$ pad radius............. 72

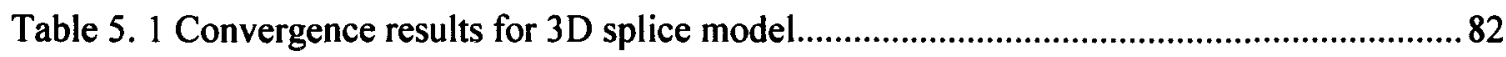

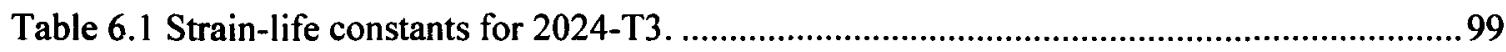

Table 6.2 Test matrix for riveted single lap splice coupons............................................... 101

Table 7. 1 Parameters for fretting test series...................................................................... 136

Table F- 1 Part list of components purchased for fretting carriage..........................................201 


\section{TABLE OF FIGURES}

Figure 1.1 Aloha airlines flight 243 with portion of upper fuselage missing..............................

Figure 1.2 Aloha airlines flight 243 with portion of upper fuselage missing (seats removed)....... 3

Figure 1.3 A single lap splice with multiple site damage (MSD). ..........................................

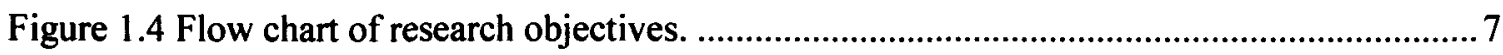

Figure 2.1 Comparison of fatigue lives for three basic splice designs [2] .............................. 12

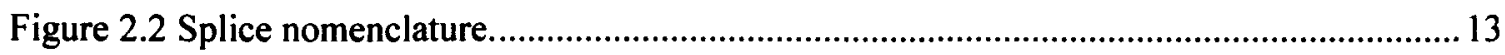

Figure 2.3 (a-f) Examples of common rivet styles................................................................. 14

Figure 2.4 Limits placed on cylindrical portion of hole and knife-edge condition..................... 16

Figure 2.5 Illustration of a conventional dimple tool set [6] ............................................... 18

Figure 2.6 Dimpled sheets with installed rivet: (a) coin dimpled sheets, (b) radius dimpled

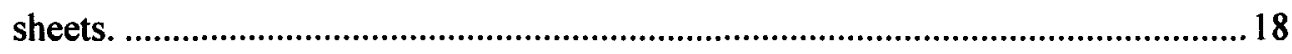

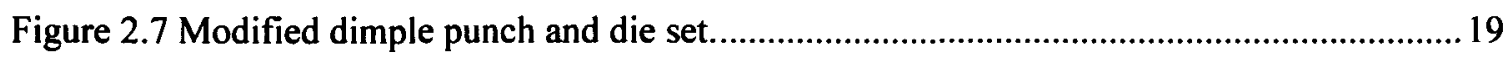

Figure 2.8 Machine countersunk and dimpled splice coupon fatigue results..............................20

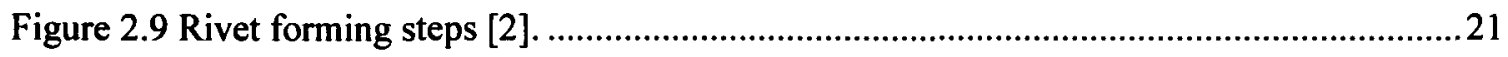

Figure 2.10 Measurable rivet dimensions for quality assurance ...............................................22

Figure 2.11 Example of a poorly formed, "dumped", rivet head..............................................22

Figure 2.12 Example of stresses on a fuselage lap splice for a single flight...............................23 
Figure 2.13 Stress state in an aircraft fuselage due to pressurization..........................................24

Figure 2.14 Components contributing to the stress field in a riveted lap splice...........................25

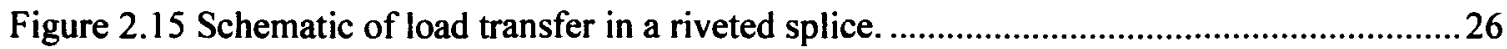

Figure 2.16 Percentage of load transfer through each rivet in a 3 rivet splice [2]. ......................28

Figure 2.17 Percentage of load transfer through each rivet in a 5 rivet splice [2] .......................29

Figure 2.18 Locations of maximum moments in a splice due to secondary bending [2].............29

Figure 2.19 Application of the neutral line model to a 3-rivet row splice. ...................................30

Figure 2.20 Secondary bending stress as a function of the applied stress in a three row

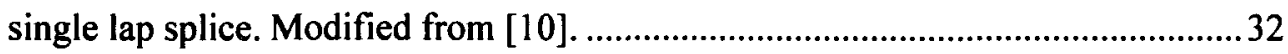

Figure 2.21 Plot relating hole expansion to the rivet squeeze force for three rivet material

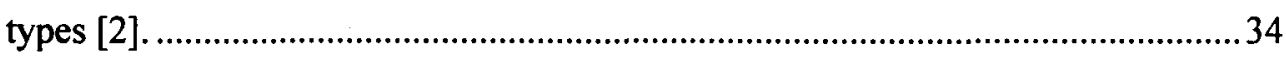

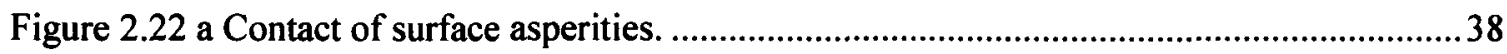

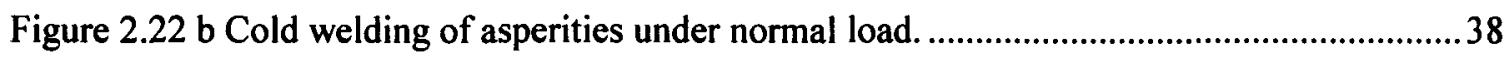

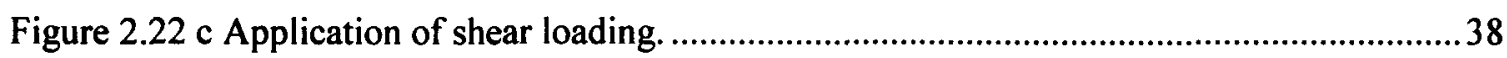

Figure $2.22 \mathrm{~d}$ Breaking of cold welds. Formation of debris..................................................... 38

Figure 2.22 e Reversal of loading. Re-establishing cold welds. ................................................ 38

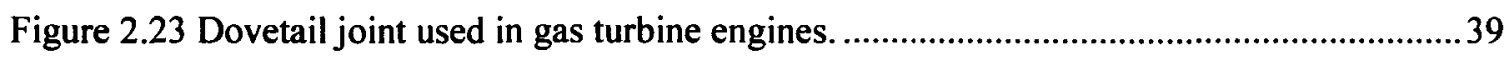

Figure 2.24 Schematic of an aero-engine spline coupling [21] .............................................40

Figure 2.25 Crack formed from region of fretting damage in an aero-engine spline coupling

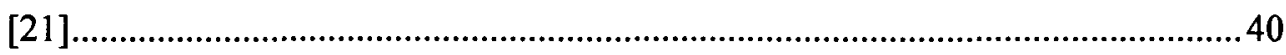

Figure 2.26 Schematic of total hip replacement prosthetic subject to fretting [22] .....................41

Figure 2.27 Line stress matching for notch analogy [24] ................................................ 42

Figure 2.28 Surface micro-cracks in a region of fretting damage. ...........................................44

Figure 2.29 Fretting damage on the sheet faying surface around a rivet hole..............................4 
Figure 3.1 Formed mesh and boundary conditions of countersunk rivet forming model. .48

Figure 3.2 Formed mesh and boundary conditions of universal rivet forming model. .49

Figure 3.3 Hoop residual stress through the outer sheet thickness. Machine countersunk rivets.

Figure 3.4 Radial residual stress through the outer sheet thickness. Machine countersunk rivets. 52

Figure 3.5 Hoop residual stress through the inner sheet thickness. Machine countersunk rivets. .53

Figure 3.6 Radial residual stress through the inner sheet thickness. Machine countersunk rivets. .53

Figure 3.7 Hoop residual stress through the outer sheet thickness. Universal rivets. .54

Figure 3.8 Radial residual stress through the outer sheet thickness. Universal rivets....................55

Figure 3.9 Hoop residual stress through the inner sheet thickness. Universal rivets. ...................55

Figure 3.10 Radial residual stress through the outer sheet thickness. Universal rivets.................56

Figure 3.11 Faying surface clamping pressure around a machine countersunk rivet hole.............57

Figure 3.12 Faying surface clamping pressure around a universal rivet hole.............................57

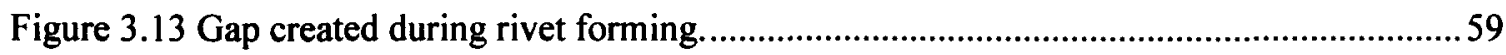

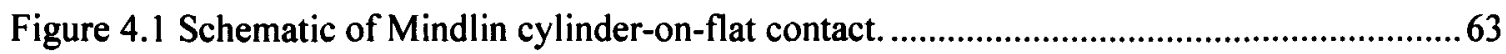

Figure 4.2 Normal and shear tractions as given by the Mindlin contact analytical solution..........66

Figure 4.3 Stress in the $\mathrm{x}$-direction along the surface of a plate in contact with a cylinder

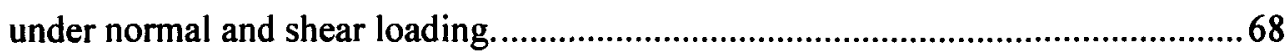

Figure 4.4 Mesh for 2D Mindlin contact problem. ........................................................ 70

Figure 4.5 Sub-modelling technique as applied to the 3D Mindlin contact problem................... 72

Figure 4.6 Comparison of normal stress and shear tractions for Mindlin - type contact...............73 


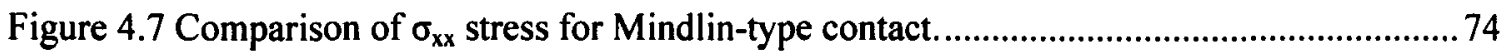

Figure 5.1 Splice coupon and FEM model geometry...........................................................

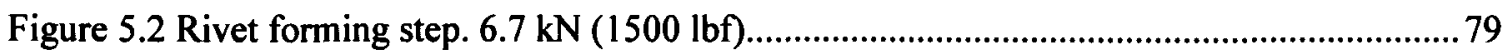

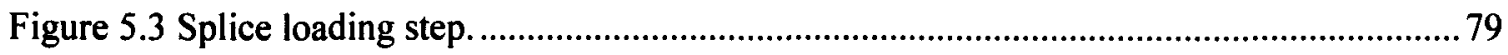

Figure 5.4 Illustration of sub-modelling technique applied to splice simulation.........................81

Figure 5.5 Locations for neutron diffraction residual stress measurements................................83

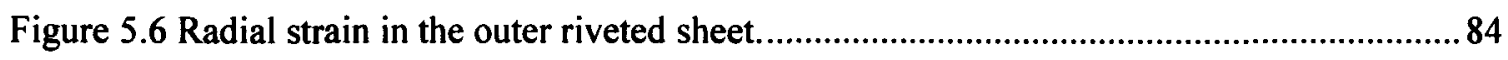

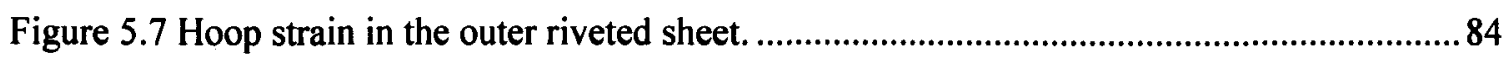

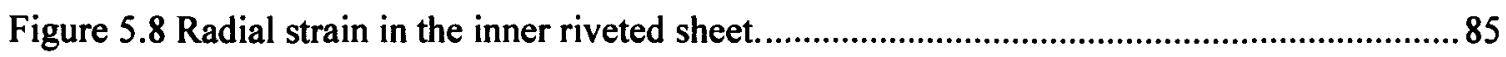

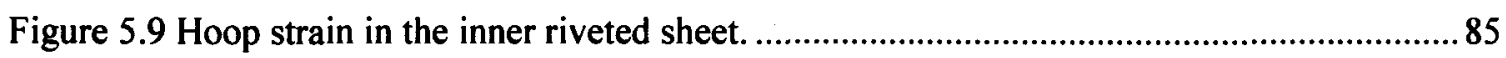

Figure 5.10 Placement of pressure sensitive film during hole drilling and rivet forming.............87

Figure 5.11 Pressure film imprint from $13.3 \mathrm{kN}$ (3000 lbf) rivet squeeze force case (top)

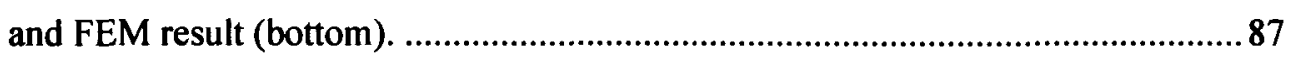

Figure 5.12 Countersunk rivet faying surface forming pressure measurement............................88

Figure 5.13 Universal rivet faying surface forming pressure measurement...................................88

Figure 5.14 FEM predicted contact area outline superimposed onto countersunk fretted

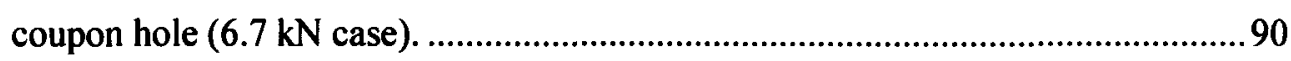

Figure 5.15 FEM predicted contact area outline superimposed onto countersunk fretted

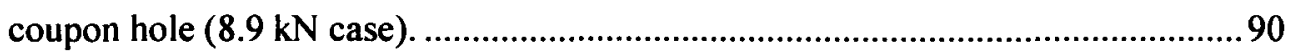

Figure 5.16 FEM predicted contact area outline superimposed onto countersunk fretted

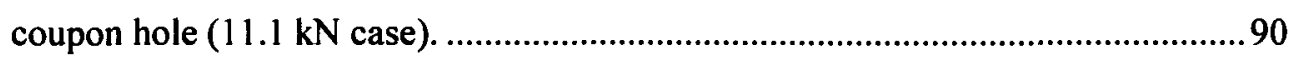

Figure 5.17 FEM predicted contact area outline superimposed onto countersunk fretted

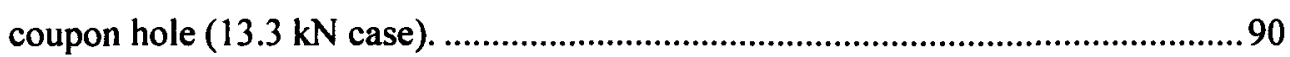


Figure 5.18 FEM predicted contact area outline superimposed onto universal fretted coupon hole $(6.7 \mathrm{kN}$ case $)$

Figure 5.19 FEM predicted contact area outline superimposed onto universal fretted coupon hole $(8.9 \mathrm{kN}$ case $)$

Figure 5.20 FEM predicted contact area outline superimposed onto universal fretted coupon hole $(11.1 \mathrm{kN}$ case $)$ 92

Figure 5.21 FEM predicted contact area outline superimposed onto universal fretted coupon hole $(13.3 \mathrm{kN}$ case $)$

Figure 6.1 Stress state at a node or integration point in an FE model. .98

Figure 6.2 Incremental stress transformations to find the maximum SWT parameter on the critical plane. .98

Figure 6.3 Geometry and nomenclature of test coupon splice. 100

Figure 6.4 Fretting fatigue life prediction for countersunk rivets.

Figure 6.5 Fretting fatigue life prediction for universal rivets. 103

Figure 6.6 Contour plot of SWT parameter with cracks from typical failed countersunk coupons superimposed. $6.7 \mathrm{kN}$ case. 105

Figure 6.7 Contour plot of SWT parameter with cracks from typical failed countersunk coupons superimposed. $8.9 \mathrm{kN}$ case.

Figure 6.8 Contour plot of SWT parameter with cracks from typical failed countersunk coupons superimposed. $11.1 \mathrm{kN}$ case. 106

Figure 6.9 Contour plot of SWT parameter with cracks from typical failed countersunk coupons superimposed. $13.3 \mathrm{kN}$ case.

Figure 6.10 Contour plot of SWT parameter with cracks from typical failed universal coupons superimposed. $6.7 \mathrm{kN}$ case. 
Figure 6.11 Contour plot of SWT parameter with cracks from typical failed universal coupons superimposed. $8.9 \mathrm{kN}$ case.

Figure 6.12 Contour plot of SWT parameter with cracks from typical failed universal coupons superimposed. $11.1 \mathrm{kN}$ case.

Figure 6.13 Contour plot of SWT parameter with cracks from typical failed universal coupons superimposed. $13.3 \mathrm{kN}$ case. 108

Figure 7.1 Fatigue life of countersunk riveted coupons with different surface treatments. 114

Figure 7.2 Fatigue life of universal riveted coupons with different surface treatments. 114

Figure 7.3 Countersunk rivet hole fretting damage. $11.1 \mathrm{kN}$ rivet forming load.. 117

Figure 7.4 Countersunk rivet hole fretting damage. $11.1 \mathrm{kN}$ rivet forming load. 117

Figure 7.5 Countersunk rivet hole fretting damage. $11.1 \mathrm{kN}$ rivet forming load. 117

Figure 7.6 Universal rivet hole fretting damage. $11.1 \mathrm{kN}$ rivet forming load.

Figure 7.7 Universal rivet hole fretting damage. $11.1 \mathrm{kN}$ rivet forming load.

Figure 7.8 Universal rivet hole fretting damage. $11.1 \mathrm{kN}$ rivet forming load.

Figure 7.9 Identifying peak secondary bending factor contour [8].

Figure 7.10 Superimposing peak SBF contour and peak critical plane SWT contour.

Figure 7.11 Peak SBF contour superimposed on critical plane SWT contour.

Figure 7.12 Peak SBF contour superimposed on critical plane SWT contour.

Figure 7.13 Peak SBF contour superimposed on critical plane SWT contour.

Figure 7.14 Peak SBF contour superimposed on critical plane SWT contour.

Figure 7.15 Peak SBF contour superimposed on critical plane SWT contour. 122

Figure 7.16 Peak SBF contour superimposed on critical plane SWT contour. 123

Figure 7.17 Peak SBF contour superimposed on critical plane SWT contour. 123

Figure 7.18 Peak SBF contour superimposed on critical plane SWT contour. 124 
Figure 7.19 Residual hoop stress distribution on the faying surface of a countersunk sheet...... 125

Figure 7.20 Residual hoop stress distribution on the faying surface of a universal sheet........... 126

Figure 7.21 Schematic of fretting test set-up using bridge-type pads [23].............................. 127

Figure 7.22 Schematic of Mindlin-type fretting fatigue test............................................... 128

Figure 7.23 Solid model representation of fretting test fixture. ............................................ 129

Figure 7.24 Physical realization of fretting test fixture..................................................... 130

Figure 7.25 Illustration of a skew misalignment between a fretting pad and coupon.................. 131

Figure 7.26 Illustration of a tilted misalignment between a fretting pad and coupon.................. 131

Figure 7.27 Carriage used to apply normal load to coupons in fretting test fixture....................132

Figure 7.28 LabVIEW front panel used to monitor the normal and shear loads on the

Mindlin-type coupons.

Figure 7.29 MTS Station Manager used to operate hydraulic test frame and monitor bulk

loads in the Mindlin-type coupons............................................................... 134

Figure 7.30 Fretting fatigue coupon and pad geometry. ..................................................... 135

Figure 7.31 Pressure film impression for Pad/coupon contact..................................................136

Figure 7.32 Fretting damage at edge of contact on pad after fretting test.................................136

Figure 7.33 Results of fretting fatigue tests for three different surface treatments. ................... 137

Figure 7.34 Fretting damage on pad from alclad coupon tests............................................... 138

Figure 7.35 Fretting damage on pad from bare coupon tests............................................. 138

Figure 7.36 Fretting damage on pad from anodized coupon tests........................................... 138

Figure 7.37 Fretting damage on pad from alclad coupon tests.................................................. 139

Figure 7.38 Fretting damage on pad from bare coupon tests. .............................................. 139

Figure 7.39 Fretting damage on pad from anodized coupon tests.......................................... 139

Figure 8.1 Example S-N curve showing fatigue trend in metals. Modified from [37].............. 145

xviii 
Figure A - 1 Outer sheet residual hoop stress (through thickness). Rivets formed to $6.7 \mathrm{kN}$...... 161

Figure A - 2 Outer sheet residual radial stress (through thickness). Rivets formed to $6.7 \mathrm{kN}$..... 161

Figure A - 3 Inner sheet residual hoop stress (through thickness). Rivets formed to $6.7 \mathrm{kN}$....... 161

Figure A - 4 Inner sheet residual radial stress (through thickness). Rivets formed to $6.7 \mathrm{kN} \ldots \ldots .161$

Figure A - 5 Outer sheet residual hoop stress (through thickness). Rivets formed to $8.9 \mathrm{kN}$..... 162

Figure A - 6 Outer sheet residual radial stress (through thickness). Rivets formed to $8.9 \mathrm{kN} \ldots . .162$

Figure A - 7 Inner sheet residual hoop stress (through thickness). Rivets formed to $8.9 \mathrm{kN} \ldots \ldots .162$

Figure A - 8 Inner sheet residual radial stress (through thickness). Rivets formed to $8.9 \mathrm{kN}$...... 162

Figure A - 9 Outer sheet residual hoop stress (through thickness). Rivets formed to $11.1 \mathrm{kN} \ldots 163$

Figure A - 10 Outer sheet residual radial stress (through thickness). Rivets formed to 11.1

$\mathrm{kN}$.

Figure A - 11 Inner sheet residual hoop stress (through thickness). Rivets formed to 11.1

$\mathrm{kN}$.

Figure A - 12 Inner sheet residual radial stress (through thickness). Rivets formed to 11.1

$k N$.

Figure A - 13 Outer sheet residual hoop stress (through thickness). Rivets formed to 13.3

kN. 164

Figure A - 14 Outer sheet residual radial stress (through thickness). Rivets formed to 13.3

kN. 164

Figure A - 15 Inner sheet residual hoop stress (through thickness). Rivets formed to 13.3

kN. 164

Figure A - 16 Inner sheet residual radial stress (through thickness). Rivets formed to 13.3

$\mathrm{kN}$. 164

Figure A - 17 Outer sheet residual hoop stress (through thickness). Rivets formed to $6.7 \mathrm{kN} . . .165$ 
Figure A - 18 Outer sheet residual radial stress (through thickness). Rivets formed to 6.7

$\mathrm{kN}$.

Figure A - 19 Inner sheet residual hoop stress (through thickness). Rivets formed to $6.7 \mathrm{kN}$.... 165

Figure A - 20 Inner sheet residual radial stress (through thickness). Rivets formed to 6.7

$\mathrm{kN}$. 165

Figure A - 21 Outer sheet residual hoop stress (through thickness). Rivets formed to $8.9 \mathrm{kN} \ldots .166$

Figure A - 22 Outer sheet residual radial stress (through thickness). Rivets formed to 8.9

kN. 166

Figure A - 23 Inner sheet residual hoop stress (through thickness). Rivets formed to $8.9 \mathrm{kN}$.... 166 Figure A - 24 Inner sheet residual radial stress (through thickness). Rivets formed to 8.9

kN. 166

Figure A - 25 Outer sheet residual hoop stress (through thickness). Rivets formed to 11.1

kN.

Figure A - 26 Outer sheet residual radial stress (through thickness). Rivets formed to 11.1

kN. 167

Figure A - 27 Inner sheet residual hoop stress (through thickness). Rivets formed to 11.1

kN. 167

Figure A - 28 Inner sheet residual radial stress (through thickness). Rivets formed to 11.1

kN. 167

Figure A - 29 Outer sheet residual hoop stress (through thickness). Rivets formed to 13.3

kN. 168

Figure A - 30 Outer sheet residual radial stress (through thickness). Rivets formed to 13.3

kN. 168 
Figure A - 31 Inner sheet residual hoop stress (through thickness). Rivets formed to 13.3

kN.

Figure A - 32 Inner sheet residual radial stress (through thickness). Rivets formed to 13.3

$\mathrm{kN}$. 168

Figure B - 1 Outer sheet residual radial strains. Rivet forming load: $44.5 \mathrm{kN}$ 170

Figure B - 2 Outer sheet residual radial strains. Rivet forming load: $53.4 \mathrm{kN}$ 170

Figure B - 3 Inner sheet residual radial strains. Rivet forming load: $44.5 \mathrm{kN}$. 170

Figure B - 4 Inner sheet residual radial strains. Rivet forming load: $53.4 \mathrm{kN}$. 170

Figure B - 5 Outer sheet residual hoop strains. Rivet forming load: $44.5 \mathrm{kN}$. 171

Figure B - 6 Outer sheet residual hoop strains. Rivet forming load: $53.4 \mathrm{kN}$. 171

Figure B - 7 Inner sheet residual hoop strains. Rivet forming load: $44.5 \mathrm{kN}$ 171

Figure B - 8 Inner sheet residual hoop strains. Rivet forming load: $53.4 \mathrm{kN}$. 171

Figure B - 9 Outer sheet residual clamping strains. Rivet forming load: $44.5 \mathrm{kN}$. 172

Figure B - 10 Outer sheet residual clamping strains. Rivet forming load: $53.4 \mathrm{kN}$. 172

Figure B - 11 Inner sheet residual clamping strains. Rivet forming load: $44.5 \mathrm{kN}$ 172

Figure B - 12 Inner sheet residual clamping strains. Rivet forming load: $53.4 \mathrm{kN}$ 172

Figure E - 1 Fretting damage on faying surface of alclad countersunk splice $(6.7 \mathrm{kN})$. 186

Figure E - 2 Fretting damage on faying surface of alclad countersunk splice $(8.9 \mathrm{kN})$. 186

Figure E - 3 Fretting damage on faying surface of alclad countersunk splice (11.1 kN). 186

Figure E - 4 Fretting damage on faying surface of alclad countersunk splice (13.3 kN). 186

Figure E - 5 Fretting damage on faying surface of bare countersunk splice $(6.7 \mathrm{kN})$. 187

Figure E - 6 Fretting damage on faying surface of bare countersunk splice $(8.9 \mathrm{kN})$. 187

Figure E - 7 Fretting damage on faying surface of bare countersunk splice (11.1 kN). 187

Figure E - 8 Fretting damage on faying surface of bare countersunk splice (13.3 kN). 187 
Figure E - 9 Fretting damage on faying surface of anodized countersunk splice $(6.7 \mathrm{kN}) \ldots \ldots \ldots 188$

Figure E - 10 Fretting damage on faying surface of anodized countersunk splice $(8.9 \mathrm{kN}) \ldots \ldots . .188$

Figure E - 11 Fretting damage on faying surface of anodized countersunk splice $(11.1 \mathrm{kN}) \ldots . .188$

Figure E - 12 Fretting damage on faying surface of anodized countersunk splice $(13.3 \mathrm{kN}) \ldots . .188$

Figure E - 13 Fretting damage on faying surface of alclad universal splice $(6.7 \mathrm{kN}) \ldots \ldots \ldots \ldots \ldots \ldots . . . .189$

Figure E - 14 Fretting damage on faying surface of alclad universal splice $(8.9 \mathrm{kN}) \ldots \ldots \ldots \ldots \ldots . . .189$

Figure E - 15 Fretting damage on faying surface of alclad universal splice $(11.1 \mathrm{kN}) \ldots \ldots \ldots \ldots . . .189$

Figure E - 16 Fretting damage on faying surface of alclad universal splice $(13.3 \mathrm{kN}) \ldots \ldots \ldots \ldots . . .189$

Figure E - 17 Fretting damage on faying surface of bare universal splice $(6.7 \mathrm{kN})$. ............... 190

Figure E - 18 Fretting damage on faying surface of bare universal splice $(8.9 \mathrm{kN})$............... 190

Figure E - 19 Fretting damage on faying surface of bare universal splice $(11.1 \mathrm{kN}) \ldots \ldots \ldots \ldots \ldots 190$

Figure E - 20 Fretting damage on faying surface of bare universal splice $(13.3 \mathrm{kN})$............... 190

Figure E - 21 Fretting damage on faying surface of anodized universal splice $(6.7 \mathrm{kN}) \ldots \ldots \ldots . .191$

Figure E - 22 Fretting damage on faying surface of anodized universal splice $(8.9 \mathrm{kN})$............ 191

Figure E - 23 Fretting damage on faying surface of anodized universal splice $(11.1 \mathrm{kN}) \ldots \ldots \ldots .191$

Figure E - 24 Fretting damage on faying surface of anodized universal splice $(13.3 \mathrm{kN}) \ldots \ldots \ldots .191$ 


\section{NOMENCLATURE}

\section{Greek Symbols}

$\begin{array}{ll}\delta & \text { Fastener displacement } \\ \Delta \varepsilon & \text { Strain range } \\ \varepsilon_{\mathrm{f}}^{\prime} & \text { Tensile fatigue ductility coefficient } \\ \xi & \text { Complex function } \\ \theta & \text { Angle about z-axis } \\ v & \text { Poisson's ratio } \\ \sigma_{\text {applied }} & \text { Applied sheet stress } \\ \sigma_{\text {bending }} & \text { Sheet secondary bending stress } \\ \sigma_{\mathrm{f}}^{\prime} & \text { Tensile fatigue strength coefficient } \\ \sigma_{\text {hoop }}, \sigma_{\theta} & \text { Hoop stress } \\ \sigma_{\text {long }} & \text { Longitudinal stress } \\ \sigma_{\text {max }} & \text { Maximum stress } \\ \sigma_{\text {radial }}, \sigma_{\mathrm{r}} & \text { Radial stress } \\ \sigma_{\mathbf{x x}} & \text { Stress in x-direction } \\ \sigma_{\mathbf{x x}, \text { normal }} & \text { Stress in x-direction due to applied normal load } \\ \sigma_{\mathbf{x x}, \text { peak }} & \text { Peak surface stress in x-direction } \\ \sigma_{\mathbf{x x}, \text { shearl }} & \text { Stress in x-direction due to shear traction in slip zone }\end{array}$




$\begin{array}{ll}\sigma_{\mathrm{xx}, \text { shear2 }} & \text { Stress in } \mathrm{x} \text {-direction due to shear traction in stick zone } \\ \sigma_{\mathrm{xyz}} & \text { 3D stress matrix } \\ \sigma_{\mathrm{x}^{\prime} \mathrm{y}^{\prime} \mathrm{z}^{\prime}} & \text { Transformed 3D stress matrix } \\ \sigma_{\mathrm{y}} & \text { Yield stress } \\ \tau & \text { Plane shear stress } \\ \Phi & \text { Angle about } y \text {-axis }\end{array}$

\section{Latin Symbols}
A, B
Integration constants

Contact half-width

b

Fatigue strength exponent

c

Stick zone half-width, Fatigue ductility exponent

C

Rivet flexibility

D

Formed rivet head diameter

$\mathrm{D}_{\mathrm{o}}$

Initial rivet shank diameter

$\mathrm{E}$

Young's modulus

$f$

Coefficient of friction

F

Fastener transfer load

H

Formed rivet head height

$\mathrm{H}_{\mathrm{o}}$

Initial rivet shank height above sheet

I

Moment of inertia

k

Sheet flexibility

$\mathrm{K}_{\mathrm{b}}$

Secondary bending factor

$M_{\max }$

Maximum secondary bending moment

$\mathbf{M}_{\mathbf{x}}$

Secondary bending moment

$\mathrm{N}_{\mathrm{f}}$

Number of cycles to formation of $1 \mathrm{~mm}$ deep crack

$\mathbf{P}$

Fretting normal force 


\begin{tabular}{ll}
$\mathrm{p}$ & Pressure \\
$\mathrm{P}$ & Splice applied force \\
$\mathrm{P}_{0}$ & Maximum contact pressure \\
$\mathrm{p}(\mathrm{x})$ & Pressure distribution \\
$\mathrm{Q}$ & Shear force \\
$q(x)$ & Total shear traction \\
$q^{\prime}(x)$ & Shear traction within slip zone \\
$q^{\prime \prime}(x)$ & Shear traction within stick zone \\
$\mathrm{R}_{\mathrm{o}}, \mathrm{r}$ & Rivet hole radius \\
$\mathrm{r}_{\mathrm{y}}$ & Radius of plastic zone around cold expanded hole \\
$\mathrm{s}$ & Rivet row spacing \\
$\Delta \mathrm{s}$ & Change in rivet row spacing \\
$\mathrm{t}$ & Sheet thickness, Asperity height \\
$\mathrm{T}$ & Transformation matrix \\
$\mathrm{w}$ & Out-of-plane sheet displacement \\
$\mathrm{z}$ & Distance from neutral axis \\
$\mathrm{Z}_{\mathrm{l}}(\xi)$ & Complex potential function for normal pressure distribution \\
$\mathrm{Z}_{I I}^{1}(\xi)$ & Complex potential function for slip shear traction \\
$\mathrm{Z}_{\mathrm{II}}^{2}(\xi)$ & Complex potential function for stick shear traction \\
\hline
\end{tabular}




\section{Introduction}

Ensuring the safety of modern aircraft structures subject to fatigue loading is a goal that has been pursued for decades. Since fatigue was first identified as a serious issue in airframe structural failure in the late 1940's and early 1950's, advances in design against fatigue have helped make flight the safest method of transportation. Modern aircraft structural integrity programs (ASIPs) now give confidence in the structural integrity of airframes between inspections that can be spaced as far apart as every 4000 flights. The ASIP most commonly used at the moment is called Damage Tolerance and it has largely replaced the first widely accepted structural integrity program called Safe-life.

Using the Safe-life philosophy, a component is tested to determine its fatigue life, a safety factor is applied to obtain the 'safe life', and after the safe life of the component has been reached, it is discarded. It is assumed that the component has no initial damage and is, therefore, structurally sound until the safe life is reached. The assumption of no initial damage in the structure meant that contingencies for component failures, such as alternate load paths, were not actively investigated. A series of civil and military aircraft losses including DeHavilland Comets, F-111s, B-52s, and T-30s [1] required investigation into the Safe-life philosophy.

By assuming no damage until after the service life of a component had been reached, the Safe-life philosophy did not account for manufacturing flaws, material flaws or in-service 
damage. Under fatigue loading, it was possible for the undetected flaws to propagate leading to catastrophic failure. The drawbacks of the no damage assumption in the Safe-life philosophy, in addition to issues of over-design, brought about the concept of Damage Tolerance. The damage tolerant design philosophy assumes that damage below the detectable limit is always present in a structure. The philosophy then uses knowledge of the loading on the component, fracture mechanics, and a well defined inspection program to ensure multiple opportunities to find a crack before ultimate failure occurs.

Unfortunately, when the damage tolerant design philosophy was developed, the concepts of "multiple-site fatigue damage" (MSD) or "widespread fatigue damage" (WFD) did not exist. In these areas, the damage tolerant design philosophy was found to be lacking. The concepts of MSD and WFD are specific to aging aircraft and it was not until after the catastrophic failure of Aloha Airlines flight 243 on 28 April 1988 that these concepts were brought to the forefront of research. In the accident, a 5.5 metre long section of the upper fuselage of a Boeing 737 was torn away (Figure 1.1, 1.2) at an altitude of $7300 \mathrm{~m}(24,000 \mathrm{ft})$. Remarkably, the incident resulted in only one death and the aircraft was able to land safely - a testament to damage tolerant design.

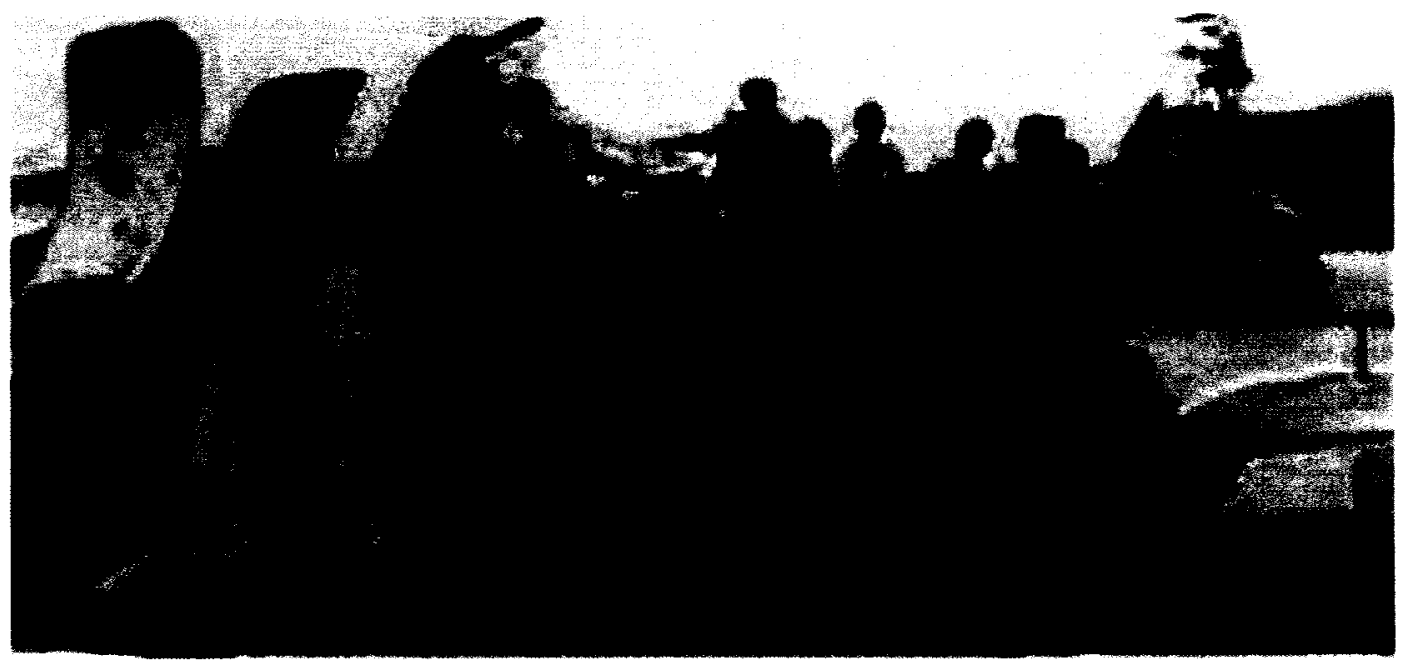

Figure 1.1 Aloha airlines flight 243 with portion of upper fuselage missing. 


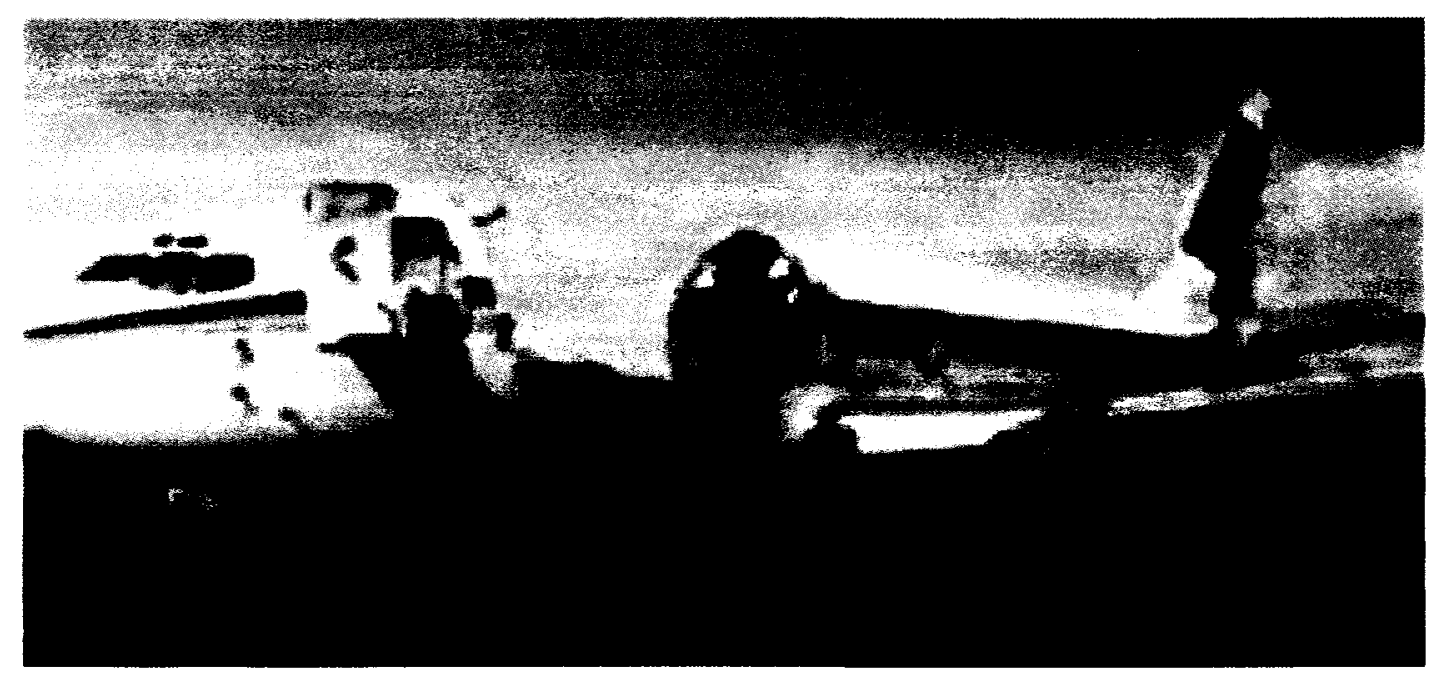

Figure 1.2 Aloha airlines flight 243 with portion of upper fuselage missing (seats removed).

The term multiple-site damage was coined as the link-up of many hard-to-detect cracks around rivet holes in the longitudinal fuselage lap splice of an aircraft (Figure 1.3). This type of splice is in the lengthwise direction of the fuselage and consists of aluminum sheets overlaid on top of one another fastened with rivets. MSD cracks, nucleating from areas of corrosion and wear, weaken nearly every hole in a joint and, in the case of Aloha Airlines flight 243, caused an "unzipping" when the cabin was pressurized. The crack link-up bypassed conventional damage tolerance features such as tear straps. The damage tolerant design philosophy depended on inspections using NDI techniques and these techniques were not able to find the cracks that existed at nearly every rivet hole in the fuselage splice. Compounding the splice damage was deterioration of a bonding material applied to the contacting or faying surface of the splice. With the bond no longer carrying load, the rivets were forced to carry more load than intended. The outcome of this accident was close scrutiny of the service and maintenance being performed as part of the aircraft structural integrity program. 


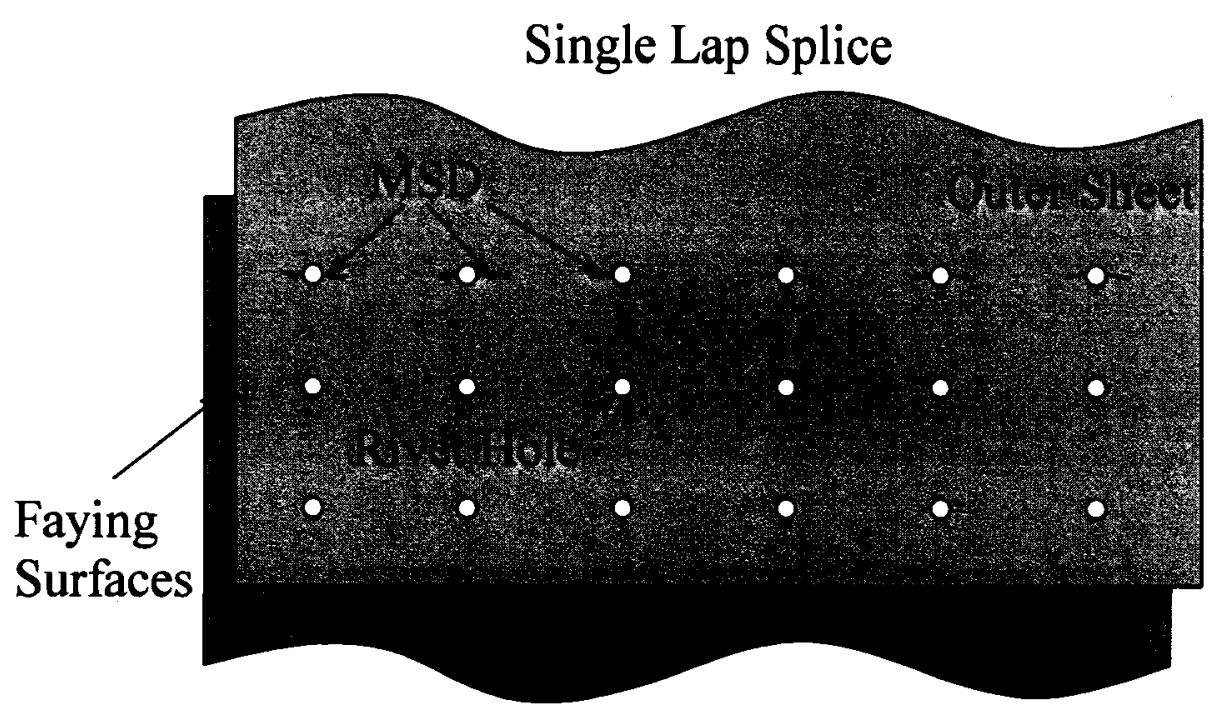

Figure 1.3 A single lap splice with multiple site damage (MSD).

The next step, beyond the damage tolerant design philosophy, is the holistic structural integrity program (HOLSIP) under development at the National Research Council of Canada (NRC) and the Defence Research and Development Canada/Department of National Defence (DRDC/DND) in collaboration with other international organizations. HOLSIP assesses the structural integrity of an aircraft from initial concept to the end of the product's life cycle including issues that arise with aging aircraft such as MSD. An important part of this program is the acknowledgment that corrosion and a tribological wear process called fretting play a critical role in the nucleation of fatigue cracks in an aircraft structure. It is the surface damage created by corrosion or fretting wear that causes cracks to nucleate. Little more than qualitative observations have been made about fretting in most aircraft structures which leaves a great deal of research to be done. As fretting wear occurs in clamped bodies undergoing relative micro-scale oscillatory motion, riveted structures subject to fatigue loading, like the longitudinal fuselage lap splice, are perfect candidates for study.

Longitudinal fuselage lap splices are most commonly fastened together with solid rivets that form a fixed connection between the two sheets by being plastically deformed in a hole. The 
plastic deformation of the rivet creates an interference fit and through-thickness clamping around the fastener. This interference and clamping, in combination with micro-scale relative displacements between the contacting bodies due to fatigue loading, are what generates fretting wear. The degree of interference affects the location and severity of fretting wear and the fatigue life of the joint. Higher interference generally produces higher fatigue lives and moves the location of fretting wear from the rivet/hole interface to the faying sheet surfaces.

Research, like that performed by R.P.G. Müller [2], is now showing that it is beneficial for the fatigue life of a splice to use load-controlled riveting and high rivet forming loads. It is possible that increasing the rivet forming loads will affect the fretting wear on the faying sheet surface and the location of crack nucleation. It is, therefore, possible that in-depth knowledge of the role that rivet forming parameters have on fretting damage can be exploited to further increase the fatigue life of riveted structures.

\subsection{Research Objectives}

A research project was developed based on the motivation provided in the previous section. The goal of the research project was to examine faying surface fretting in single lap splices. This examination was broken into three components:

- Finding a methodology to predict faying surface fretting fatigue in lap splices. This part of the investigation should provide a tool that could be used by designers within the context of the holistic structural integrity program to predict fretting fatigue in lap splices.

- Exploring the role of rivet forming load on splice faying surface fretting damage. This component should document variations in faying surface fretting damage with rivet forming load and the effect this may have on fatigue life. 
- Exploring the role of faying surface treatment on the fatigue life of lap splices. This final component should examine common surface treatments for sheet material used to make splices and document the effect (if any) that surface treatments have on the fretting fatigue life of a riveted lap splice.

To narrow the scope of the research it was decided to focus on thin sheet $(1 \mathrm{~mm}) 2024-\mathrm{T} 3$ aluminum riveted fuselage lap splices and only two rivet styles. This thickness is approximately representative of a narrow-body transport aircraft.

\subsection{Dissertation Overview}

This dissertation documents the results of an experimental and numerical investigation on faying surface fretting in single lap splices. A flow chart (Figure 1.4) is presented in this section to outline the organization of the research based on the objectives. The top level of the chart identifies the research topic. The second level of the flow chart lists the research objectives stated in the previous section and the lower levels indicate steps in the research required to reach those objectives. Each block of the flow chart includes the chapter in which that material is presented. 


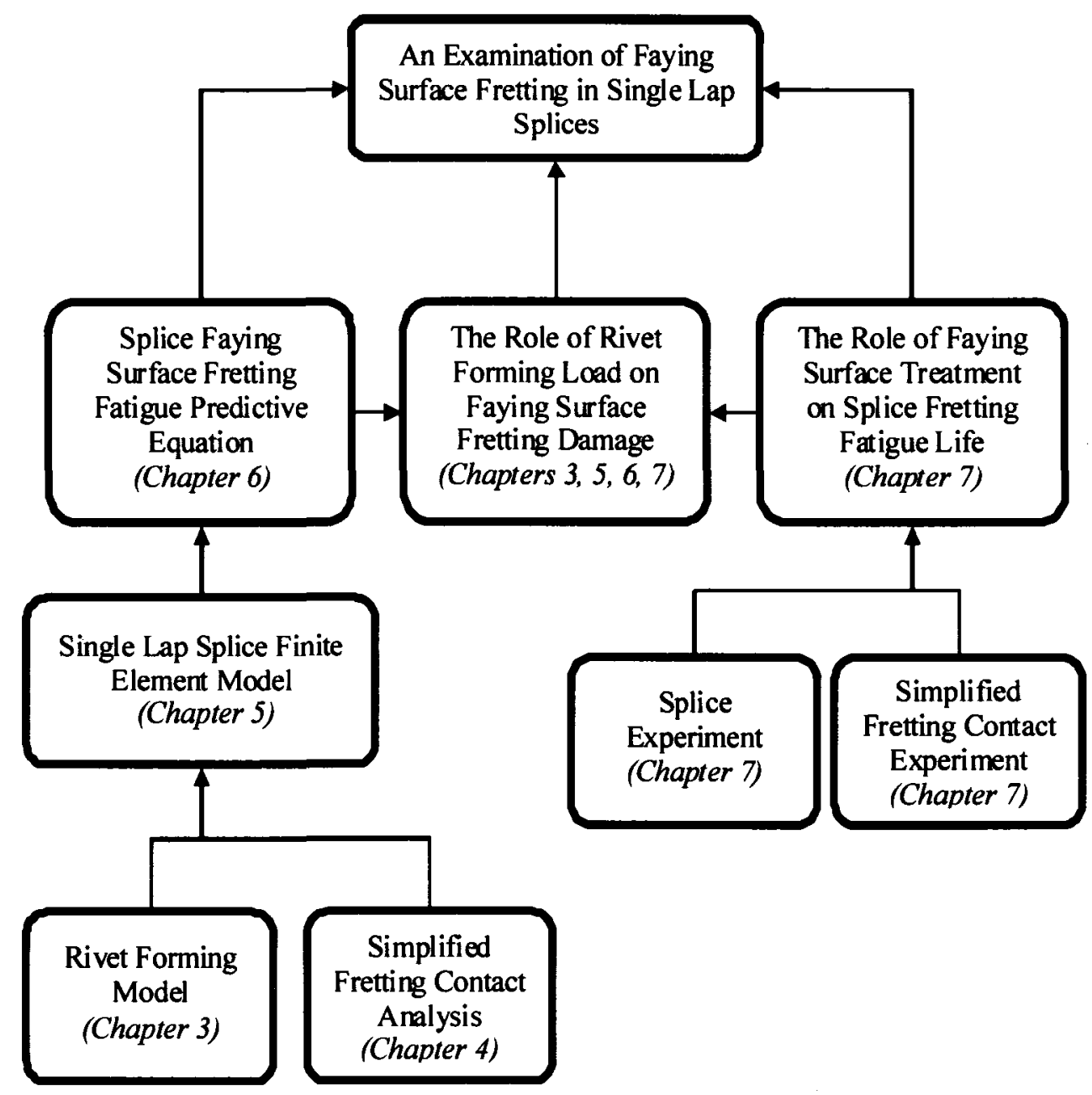

Figure 1.4 Flow chart of research objectives.

The order of chapters in this document is organized to build on initial research and work up to chapters dealing with the research objectives. In reference to the flow chart, this is working from the bottom blocks to the top. A brief summary of each chapter is provided here as part of this overview.

Chapter 2 provides background information for a better understanding of the material presented in the rest of the dissertation. The background material includes detailed information on lap splices and the stresses in a loaded splice. Detailed information on fretting fatigue, in general, 
including predictive life formulations, is presented at the end of the chapter in addition to early fretting fatigue research on riveted lap splices.

In Chapters 3 and 4, the preliminary steps in developing a finite element model of a riveted lap splice are presented. The preliminary steps verify simulation parameters that will eventually be used in a riveted lap splice model and answer questions about what modelling methodologies should be used in the lap splice model. Chapter 3 presents the results of axisymmetric rivet forming models used to investigate the need for a full 3D riveted splice simulation. The rivet forming model was also able to provide interesting results on residual sheet clamping from formed rivets. Chapter 4 details the development of a simplified contact scenario to which analytical solutions exist. Comparison of finite element model results to analytical solutions allow for validation of modelling parameters. With the fundamental modelling concerns addressed, it was possible to move on to a $3 \mathrm{D}$ riveted single lap splice model.

Chapter 5 details the development and further validation of a 3D explicit finite element model of a single lap splice. The model validation includes initial comparisons of contact areas and stresses to actual lap splices with fretting damage. Untreated 2024-T3 aluminum was examined in both the simulation and the tests. The loaded splice stress and strain results were then available for use in the predictive formulation of the following chapter.

Chapter 6 selects a fretting fatigue predictive formulation to be used on the complex geometry of a single lap splice. The methodology of generating the fretting fatigue life predictions is presented followed by the procedures used for experimental splice tests. Comparison of the predicted and the experimental fretting fatigue life results show good agreement.

Chapter 7 continues the investigation by examining the role that surface treatment has on the fatigue life of the single lap splice and also discusses how this may affect the usefulness of the 
predictive method presented in Chapter 6. Results from the splice fatigue tests showed that the fatigue life has a dependence on the surface treatment at high rivet forming loads. This fatigue life dependence was verified by a simultaneous fretting fatigue study using simplified contact geometry.

Finally, Chapter 8 presents a general discussion on the work presented here followed by conclusions in Chapter 9. Possibilities for future work on this topic are described in Chapter 10. 


\section{Background}

\subsection{Introduction}

Although riveted lap splices and fretting were touched on in the introductory chapter, it is helpful to present further details on these topics to facilitate discussion of the work presented in this study. Beginning with riveted lap splice construction, the following section presents the tools and concepts available to designers as well as the limitations restricting them. Surprisingly, much of the design of lap splices still relies on empirical data and the experience of the designer. The limitations on design primarily stem from the complex load transfer in a riveted splice and the design details that must be considered to achieve the desired fatigue life for the joint.

Following the background information on riveted lap splices are further details on fretting fatigue in general and the many areas where it is a problem. The background information includes different fretting fatigue predictive life models that have been developed followed by an overview of fretting fatigue in riveted lap splices.

\subsection{Riveted Lap Splice Construction}

Due to restrictions in raw material size and the complexity of airframe components, the need for joints in metallic (and composite) airframes will be a certainty for the foreseeable future. Metallic aircraft require both longitudinal and circumferential splices to assemble the aluminum panels of 
the fuselage. Composite aircraft require circumferential splices to fasten the individual barrel sections of the fuselage. Unfortunately, the joint in a fuselage introduces stress concentrations that weaken the structure and create complexities in the load transfer. The presence of stress concentrations makes fatigue a primary design consideration for fuselage splices. Many types of splice designs exist that attempt to produce the best fatigue lives for a given joint strength. Increasing the complexity of the joint to obtain greater fatigue life, however, often comes at the expense of greater cost and weight. Most splice designs can be categorized as derivatives of three basic geometries.

\subsubsection{Common Splice Designs}

The three most common types of splice design are the symmetric butt splice, the asymmetric butt splice and the single lap splice. A fatigue life comparison and illustration of these splices is presented in Figure 2.1. The symmetric butt splice consists of two sheets joined by doublers on both sides of the splice. This type of joint provides the highest fatigue lives due to symmetry and the elimination of stresses associated with a type of splice bending called secondary bending (discussed in detail in section 2.3.2.2). The drawback of the design is the lack of a smooth aerodynamic surface.

The asymmetric butt splice attempts to provide for a smooth surface by eliminating the outer doubler but introduces high secondary bending stresses and results in the lowest fatigue lives of the three designs. The single lap splice, although not having the fatigue performance of the symmetric butt splice, performs better than the asymmetric butt splice in fatigue and is more aerodynamic than the symmetric butt splice. An additional benefit is the simplicity and, hence, cost savings. The work presented here will focus on the single lap splice but will have significance for other splice designs. 


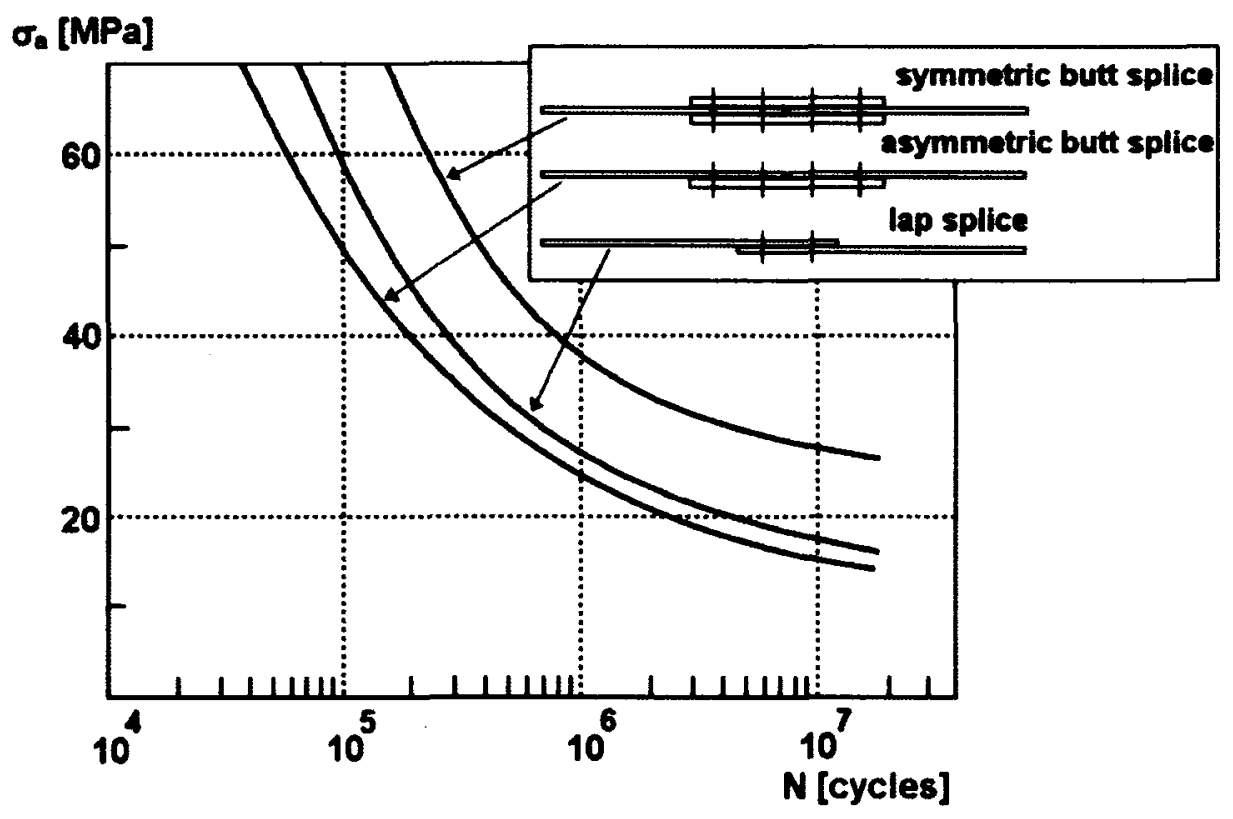

Figure 2.1 Comparison of fatigue lives for three basic splice designs [2].

\subsubsection{Splice Nomenclature}

In a single lap splice, as depicted in Figure 2.2, two sheets are overlaid and assembled with two or more fastener rows. The outer sheet has the splice overlap exposed to the environment and the inner sheet has the splice overlap facing the inside of the aircraft. The faying surface is defined as the side of each sheet that makes contact in the joint, and the row pitch and rivet pitch describe the spacing of the fasteners (usually solid rivets). The remote load or bulk load applied to the sheet is defined as the external load applied to the material away from any stress concentrations (e.g. splices). 


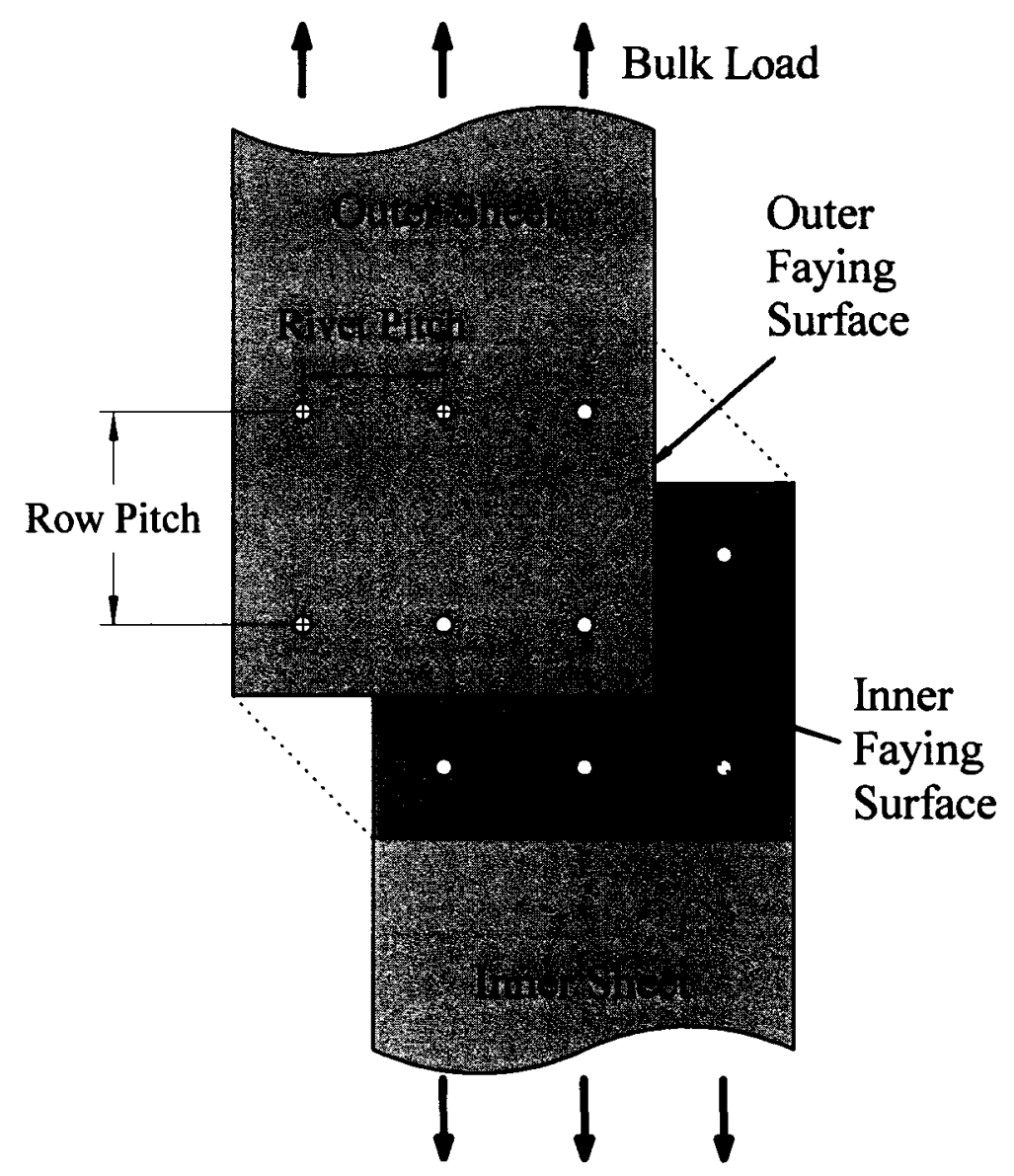

Figure 2.2 Splice nomenclature.

\subsubsection{Solid Fasteners}

Of the many different types of fasteners used in the aircraft industry, the most common is the solid rivet. The benefits of these fasteners include cost effectiveness, ease of use, and the formation of beneficial stress fields in the sheets upon installation. In addition, solid fasteners have been used in aircraft construction since the inception of metallic airframes and their behaviour under different types of loading has been well documented. Most solid fasteners are rivets designed for either a straight through hole in a splice or for a countersunk hole depending on the aerodynamic requirements of the aircraft. Some common countersunk and noncountersunk rivets are presented in Figure 2.3. 


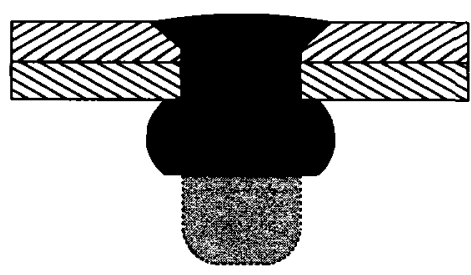

a) Reduced height countersunk rivet (NAS1097)

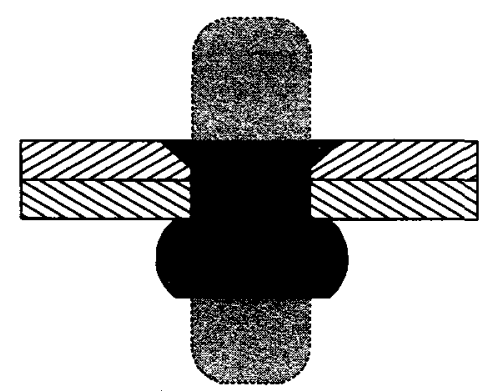

d) Slug rivet

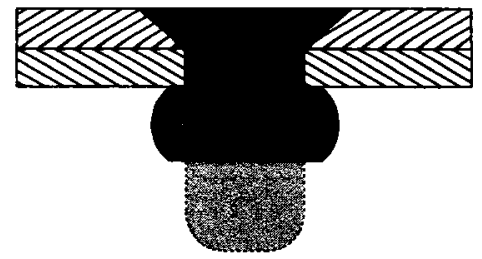

b) Countersunk rivet (MS20426)

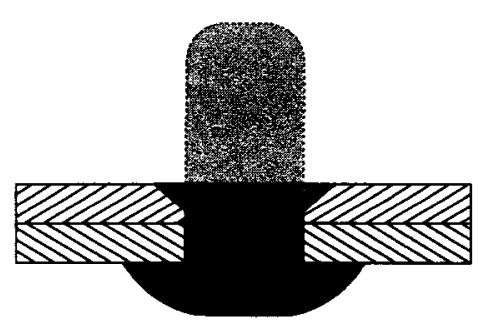

e) NACA rivet

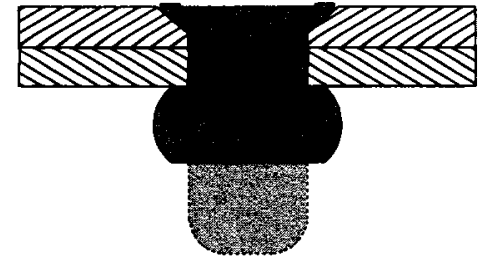

c) Briles countersink rivet

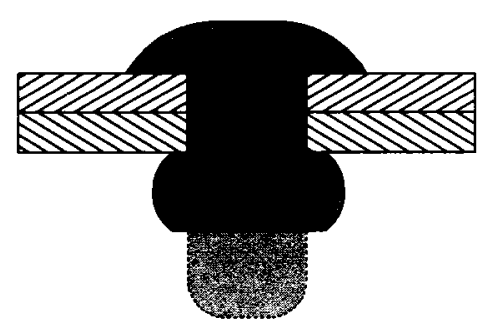

f) Universal rivet (MS20470)

Figure 2.3 (a-f) Examples of common rivet styles.

Figures $2.3 \mathrm{a}$ and $2.3 \mathrm{~b}$ show the difference between reduced-height and standard countersunk rivets. Reduced-height countersunk rivets have smaller countersunk heads for use in thin sheet material and are discussed further in section 2.2.4.1. Figure 2.3a includes a crown on the reduced-height countersunk rivet that compresses during rivet forming and improves filling of the countersunk hole. The Briles rivet, show in Figure $2.3 \mathrm{c}$, has a head design that also improves hole filling. Completely filling the countersunk hole is important to achieve proper load transfer and to prevent crevice corrosion. The slug and NACA rivets depicted in $2.3 \mathrm{~d}$ and $2.3 \mathrm{e}$ eliminate the problem of hole filling by placing the formed head on the countersunk side of the splice. Both of these processes require machining or "micro-shaving" of the surface to achieve the final flush surface. Slug rivets were introduced so that rivet wire could be used instead of individual rivets in automated installation processes. Finally, Figure $2.3 \mathrm{f}$ depicts a universal rivet. This type of rivet is stronger than the countersunk styles because there is no material removed from the sheet, but sacrifices a smooth aerodynamic surface. 
To identify each type of rivet, a naming convention is used. The first part of the rivet name identifies the rivet style, followed by a material type, then the diameter of the rivet (given in $1 / 32$ of an inch), and finally the length of the rivet (given in 1/16 of an inch). An example, provided below, gives the name for the conventional countersunk rivet shown in Figure $2.3 \mathrm{~b}$ :

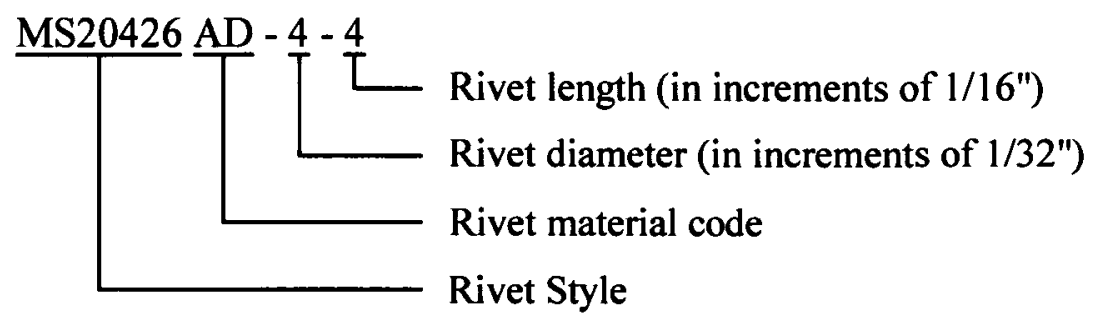

The NAS1097 (Figure 2.3 a) and the MS20470 (Figure $2.3 \mathrm{f}$ ) rivets are the two styles used in this study with a $2117-\mathrm{T} 4$ aluminum alloy. The rivet material code that follows the rivet style is a necessary part of the naming convention because of the various alloys used for aluminum rivets. Table 2.1 gives a list of the common codes and associated materials.

Table 2.1 Common material codes for aluminium alloy rivets.

\begin{tabular}{|c|c|}
\hline Material Code & Aluminum Rivet Alloy \\
\hline A & 1100 \\
B & $5056-\mathrm{H} 32$ \\
AD & $2117-\mathrm{T} 4$ \\
D & $2017-\mathrm{T} 4$ \\
DD & $2024-\mathrm{T} 4$ \\
E & $7050-\mathrm{T} 73$ \\
\hline
\end{tabular}

\subsubsection{Methods of Countersinking}

\subsubsection{Machine Countersinking}

Aerodynamic requirements of high speed aircraft often require the use of flush fasteners. The most common method of creating a flush riveted surface is through machine countersinking where material is removed from around the hole. Unfortunately, the removal of material weakens the sheet so adhering to aerodynamic requirements can be a trade-off for joint strength. 
Due to the weakening of the sheet during countersinking, manufacturers place limits on countersink dimensions to ensure the quality of the joint. A minimum height is placed on the cylindrical portion of the countersunk hole (Figure 2.4) as well as the height of the formed rivet head above the surface of the outer sheet. Müller [2] presents tolerances, based on several manufacturers specifications, for the cylindrical portion of the countersink as being between 0.1 $0.2 \mathrm{~mm}$. The height of the flush rivet head above the sheet surface should be at least $0.01 \mathrm{~mm}$.

If the countersink penetrates too deep into the outer sheet the fatigue life of the joint decreases due to an increasing stress concentration at the narrowed portion of the countersunk hole. In the limiting case, the countersink completely penetrates the outer sheet causing what is known as a "knife-edge" condition at the faying surface (Figure 2.4). Having a knife-edge in the outer sheet has been shown to increase the elastic stress concentration in the sheet by $72 \%$ [3].

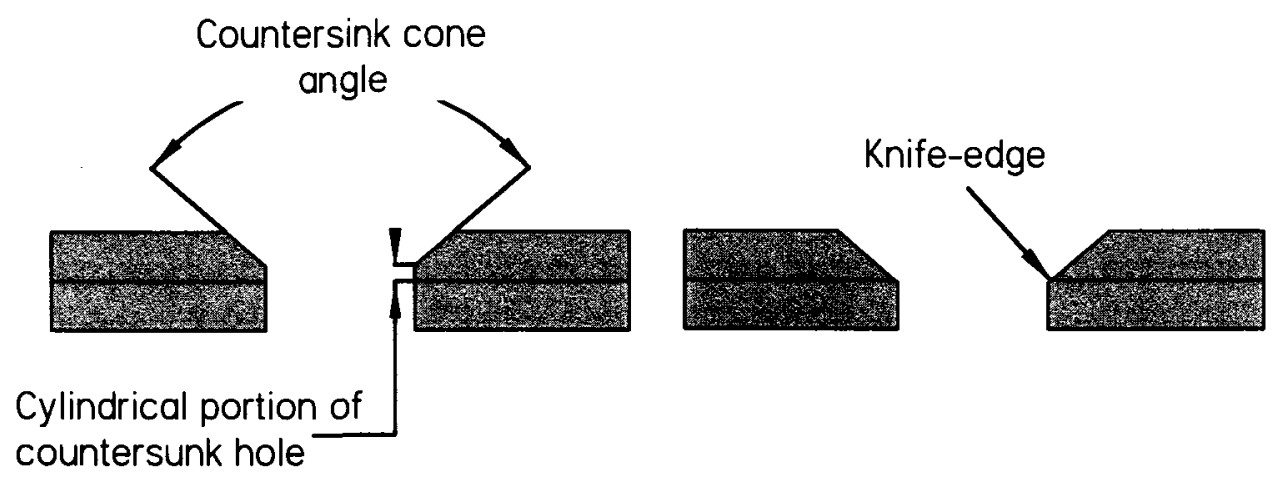

Figure 2.4 Limits placed on cylindrical portion of hole and knife-edge condition.

In thin sheet material, below $1 \mathrm{~mm}$ in thickness, the conventional MS20426 countersunk rivets cannot be used because the head height is greater than the sheet thickness. To solve this problem, the reduced-height NAS1097 rivet style is normally used. The use of the reduced height countersunk rivet does, however, reduce the joint strength. 


\subsubsection{Dimple Countersinking}

Another, less popular, method of creating a flush surface is through dimpling. This is where a recess is formed in both sheets by pressing them between mated countersunk tools. The dimple tools are aligned with pre-drilled holes and the sheets are formed to a prescribed load. An illustration of a conventional dimple tool set is shown in Figure 2.5. In sheet material below 1.6 $\mathrm{mm}$ in thickness, the dimpling process is performed at room temperature whereas thicker sheets require a hot dimpling method to avoid cracking around the periphery of the dimple. Hot dimpling should always be used on thick or brittle materials.

Two variations of the dimpling process exist: coin dimpling and radius dimpling (Figure $2.6 \mathrm{a}$ and $\mathrm{b}$ ). The difference between the two processes is the manner in which the sheets are dimpled. Coin dimpling is a forging process; the sheets are dimpled individually and rely on a reduction in the dimple cone wall thickness to allow for proper nesting of the two mating sheets. For a $100^{\circ}$ countersink, a $23 \%$ reduction in wall thickness is required. The benefit of the forging process is that it produces a smooth, cylindrical hole that the rivet shank will contact. In practice, applying this method to large panels produces dimple cones that may not align easily when it is time to rivet the sheets.

Radius dimpling is a bending process where the sheets are compressed between the tools simultaneously and lower forming pressures are required. Proper nesting of the sheets is ensured by the simultaneous forming of the dimple cones resulting in different cone geometry for the inner and outer sheets. Radius dimpling produces a non-cylindrical fastener hole as a result of the varying degrees of hole stretch through the joint thickness (Figure 2.6b). Further details on coin and radius dimpling can be found elsewhere $[4,5]$. 


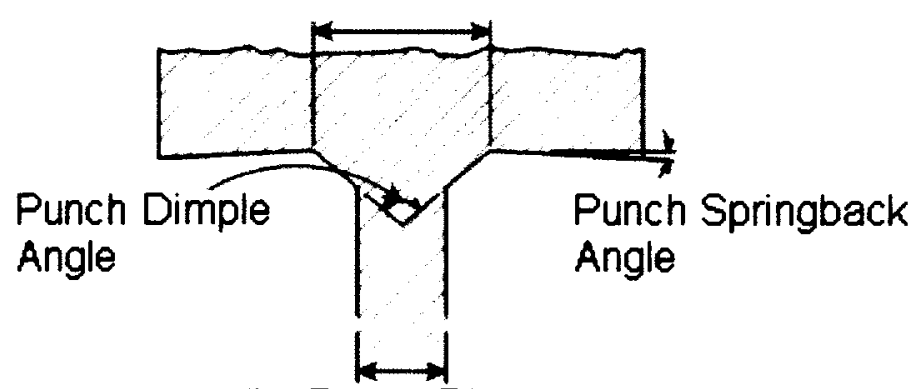

Min. Punch Diameter

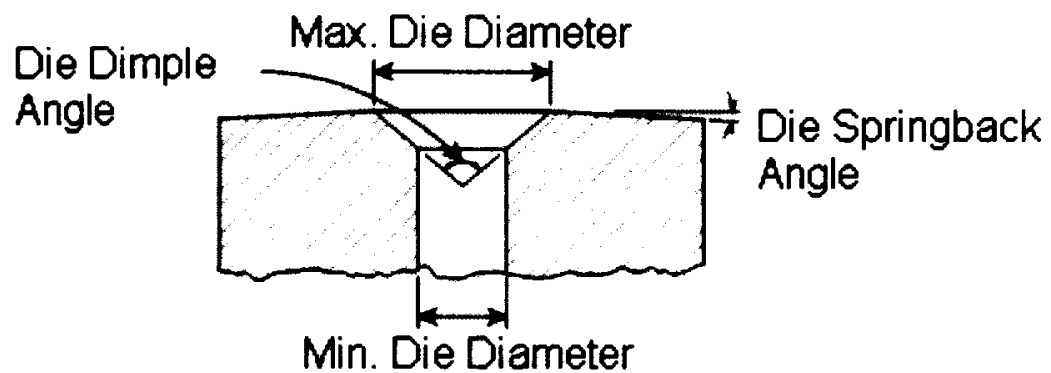

Figure 2.5 Illustration of a conventional dimple tool set |6|.

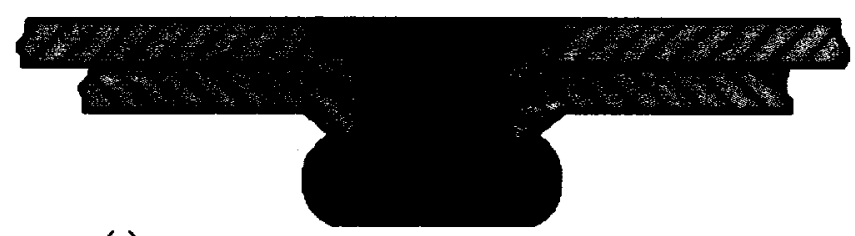

(a)

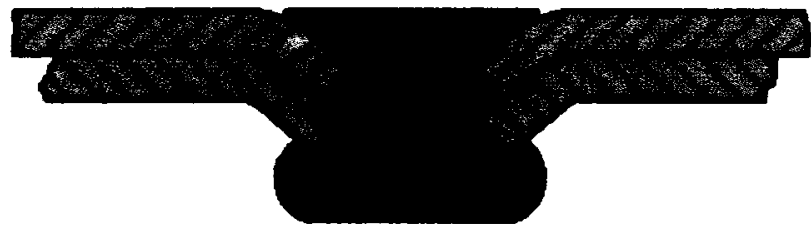

(b)

Figure 2.6 Dimpled sheets with installed rivet: (a) coin dimpled sheets, (b) radius dimpled sheets. 
The dimpling method was originally thought to be superior to machine countersinking because load transfer in the sheets is through nesting of the dimple cones and not through bearing on the hole [6]. In addition, no material is removed in the dimpling process. Advances in machine countersunk splice design and quality control have since relegated dimpling to use on secondary structures. Early research conducted by the author, however, has shown that dimpling may still be an option for use on primary structures $[5,7]$.

Most notably, the dimpling research presented in [7] describes modification of conventional dimpling tools to tailor the stress state in the sheet surrounding the rivet hole during dimple forming. Modification of the dimpling tools involves the inclusion of an elevated ridge at the periphery of the dimple die (Figure 2.7) instead of the flat surface normally found on commercially available dies. The punch half of the dimple set is kept unchanged. During the dimple forming process, the elevated ridge causes plastic deformation of the sheet surrounding the rivet hole creating a beneficial stress field. These residual stresses are discussed in detail in section 2.3.2.3.

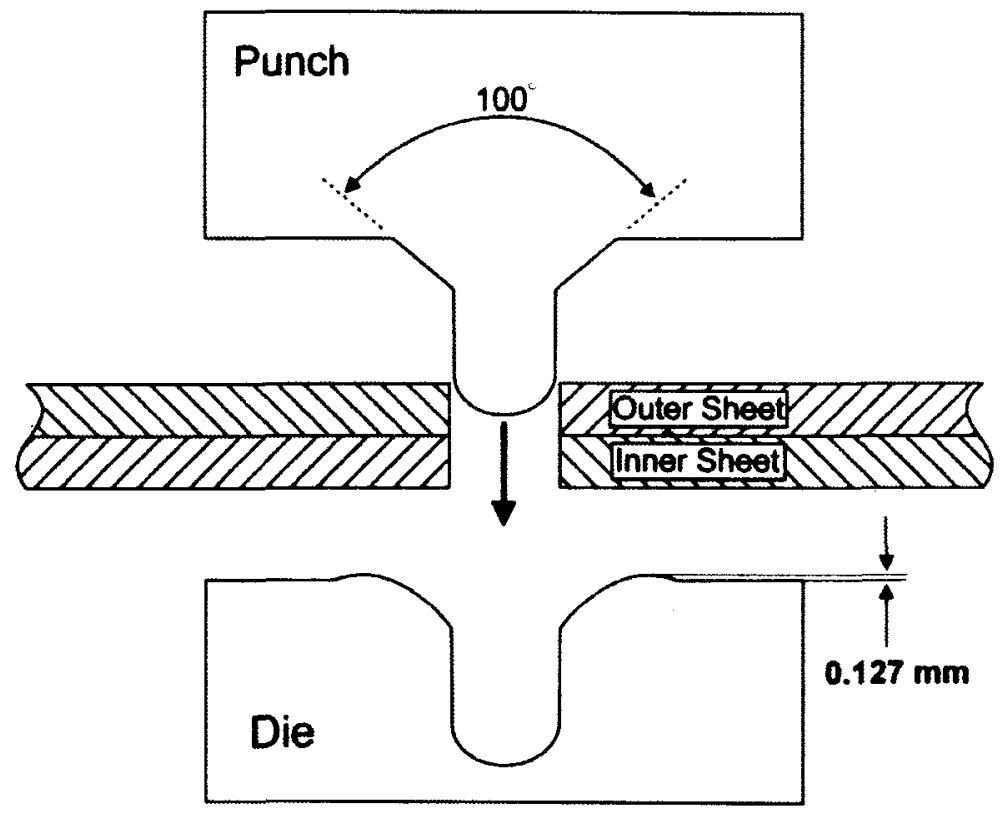

Figure 2.7 Modified dimple punch and die set. 
Results of splice coupon fatigue tests performed by the author (Figure 2.8) showed higher fatigue lives for modified dimple splices than for machine countersunk splices. In addition, dimpled splice coupons tested with a solid lubricant applied to the faying surface were found to have fatigue lives nearly three times that of machine countersunk coupons. The solid lubricant was added as a way to reduce the amount of fretting damage on the faying surface of the dimple cones. A lubricant would normally never be applied to the faying surface of a splice because the reduction in load transfer through friction between the sheets is known to severely reduce the fatigue life. With a dimpled splice, however, the dimple cones of the two sheets are seated within each other and friction plays a less important role in load transfer.

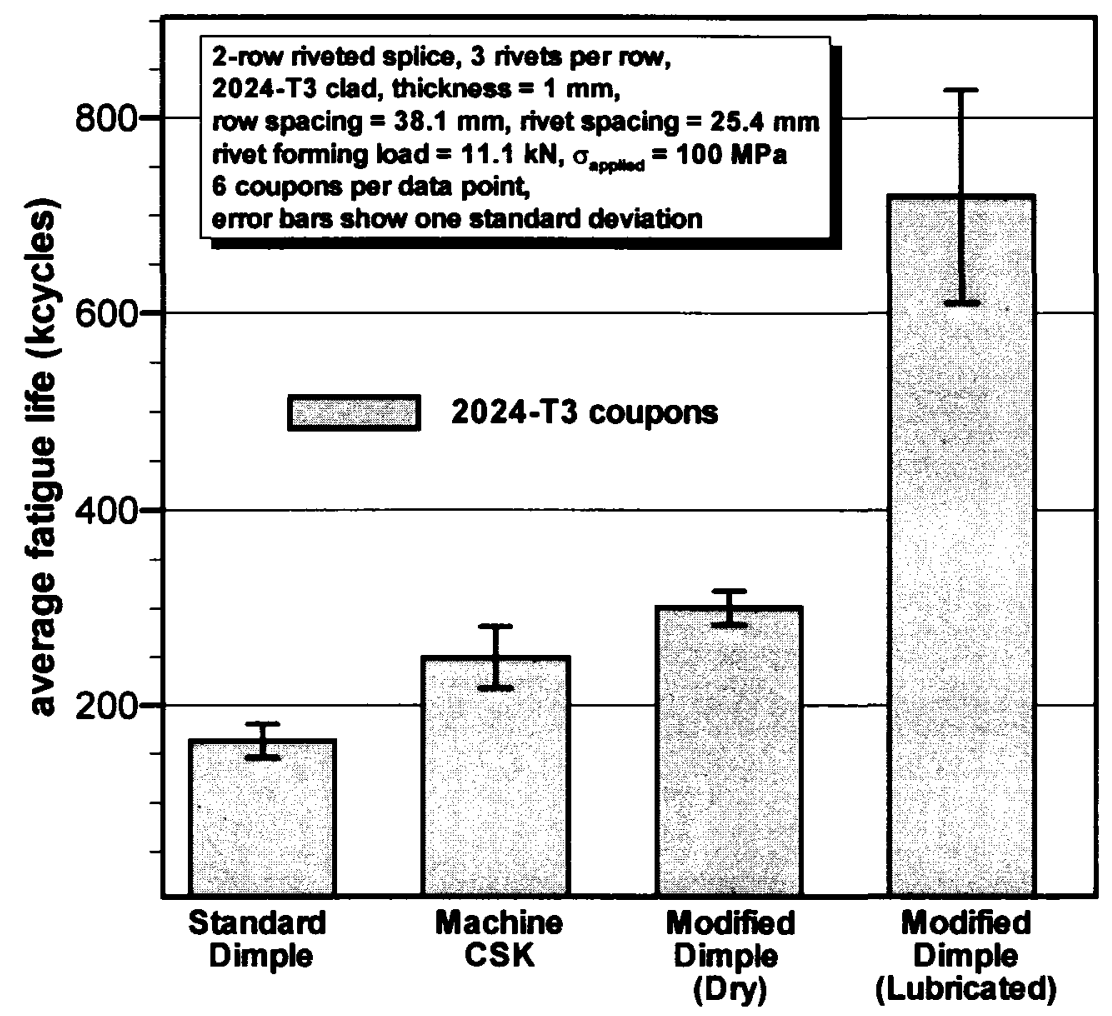

Figure 2.8 Machine countersunk and dimpled splice coupon fatigue results.

The study of dimpled joints and fretting fatigue will be discussed further in Chapter 10 . 


\subsubsection{Rivet Forming}

There are four basic steps involved with rivet forming. The steps are described here with reference to Figure 2.9.

a) Rivet insertion. Assuming a pre-drilled and countersunk hole with a diameter approximately $0.1 \mathrm{~mm}$ larger than the rivet diameter, the first step is insertion of the rivet and making contact with the forming tools. The forming tools can consist of dies attached to a displacement or load controlled riveter or can consist of a rivet gun and bucking bar.

b) Hole filling. As rivet forming begins, the rivet starts to plastically deform and fill the hole. Any expansion of the sheets due to rivet forming would be elastic at this point.

c) Sheet expansion. Continued increase in load causes the formed rivet head to mushroom, providing a clamping pressure to the sheets. Further expansion of the rivet shank compresses the sheet material surrounding the hole. With high forming loads, plastic deformation of the hole occurs as it is enlarged.

d) Rivet springback. The forming load is released and elastic springback of the rivet and hole occurs.

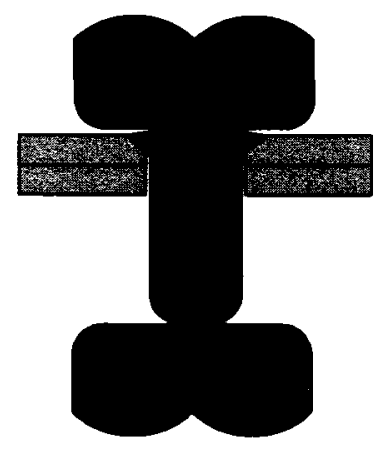

(a)

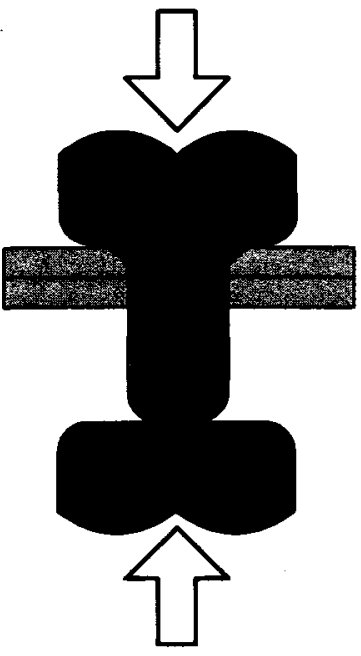

(b)

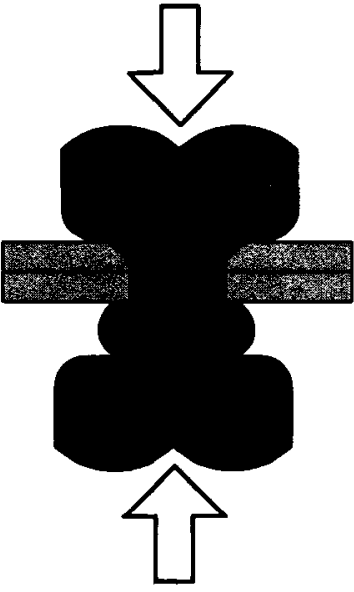

(c)

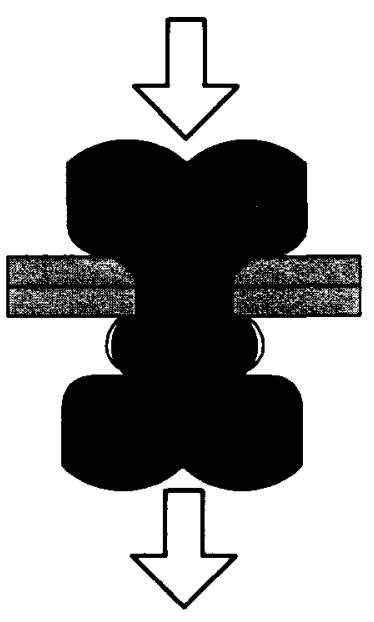

(d)

Figure 2.9 Rivet forming steps [2]. 
The quality of a riveted splice is dependent on the quality of the formed rivets. Traditional methods of verifying rivet quality involve measuring the diameter and height of a formed rivet head. The problem with this method of verification is that wide bounds are placed on the acceptable range of formed head dimensions. The conventional method of assuring rivet quality is to look at the dimensionless ratio of the formed rivet head diameter over the initial shank diameter $\mathrm{D} / \mathrm{D}_{0}$ (Figure 2.10). A ratio of 1.5 is deemed nominal; however, a range of 1.3-1.8 is normally acceptable.

The wide bounds on the $\mathrm{D} / \mathrm{D}_{0}$ range are the result of old manufacturing methods where control of the rivet forming step was difficult. The introduction of load-controlled riveting, as well as automated processes, has made it possible to produce repeatable rivet head dimensions within a tight tolerance. Müller [2] showed that by controlling rivet forming and using high rivet forming loads, joints with greater fatigue lives can be produced.

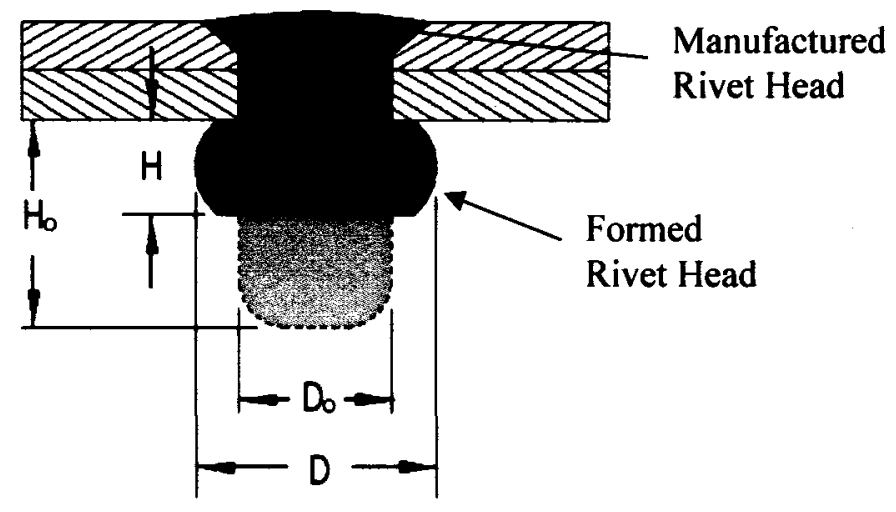

Figure 2.10 Measurable rivet dimensions for quality assurance.

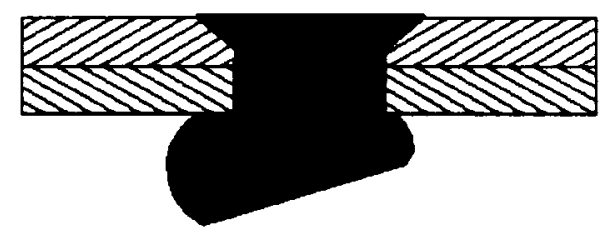

Figure 2.11 Example of a poorly formed, “dumped", rivet head. 
The quality of a splice is also dependent on the rivet head being properly formed. Poor control of the riveter can produce "dumped" or otherwise poorly formed rivet heads as illustrated in Figure 2.11. This type of defect would not pass inspection and would have to be repaired due to the significant loss in fatigue strength.

\subsection{Lap Splice Loading}

\subsubsection{Introduction}

Loading of aircraft fuselage splices is a combination of static and dynamic loads from taxi, flight, takeoff, and from pressurization. In terms of fatigue of longitudinal fuselage splices, pressurization loads are the most important. All other loads on the joint are secondary. Because pressurization is the largest of the loads, fatigue testing is defined in terms of ground-air-ground cycles (GAG) where each GAG cycle represents one pressurization of the fuselage. An example of loading that would be experienced in a longitudinal splice during a typical flight is presented in Figure 2.12.

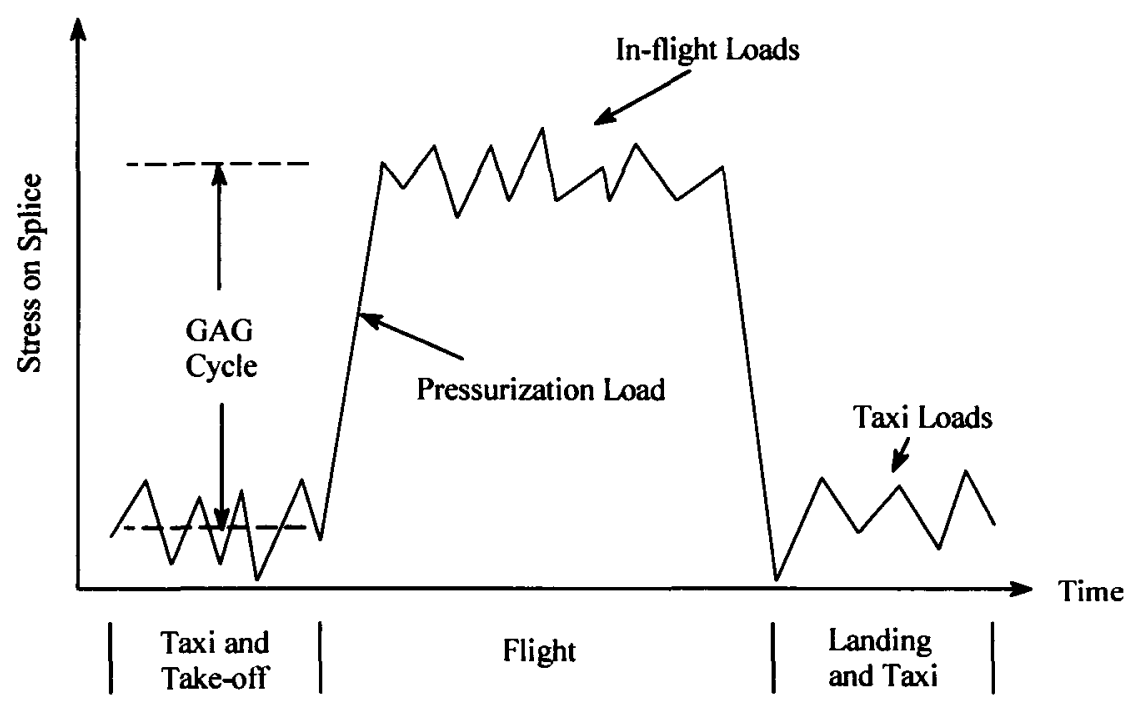

Figure 2.12 Example of stresses on a fuselage lap splice for a single flight. 
It is the longitudinal fuselage lap splice, rather than the circumferential, that is of critical importance in terms of loading because an aircraft fuselage is a thin-walled pressure vessel (Figure 2.13). In any thin-walled, unstiffened, cylindrical pressure vessel, the stresses acting on the longitudinal splice (hoop stresses) are double the stresses acting on the circumferential splice (longitudinal stresses). Equations providing the longitudinal and hoop stresses in a thin-walled pressure vessel are given as:

$$
\begin{gathered}
\sigma_{\text {long }}=\frac{P r}{2 t} \\
\sigma_{\text {hoop }}=\frac{P r}{t}
\end{gathered}
$$

Where $\mathrm{P}$ is the internal pressure, $\mathrm{r}$ is the cylinder radius, and $\mathrm{t}$ is the wall thickness.

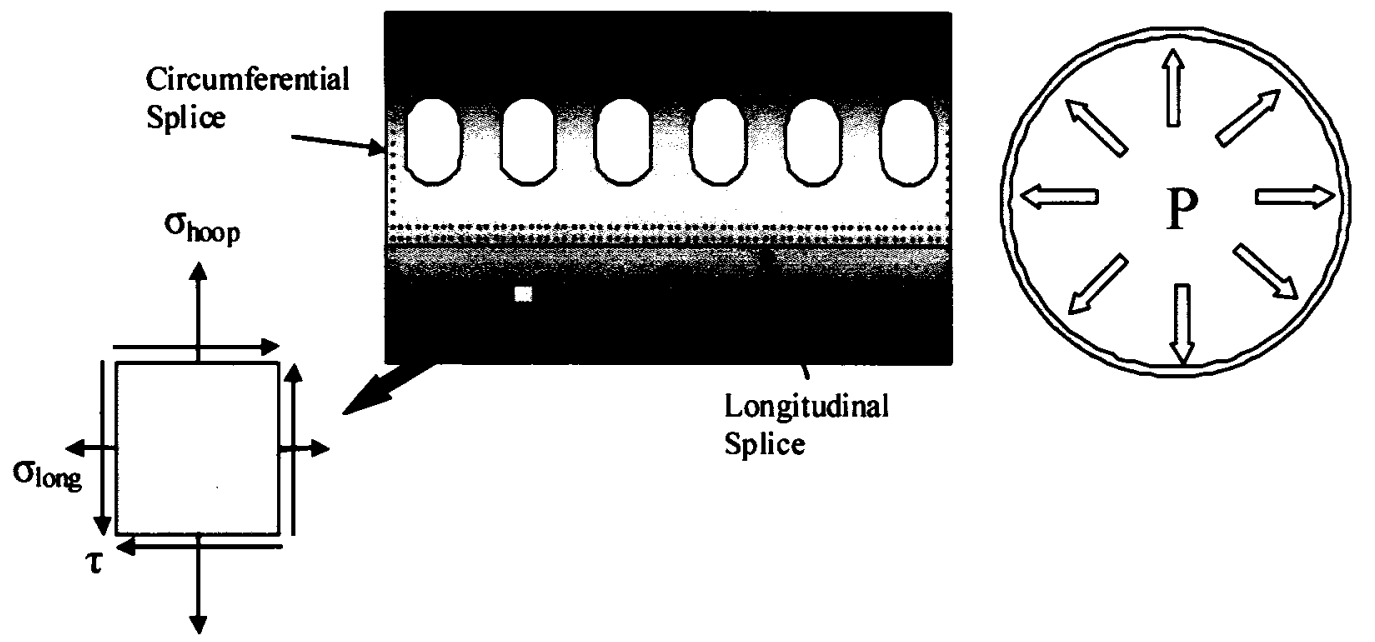

Figure 2.13 Stress state in an aircraft fuselage due to pressurization.

\subsubsection{Lap Splice Stress Field}

The stress field generated around rivets in a loaded splice is complicated and the result of three interacting components: load transfer, secondary bending, and residual stresses generated due to 
interference of a formed rivet in the hole. All three components are illustrated in Figure 2.14 and are discussed in detail in this section.

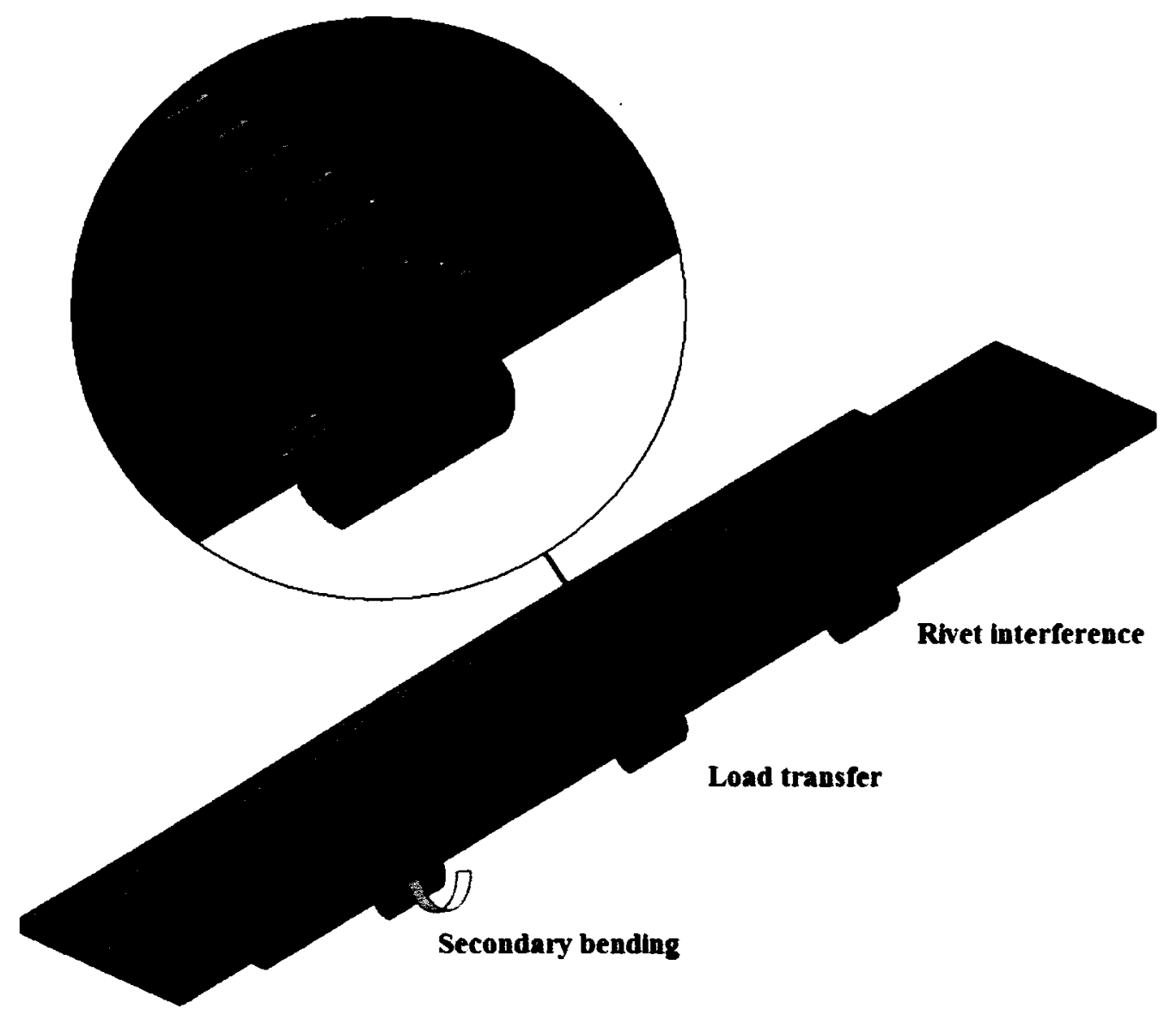

Figure 2.14 Components contributing to the stress field in a riveted lap splice.

\subsubsection{Load Transfer}

Load transfer from one sheet to the other in a lap splice is primarily achieved through rivet bearing on the holes and to a lesser degree through friction on the faying surface of the sheets. The number of fasteners used in a splice and the amount of sheet overlap has an influence on the load transferred through each rivet. The impact of these parameters on load transfer in a splice is 
best shown through a 1-D model based on displacement compatibility and rivet flexibility. Application of this model requires the following simplifications:

- The frictional component of the load transfer is neglected.

- The interference effect is accounted for by the rivet flexibility.

- The rivet bearing load is assumed to be linearly related to displacements from rivet flexibility.

A schematic of the load transfer and displacement in a splice is presented in Figure 2.15.
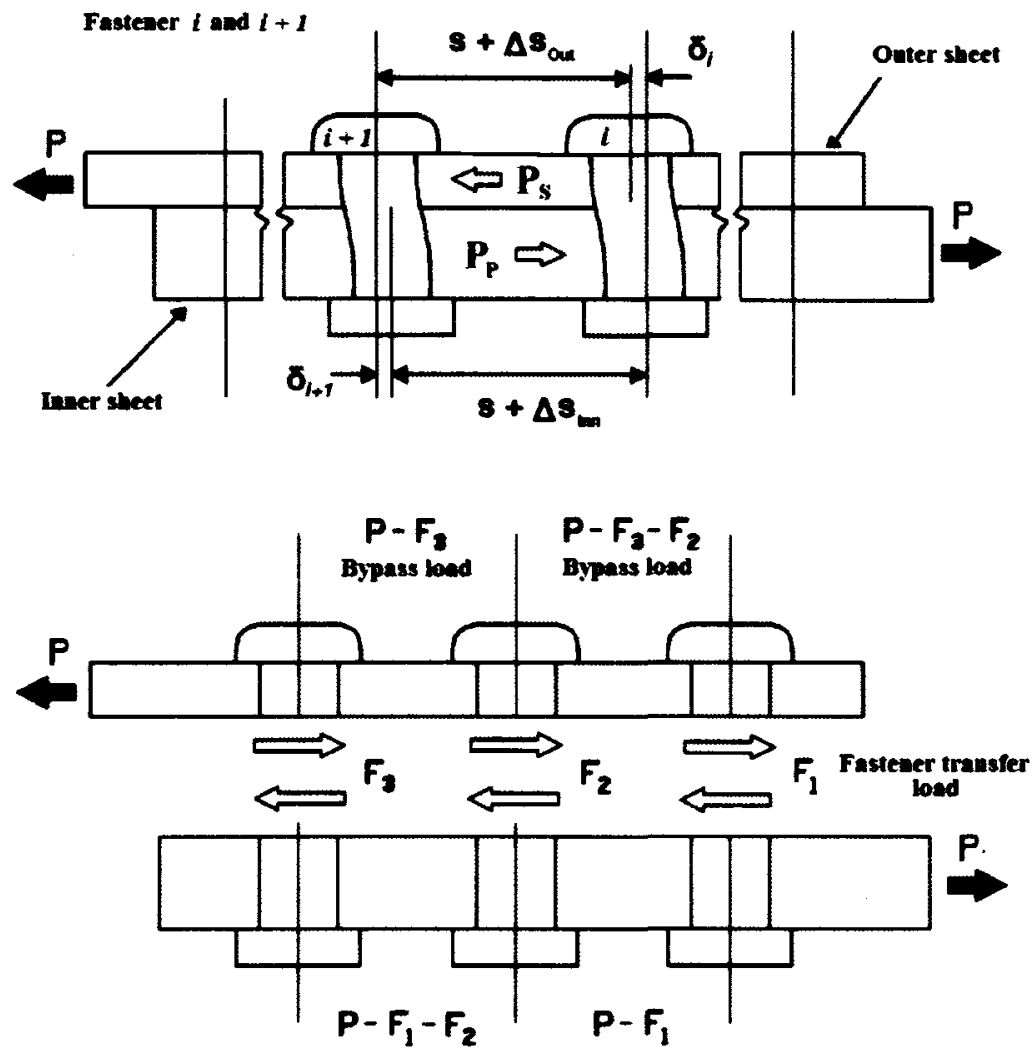

Figure 2.15 Schematic of load transfer in a riveted splice.

The general model can be applied to any number of rivet rows, $\mathrm{n}$. Referring to Figure 2.15 , and applying displacement compatibility between the rivet rows gives 


$$
s+\Delta s_{\text {Out }}+\delta_{i}=s+\Delta s_{\text {Inn }}+\delta_{i+1}
$$

Rearranging for $\delta_{i+1}$ gives

$$
\delta_{i+1}=\delta_{i}+\Delta s_{\text {Out }}-\Delta s_{\text {Inn }}
$$

Using Hooke's law and replacing the displacements of the rivets and the sheets with forces and flexibilities gives

Fasteners $\quad \delta_{i}=C_{i} F_{i} \quad \delta_{i+1}=C_{i+1} F_{i+1}$

Sheets $\quad \Delta s_{\text {Out }}=k_{\text {Out }} P_{\text {Out }} \quad \Delta s_{\text {Inn }}=k_{\text {Inn }} P_{\text {Inn }}$

Assuming equally spaced rivet rows, the sheet flexibilities can be estimated as

$$
k=\frac{s_{\text {row }}}{E A}
$$

and substitution gives an equation for the force in each fastener

$$
F_{i+1}=\frac{C_{i} F_{i}}{C_{i+1}}+\frac{k_{\text {Out }} P_{\text {Out }}}{C_{i+1}}-\frac{k_{\text {Inn }} P_{\text {Inn }}}{C_{i+1}}
$$

To get values for $\mathrm{P}_{\mathrm{Out}}$ and $\mathrm{P}_{\mathrm{Inn}}$ in terms of the applied force, $\mathrm{P}$, force equilibrium is applied for the bypass load between the rivet rows as illustrated in the bottom of Figure 2.15.

$$
\begin{gathered}
P=\sum_{i=1}^{n} F_{i} \\
P_{\text {Out }}=\sum_{i=1}^{k} F_{i} \\
P_{\text {Inn }}=P-\sum_{i=1}^{k} F_{i}
\end{gathered}
$$

where $\mathrm{k}$ is the number of rivet rows below the location of measurement. 
Finally, this gives an expression for the force in each fastener of a splice in terms of the rivet and sheet flexibilities and the applied load.

$$
F_{i+1}=\frac{C_{i} F_{i}}{C_{i+1}}+\frac{\left(k_{\text {out }}+k_{\operatorname{lnn}}\right)}{C_{i+1}} \sum_{i=1}^{n} F_{i}-\frac{k_{\text {Inn }} P}{C_{i+1}}
$$

When solved for the ratio $F_{2} / F_{1}$, equation 2.12 shows that the load transferred through the rivets is only equal in the case of a two rivet row splice. As more rivets are added, the outer rivets take a greater percentage of the load and the benefit of adding each additional row quickly decreases. Due to the reduced amount of load transfer and the cost associated with adding additional rows, manufacturers do not normally use more than three rows in commercial aircraft splices (Figure 2.16 and Figure 2.17).

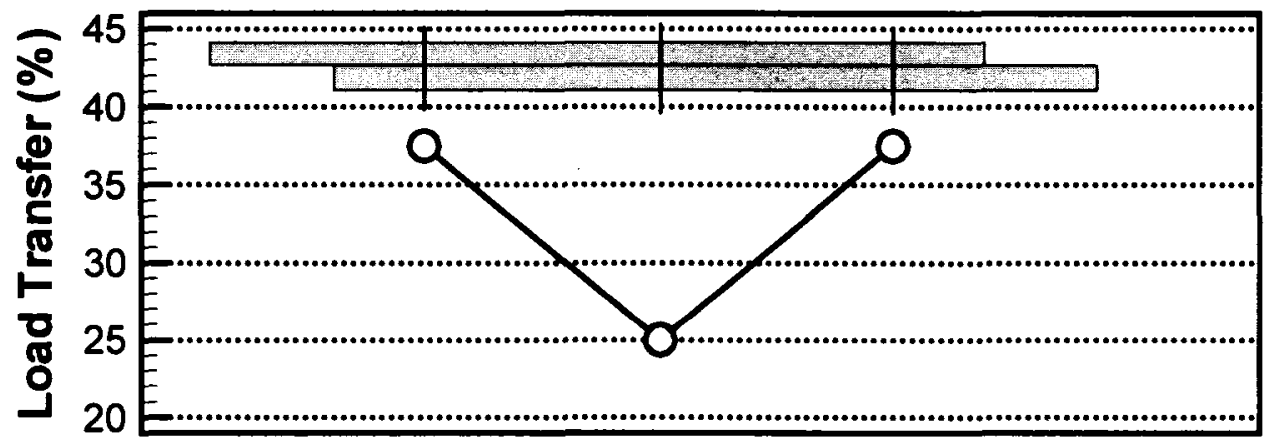

Rivet Location

Figure 2.16 Percentage of load transfer through each rivet in a 3 rivet splice [2].

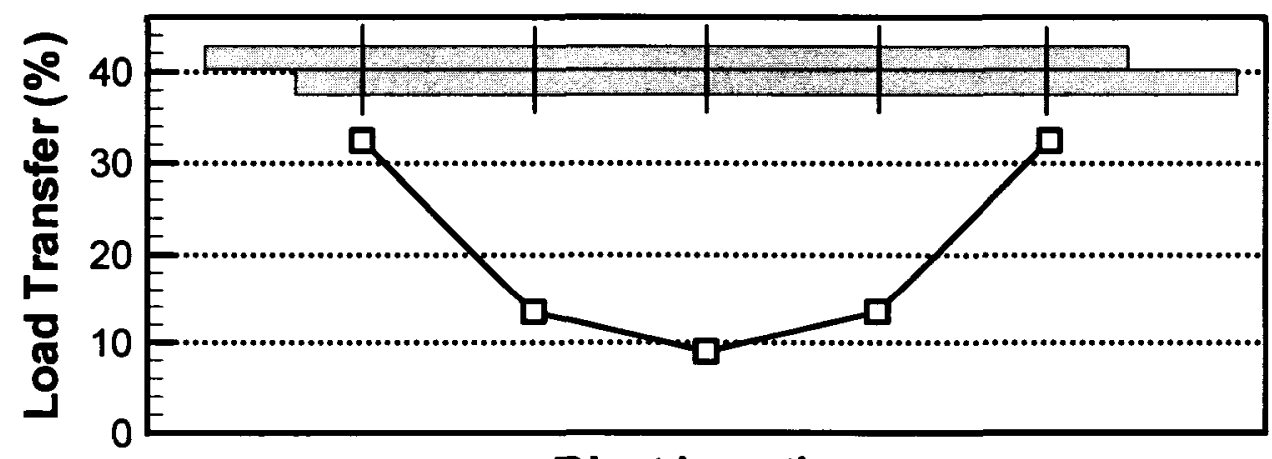

Rivet Location 
Figure 2.17 Percentage of load transfer through each rivet in a 5 rivet splice [2].

The previous equation represents load transfer for an idealized model that can only approximate reality. The equation will not represent load transfer in a dimpled splice nor will it accurately take into account details such as a countersunk hole, frictional load transfer, or secondary bending. To properly simulate the details of a loaded splice, a finite element model is best used. To get a good approximation of the secondary bending effects, a neutral line model, described in the next section, may be used.

\subsubsection{Secondary Bending}

The geometry of the single lap splice introduces secondary bending through asymmetry of the joint. Secondary bending is the term used to refer to the moment generated by the centres of the joining sheets being offset by the sheet thickness (Figure 2.18). This loading introduces stress concentrations at the outer rivet rows on the faying sheet surface. Sheet thickness and rivet spacing will affect the magnitude of these stresses with greater thicknesses and smaller row spacing contributing to greater bending.

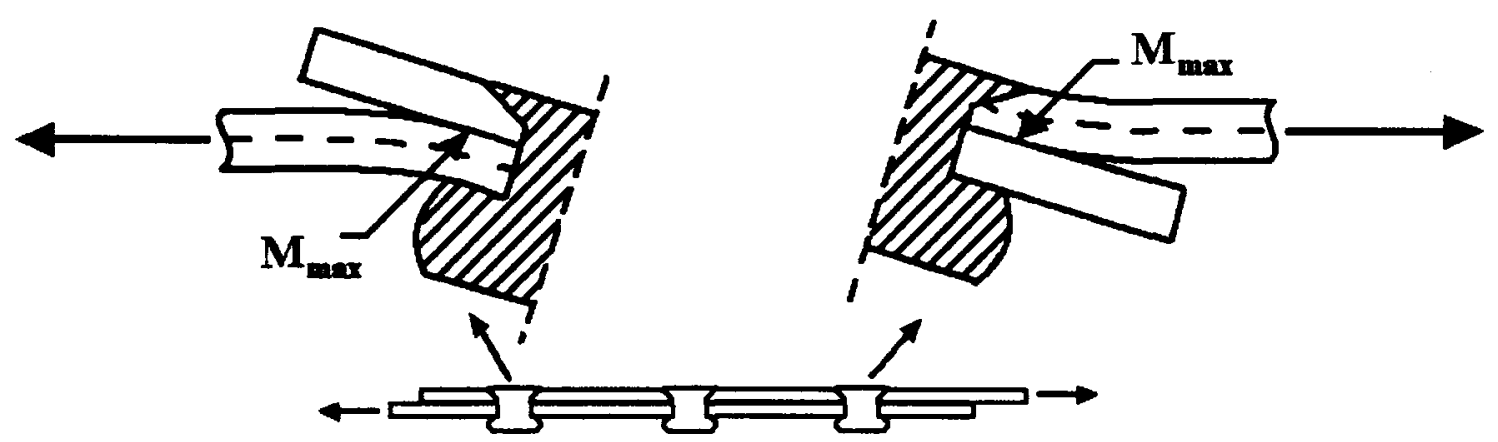

Figure 2.18 Locations of maximum moments in a splice due to secondary bending [2].

The moments and stresses generated from secondary bending in a particular splice can be predicted through the use of a neutral line model $[2,8,9]$ where a line is used to represent the transfer of load along the joint. Steps in the neutral line are included at the fastener locations 
(Figure 2.19). The neutral line model simplifies the joint by assuming infinitely stiff fasteners and a 2-D representation of the stress state.

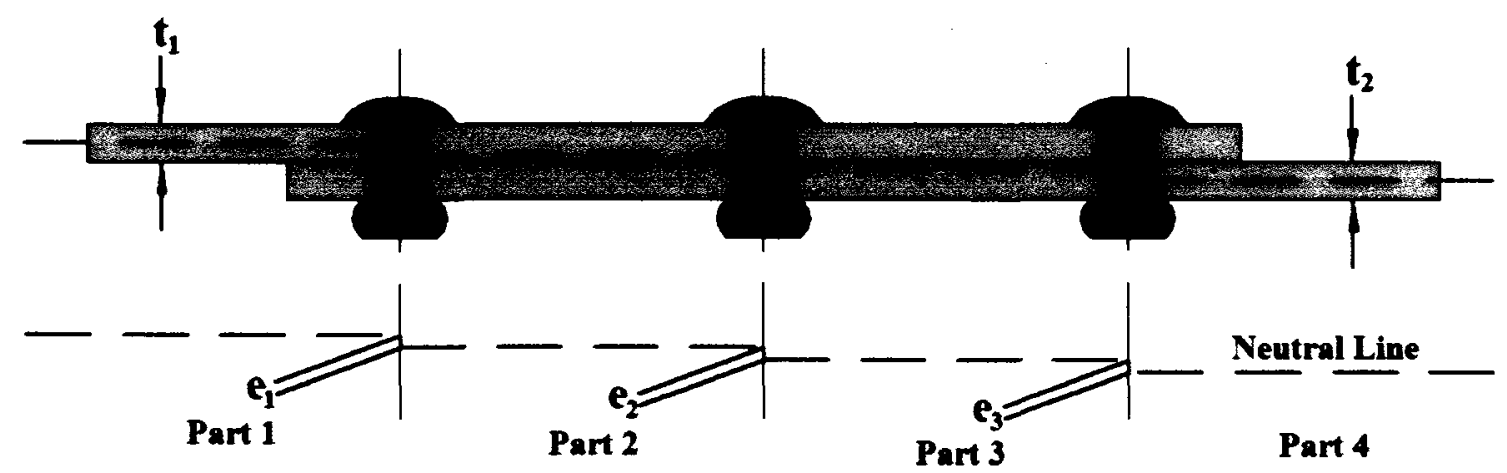

Figure 2.19 Application of the neutral line model to a 3-rivet row splice.

The differential equation that describes the deflection of the neutral line is given as

$$
\begin{gathered}
M_{x}=P \cdot w=E_{i} I_{i} \cdot \frac{d^{2} w}{d x^{2}} \Longrightarrow \frac{d^{2} w}{d x^{2}}-\alpha_{i}^{2} \cdot w=0 ; \\
\text { with } \alpha_{i}^{2}=\frac{P}{E_{i} I_{i}}
\end{gathered}
$$

which has the solution

$$
w_{i}=A_{i} \cdot \sinh \left(\alpha_{i} \cdot x\right)+B_{i} \cdot \cosh \left(\alpha_{i} \cdot x\right)
$$

given that

$M_{x} \quad$ is the secondary bending moment

P is the applied splice load (per unit width)

w is the out-of-plane sheet displacement

$E_{i} I_{i} \quad$ is the flexural rigidity of part $i$

$A_{i}, B_{i} \quad$ are the constants associated with the boundary conditions 
Boundary conditions for the solution are found by assuming equal slopes at either side of the rivet rows and solving for the unknown constants $A_{i}$ and $B_{i}$. The bending stress can then be found from the formula

$$
\sigma_{\text {bending }}=\frac{M_{x} \cdot z}{I}=\frac{P \cdot w(x) \cdot z}{I}=w(x)^{\prime \prime} \cdot E \cdot z
$$

where $\mathrm{z}$ is the distance from the neutral axis.

The degree of secondary bending is often given in terms of a secondary bending factor $\left(\mathrm{K}_{\mathrm{b}}\right)$ defined as

$$
K_{b}=\frac{\sigma_{\text {bending }}}{\sigma_{\text {applied }}}
$$

An example of the secondary bending stress compared to the applied bulk stress in a three rivet row lap splice is presented in Figure 2.20. The example shows how secondary bending stress at the outer rivet row is higher then the applied bulk stress. 


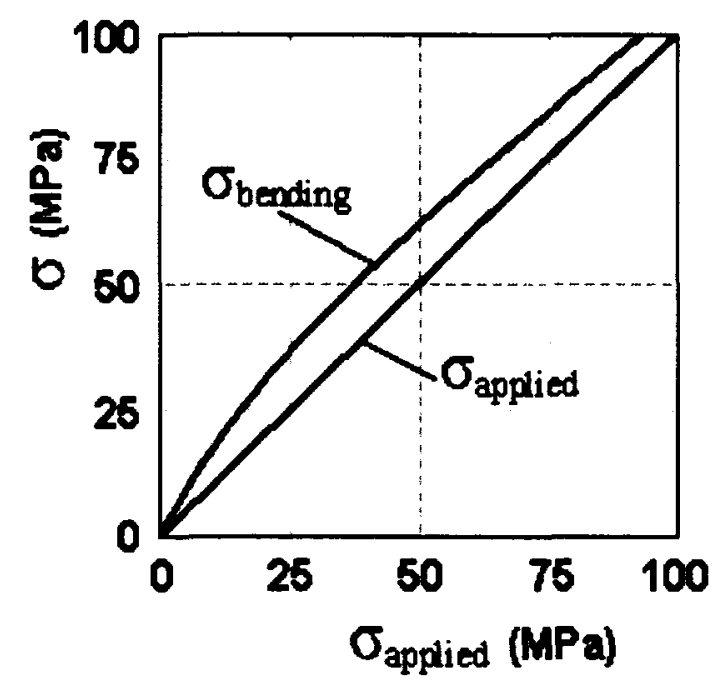

Figure 2.20 Secondary bending stress as a function of the applied stress in a three row single lap splice. Modified from [10].

The tensile stress field created by secondary bending interacts with the stress concentration at fastener holes and with regions of fretting damage to nucleate fatigue cracks. This effect can be compounded when countersunk rivets are required for aerodynamic performance since the presence of a countersink further weakens the sheet. As mentioned earlier, symmetrical designs exist that eliminate secondary bending but aerodynamic and cost constraints continue to make the single lap splice attractive to manufacturers. While secondary bending stresses decrease the fatigue life of a joint, residual stresses generated in the sheets during rivet forming can increase the fatigue life.

\subsubsection{Residual Stresses}

The last major contributor to the stress field in a loaded lap splice are residual stresses created through rivet squeezing and hole expansion. Residual stresses are formed in a material due to plastic deformation. When a rivet plastically expands a rivet hole both compressive and tensile stresses become locked in the material. Upon application of external loads, the total stress in the material becomes the sum of the residual stresses and the applied stresses. If the residual stresses are compressive, the applied tensile stresses in that region are effectively reduced. A compressive 
residual stress field can be especially beneficial for fatigue. A crack nucleating or propagating through a compressive residual stress field can slow or arrest due to the reduction in stress concentration at the crack tip. It is for this reason that interference fasteners are used in aircraft construction. Conversely, the formation of tensile residual stresses in a critical region can lead to premature failure of the component. Compressive residual stresses are typically located adjacent to the hole edge and tensile residual stresses are located outside the compressive stress field.

The effect of squeeze force on the formation of residual stresses has been widely studied $[2,3,11-13]$ to try and exploit compressive residual stress fields. The landmark work relating rivet squeeze force and fatigue life in riveted lap joints was performed by R.P.G. Müller [2]. Figure 2.21 shows the trend observed by Müller for expansion of a rivet hole as the rivet squeeze force is increased. At high squeeze forces, large hole expansions cause the formation of higher residual stresses, both tensile and compressive. Normally, the compressive region is closest to the rivet hole and is helpful in retarding crack nucleation. 


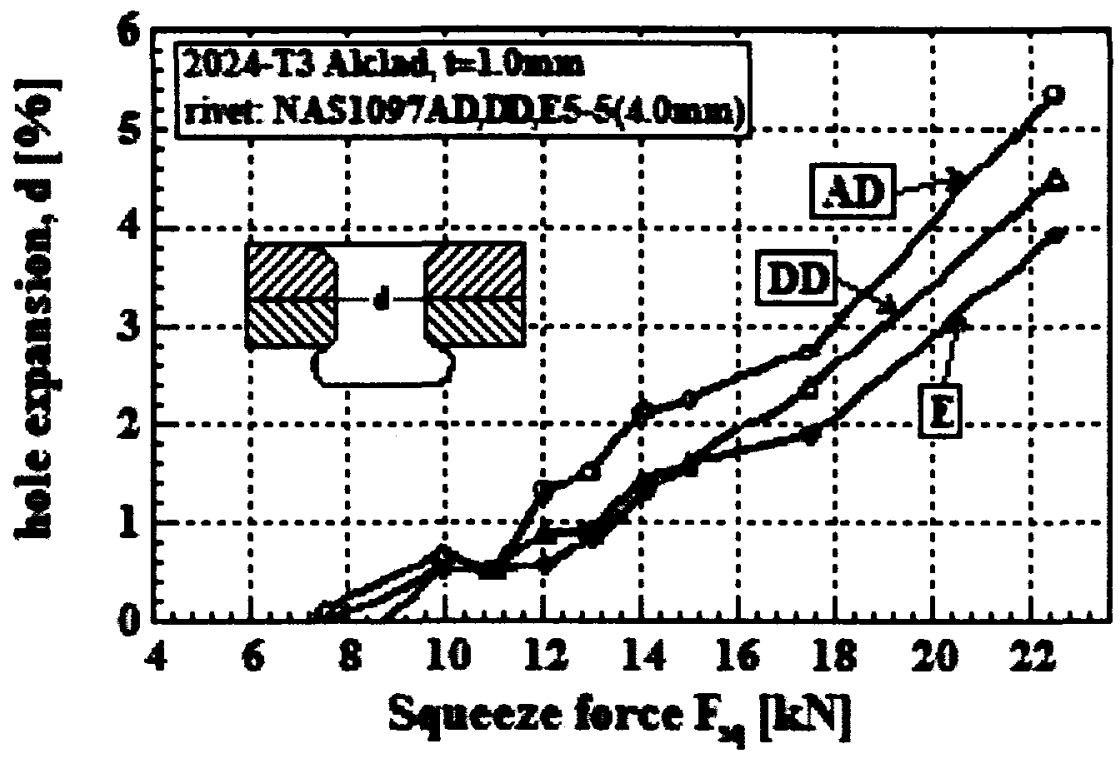

Figure 2.21 Plot relating hole expansion to the rivet squeeze force for three rivet material types $[2]$.

An elastic-perfectly-plastic hole expansion expression has been developed as a tool to predict the residual stresses formed around a hole. The expression, developed by Park and Atluri [14], consists of different components for the plastic region and for the elastic region surrounding a hole that is subject to a uniform pressure, $\mathrm{p}$. The uniform pressure is an idealization of the expansion in an actual riveted hole. Within the plastic region, the radial and hoop residual stresses are defined by

$$
\begin{gathered}
\sigma_{\text {radial }}=-p+\sigma_{y} \cdot \ln \left(\frac{r}{R_{0}}\right) \text { for }\left(R_{0} \leq r \leq r_{y}\right) \\
\sigma_{\text {hoop }}=\left(\sigma_{y}-p\right)+\sigma_{y} \cdot \ln \left(\frac{r}{R_{0}}\right) \text { for }\left(R_{0} \leq r \leq r_{y}\right)
\end{gathered}
$$

and outside the plastic region, the radial and hoop residual stresses are defined by

$$
\sigma_{\text {radial }}=-\frac{\sigma_{y}}{2} \cdot\left(\frac{r_{y}}{r}\right)^{2} \text { for }\left(r>r_{y}\right)
$$




$$
\sigma_{\text {hoop }}=\frac{\sigma_{y}}{2} \cdot\left(\frac{r_{y}}{r}\right)^{2} \text { for }\left(r>r_{y}\right)
$$

where $R_{0}$ is the hole radius and $r_{y}$ is the radius of the plastic zone. The radius of the plastic region around the hole is related to the applied pressure through the expression

$$
p=\sigma_{y} \cdot\left[\frac{1}{2}+\ln \left(\frac{r_{y}}{R_{0}}\right)\right]
$$

The expressions given above should only be used with the knowledge of several limiting assumptions made in the description of the residual stress field around a hole:

1. The material is assumed to be elastic-perfectly-plastic when it is known that strainhardening occurs during the plastic deformation of the hole.

2. The applied pressure simulates a uniform expansion though the sheet thickness when it is known that the amount of hole expansion changes through the thickness; especially with countersunk rivets.

3. The problem is considered one-dimensional when through-thickness clamping of the rivets actually makes it three-dimensional.

The previous sections have shown that the single lap splice has a complex stress state due to load transfer through fasteners, secondary bending, and residual stresses. The analytical methods that have been presented to calculate the contribution of each mechanism to the stress field only provide good first estimates. For a more rigorous evaluation of the stress field in a loaded splice, finite element methods are necessary.

Now that the basics of single lap splice design have been covered, a detailed explanation of fretting fatigue and of the work that has been performed on fretting fatigue in riveted lap splices will be presented. 


\section{$2.4 \quad$ Fretting Fatigue}

Nearly fifty years after the study of fatigue was introduced in the 1880's with the investigation of railway axle failures, the first work on fretting was conducted by Tomlinson [15] who focused on fretting damage and corrosion. The combination of fretting and fatigue, however, was not included in the study. It was not until 1941 that Warlow-Davies [16] began fatigue tests of prefretted coupons and 1953 that McDowell [17] performed simultaneous fretting fatigue tests. In the second half of the twentieth century, significant work was undertaken by Waterhouse with much of his work summarized in two books on the subject $[18,19]$. Despite the decades of research into the fretting phenomenon, there still remains a great deal of work to be done on fretting fatigue including the development of standardized tests.

It is known that fretting occurs when two clamped bodies undergo relative micro-scale oscillatory motion. Although no standardized description of fretting fatigue has been agreed upon to date, it is widely accepted that fretting fatigue is a "synergistic competition among wear, corrosion and fatigue phenomena driven by both the micro-slip at the contact surface and cyclic fretting contact stresses [20].”

At the micro-scale level the fretting process is believed to be a progression of damage taking place over many cycles. The damage incurred during each cycle is described below and illustrated in Figure 2.22 a-e:

a) Contact. At the micro-scale level, nearly all smooth surfaces have a distinguishable roughness. The peaks on the surface, called asperities, are the points that will touch when two surfaces are placed in contact. In a typical cold rolled aluminum sheet, the height of the asperities (t) can be on the order of $0.01 \mu \mathrm{m}$. 
b) Normal loading. Upon the application of pressure between the two surfaces, asperities in contact will plastically deform and cold weld together. If surface oxides are present, these are normally worn away under shear loading before cold welding occurs.

c) Shear loading. When relative shear loading is applied between the contacting surfaces, in addition to the normal pressure, further yielding will result as well as the formation of micro-cracks in the surface. These micro-cracks may be worn away under future loading cycles or may propagate into the substrate as fatigue cracks in the presence of a tensile stress field.

d) Breaking contact. If the shear loads are high enough, they will eventually break the cold welds between the asperities. This will expose bare surface material that will oxidize and may form debris that is also subject to oxidization. The debris often remains between the surfaces and can contribute to the wearing away of surface micro-cracks. Evidence of fretting debris formation can be found as a powder around the contacting surfaces.

e) Shear reversal. Reversal of the cyclic shear load causes new cold welds to form. Every cycle has the potential to form new wear particles, expose bare substrate for oxidation, and create new micro-cracks. 


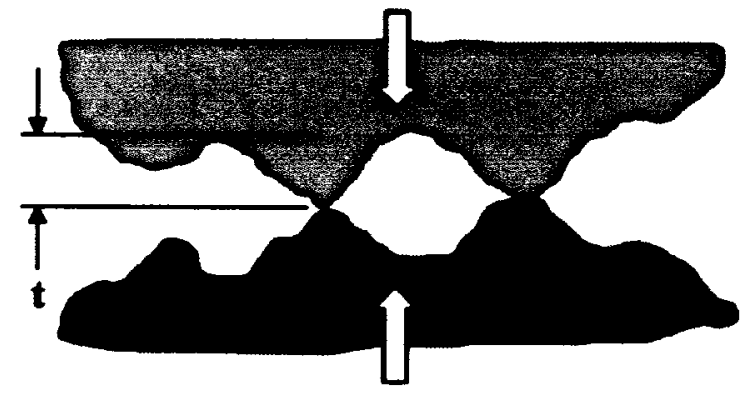

Figure 2.22 a Contact of surface asperities.

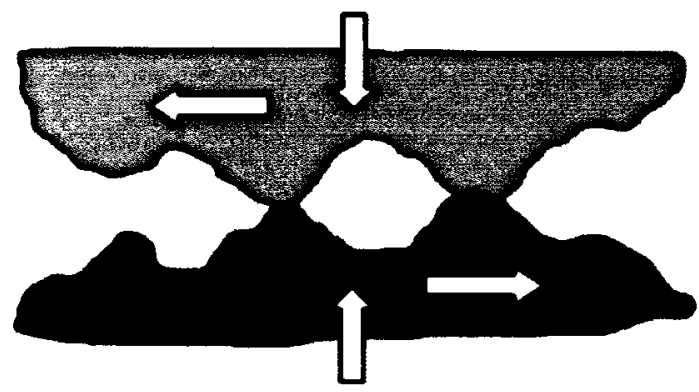

Figure 2.22 c Application of shear loading.

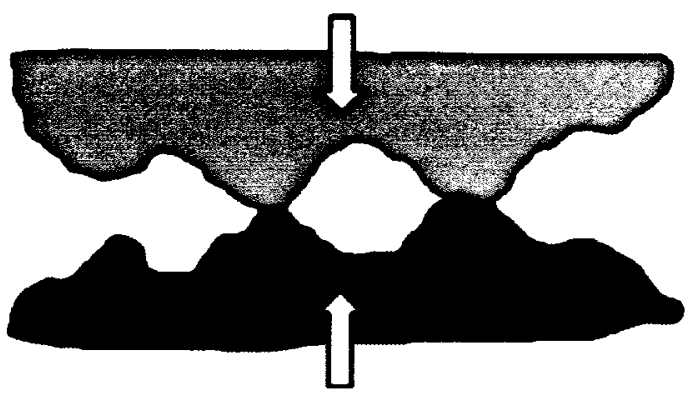

Figure 2.22 b Cold welding of asperities under normal load.

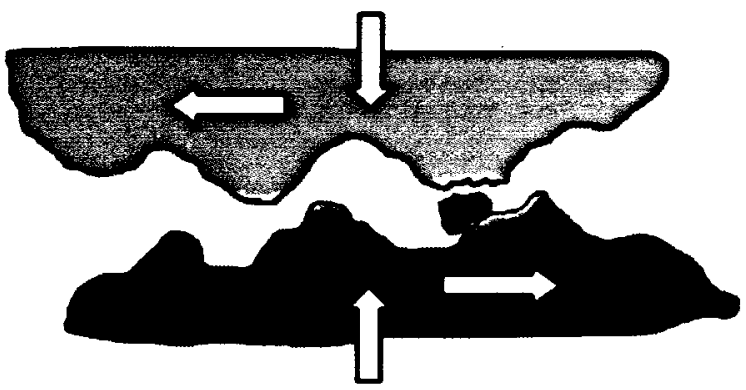

Figure 2.22 d Breaking of cold welds. Formation of debris.

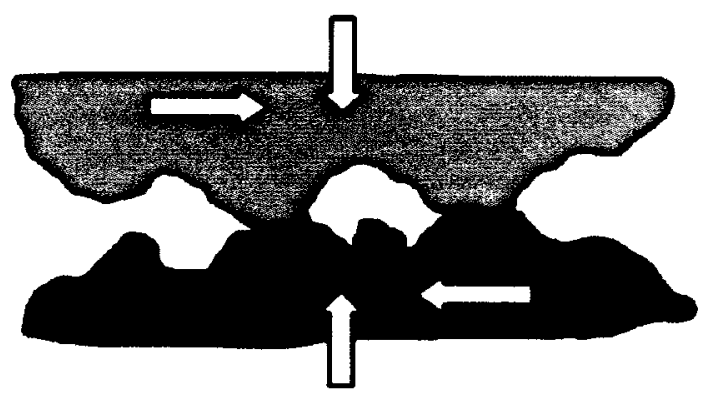

Figure 2.22 e Reversal of loading. Re-establishing cold welds. 
Since fretting damage can occur between any clamped components that are subjected to relative motion, fretting damage is common throughout aircraft components. Most notably, fretting is a problem for the components in gas turbine engines. Many types of gas turbine engines use a dovetail joint to fix fan and compressor blades to the rotor disk. A schematic of a dovetail design is shown in Figure 2.23. Micro-scale relative motion is generated between the blade root and the disk whenever the engine power is changed. The most severe fretting damage occurs at the edge of contact where the relative displacement is largest. The edge of contact is also where fatigue cracks will nucleate. Research on this contact problem is ongoing for both bare and coated advanced alloys such as titanium and nickel-based superalloys.

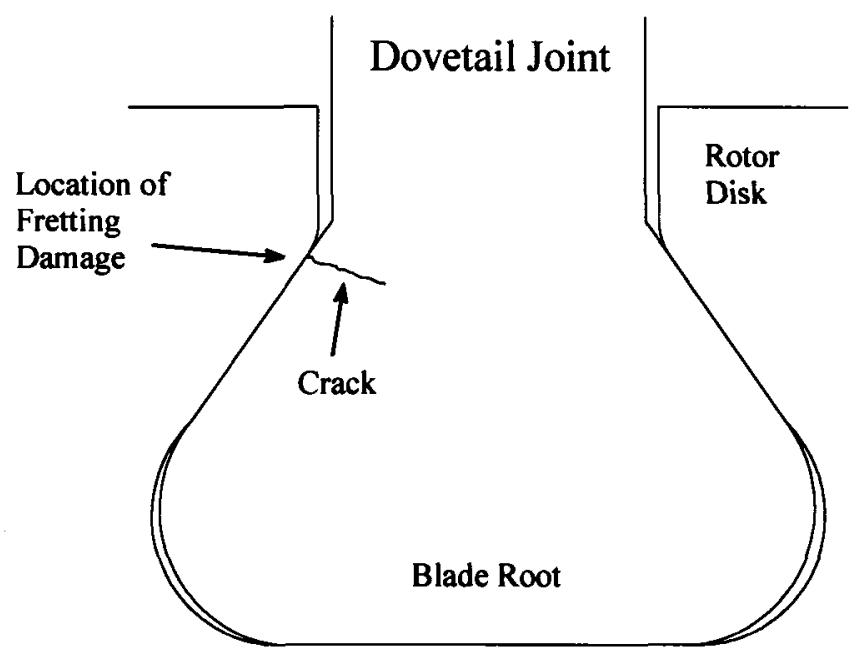

Figure 2.23 Dovetail joint used in gas turbine engines.

Another aeroengine component subject to fretting fatigue is a spline coupling. Spline couplings are normally used between connected shafts that transfer torque. Figure 2.24 provides an illustration of a mated splined shaft and Figure 2.25 provides a photo of cracks in a splined shaft that nucleated from fretting damage. Research on predicting fretting fatigue failure in splined shafts has been performed with the goal of reducing some of the costly fatigue test requirements for aeroengines [21]. 


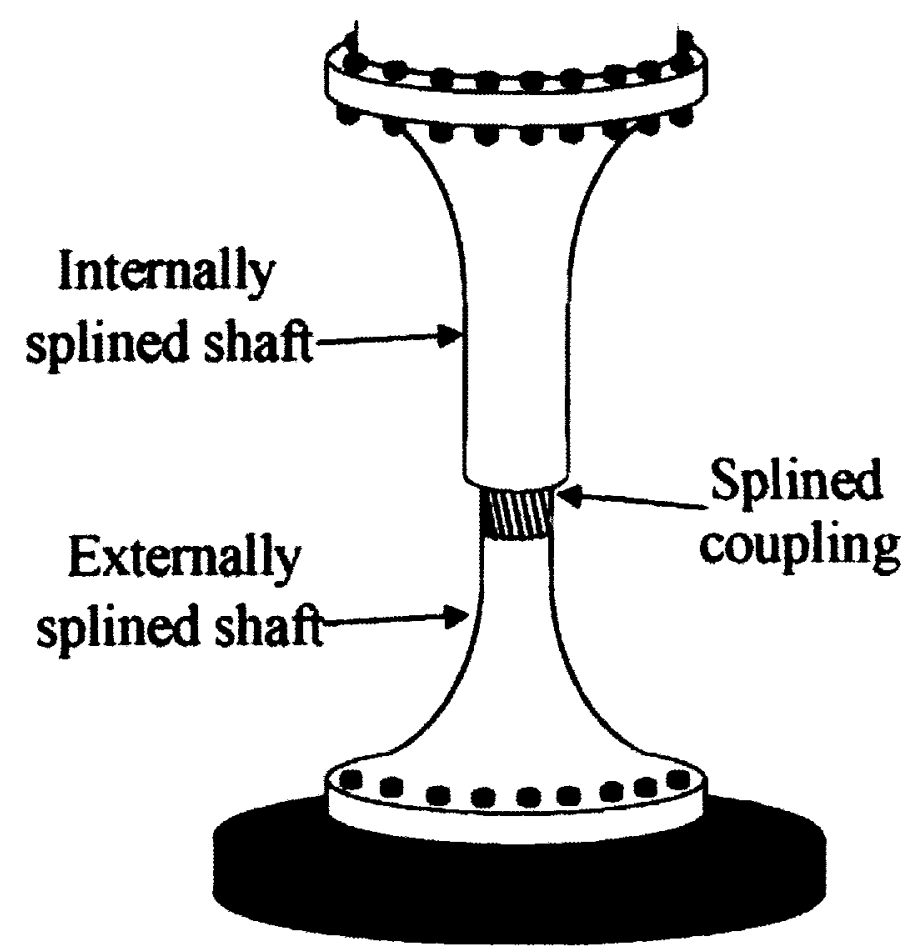

Figure 2.24 Schematic of an aero-engine spline coupling [21].

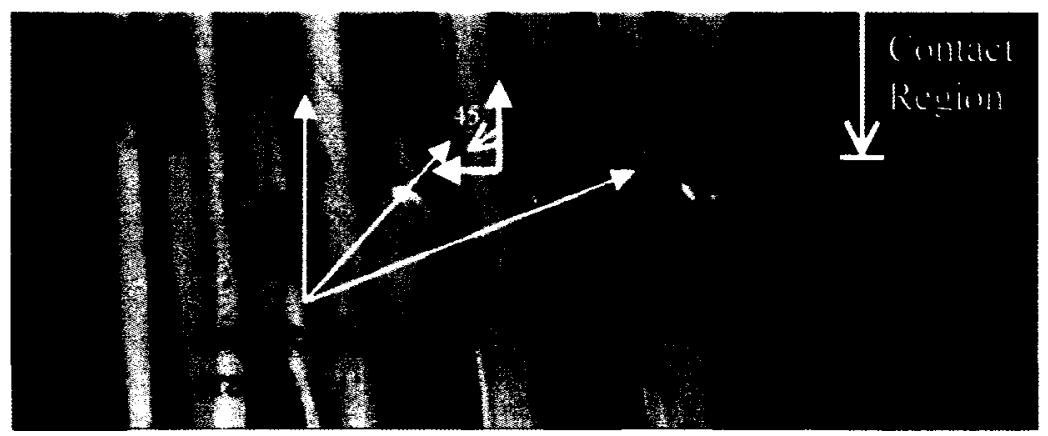

Figure 2.25 Crack formed from region of fretting damage in an aero-engine spline coupling [21].

Other industries also face problems with fretting; one being the bio-medical industry. In prosthetic implants, such as total hip or knee replacements, fretting wear is of great concern as it may cause premature failure or the wear debris may be harmful to the patient. Some wear debris may be considered harmful because titanium alloys are a commonly used material and the constituent components vanadium and aluminum are known to be toxic. Figure 2.26 illustrates a prosthetic hip joint and indicates that fretting damage can occur between the implant/bone 
interface in the femur or between the contacting surfaces of the hip ball joint. To reduce the impact of fretting in biomedical devices, research is being conducted into various types of fretting resistant surface treatments.

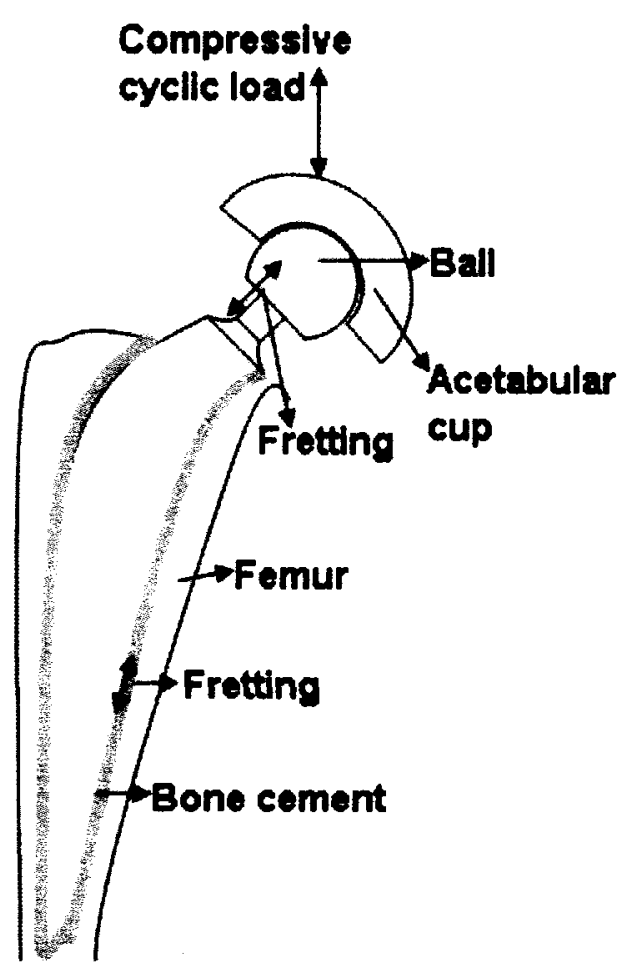

Figure 2.26 Schematic of total hip replacement prosthetic subject to fretting [22].

Nowell and Hills [23] note that fretting fatigue conditions also frequently, "occur in bolted or mechanically fastened joints" which includes aircraft structural components. Black oxide powder, indicative of fretting in aluminum, is often observed coming from riveted fuselage lap splices. It has been noted by several researchers that cracks in splices, subject to fatigue, nucleate from regions of fretting damage at and around the rivet holes.

In all of these examples attempts have been made to predict the fretting fatigue life. Some of these predictive models are presented in the following section. 


\subsubsection{Predictive Life Models for Fretting}

Several methods have been proposed to predict fretting fatigue and summaries of three more common approaches are presented here. The methods include notch analogies, asymptotic approaches, and critical plane multi-axial fatigue approaches.

In notch analogy methods, it is suggested that it may be possible to apply traditional notch fatigue life prediction approaches to fretting fatigue. This method requires the matching of stresses along a line at the location of contact peak stresses (the location must be previously known) to a line at the notch bisector (Figure 2.27). Good life prediction results can be achieved by altering the notch size, bulk load, opening angle, and root radius. Requiring previous knowledge of the critical location and magnitude of the stresses in the component can cause a problem as these may not be known in more complex geometries.
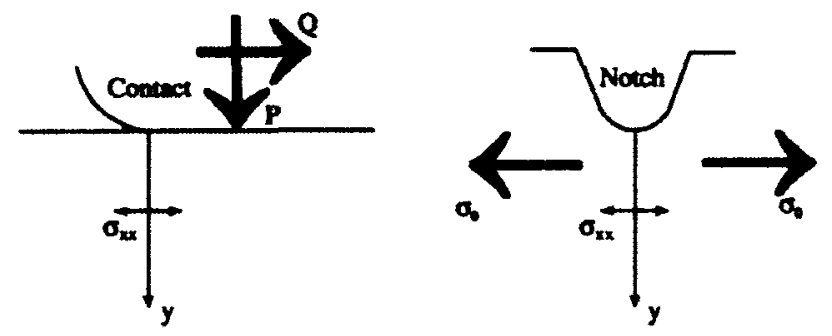

Figure 2.27 Line stress matching for notch analogy [24].

Asymptotic predictive approaches are based on parallels between stresses close to the edges of a flat punch and stresses at the tip of an elastic crack [25]. Tangential loading of the punch in contact with a flat plane would therefore be represented as mode II loading of the crack. The fretting fatigue crack growth would then be related to the problem of a branch crack growing from the tip of an elastic crack. Recent work by Giannakopoulos [26] has extended the previous method to a flat punch with rounded corners. The analogy for this geometry is with a blunt notch 
rather than a crack. The geometries to which this method applies, however, are restricted and do not have much potential for complex fretting situations.

Multi-axial fatigue approaches have also been developed based on 'critical plane' methods. Fatigue loading in fretting contact is multi-axial because of the applied fatigue loads and the contact between the bodies. The critical plane method focuses on a plane within the material where maximum damage occurs. Socie [27] modified the definition of the SmithWatson-Topper strain life parameter to make it a multi-axial fatigue critical plane parameter. Socie defined the critical plane as the plane where the product of the principal strain amplitude and the maximum normal stress on the principal plane is a maximum. Two different predictive life models were proposed based on whether the primary failure mode was tensile or shear. The characteristic failure mode had to be identified before applying the appropriate fatigue life model. The tensile failure SWT model was later used by Szolwinski and Farris [20] from Purdue University to predict failure in cylinder-on-flat geometries subject to fretting fatigue. The definition of the critical plane was changed, however, to that where the product of the strain amplitude and maximum normal stress is a maximum. The critical plane SWT parameter has since been studied by a number of authors [21, 28-30].

Use of multi-axial approaches normally involves developing an algorithm that uses stress and strain data from a component to incrementally search for the critical plane. Good results have been obtained for fretting fatigue life predictions using the critical plane SWT parameter in conjunction with finite element methods $[12,21]$.

\subsection{Fretting Fatigue of Riveted Lap Splices}

Although it is recognized that fatigue cracks nucleate from regions of fretting damage, the phenomenon has largely been ignored or treated in a qualitative way when designing for fatigue 
in riveted lap splices. It is only recently that some focus has been placed on fretting damage in splices and its effect on crack nucleation. The largest drivers for crack growth in lap splices are the stress concentrations due to the presence of the hole and secondary bending stresses caused by the splice geometry. Nucleation of a crack, however, begins with a flaw in the material. A flaw may come in the form of persistent slip bands, inclusions, voids, pits, etc. Often in splices, the flaw is a surface micro-crack created from fretting damage. Micro-cracks (Figure 2.28) form at the edge of contact between clamped regions such as the rivet/hole interface or between the faying sheet surfaces under a rivet (Figure 2.29).

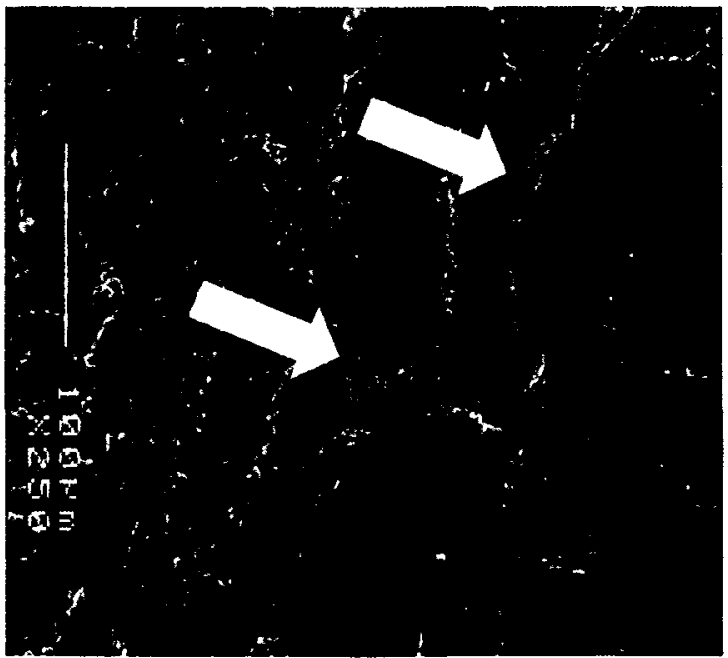

Figure 2.28 Surface micro-cracks in a region of fretting damage.

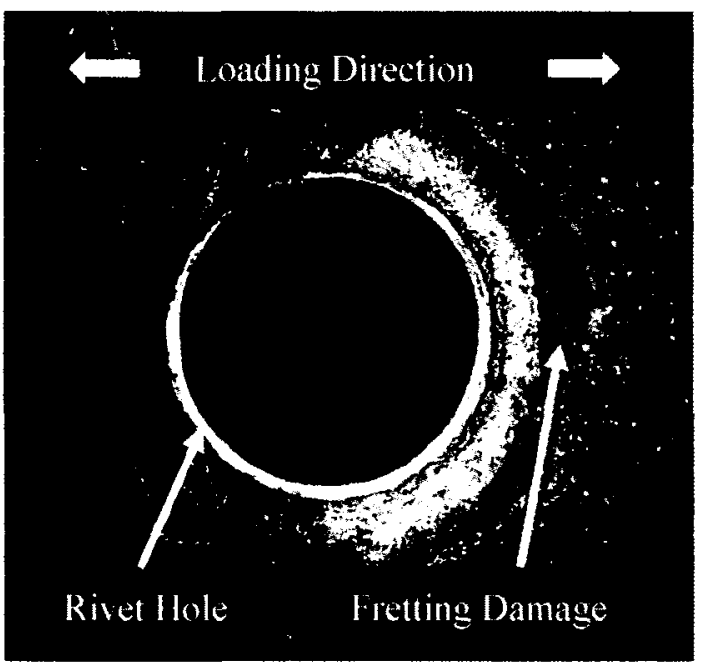

Figure 2.29 Fretting damage on the sheet faying surface around a rivet hole.

The severity of the fretting damage will depend on the degree of clamping provided by the formed rivet, the surface treatment of the contacting surfaces, and the slip amplitude created by the application of a bulk load in the splice. Simple contact geometries have been used to study these parameters in the past but for complex geometries, such as lap splices, finite element methods are required. Prediction of fretting fatigue life in complex components remains a subject of interest for researchers. 


\subsubsection{Finite Element Simulation of Fretting in Splices}

A research group at Purdue University has done some introductory investigations into fretting crack nucleation in single lap splices $[12,13,31,32]$. The research was limited, however, to splice geometry consisting of three rows of universal (MS20470) rivets and relatively thick (1.8$2.3 \mathrm{~mm}$ ) untreated 2024-T3 aluminum sheet. In joints of that thickness, with low rivet interference, it was found that the critical fretting region is the rivet/sheet interface and that cracks did not nucleate from the faying sheet surface. The assumption of low interference between the rivet and sheet is a simplification that does not represent real riveted fuselage structure. In splices used in this study, rivet interference is considerable and the critical fretting region and location of crack nucleation is on the faying sheet surface surrounding the hole $[8,33,34]$. This means that the type of surface treatment applied to the sheet becomes an important variable.

Finite element models created by the Purdue group utilized a variety of methods to simulate the riveted joints. These included 2D and 3D shell models as well as axi-symmetric rivet forming models. Szolwinski and Farris simulated rivet forming in $2.3 \mathrm{~mm}$ sheet and found the rivet clamping to be negligible [13]. As a result, Harish and Farris later used a $2 \mathrm{D}$ model to simulate splice loading [32]. The 2D model from [32] included representative mid-plane residual stresses obtained from a rivet forming model but this could be a significant simplification. Secondary bending stresses were also excluded from the shell models which is a considerable oversight. In addition, the models did not provide results for the contact distribution on the surface of the splice during sheet loading. Knowledge of the contact area is important for correlating the location of crack nucleation in sheets with high rivet interference to actual tested splices.

Another group, from Vanderbilt University, examined fretting in pinned connections with coarse finite element models [35]. The coarseness of the models did not allow for accurate 
determination of fretting contact stresses or faying surface clamping. Interference was included but the rivet forming step was not performed in the simulation. The interference was introduced by forcing conformity of an oversized rivet into the rivet hole. This provided a simplified estimation of uniform interference between the rivet and the hole. Other studies have shown that hole expansion with driven solid rivets is not uniform through the sheet thickness [36].

The work discussed here on fretting in lap splices has shown that there is a need for a more rigorous study of the problem. Therefore, it was decided that the next step in this research would be the development of a finite element splice model that included the effects of high rivet interference, rivet clamping, and secondary bending. The model development will begin, as described in the dissertation overview, with the verification and validation of simulation parameters and the modelling methodology to be used. 


\section{Rivet Forming Model}

\subsection{Introduction}

A rivet forming simulation was performed for two reasons. First, it was beneficial to know the variation in residual stress through the sheet thickness. As previously discussed, the assumption made by Harish and Farris [32] in their study of lap splice fretting was that the mid-plane residual sheet stress was sufficient for fatigue life predictions; therefore, a 2D splice model was used. It was important in this work to identify if, for $1 \mathrm{~mm}$ thick sheet material, variation in the throughthickness residual stress state was significant enough to require a 3D lap splice simulation. A previous study by Rans [36] had shown a significant difference in through-thickness hole expansion due to rivet forming in thin sheet. The expansion increased with increasing rivetforming load. The results presented by Rans suggest that a mid-plane approximation is not suitable.

Second, a refined simulation focusing only on rivet forming created an opportunity to examine the residual sheet clamping provided by rivets. As mentioned in section 2.5.2, Szolwinski and Farris simulated rivet forming of MS20470 universal rivets in $2.3 \mathrm{~mm}$ sheet material and found the faying surface rivet clamping to be negligible [13]. Early in this research, observations from failed splice coupons manufactured with thin sheet showed evidence of considerable sheet clamping beneath the rivet which brought doubt to the results of Szolwinski 
and Farris' simulations. The following presents results for both residual stresses through the sheet thickness and residual clamping of the sheets after rivet springback.

\subsection{Modelling Details}

The finite element simulations presented throughout this document made use of large strain, large displacement (small strain, small displacement for 2D implicit simplified fretting contact geometry) elasto-plastic constitutive models that included isotropic hardening. Linear 2D quadrilateral and linear 3D brick continuum elements used single point integration with hourglass control. The constitutive equations made use of the centroidal strain measure. The $2 \mathrm{D}$ implicit simulations employed Green-Naghdi stress rates whereas the 3D explicit simulations made use of Jaumann stress rates. In terms of mesh refinement, all simulation cases used h-refinement. By default, nonlinear convergence in Abaqus is based on both force and displacement criteria.

Specific to the rivet forming study, 2D axi-symmetric models were developed for machine countersunk (NAS1097AD-4-4) and universal (MS20470AD-4-4) rivet forming scenarios. The explicit solver of Abaqus v6.6.1 was used and all mesh generation was performed using Hyperworks Hypermesh v8.0. The rivet and sheet meshes after forming are shown in Figure 3.1 and Figure 3.2 for the machine countersunk and the universal rivets respectively.

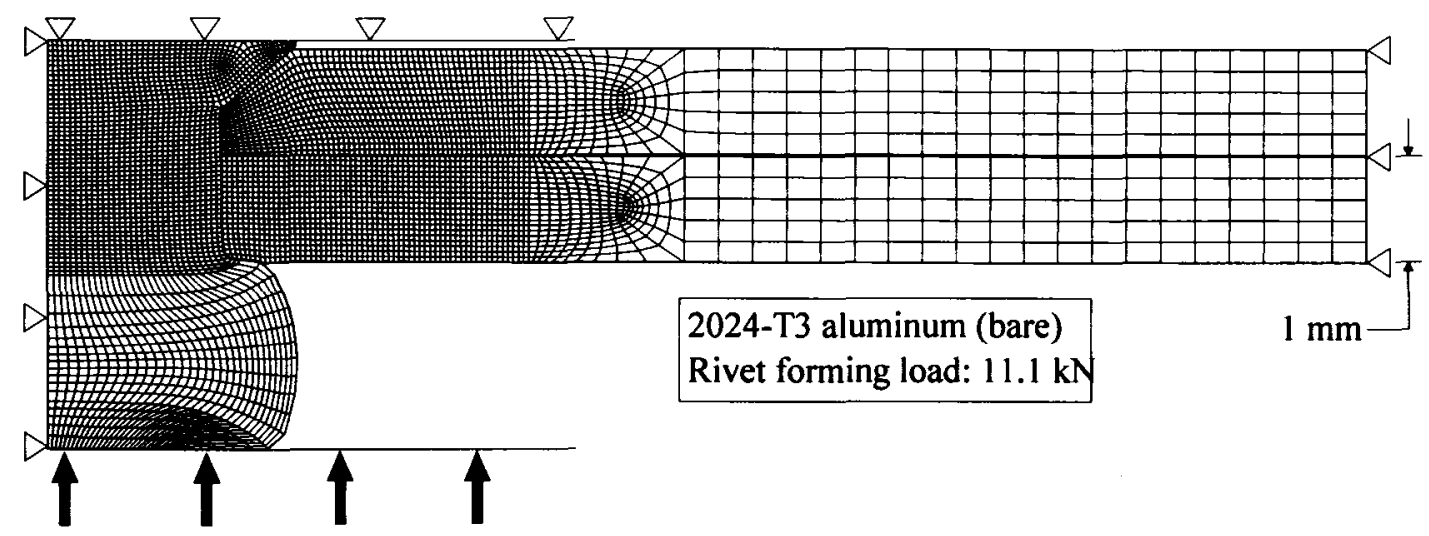

Figure 3.1 Formed mesh and boundary conditions of countersunk rivet forming model. 


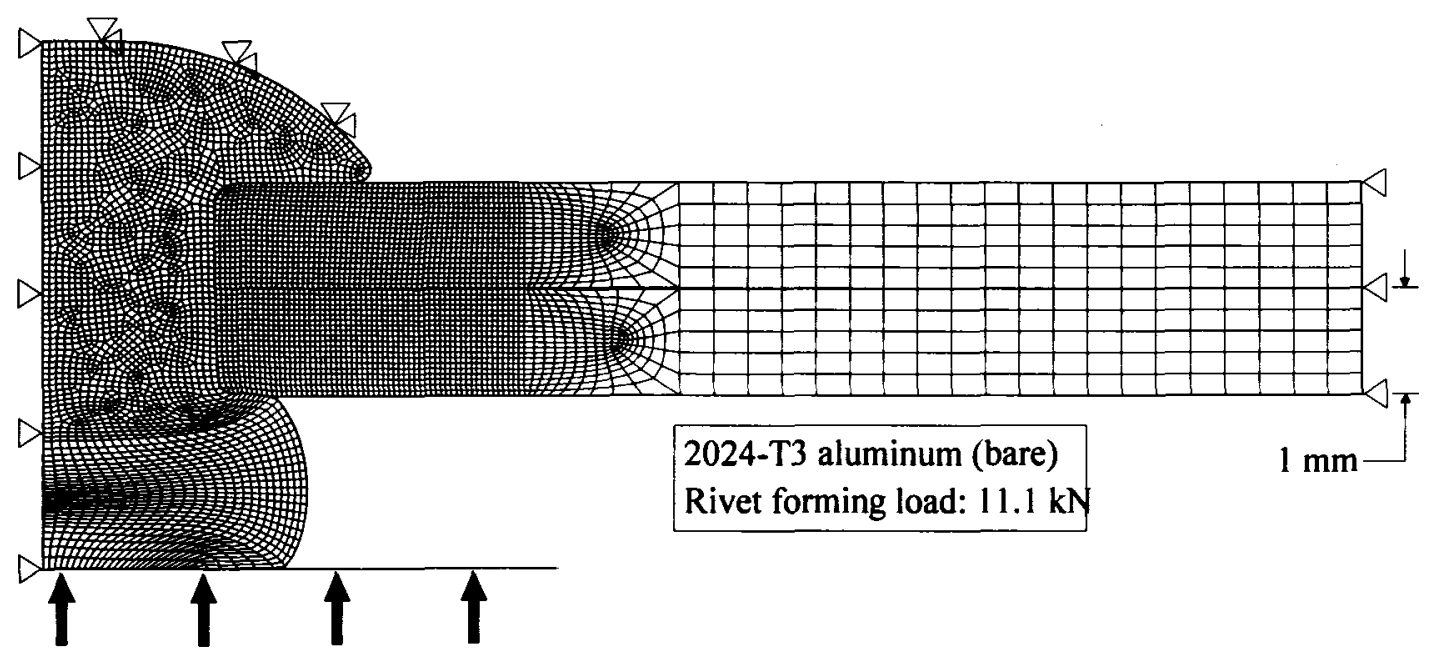

Figure 3.2 Formed mesh and boundary conditions of universal rivet forming model.

Contact was enforced using a penalty contact definition and a coefficient of friction of 0.178 [37]. The 2024-T3 sheet material model was based on Ramberg-Osgood parameters [38] whereas the 2117-T4 rivet material was based on two power law curves taken from [12]. CAX4 elements (4-node bilinear axi-symmetric quad) were used in the mesh of the rivets and sheets and RAX2 elements (2-node linear axi-symmetric rigid link) were used to simulate the forming tools. Four different rivet squeeze forces were simulated: $6.7 \mathrm{kN}, 8.9 \mathrm{kN}, 11.1 \mathrm{kN}$, and $13.3 \mathrm{kN}(1500$ $\mathrm{lbf}, 2000 \mathrm{lbf}, 2500 \mathrm{lbf}$, and $3000 \mathrm{lbf}$ ). The ends of both sheets were constrained in the $\mathrm{x}$-direction at $12.7 \mathrm{~mm}(0.5 \mathrm{in})$ from the hole centre and the top forming die was fixed in the $\mathrm{x}$ and $\mathrm{y}$ directions to prevent rigid body motion.

Two steps were used in the model; rivet loading and rivet springback. The loading and springback steps were each performed over 0.06 seconds due to the quasi-static nature of the problem. To obtain confidence in the results, comparisons were made to similar analyses performed by Rans [8] and a convergence study was performed. The results of the convergence study are presented in the following section. 


\subsubsection{Convergence Results}

Convergence was based on the residual hoop stress present in the sheets after springback of the rivet. The convergence results are shown in Table 3.1. The fine rivet mesh was used for the remainder of the axi-symmetric analyses.

Table 3.1 Convergence results for universal rivet forming model.

\begin{tabular}{|c|c|c|c|c|}
\hline Model & $\begin{array}{c}\text { Number of through- } \\
\text { thickness elements in } \\
\text { sheet }\end{array}$ & $\begin{array}{c}\text { Max. Hoop stress } \\
\text { in sheets MPa (psi) }\end{array}$ & $\begin{array}{c}\text { Difference in stress } \\
\text { value from previous } \\
\text { model MPa (psi) }\end{array}$ & $\begin{array}{c}\text { \% Difference } \\
\text { from previous }\end{array}$ \\
\hline Coarse & 5 & $111.2(16132)$ & - & - \\
\hline Med & 10 & $132.4(19210)$ & $21.2(3077.9)$ & 16.0 \\
\hline Fine & 20 & $184.4(26751)$ & $52.0(7541.5)$ & 28.2 \\
\hline XFine & 40 & $188.6(27353)$ & $4.2(601.5)$ & 2.2 \\
\hline
\end{tabular}

\subsection{Results and Discussion}

The results of the through-thickness residual stress distributions are plotted in Figure 3.3 to Figure 3.6 for splices riveted with NAS1097AD-4-4 rivets and in Figure 3.7 to Figure 3.10 for splices riveted with MS20470AD-4-4 rivets. Splices with these two rivet styles will be referred to as "machine countersunk", and "universal" from here on in this document to simplify discussion. The residual stress distributions for both the machine countersunk and universal splices were examined for the four rivet squeeze forces listed earlier. Only the results for the $13.3 \mathrm{kN}$ rivet squeeze force are presented here with the results for the other squeeze forces available in Appendix A.

The plots show data extracted from trace lines at the outer, middle, and faying sections of the inner and outer sheets. In this manner, the variation of the residual stresses through the thickness can be quantified without requiring a contour plot. Both the residual hoop stresses, widely recognized as a primary factor behind crack retardation, and residual radial stresses are presented. The distance and the stress variables on the plots have been normalized for clarity. 


\subsubsection{Residual Stress Results for Machine Countersunk Rivets}

For the outer sheet of the machine countersunk splice, the most important data is that of the middle and faying surface residual stresses. Due to the countersink, the data for the outer portion of the sheet is only up to the countersunk rivet head. Evident is a distinct difference between both the hoop and radial residual stresses for the mid-surface and faying surface plots. Figure 3.3 shows the mid-sheet residual hoop stresses as more compressive than the faying surface residual stresses. This finding agrees with observations of cracks nucleating on the faying surface of thin sheet splices. It is recognized that this is not the only driver for crack nucleation on the splice faying sheet surface. Figure 3.4 shows less variation between the mid-surface and faying surface stresses but the difference is noticeable.

Figure 3.5 and Figure 3.6 show the greatest difference between the residual stresses at the rivet hole edge and at a distance of approximately one radius from the hole edge. As the formed rivet head creates greater expansion than the manufactured rivet head, the radial residual stress in Figure 3.6 shows large compressive residual stresses at the hole edge for the outer surface of the inner sheet. 


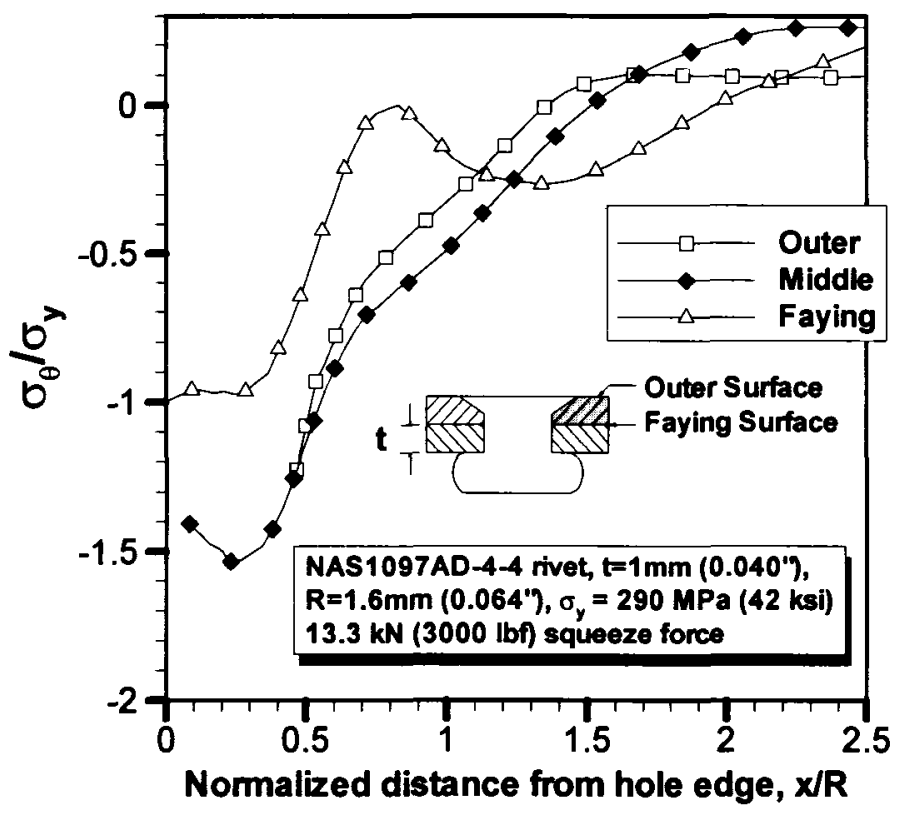

Figure 3.3 Hoop residual stress through the outer sheet thickness. Machine countersunk rivets.

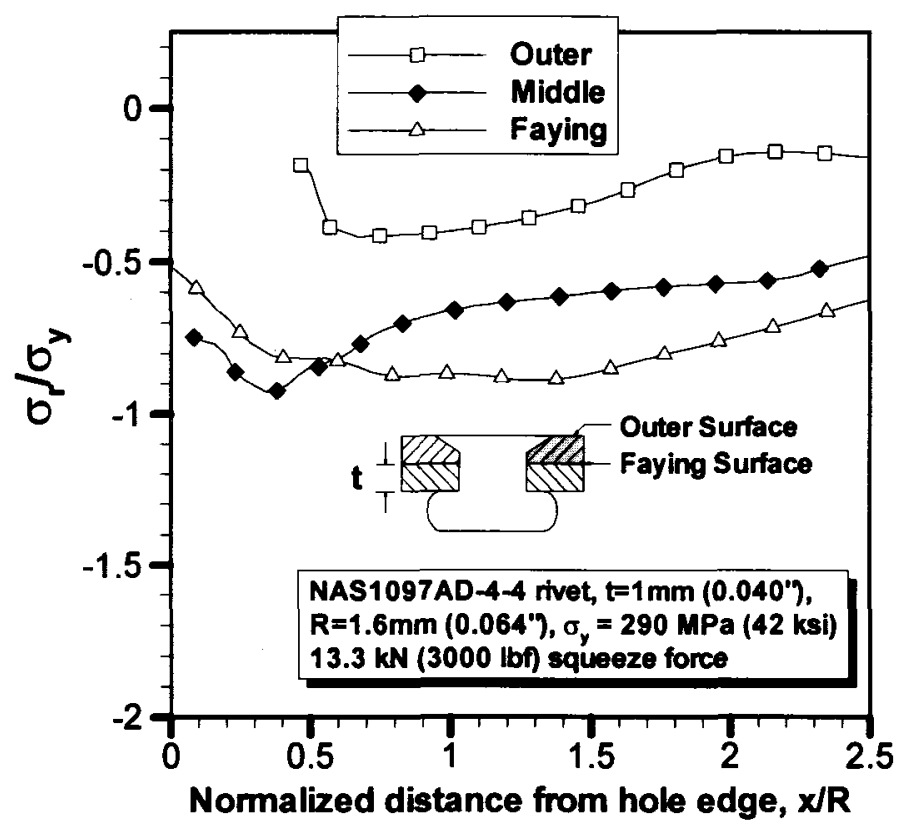

Figure 3.4 Radial residual stress through the outer sheet thickness. Machine countersunk rivets. 


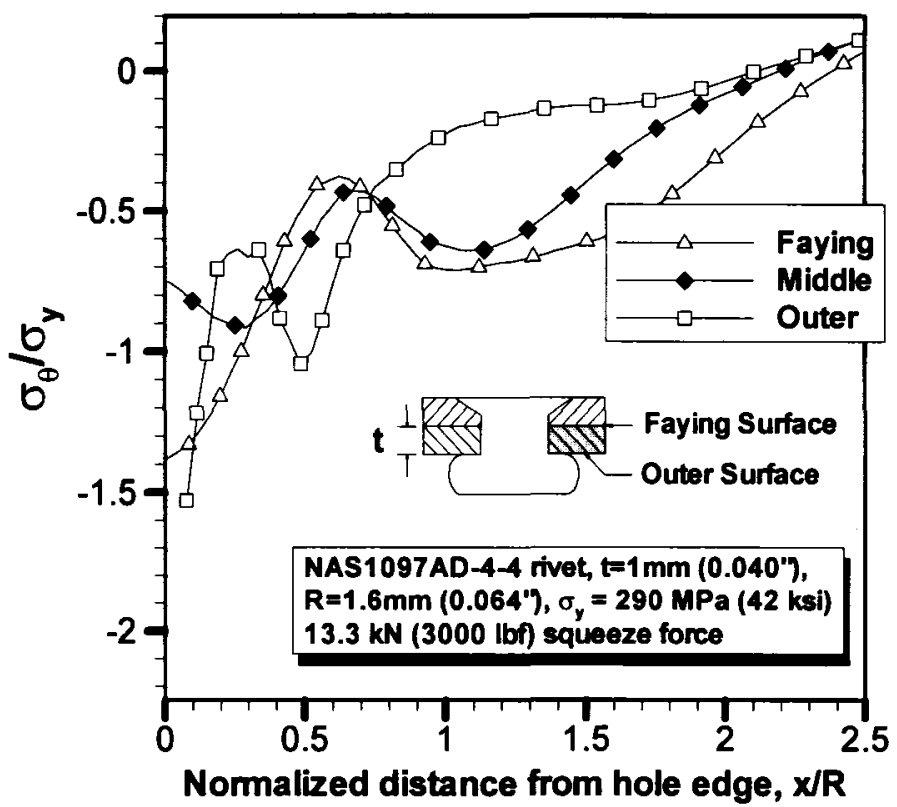

Figure 3.5 Hoop residual stress through the inner sheet thickness. Machine countersunk rivets.

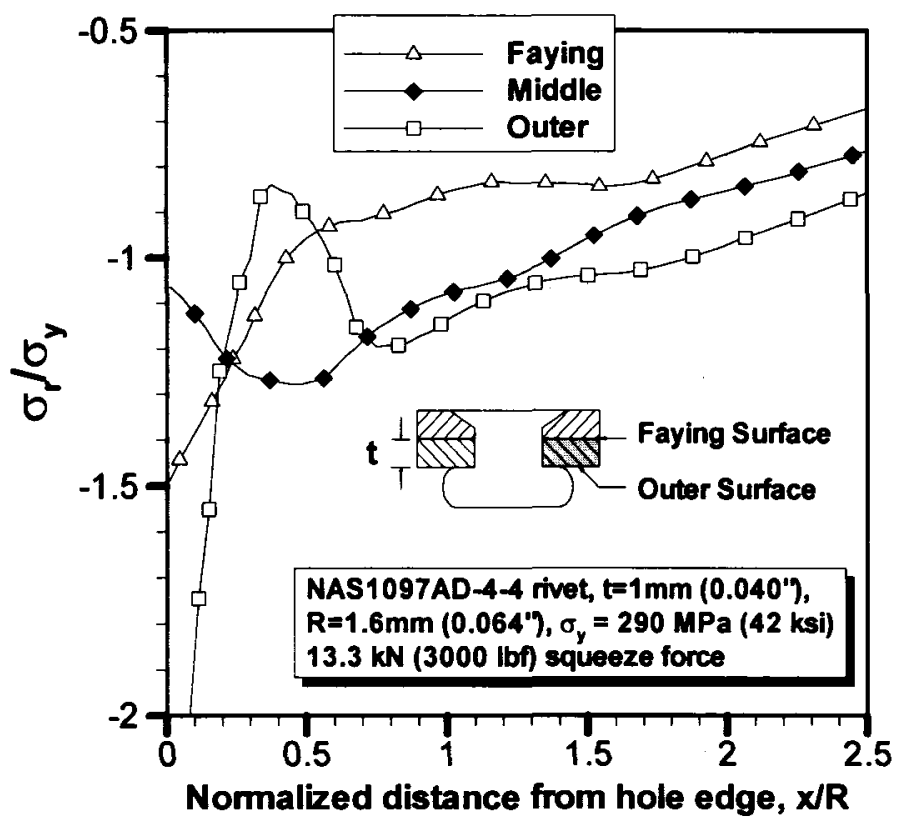

Figure 3.6 Radial residual stress through the inner sheet thickness. Machine countersunk rivets. 


\subsubsection{Residual Stress Results for Universal Rivets}

Variation in the universal splice outer sheet residual hoop stress, plotted in Figure 3.7, was much less significant than in the machine countersunk case. Judging by this figure, it is understandable how the middle surface residual stress state might be used as an average for the entire thickness in a fatigue life prediction. Variation in the radial residual stress field (Figure 3.8), however, is quite large. There are also noticeable differences between the residual stresses at the three trace lines through the sheet thickness below a distance of one radius in Figure 3.9 and Figure 3.10.

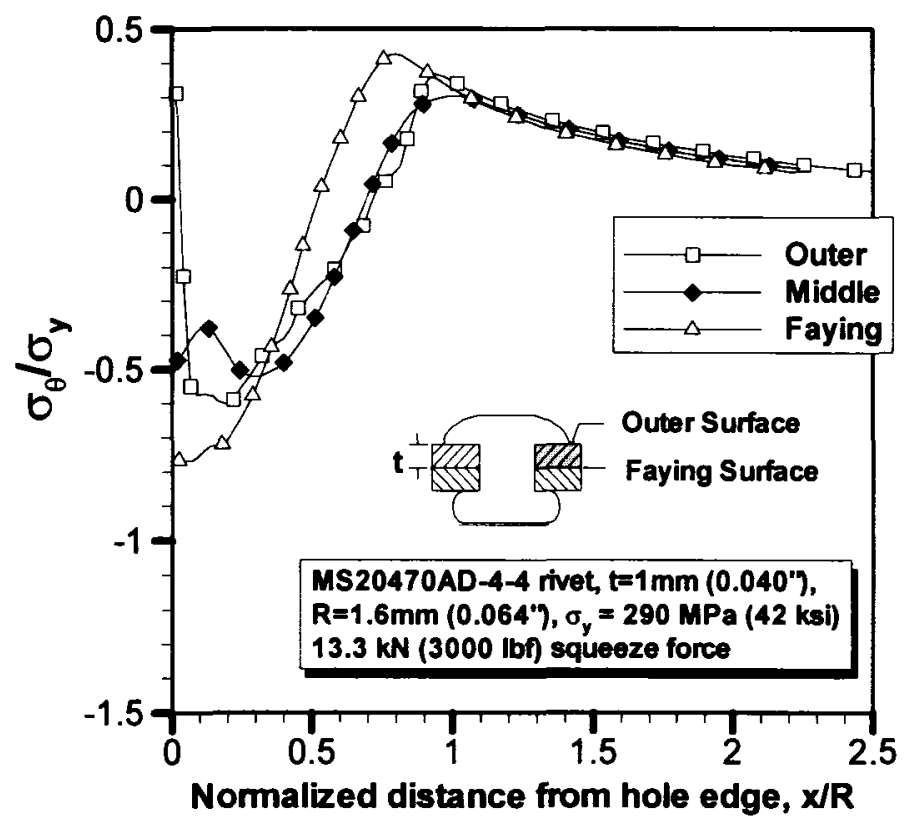

Figure 3.7 Hoop residual stress through the outer sheet thickness. Universal rivets. 


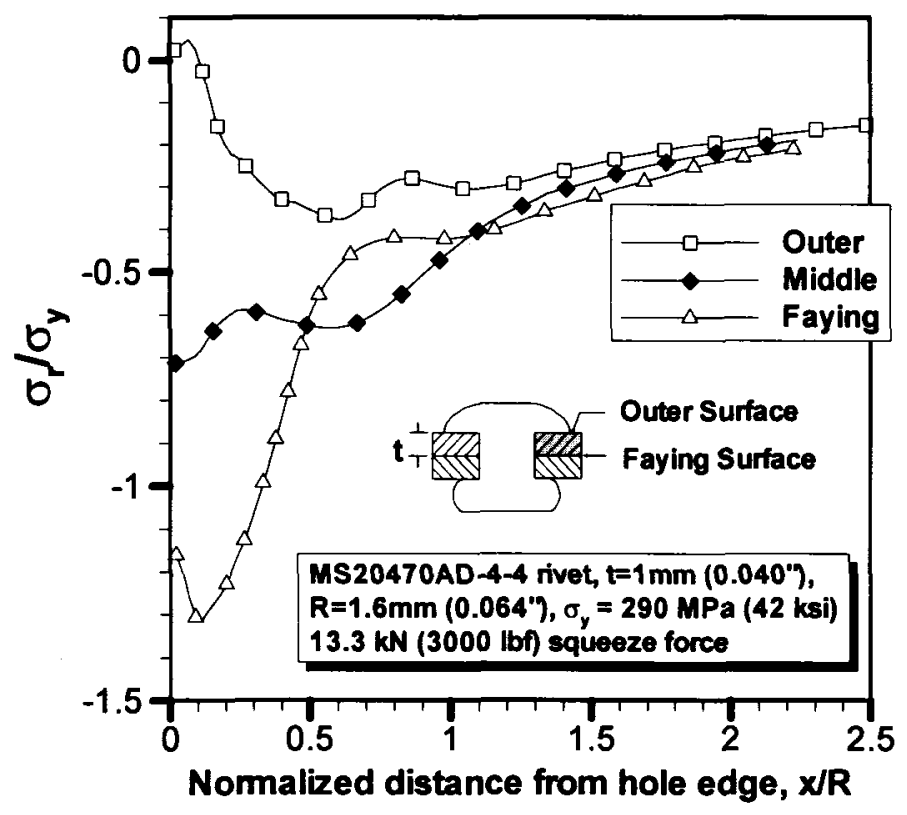

Figure 3.8 Radial residual stress through the outer sheet thickness. Universal rivets.

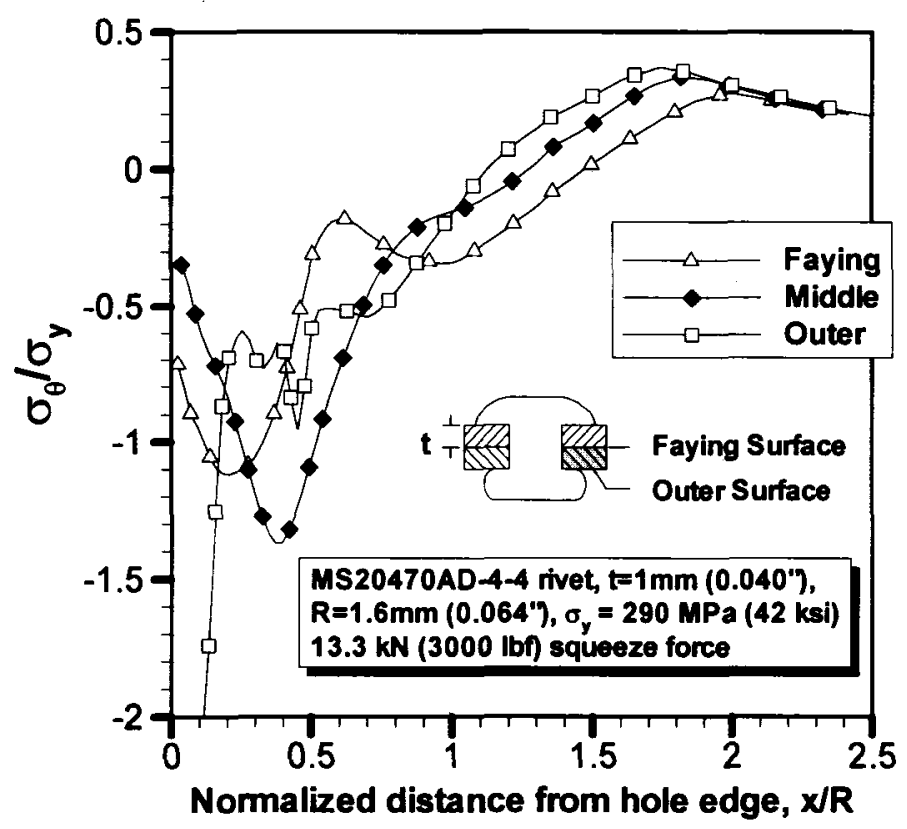

Figure 3.9 Hoop residual stress through the inner sheet thickness. Universal rivets. 


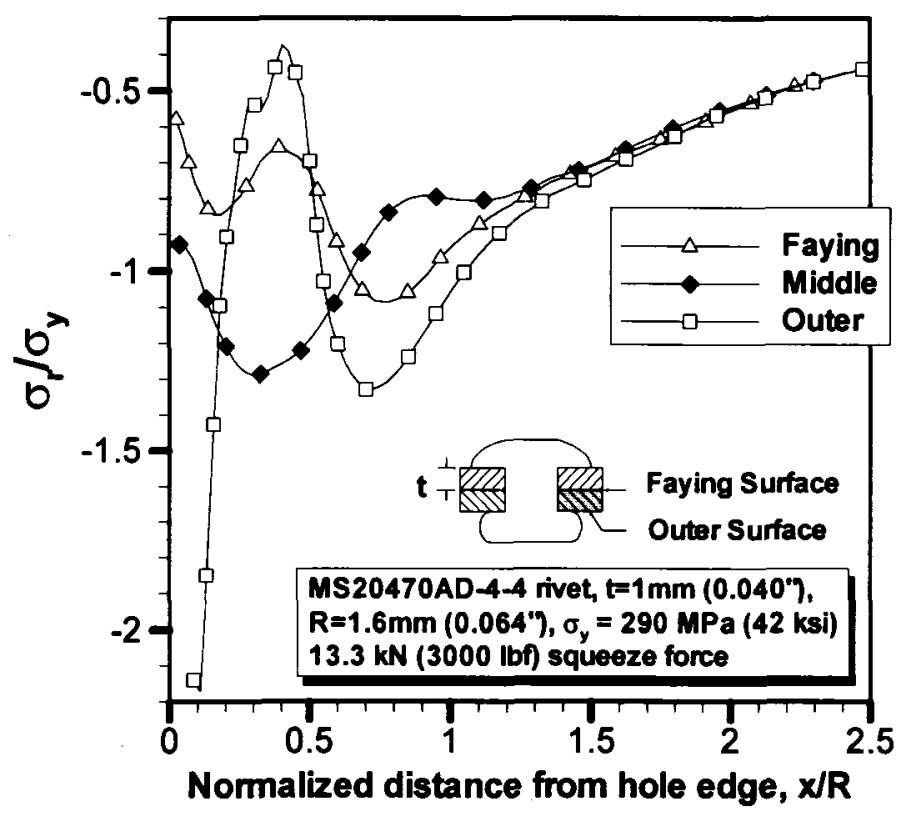

Figure 3.10 Radial residual stress through the outer sheet thickness. Universal rivets.

\subsubsection{Sheet Clamping Results}

The degree of residual faying surface clamping varies in thin sheet splices for different rivet types and rivet forming loads. Simulation of the refined $2 \mathrm{D}$ axi-symmetric rivet forming models provided an opportunity to examine the variation in sheet clamping for the splice geometries of this study.

The results of the sheet clamping pressure are plotted in Figure 3.11 and Figure 3.12 for the machine countersunk and the universal splices respectively. 


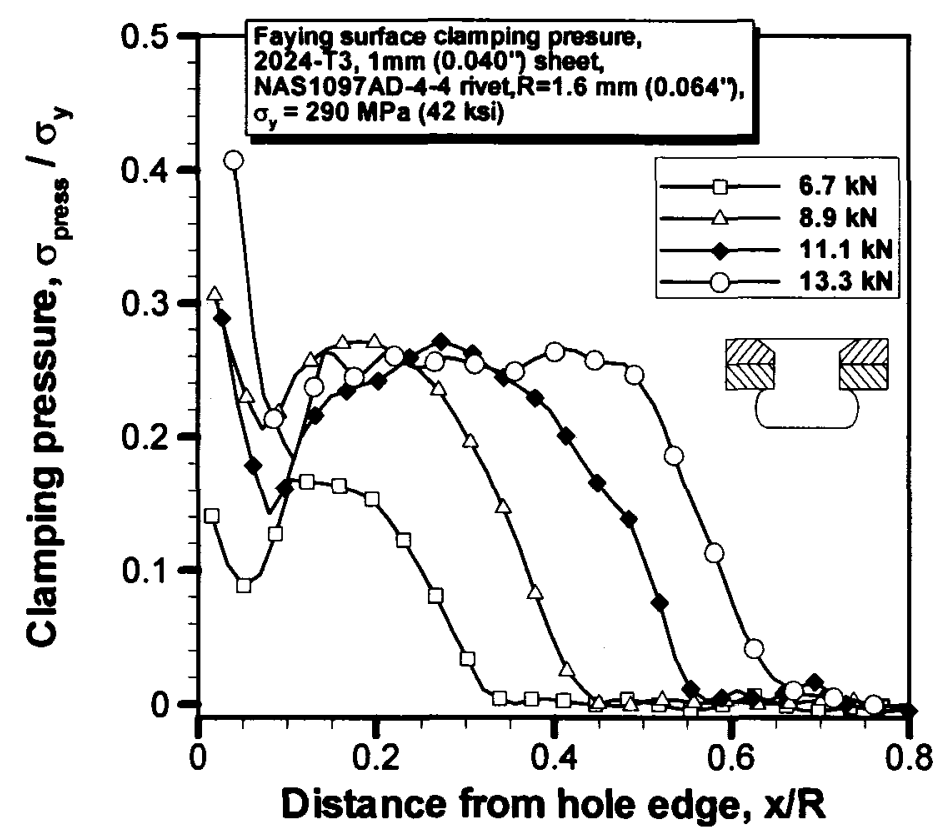

Figure 3.11 Faying surface clamping pressure around a machine countersunk rivet hole.

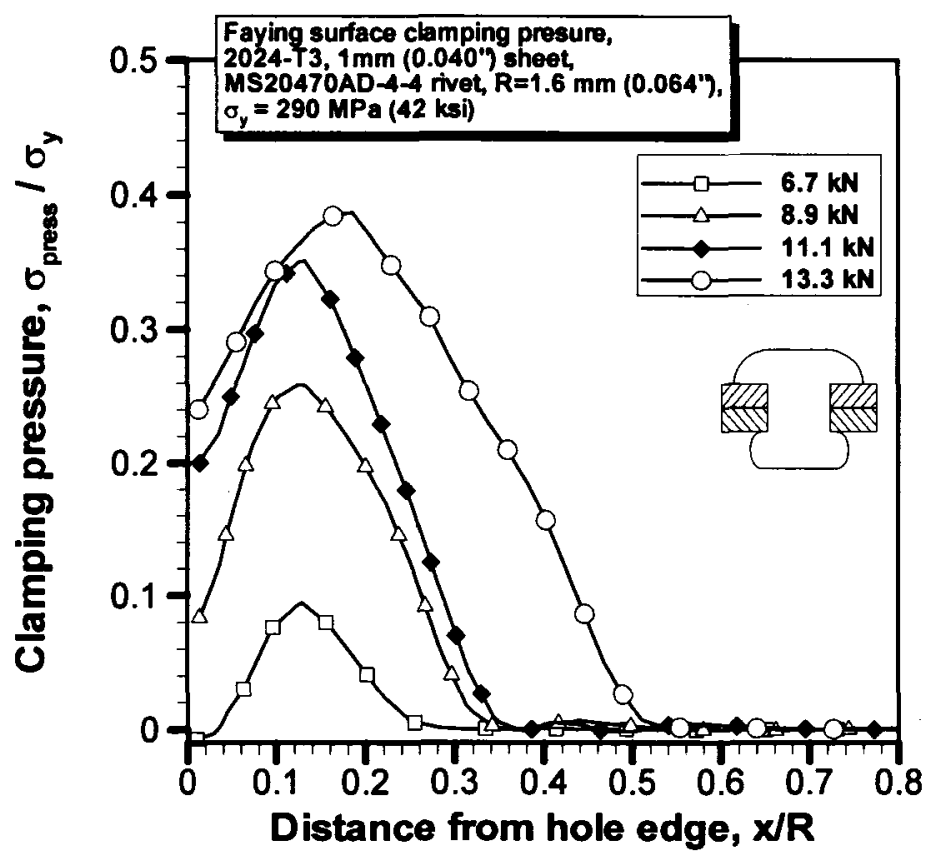

Figure 3.12 Faying surface clamping pressure around a universal rivet hole.

The most notable difference in residual clamping between the two rivet styles is that the faying surface pressure distribution for the machine countersunk splices is lower in magnitude 
than for the universal splices but encompasses a greater area. In addition, the peak clamping pressure for the countersunk rivets does not increase when moving from the $8.9 \mathrm{kN}$ forming load to the $11.1 \mathrm{kN}$ and $13.3 \mathrm{kN}$ rivet forming loads. This clamping pressure limit is in contrast to the universal rivet results where the peak clamping pressure increases with each rivet forming load. The difference in clamping between the two rivet styles is due to the size of the manufactured rivet heads. In the universal rivet case, the manufactured head has a large radius and therefore provides through-thickness resistance for the formed rivet head. As the rivet forming load increases and the expansion of the formed rivet head continues, the manufactured rivet head is large enough to provide resistance. The small diameter of the manufactured countersunk rivet head cannot provide the same degree of resistance through the thickness; therefore, a limited clamping pressure is developed.

The difference in the manufactured head geometry shows its importance in two other areas: the difference in the clamping pressure at $x=0$, and the difference in clamping for the 6.7 $\mathrm{kN}$ rivet forming load. The countersunk rivet head wedges itself into the hole upon rivet forming and compresses the sheet from $\mathrm{x}=0$ outward. This wedging action accounts for the relatively high clamping pressures; even at the lowest rivet forming load. The universal rivet head, however, forms a gap at the intersection of the rivet shank and the rivet head during forming (Figure 3.13). This gap becomes more distinct as the rivet forming load increases and the rivet shank is pushed upward. Therefore, at low rivet forming loads, when the formed rivet head is not large enough to apply significant clamping on the sheets, the faying surface clamping is much lower (peak approximately $60 \%$ lower) than the countersunk rivet case. 


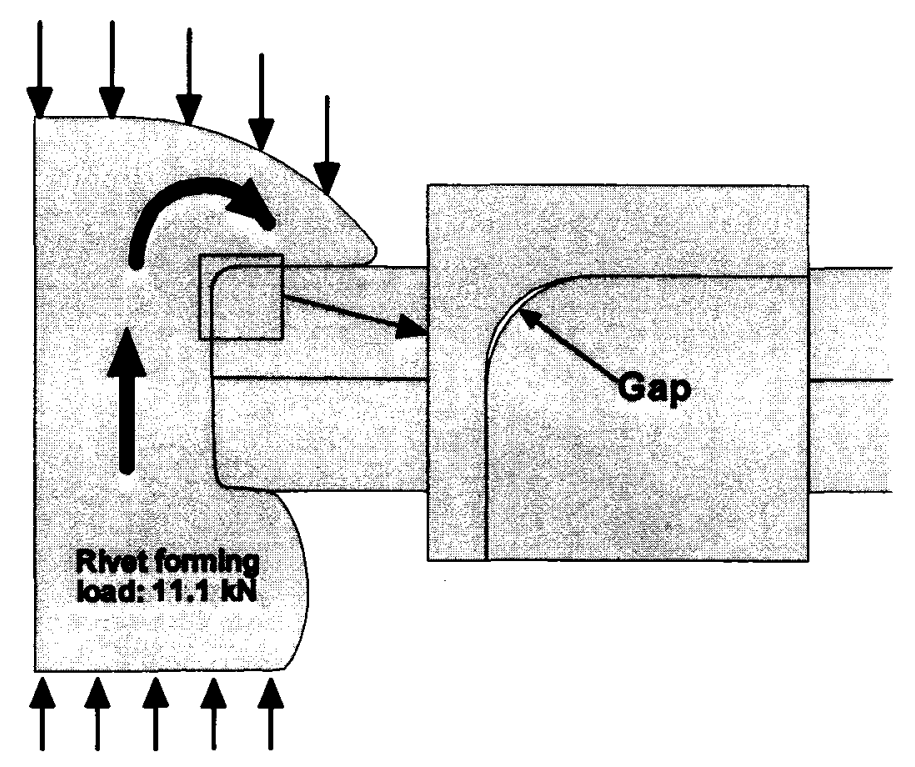

Figure 3.13 Gap created during rivet forming.

\subsection{Conclusions}

It is clear from the residual stress plots presented in Figure 3.3 to Figure 3.10 that the variation in the residual stress field of a riveted sheet requires a $3 \mathrm{D}$ representation of a riveted single lap splice. The need for a 3D finite element lap splice is compounded by the presence of high secondary bending stresses at the outer rivet rows of a splice.

The residual faying surface pressure distribution for the machine countersunk rivets was found to be smaller in magnitude than for the universal rivets with the exception of the $6.7 \mathrm{kN}$ rivet forming case. The extent of the pressure distribution, however, was larger with the countersunk rivets having greater clamping radii. A limit on the peak clamping pressure existed for the machine countersunk rivets due to the lower constraint provided by the manufactured rivet head. No such limit was observed for the universal rivets.

The manufactured rivet head style also plays a role in the sheet clamping at the hole edge. The machine countersunk rivets create a wedging effect that provides high clamping pressures up to the hole edge for all rivet forming loads. The universal rivets produce a gap in the contact 
between the manufactured rivet head and the outer sheet at the hole edge. The presence of the gap causes much smaller clamping pressures at the hole edge compared to the countersunk rivets.

Determining the amount of clamping on the faying sheet surface after rivet springback is important in illustrating where peaks in stress may occur at the edge of contact during splice loading. This does not, however, provide the complete picture as the clamping area will change during splice loading due to secondary bending. To observe the changes in contact during joint loading, a full splice simulation is required.

Since the residual stress distributions through the thickness of the sheets showed significantly different distributions, it was concluded that a 3D lap splice model would be necessary. Before modelling of the splice, however, the modelling parameters were selected for a simplified contact problem and verified by comparing the results to analytical solutions. Determining the best modelling parameters with a smaller model saves on computational cost. 


\section{Simplified Fretting Contact Problem}

\subsection{Introduction}

It is rare that complex geometries are studied in the area of fretting fatigue because the system becomes too complicated to analyze. Instead, an understanding of the mechanics behind fretting fatigue is often obtained through the study of simpler geometries. The most common geometry studied in the field of fretting is an infinitely long cylinder on a flat plane. Solutions for this scenario are found as a special case of the Hertzian contact solutions developed for two infinitely long cylinders in contact under a normal load. The only difference is that one of the cylinders has an infinite radius. Shear tractions were later included in the Hertzian solution through work performed independently by Mindlin [39] and Cattaneo [40]. For this reason, the cylinder-on-flat geometry, subject to normal and shear loading, is referred to as the Mindlin contact problem.

A basic introduction to contact mechanics for the Mindlin geometry is presented here followed by a description of a 2D implicit finite element model. Stresses obtained from the Mindlin analytical solution, as well as the 2D finite element model, are compared to those obtained from a 3D explicit finite element model. The comparison was used to show that 3D models can be used to simulate fretting contact. 


\subsection{Analytical Solution}

The 2D analytical solutions developed for the Mindlin contact problem apply to parallel, infinitely long cylinders in contact that:

- can have a convex, concave or infinite radius of curvature,

- have a contact half-width, a, much smaller than the radius of curvature so that a halfplane approximation may be used when determining the stresses and strains,

- have separate, uncoupled, results from the application of normal and shear loads.

In reality, edge effects are present for finite bodies in contact and the stress concentrations at the edges mean that the Mindlin solution does not apply at those locations. Edge effect stress concentrations are the reason that roller bearings commonly have barrelled edges. Finite contact away from the edges, however, provides a good approximation of a $2 \mathrm{D}$ plane situation [23].

\subsubsection{Determination of Surface Tractions}

The focus of this overview will be the contact mechanics of a cylinder with a radius of $127 \mathrm{~mm}$ ( 5 in) contacting an infinite half-plane. This pad radius was chosen so that comparisons could be made to similar studies performed by Szolwinski [12]. To begin, it is useful to mention the concept of frictional contact. The commonly accepted law of friction between two rigid bodies is called Amontons-Coulomb friction or just Coulomb friction. As presented in [23], there are three major components to the Coulomb friction law:

i) The frictional force, $\mathrm{Q}$, is proportional to the normal force, $\mathrm{P}$, between the bodies

$$
\mathrm{Q}=f \mathrm{P}
$$


where $f$ is the coefficient of friction. Further, the frictional force acts orthogonal to $\mathrm{P}$ and opposite to the direction of relative motion.

ii) The frictional force, $Q$, is independent of the contact area. This means that the same frictional force will be developed for any contact area as long as the same normal force is applied and the surface texture does not change.

iii) The frictional force developed during sliding is independent of the velocity.

Given the equation provided in i), no relative motion will occur between two points as long as $\mathrm{Q} \leq f \mathrm{P}$ (stick) and motion will occur if $\mathrm{Q}>f \mathrm{P}$ (slip).

Next, looking at contact between a cylinder and plane (Figure 4.1) under a normal load, $P$, the interfacial elements will move through mutual compression and tangential displacement. If the materials are elastically similar, the tangential displacement of the mating elements will be equal and, therefore, no relative slip will occur.

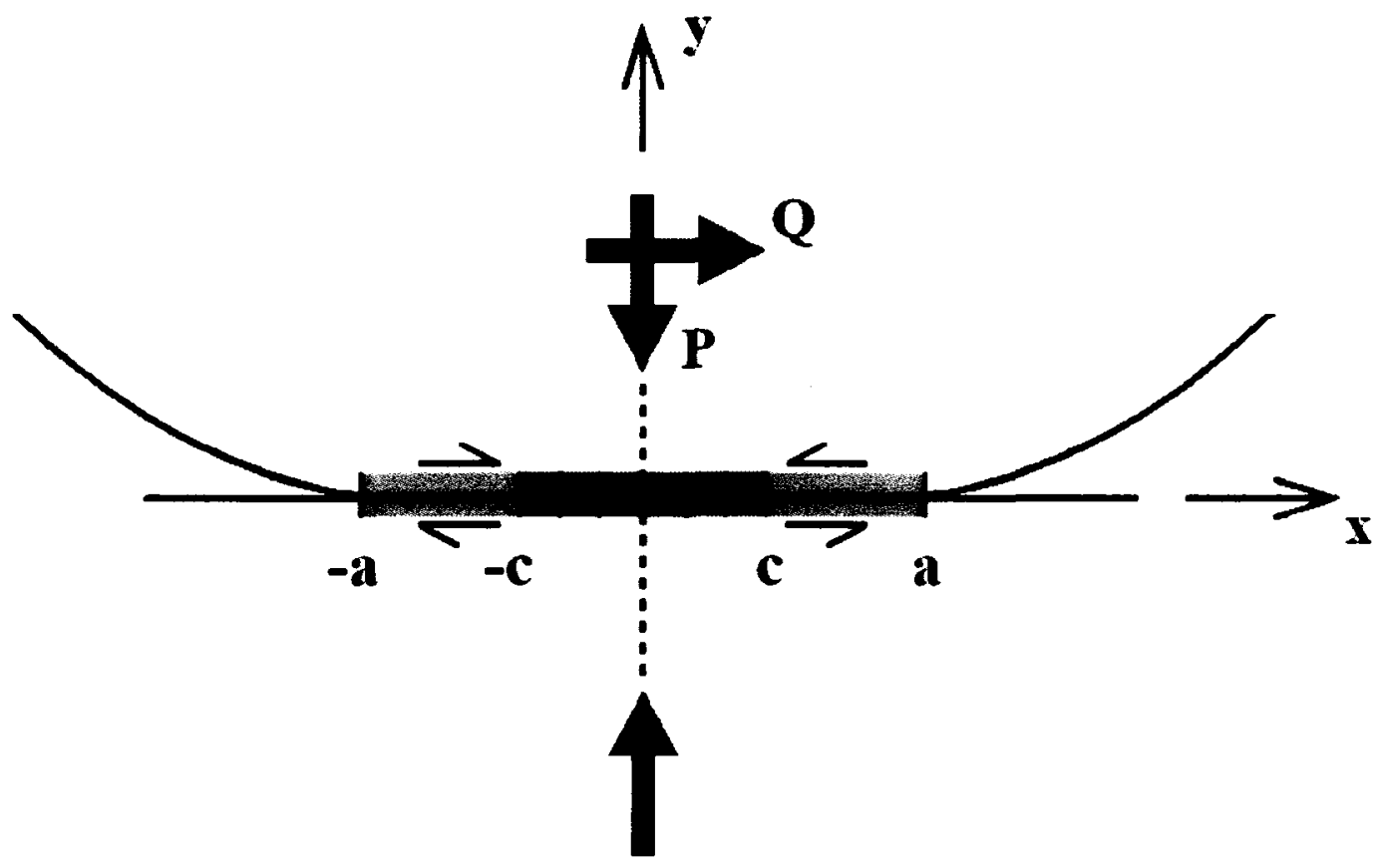

Figure 4.1 Schematic of Mindlin cylinder-on-flat contact. 
The contact half-width of the bodies depicted in Figure 4.1, is defined as a. The value of a can be determined with the equation [12]

$$
a=\sqrt{\frac{4 P R}{\pi E^{*}}}
$$

where $P$ is the normal load (per unit depth), $R$ is a relative radius of curvature, and $E^{*}$ is a relative Young's modulus. The equations for $R$ and $E^{*}$ are provided below in equations 4.2 and 4.3 respectively.

$$
\begin{gathered}
\frac{1}{R}=\frac{1}{R_{1}}+\frac{1}{R_{2}} \\
\frac{1}{\mathrm{E}^{*}}=\frac{1-v_{1}^{2}}{\mathrm{E}_{1}}+\frac{1-v_{2}^{2}}{\mathrm{E}_{2}}
\end{gathered}
$$

The constants used in equation 4.2 and 4.3 are defined below:

$$
\begin{array}{ll}
R_{1} & \text { Radius of body } 1 \text { (cylinder) } \\
R_{2} & \text { Radius of body } 2 \text { (plane, infinite) } \\
E_{1} & \text { Young's modulus of body } 1 \text { (cylinder) } \\
E_{2} & \text { Young's modulus of body } 2 \text { (plane) } \\
v_{1} & \text { Poisson's ration of body } 1 \text { (cylinder) } \\
v_{2} & \text { Poisson's ratio of body } 2 \text { (plane) }
\end{array}
$$

The application of the normal load between the cylinder and plane results in an elliptical pressure distribution over the contact area given by

$$
p(x)=-P_{0} \sqrt{1-\left(\frac{x}{a}\right)^{2}}
$$

where $\mathrm{x}$ is the positive or negative distance along the $\mathrm{x}$-axis from the centre of contact. $\mathrm{P}_{0}$ is the maximum pressure given by equation 4.5 . 


$$
\mathrm{P}_{0}=\frac{2 \mathrm{P}}{\pi \mathrm{a}}=\sqrt{\frac{\mathrm{E}^{*} \mathrm{P}}{\pi \mathrm{R}}}
$$

If the cylinder is subsequently loaded with a tangential shear force, $\mathrm{Q}$, different portions of the contact interface will either stick or slip depending on the local value of the coefficient of friction (COF), $f$. As shown by Hills and Nowell [23], an assumption of all points along the contact surface remaining stuck would result in stress singularities at the boundaries of the contact zone, $\pm \mathrm{a}$. This conclusion is reasonable since it was noted by Johnson [41] that completely stuck bodies would resemble a single body with two edge cracks loaded in shear. Therefore, it would be expected to have a singularity at the crack tips.

It is then reasonable to conclude that, if the shear loading is not large enough to cause gross sliding, there will be a central region of stick within the contact zone bordered by a region of slip. As depicted in Figure 4.1, the slip region would be bounded by $\mathrm{c}<|\mathrm{x}| \leq \mathrm{a}$ and the stick region would be bounded by $|x| \leq c$. Within the slip zone the shear traction developed would be the solution for frictional sliding

$$
\mathrm{q}^{\prime}(\mathrm{x})=-\mathrm{fP}_{0} \sqrt{1-\left(\frac{\mathrm{x}}{\mathrm{a}}\right)^{2}} \quad \mathrm{c}<|\mathrm{x}| \leq \mathrm{a}
$$

and in the stick zone the shear traction developed would be a perturbation of the frictional sliding equation given as [23]

$$
q^{\prime \prime}(x)=f P_{0} \frac{c}{a} \sqrt{1-\left(\frac{x}{a}\right)^{2}} \quad|x| \leq c
$$

where $\mathrm{c}$ can be determined from the equation

$$
\frac{c}{\mathrm{a}}=\sqrt{1-\left|\frac{\mathrm{Q}}{\mathrm{fP}}\right|}
$$


The total shear traction over the contact surface, $q(x)$, then becomes the superposition of equations 4.6 and 4.7. A plot of the normal and shear tractions over the contact zone is presented in Figure 4.2.

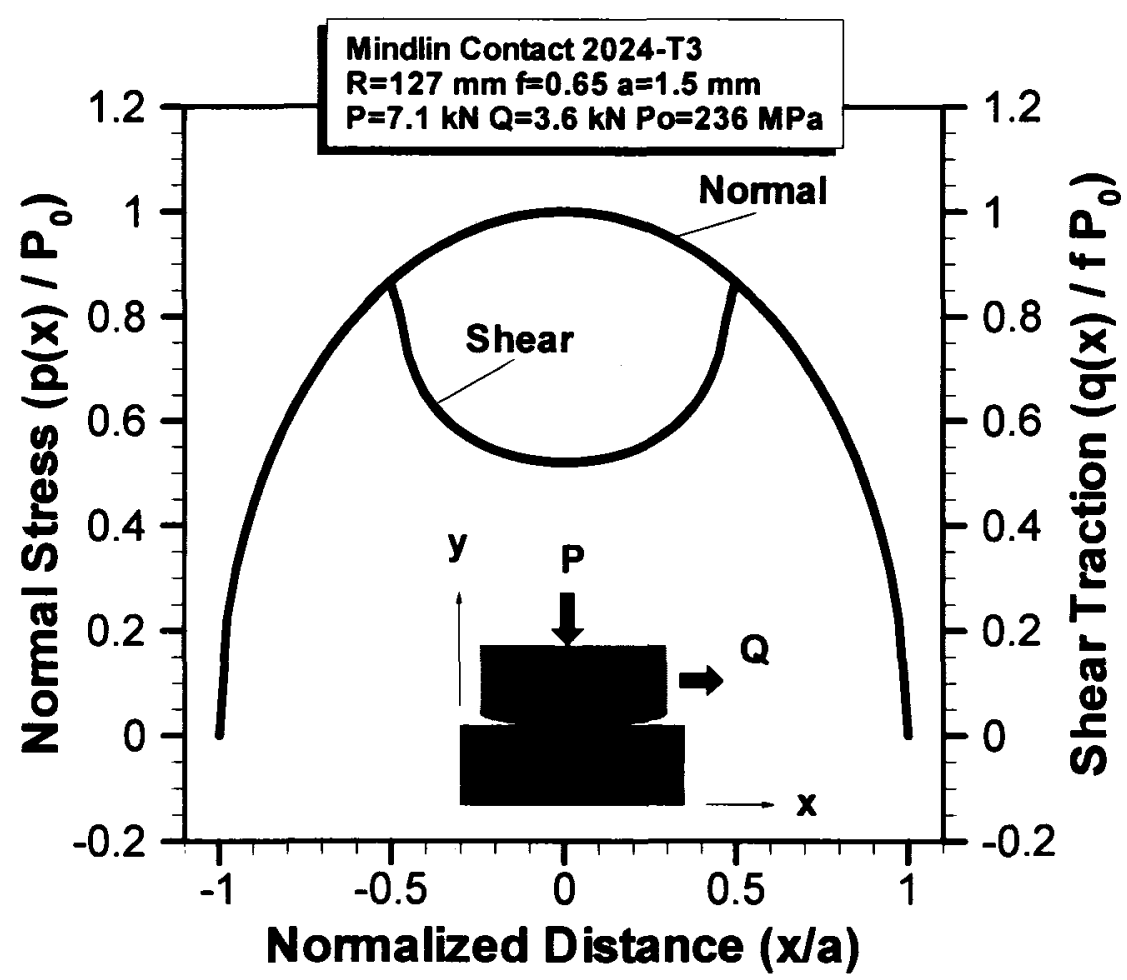

Figure 4.2 Normal and shear tractions as given by the Mindlin contact analytical solution.

In addition to the surface tractions, it is beneficial to compare the surface stress in the $\mathrm{x}$ direction of the plate since this is where stress concentrations will arise at the edge of contact.

\subsubsection{Determination of Surface X-Stress}

The method of obtaining the surface $\mathrm{x}$-stress presented here is a simplification of a solution used by Szolwinski and Farris to determine the sub-surface stresses of a plane in contact with a cylinder [20]. The solution uses complex potential functions called Westergaard stress functions [42] to solve for the sub-surface stresses in a contact problem. The surface $x$-stress was 
determined using the Westergaard functions for comparison to edge of contact stress results produced by finite element simulations.

The surface stress state is found through superposition of stresses developed by the aforementioned symmetric normal and skew-symmetric shear tractions. The surface component of the $x$-stress from normal loading, $P(x)$, is found from the complex potential function

$$
\sigma_{x x, \text { normal }}=\operatorname{Re}\left[Z_{I}(\xi)\right]-z \operatorname{Im}\left[\frac{d Z_{I}(\xi)}{d \xi}\right]
$$

where

$$
Z_{I}(\xi)=-\frac{2 P}{\pi a^{2}}\left(\sqrt{a^{2}-\xi^{2}}+i \xi\right)
$$

and

$$
\xi=x+i z
$$

Contributions to the $x$-stress from the two anti-symmetric surface tractions $q^{\prime}(x)$ and q"(x) are found with the equations provided below listed as shear 1 and shear 2 respectively.

$$
\begin{aligned}
& \sigma_{x x, \text { shear } 1}=2 \operatorname{Im}\left[Z_{I I}^{1}(\xi)\right]+z \operatorname{Re}\left[\frac{d Z_{I I}^{1}(\xi)}{d \xi}\right] \\
& \sigma_{x x, \text { shear } 2}=2 \operatorname{Im}\left[Z_{I I}^{2}(\xi)\right]+z \operatorname{Re}\left[\frac{d Z_{I I}^{2}(\xi)}{d \xi}\right]
\end{aligned}
$$

The two Westergaard functions for the shear components of the contact are given as

$$
\begin{aligned}
& Z_{I I}^{1}(\xi)=-\mu \frac{P o}{a}\left(\sqrt{a^{2}-\xi^{2}}+i \xi\right) \\
& Z_{I I}^{2}(\xi)=\mu \frac{P o}{a}\left(\sqrt{c^{2}-\xi^{2}}+i \xi\right)
\end{aligned}
$$

To obtain the state of stress in the $x$-direction, the normal component of the stress and the two shear components in the area of contact must be superimposed. Since only the surface stresses are being compared, $\mathrm{z}=0$ and there is no need to calculate the derivative portions of equations $4.9,4.12$, and 4.13 . The equation for the surface $x$-stress then simplifies to 


$$
\sigma_{x x}=\operatorname{Re}\left[Z_{I}(\xi)\right]+2 \operatorname{Im}\left[Z_{I I}^{1}(\xi)\right]+2 \operatorname{Im}\left[Z_{l I}^{2}(\xi)\right]
$$

The value of the $\mathrm{x}$-stress over the vicinity of contact is plotted in Figure 4.3 for a pad with a radius of $127 \mathrm{~mm}(5 \mathrm{in})$ subject to a normal load of $7.1 \mathrm{kN}$ and a shear load of $3.6 \mathrm{kN}$.

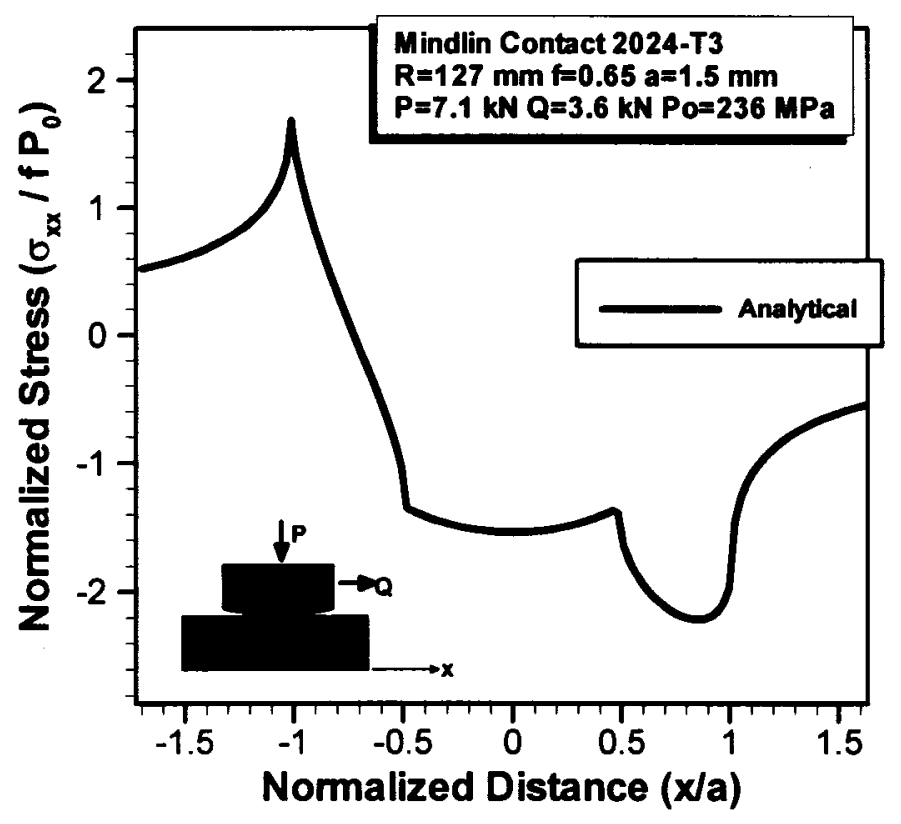

Figure 4.3 Stress in the $x$-direction along the surface of a plate in contact with a cylinder under normal and shear loading.

It can be observed in Figure 4.3 that a tensile peak in stress is located at the edge of contact at a normalized distance of -1 . This peak stress value can be obtained from the equation

$$
\sigma_{x x, p e a k}=2 P_{o} \sqrt{\frac{\mu Q}{P}}
$$

The plot also shows a clear region of stick between the approximate distance values of 0.5 and 0.5 . A dip in stress values is present on the compressive side of the shear loading between the boundaries of stick $(\mathrm{x} / \mathrm{a}=0.5)$ and the edge of contact $(\mathrm{x} / \mathrm{a}=1)$. With this result now available for comparison, in addition to contact results for the surface tractions, it is possible to move on to a description of a 2D finite element model of the same problem. 


\subsection{D Finite Element Model}

\subsubsection{Modelling Details}

A 2D plane strain finite element model of the Mindlin contact problem, introduced in the previous section, was developed using the commercially available code Abaqus v.6.6.1. This code was selected because it has been shown to be effective in other fretting contact studies [21, 43, 44]. Hyperworks Hypermesh was chosen for all geometry creation and meshing whereas Tecplot 360 was chosen for post-processing.

Properly capturing the surface and sub-surface stresses in a finite element fretting contact problem normally requires fine meshes in conjunction with strict contact formulations. To this end, several researchers have simulated the Mindlin problem using 2D implicit finite element simulations with contact that uses the Lagrange multiplier method $[21,28,45]$. This method enforces exact frictional sticking of the contacting nodes. Due to the expected size and complexity of a finite element lap splice model that would include large plastic deformations due to rivet forming, it was determined that an explicit simulation would be required. Use of an explicit simulation meant that the Lagrange multiplier method could not be used. This is one of the reasons that a comparison of $3 \mathrm{D}$ explicit finite element solutions to $2 \mathrm{D}$ implicit finite element and analytical solutions is necessary.

The 2D implicit finite element model consisted of a pad with the same radius as the analytical solution $(127 \mathrm{~mm})$ in contact with a flat plate $6.35 \mathrm{~mm}$ thick (Figure 4.4 ). First, a normal load of $7117 \mathrm{~N}$ (1600 lbf) was distributed over the top of the pad followed by a shear load of $3559 \mathrm{~N}(800 \mathrm{lbf})$ distributed over the right side of the plate. The material model for both the pad and plate was based on Ramberg-Osgood parameters for 2024-T3 [38]. Friction between the pad and plate was imposed using the Lagrange Multiplier method and a coefficient of friction of 0.65 was used [12]. Contact was imposed through a master-slave approach. 


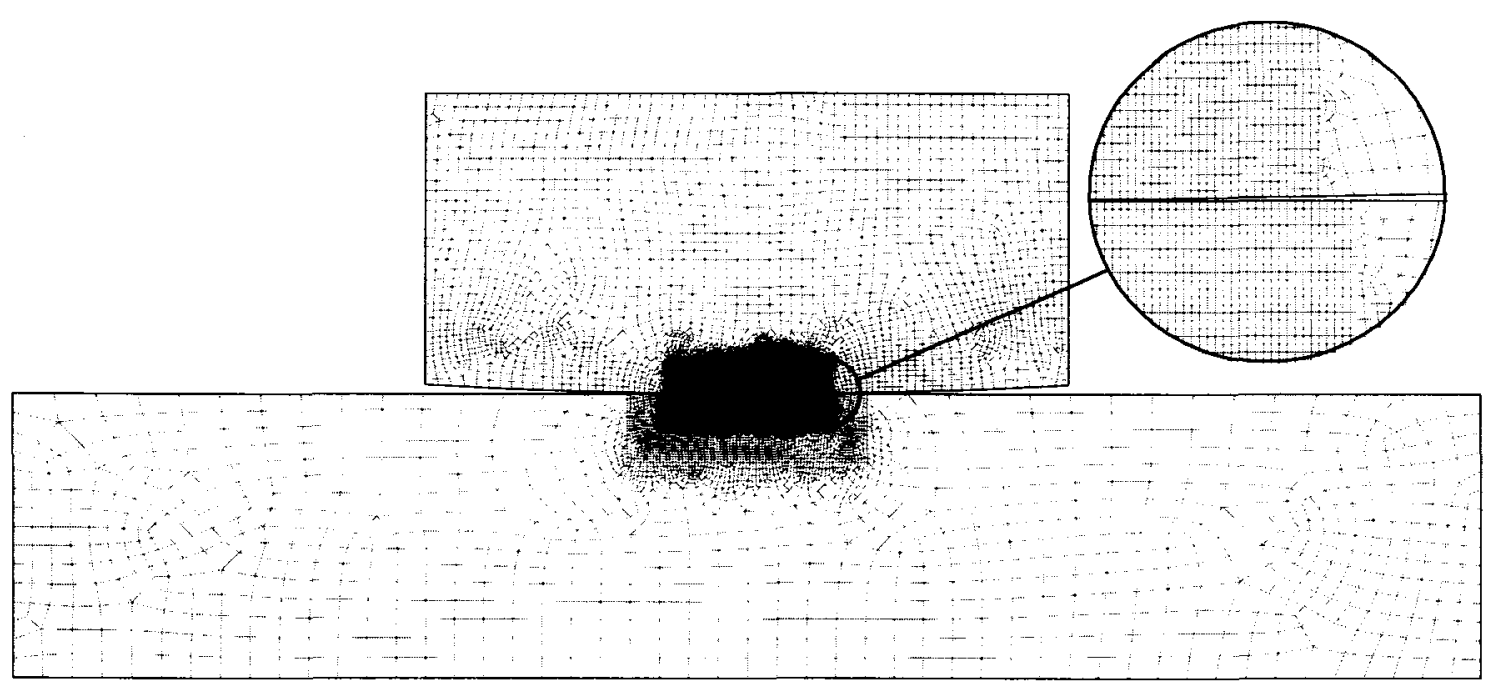

Figure 4.4 Mesh for 2D Mindlin contact problem.

2D simulations of Mindlin-type contact often have elements with edge lengths on the order of $10 \mu \mathrm{m}$ in the contact region [21, 28, 29]. The CPE4R elements (4-node bilinear plane strain quad with reduced integration and hourglass control) used in this simulation had minimum element edge lengths of $6.4 \mu \mathrm{m}$. Results for the surface tractions and stresses are presented, along with the analytical and 3D results in Section 4.5; after a description of the 3D finite element model.

\subsection{D Finite Element Model}

A 3D explicit model of the Mindlin contact problem was created by extending the basic geometry of the pad and plate used in the 2D simulation to 3D. The depth of both the pad and plate was extended in the third dimension to a depth of $12.7 \mathrm{~mm}$. A normal load of $7117 \mathrm{~N}$ (1600 lbf) was, again, applied to the top surface of the pad followed by a shear load of $3559 \mathrm{~N}(800 \mathrm{lbf}$ ) applied over the side of the plate. The material model and the contact coefficient of friction remained the same as that used in the $2 \mathrm{D}$ simulation described in Section 4.3. Kinematic contact was used along with a master-slave contact definition C3D8R brick elements (8-node linear brick with reduced integration and hourglass control) were chosen. 
As mentioned earlier, Mindlin-type contacts often have elements with edge lengths on the order of $10 \mu \mathrm{m}$ and the elements used in the 2D simulation described above had minimum edge lengths of $6.4 \mu \mathrm{m}$. It can be seen that expanding these meshes into 3D can quickly produce prohibitively large simulations. The solution, shown to be effective in $3 \mathrm{D}$ contact simulations by Kim et al. [46], was to use sub-modelling techniques.

\subsubsection{Sub-modelling}

Sub-modelling is an option for large finite element problems when only a small area of the model, such as a stress concentration, requires scrutiny. The first step is to run a global model of the entire problem with a set of driving elements defined in the area of interest. A smaller submodel is then created that includes only elements from that area (Figure 4.5). As this geometry is smaller, a finer mesh can be defined. The displacements from the driving elements in the global model are then applied to the outer boundary of the sub-model during the sub-model simulation. The sub-model can then be used as a global model for further refinement until sufficient convergence of the results is achieved [47].

This technique was applied to the 3D Mindlin model described here resulting in a global model and four sub-models to achieve stress convergence. The minimum sub-model edge length was $6.4 \mu \mathrm{m}$ and the convergence details are presented in Table 4.1. Both the percent difference in the peak $\mathrm{x}$-stress from the previous model and the percent difference from the analytical solution are provided. The percent difference from the previous model was calculated using equation (4.18) where $\sigma^{n+1}$ is the maximum surface x-stress in the current model and $\sigma^{n}$ is the maximum surface $\mathrm{x}$-stress in the previous model. Both methods showed that reasonable convergence was obtained with four sub-models. The comparison also showed that the percent difference from the previous mesh refinement was a reasonable way to show convergence in a finite element (FE) study where comparison to experiment or an analytical solution is not available. 


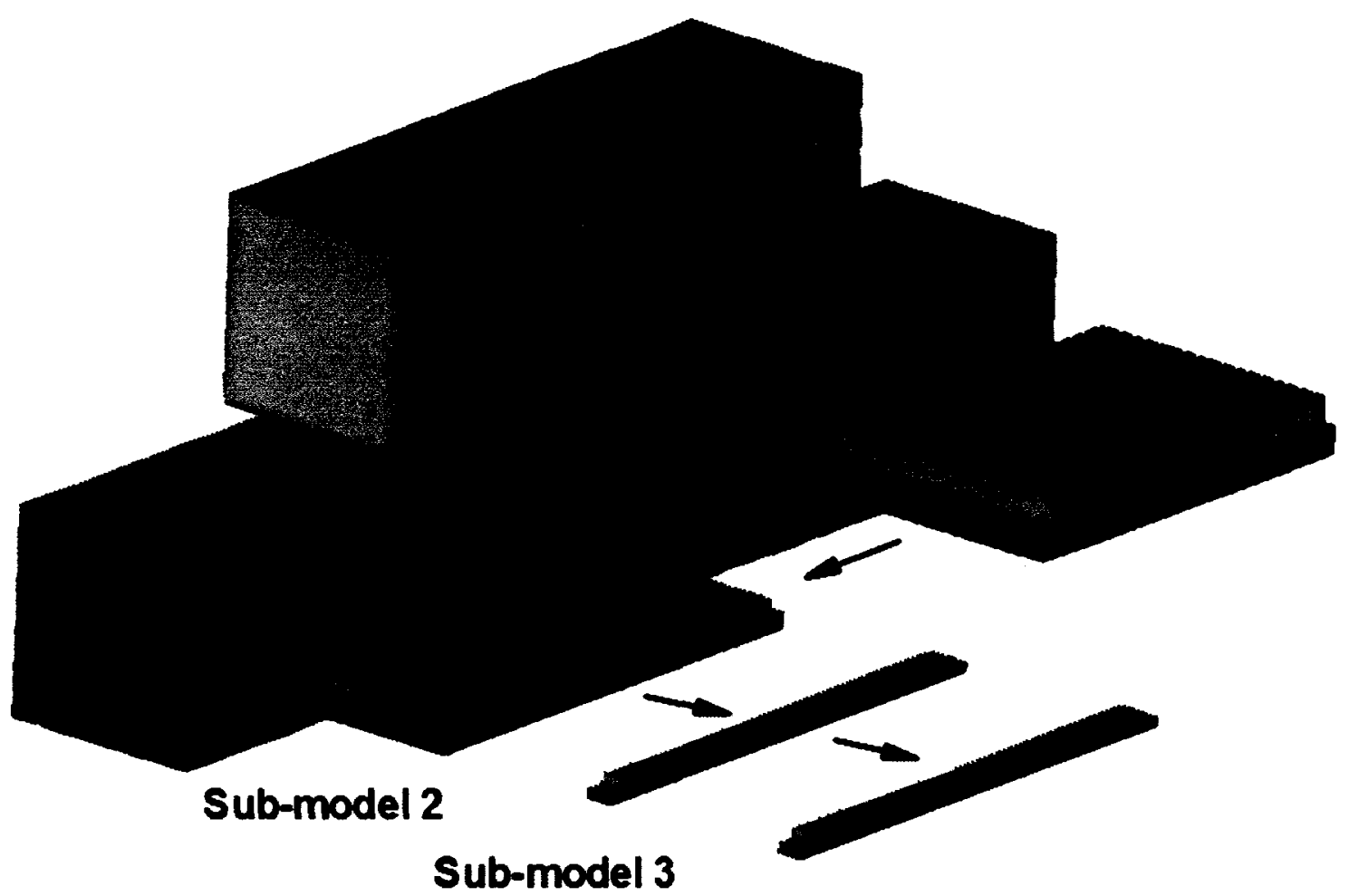

Sub-model 4

Figure 4.5 Sub-modelling technique as applied to the 3D Mindlin contact problem.

Table 4.1 Convergence results for 3D Mindlin sub-model analysis. $127 \mathrm{~mm}$ pad radius.

\begin{tabular}{|c|c|c|c|c|}
\hline Model & $\begin{array}{c}\text { Element edge length } \\
\mathrm{mm} \text { (Inches) }\end{array}$ & $\begin{array}{c}\text { Peak } \sigma_{\mathrm{xx}} \text { Stress } \\
\mathrm{MPa}(\mathrm{psi})\end{array}$ & $\begin{array}{c}\text { \% Difference } \\
\text { from Previous }\end{array}$ & $\begin{array}{c}\% \text { Difference } \\
\text { from Analytical } \\
(269.5 \mathrm{MPa})\end{array}$ \\
\hline Global & $0.102(0.004 ”)$ & $152.9(22182)$ & - & $43.2 \%$ \\
\hline Sub-model 1 & $0.051(0.002 ”)$ & $205.7(29838)$ & $25.6 \%$ & $23.7 \%$ \\
\hline Sub-model 2 & $0.025(0.001 ")$ & $228.6(33151)$ & $10 \%$ & $15.2 \%$ \\
\hline Sub-model 3 & $0.013(0.0005 ")$ & $246.4(35731)$ & $7.2 \%$ & $8.6 \%$ \\
\hline Sub-model 4 & $0.0064(0.00025 ")$ & $253.1(36706)$ & $2.6 \%$ & $6.1 \%$ \\
\hline
\end{tabular}

$$
\% \text { Diff } f_{\text {previous }}=\left|\frac{\sigma^{n+1}-\sigma^{n}}{\sigma^{n}}\right| \times 100
$$

The convergence results shown in Table 4.1 are good considering the size of the pad being modelled (127 $\mathrm{mm}$ radius). In modelling Mindlin-style fretting contact, the contact halfwidth (associated with the pad radius) has an effect on how quickly stress convergence can be 
obtained because the magnitude of the peak edge of contact stress decreases with increasing contact size. In smaller pad geometries, therefore, finer mesh densities are required to obtain reasonable solutions.

As the sub-modelling technique was able to achieve the proper mesh density in the 3D model, what remained was a comparison of the two finite element model results to each other and to the analytical solution.

\subsection{FE Model Comparison Results and Discussion}

Comparisons of the analytical, 2D FEM and 3D FEM solutions for the Mindlin contact problem are presented in Figure 4.6 and Figure 4.7. The x-stress and shear stress values in the figures have been normalized by the coefficient of friction and the maximum normal pressure whereas the distance has been normalized by the half-contact length a. The normal stress in Figure 4.6 was normalized by the maximum pressure alone.

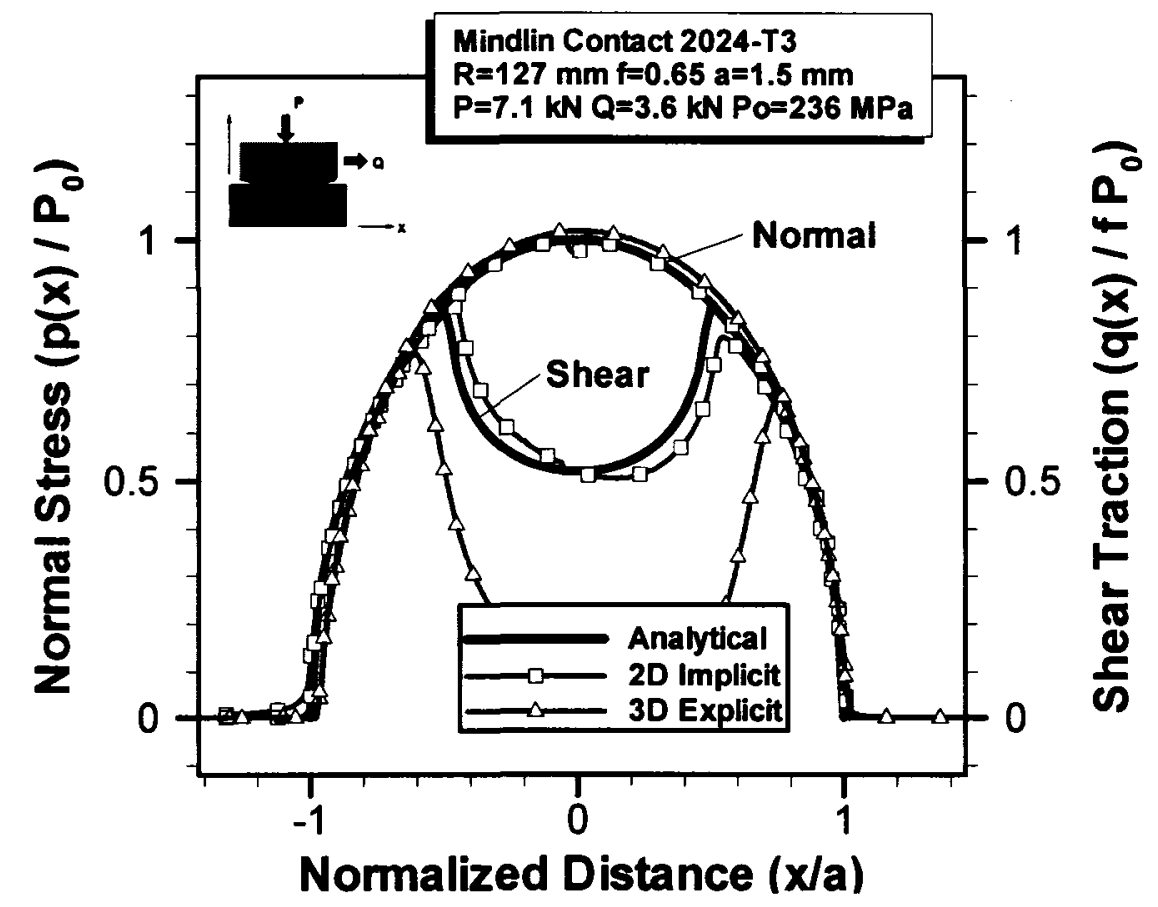

Figure 4.6 Comparison of normal stress and shear tractions for Mindlin - type contact. 


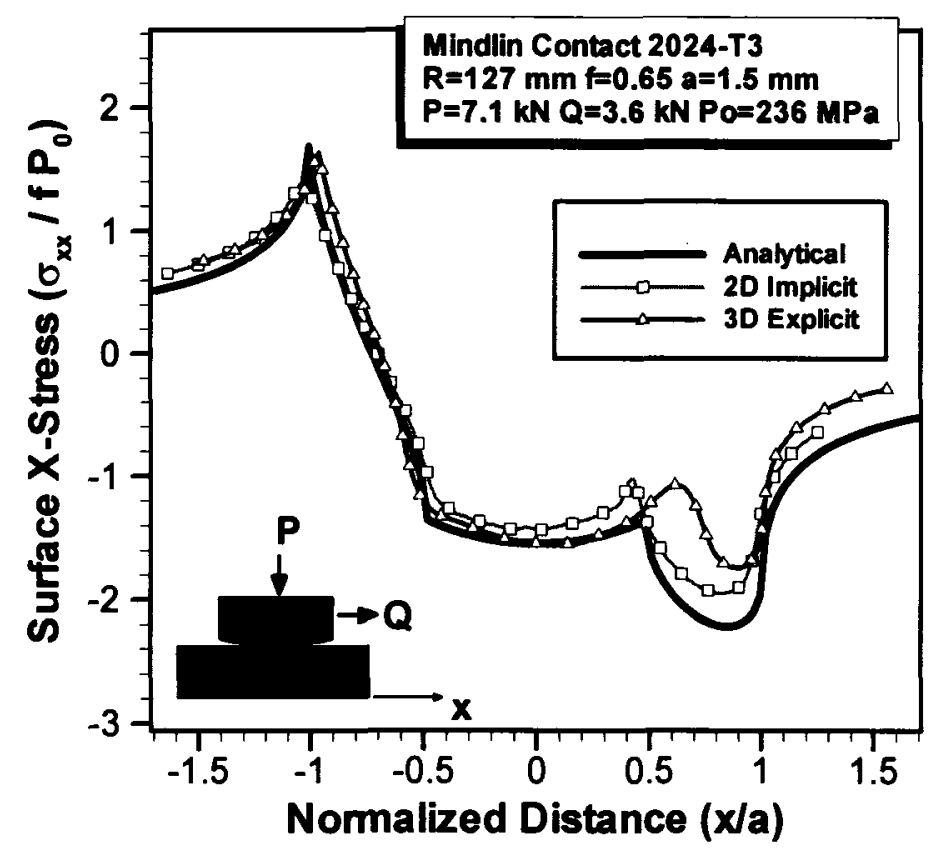

Figure 4.7 Comparison of $\sigma_{x x}$ stress for Mindlin-type contact.

The shear traction results in Figure 4.6 show that the 3D solution has a much larger variation than the $2 \mathrm{D}$ solution when compared to the analytical result. The variation between the finite element models is smaller, however, at the edges of the central stick zone. The differences between the surface traction results are because of the way that frictional contact is enforced for each simulation. In the kinematic contact formulation used in the $3 \mathrm{D}$ model, the frictional constraint is imposed using a penalty based method that allows elastic slip (relative motion) between the contacting bodies when they should be sticking [47]. Although the slip is small, it still allows for variation in the results. The Lagrange Multiplier method used in the 2D model, however, enforces the stick-slip nodal constraints exactly, at the expense of greater simulation cost, and produces results that more closely match the analytical solution. Another factor that may have influenced the 3D explicit shear traction results is the use of Jaumann stress rates as opposed to the Green-Naghdi stress used in the 2D implicit simulation. Jaumann stress rates have been known to cause instability problems with shear. 
While the 3D shear traction results did not agree well to the analytical solution, much better agreement was found in the results of the x-stress distribution in Figure 4.7. Both the 2D and 3D results followed the analytical solution closely. The greatest variation between the models and the analytical solution was on the compressive side of the contact where a dip in stress values is observed. The $2 \mathrm{D}$ model was able to follow the analytical solution a little more closely than the 3D model. On the tensile side of contact, agreement between the finite element models and the analytical solution was good. As shown in section 4.4.1, the peak tensile stress for the 3D model only varied by $2.6 \%$ or $6.1 \%$, depending on which convergence criterion was used, and the peak tensile stress for the $2 \mathrm{D}$ model varied by $2.5 \%$.

Since the surface stresses are of interest for the life prediction method to be used in this study and the explicit surface stress results agreed well with the implicit results, the explicit modelling parameters were found to be satisfactory for use in a lap splice model.

\subsection{Conclusions}

Modelling of shear tractions with 3D explicit simulations did not produce results comparable to those of 2D implicit simulations. Normal tractions and surface stresses in the $\mathrm{x}$ direction, however, did show good agreement for the 2D, 3D and analytical solutions. As most predictive fretting fatigue life methodologies use the surface stresses rather than shear tractions, 3D solutions were found to be satisfactory for a predictive life model.

Convergence of the 3D explicit finite element stress results was shown through two different methods: comparison to the analytical solution and comparison to the previous solution for each mesh refinement level. In this way, it was shown that the comparison to the previous mesh refinement results was a reasonable way to show convergence in an FE study where analytical or experimental results are not available. 
Based on the satisfactory results from the Mindlin contact study, a 3D explicit finite element model of a single lap splice was developed and is described in the following chapter. 


\section{Lap Splice Finite Element Model}

\subsection{Introduction}

This chapter describes the development of two 3D finite element lap splice models that bring together the different facets of splice fretting into a single simulation. The simulations include a rivet forming step followed by a splice loading step. The rivet forming step incorporates residual stresses in the sheets and rivet clamping while the splice loading step allows for observation of any changes to the faying surface edge of contact. The resulting stress and strain distributions from a complete loading cycle are then available for use in a predictive life tool presented in Chapter 6.

\subsection{Modelling Overview}

\subsubsection{Modelling Details}

The single lap splice geometry was modelled with the two different rivet styles from Chapter 3 inserted in the sheet; NAS1097AD-4-4 countersunk rivets and MS20470AD-4-4 universal rivets. As discussed in Chapter 4, simulation of the complex interactions and large deformations associated with rivet forming and splice loading required that a $3 \mathrm{D}$ model and an explicit solver be used. The splices were modelled with two rivet rows having a row pitch of 38.1 $\mathrm{mm}$ and a rivet pitch of $25.4 \mathrm{~mm}$. The inner and outer sheets both consisted of $1 \mathrm{~mm}$ bare 2024- 
T3 aluminum. Figure 5.1 shows the overall dimensions of the models and illustrates how they took advantage of symmetry by modelling only half of the splice. Along with the inner sheet, outer sheet, and two rivets, four rigid platens were included in the models as rivet forming tools. The sheet and rivet material models were the same as those used in the rivet forming model of Chapter 3.

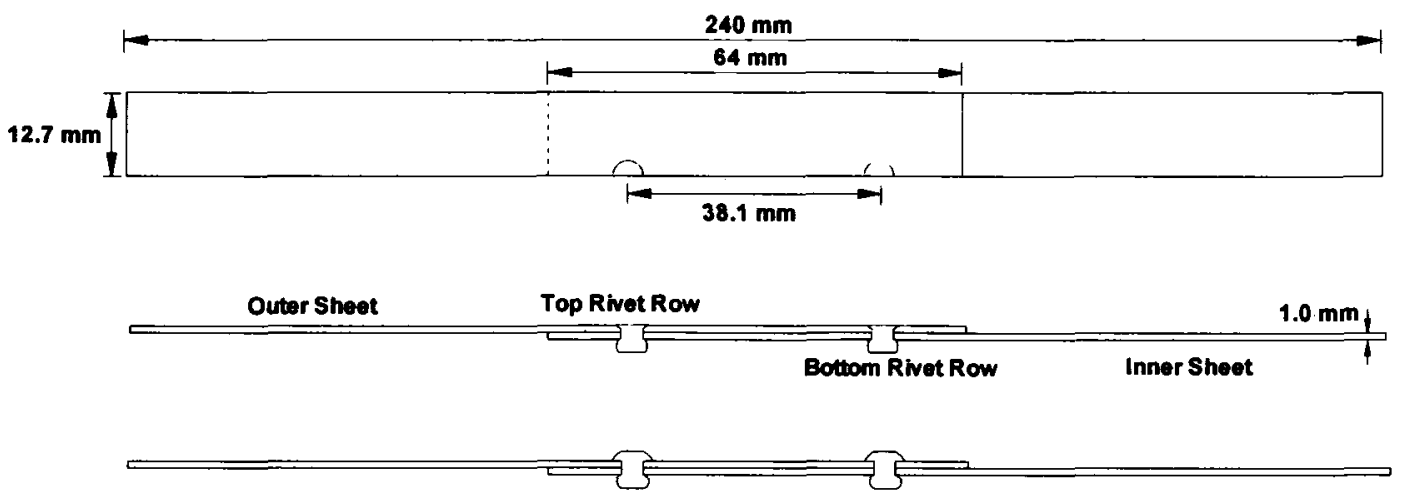

Figure 5.1 Splice coupon and FEM model geometry.

The simulations were broken into four loading steps: rivet forming, rivet springback, splice loading, and splice unloading. In the rivet forming step, all nodal degrees of freedom outside a $12.7 \mathrm{~mm}(0.5 \mathrm{in})$ radius of the rivets were constrained and the rivets were formed by the rigid die tools to a designated squeeze force (Figure 5.2). In the rivet springback step, the rivets were unloaded to $1 \%$ of the maximum forming load. This controlled any possible oscillations that could be induced by quick release of the load. This step also released the previously fully constrained portions of the sheets. Only the symmetry constraints and $\mathrm{x}$ and $\mathrm{z}$-constraints on the end of either sheet were maintained. The third step applied a stress of $79 \mathrm{MPa}$ to the end of the countersunk splice inner sheet and $100 \mathrm{MPa}$ to the universal splice inner sheet. The stress levels were chosen as typical stresses for narrow body aircraft [48]. The reason for different stress levels for the two rivet types was to keep the fretting contact stresses around the rivet holes within the elastic range. Staying within the elastic range avoided the need to simulate multiple loading 
cycles to obtain a 'shakedown state' that resolves initial plasticity. The ends of the outer sheets in both splices were fixed in the $x$ and $z$-directions (Figure 5.3). Finally, in the fourth step the splice was unloaded to $1 \%$ of the maximum splice load.

Time scaling was used in the simulation with the rivet forming, rivet springback, splice loading, and splice springback steps taking place over $0.005,0.003,0.012$, and 0.006 seconds respectively. Time scaling is generally valid in quasi-static loading situations as long as the kinetic energy of the system does not exceed $5 \%$ of the total internal energy during the simulation [47]. This criterion was met for these simulations.

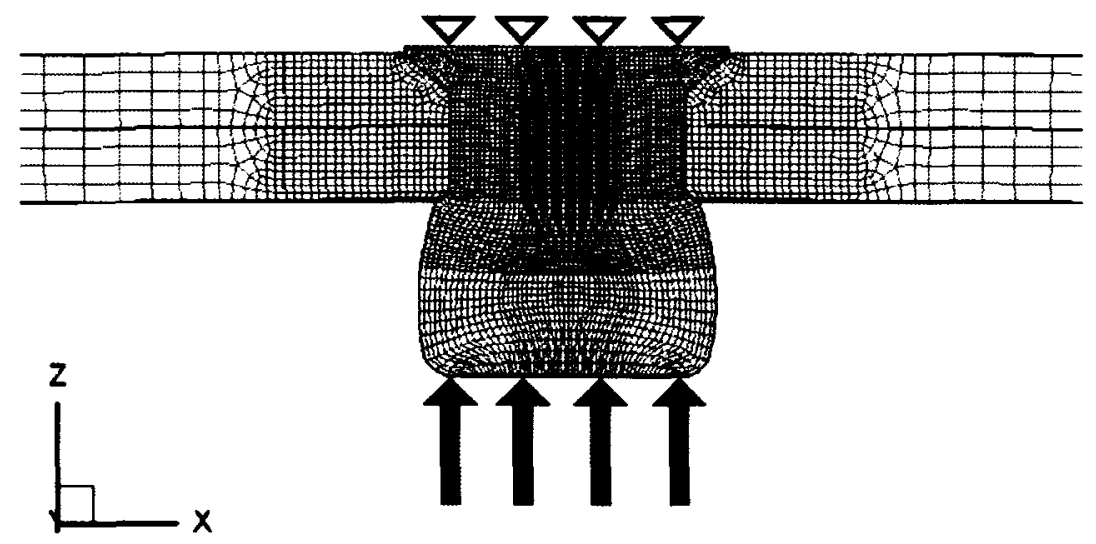

Figure 5.2 Rivet forming step. $6.7 \mathrm{kN}$ (1500 lbf)

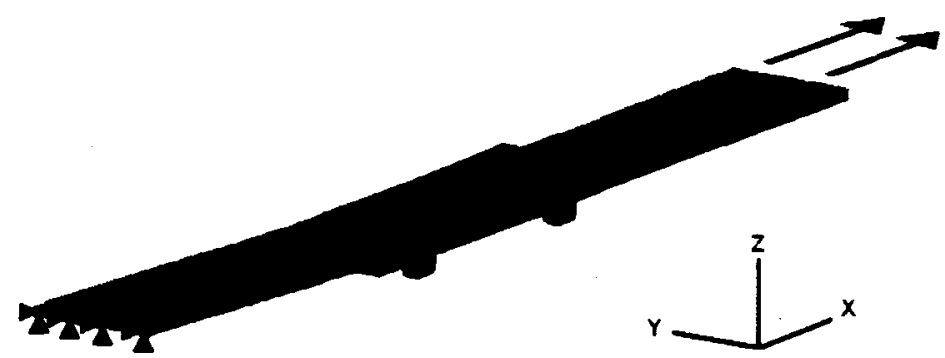

Figure 5.3 Splice loading step.

Contact was enforced through the penalty method for all contact surfaces except the faying surface where kinematic contact was used. The more strict kinematic contact definition is applied to the faying surface since it is known to experience fretting damage. Friction was 
imposed using the basic Coulomb model. For all contact surfaces except the faying surface, a coefficient of friction (COF) of 0.178 [3] was used. The faying surface coefficient of friction was changed after the rivet springback step from 0.178 to 0.65 [12] to properly represent the increase of COF in fretting contact [12]. Initially, when the sheets are riveted together, no fretting damage exists and the COF between 2024-T3 aluminum has been measured to be 0.178 . Upon the application of fatigue loading, the COF quickly increases, as measured by others $[12,49]$, due to the removal of surface oxides initially and then due to the formation of fretting damage.

C3D8R solid elements were, again, used for the sheets and rivets in the model whereas S4R elements (4-node shell with reduced integration and hourglass control) were used for the forming tools. The sheet meshes were refined in the region surrounding the rivet hole with an average element edge-length of $0.1 \mathrm{~mm}(0.004 \mathrm{in})$. Again, sub-modelling was applied, as in the Mindlin contact problem, with the region around the rivet being the area of refinement (Figure 5.4). For the machine countersunk splice model, the top row of the outer sheet was of interest. For the universal splice model, the bottom row of the inner sheet was of interest. These were the locations found to be the critical failure locations in splice fatigue tests. It should be noted that it is not necessary to model the rivets in any of the sub-model simulations as long as the driving elements along the hole edge are properly defined. Removing the rivet from the sub-model saves on the computation cost as each rivet consists of over 70000 elements. 


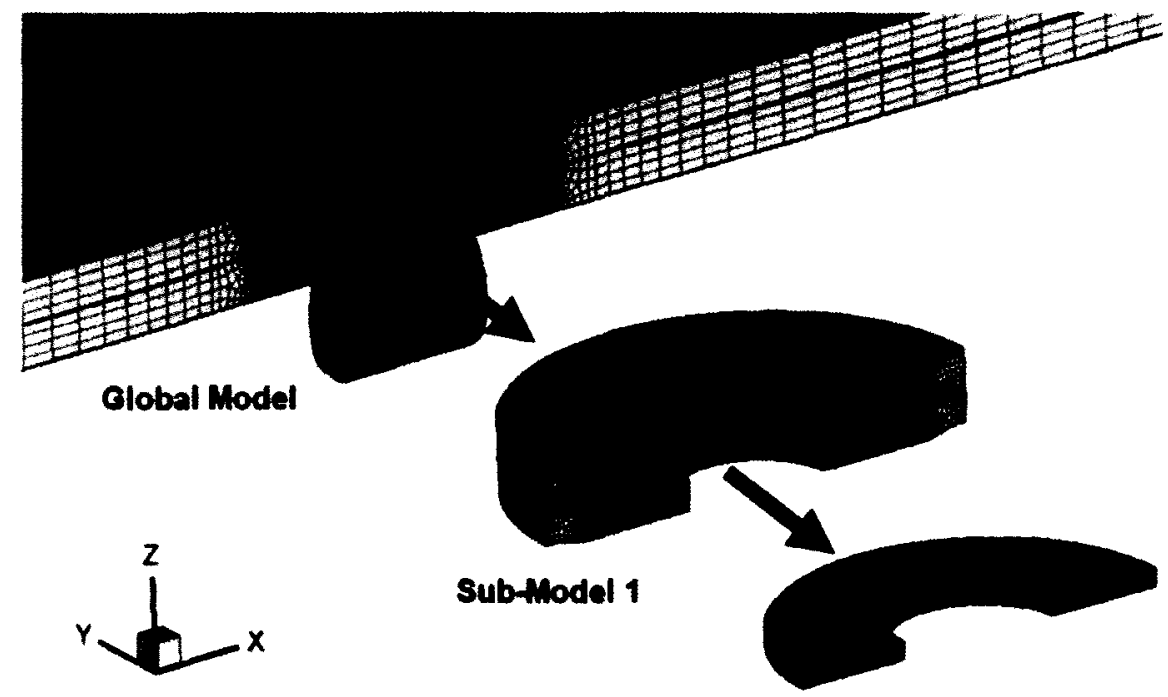

Sub-Model 2

Figure 5.4 Illustration of sub-modelling technique applied to splice simulation.

\subsubsection{Model Verification and Validation}

\subsubsection{Introduction}

Methods used to verify and validate the rivet forming step and the splice loading step are described in the following sections. Since the area of interest is under the rivet head surrounding the holes, direct comparison or measurement becomes a problem. To overcome this difficulty, indirect methods of verification and validation were used. The methods include stress convergence, indirect comparison to neutron diffraction data, and the use of pressure sensitive film.

\subsubsection{Stress Convergence}

Convergence of the stresses obtained from the sub-models was the first technique used for verification of the splice model. The maximum principal stresses at the edge of contact around the hole were compared in the $11.1 \mathrm{kN}(2500 \mathrm{lbf})$ rivet forming case for the global model and two sub-models. The element size was reduced from $0.100 \mathrm{~mm}$ in the global model to $0.050 \mathrm{~mm}$ and $0.025 \mathrm{~mm}$ in the first and second sub-models respectively. Convergence was obtained quicker in 
the splice model than in the Mindlin model of Chapter 4 with the numbers presented in Table 5 . 1. Quicker convergence is due to the smaller stress levels at the edge of contact than in the Mindlin model. Since the splice simulation is effectively two planes in contact rather than a cylinder and a plane, the edge of contact stress peak is not as large. Based on these results, it was determined that only two sub-models would be required in future splice simulations.

Table 5. 1 Convergence results for 3D splice model.

\begin{tabular}{|c|c|c|c|}
\hline Model & $\begin{array}{c}\text { Element edge length } \\
(\mathrm{mm})\end{array}$ & $\begin{array}{c}\text { Max Principal Stress } \\
\text { MPa (psi) }\end{array}$ & $\begin{array}{c}\text { \% Difference from } \\
\text { Previous }\end{array}$ \\
\hline Global & 0.100 & $202.6(29389)$ & - \\
\hline Sub-model 1 & 0.050 & $263.2(38171)$ & $23 \%$ \\
\hline Sub-model 2 & 0.025 & $274.4(39796)$ & $4 \%$ \\
\hline
\end{tabular}

\subsubsection{Residual Stresses}

As an indirect verification of the model's ability to reproduce the correct residual stress state around the rivet holes, a simulation was performed for a slightly different configuration where neutron diffraction data exists. The data was obtained by the National Research Council of Canada (NRCC) for a study on residual strains created during rivet forming [50]. For a comparison to be made to the measurements, however, the geometry of the riveted sheets had to be scaled up by a factor of approximately two.

The scaled rivet-forming model was a quarter-symmetry 3D model consisting of two 2.0 $\mathrm{mm}$ sheets and an MS20426AD-8-9 rivet. The material models, contact interactions and boundary conditions were all kept identical to those used in the splice loading simulations. By only changing the geometry, an indirect verification was made of the modelling methodology. Two different rivet forming loads were compared, $44.5 \mathrm{kN}$ and $53.4 \mathrm{kN}$. Although two forming loads were compared, only the radial and hoop strains for the $44.5 \mathrm{kN}$ case are presented here for brevity. Full results of the comparisons can be found in Appendix B. 


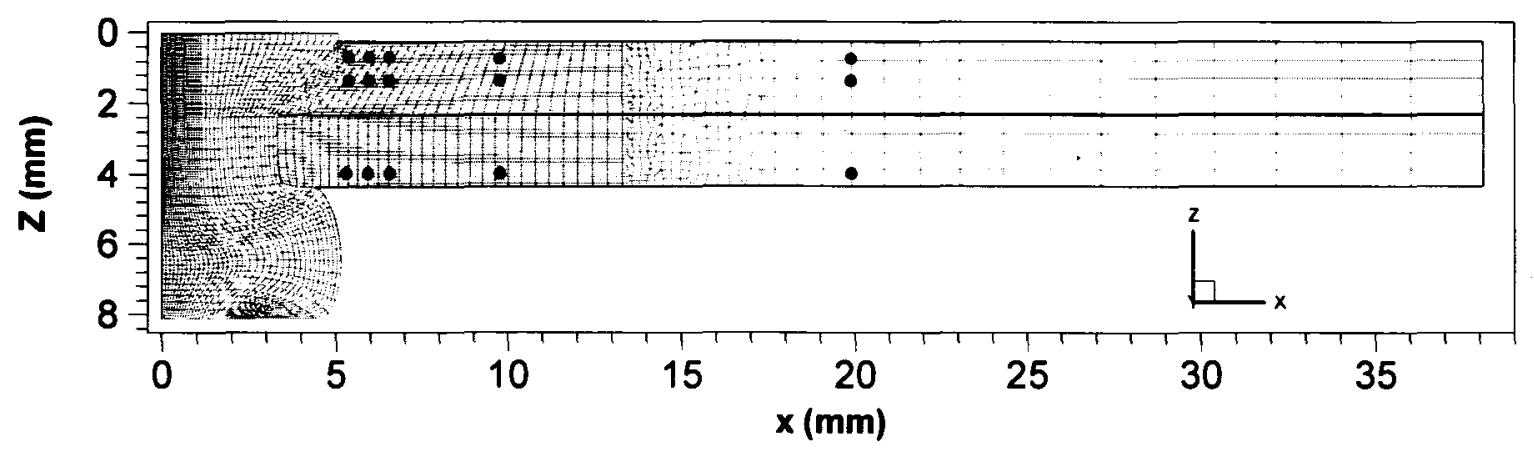

Figure 5.5 Locations for neutron diffraction residual stress measurements.

The residual stress measurement locations are indicated in Figure 5.5. Residual radial and hoop strains for different points within the sheets are shown in Figure 5.6 to Figure 5.9. The plots include residual strain results for three different finite element models: $2 \mathrm{D}$ axi-symmetric data from the NRCC using NASTRAN, 3D data from Rans [8] using LS-DYNA, and finally 3D data from this study (Abaqus). The residual strains obtained from the simulation agreed well with the neutron diffraction data points and show the same trends as the other FE data. In several cases, such as Figure 5.6, the 3D Abaqus data agreed better than the other two simulations. The discrepancies that do exist between the finite element data and the neutron diffraction measurements may be partly due to the neutron diffraction measurements being taken over a gauge volume of $1 \mathrm{~mm}^{3}$. The resolution problems of the neutron diffraction technique are discussed in detail in a paper using the same data by Li et. al. [50]. 


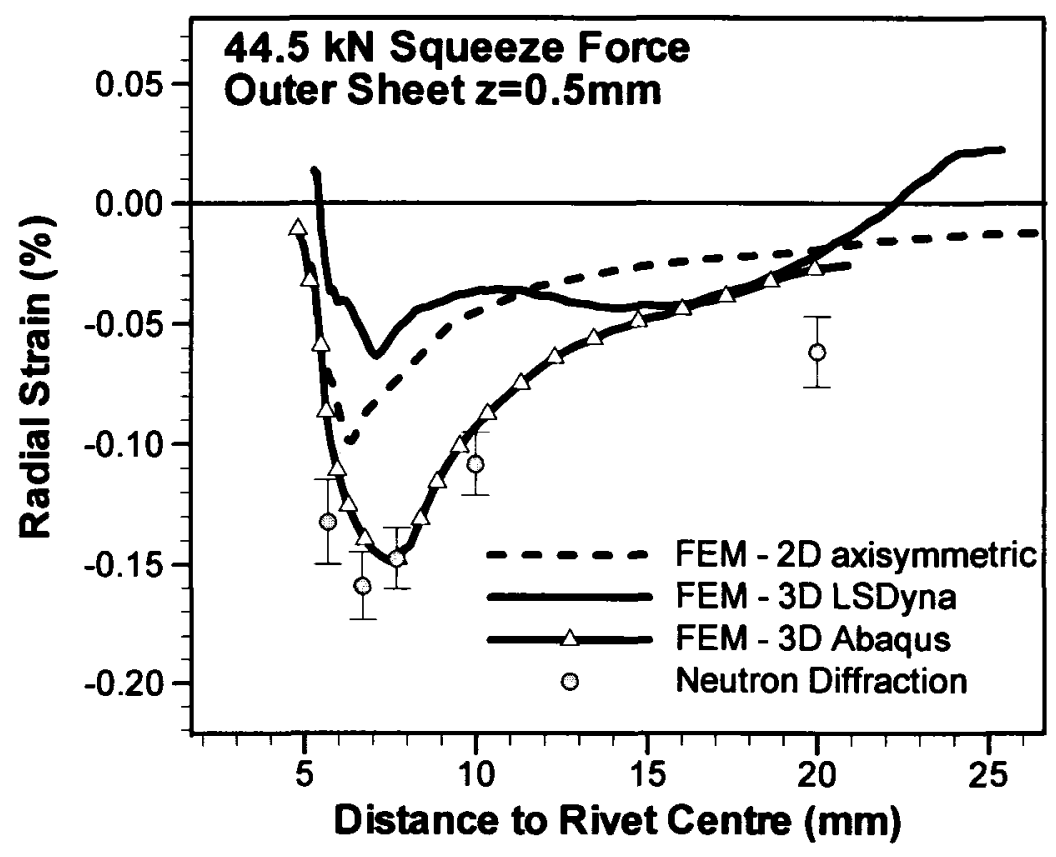

Figure 5.6 Radial strain in the outer riveted sheet.

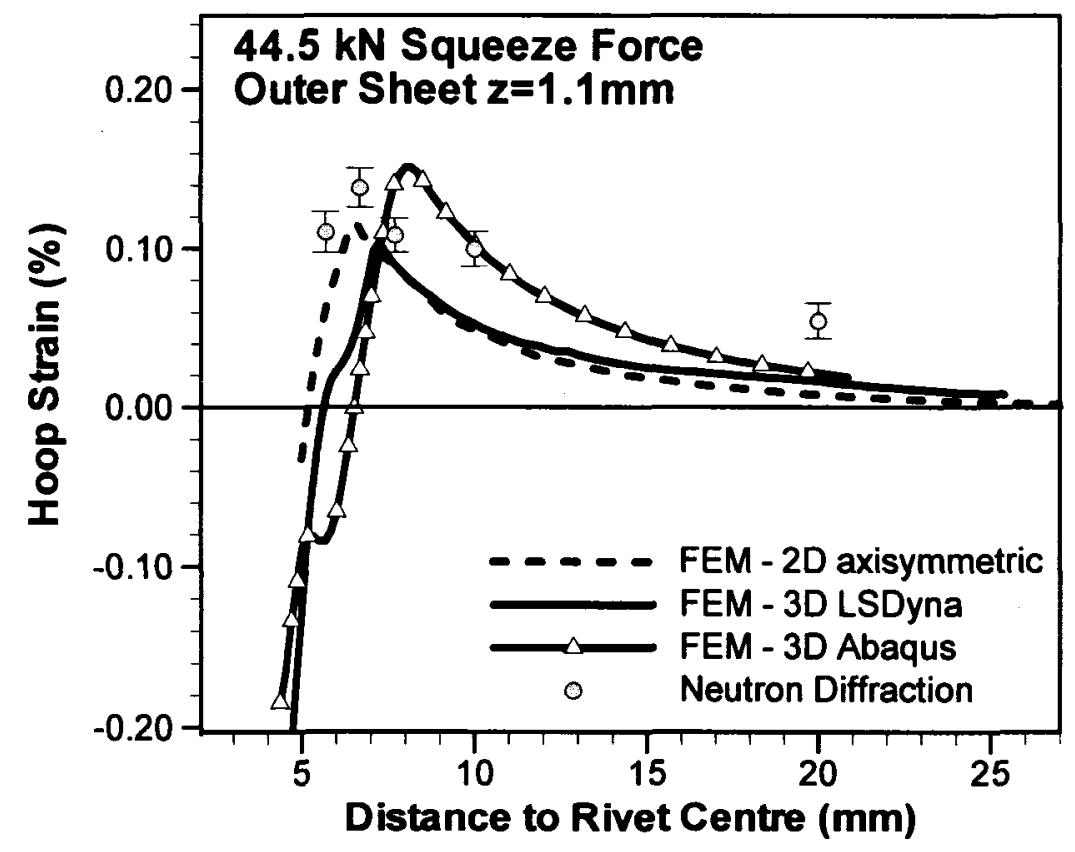

Figure 5.7 Hoop strain in the outer riveted sheet. 


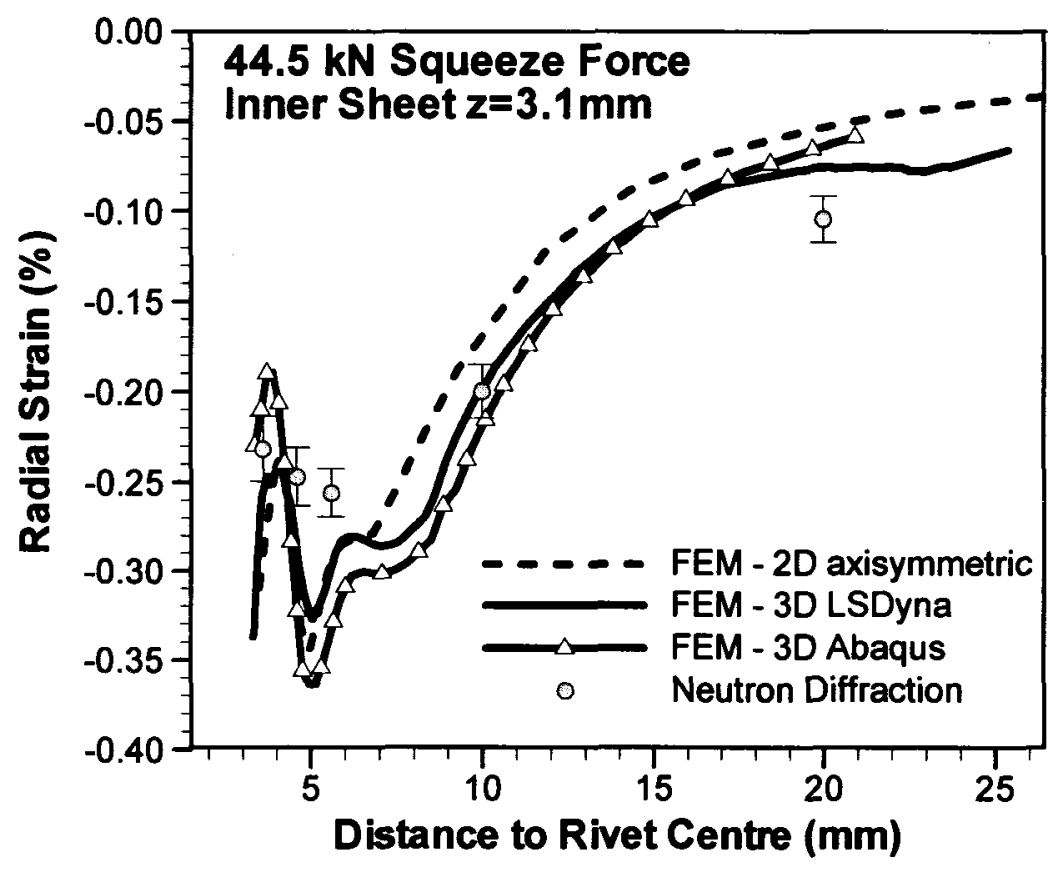

Figure 5.8 Radial strain in the inner riveted sheet.

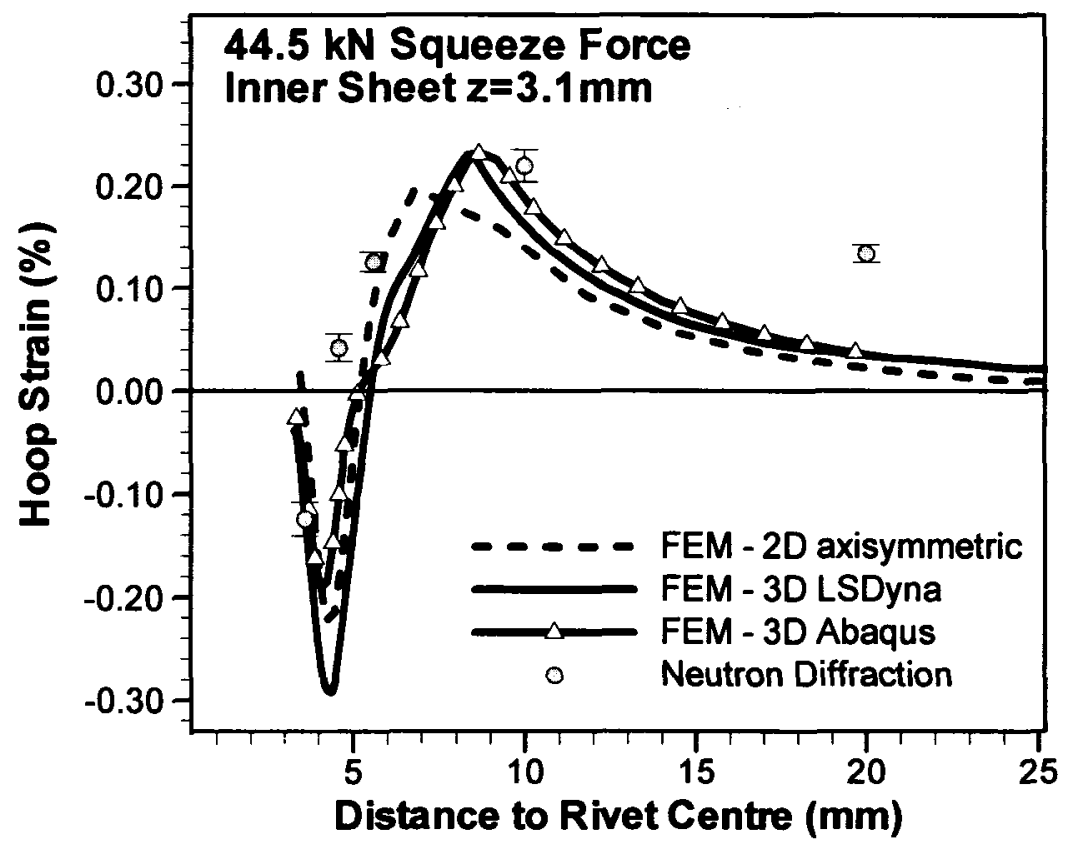

Figure 5.9 Hoop strain in the inner riveted sheet. 


\subsubsection{Rivet Forming Step - Pressure Sensitive Film}

The third method of verifying that the simulated installed rivets match actual installed rivets was the use of pressure sensitive film. Pressure sensitive film changes colour with the application of an applied pressure. The intensity of the colour is related to the amount of pressure. Different types of film are available from "Super low" to "Super high" with a pressure range associated with each. For this situation, the "Super high" film was chosen (141 MPa-300 MPa) and was placed between the sheets of both the countersunk and universal splice coupons (Figure 5.10). The holes were then drilled, rivets inserted, and formed to the prescribed load. Drilling out of the rivets and removing the film from between the sheets then provided results for the maximum pressures experienced on the faying sheet surfaces during the rivet forming step. Checks were made to ensure that the initial hole drilling step did not generate pressures large enough to activate the film. The pressure distribution of each film was digitized and the intensity was analyzed using image software and calibration curves provided by the manufacturer. This allowed for greater resolution than simple visual comparisons. Figure 5.11 shows a typical film pressure distribution and a simulated pressure distribution around a countersunk hole formed to $13.3 \mathrm{kN}$ (3000 lbf). 


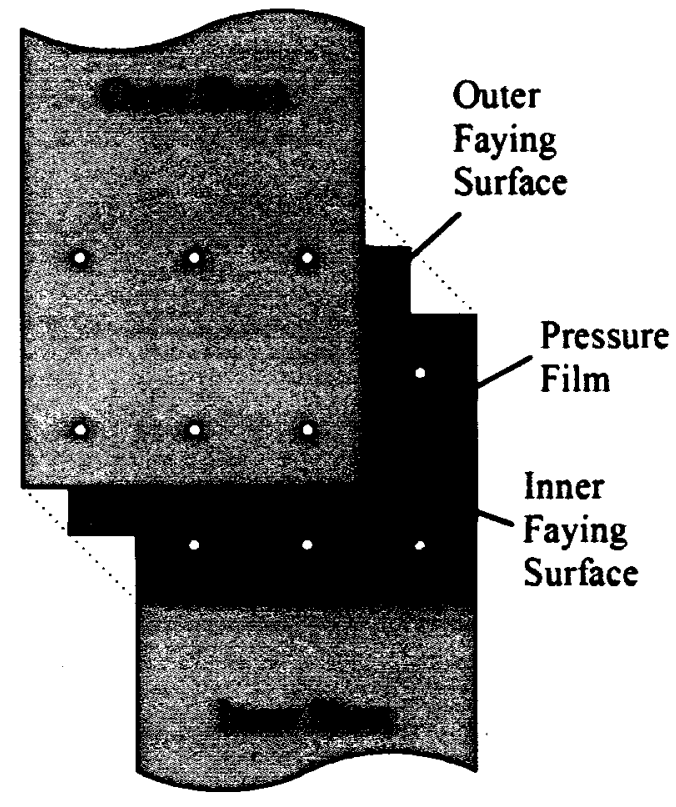

Figure 5.10 Placement of pressure sensitive film during hole drilling and rivet forming.
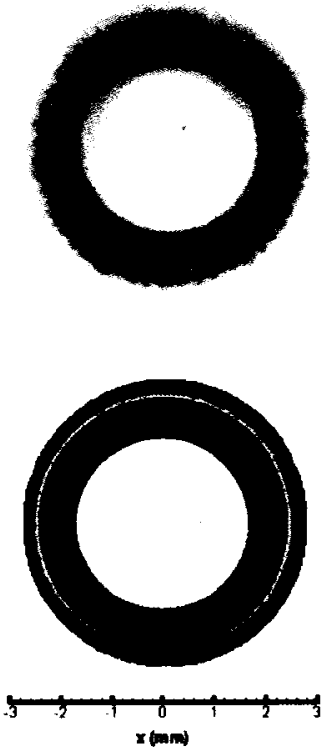

Figure 5.11 Pressure film imprint from $13.3 \mathrm{kN}$ (3000 lbf) rivet squeeze force case (top) and FEM result (bottom).

Comparison of the film results to the simulated faying surface stresses is presented in

Figure 5.12 and Figure 5.13 for the countersunk and the universal rivet cases respectively. The plots show that although the highest available pressure range was used, the $6.7 \mathrm{kN}$ rivet forming load was the only case where the pressures were low enough to capture the entire distribution. For the higher rivet forming loads, only the outer boundary of the pressure distribution could be captured. Despite the load limitation of the film, good agreement was found for the $6.7 \mathrm{kN}$ case and for the clamping area boundaries shown in the higher squeeze force cases. 


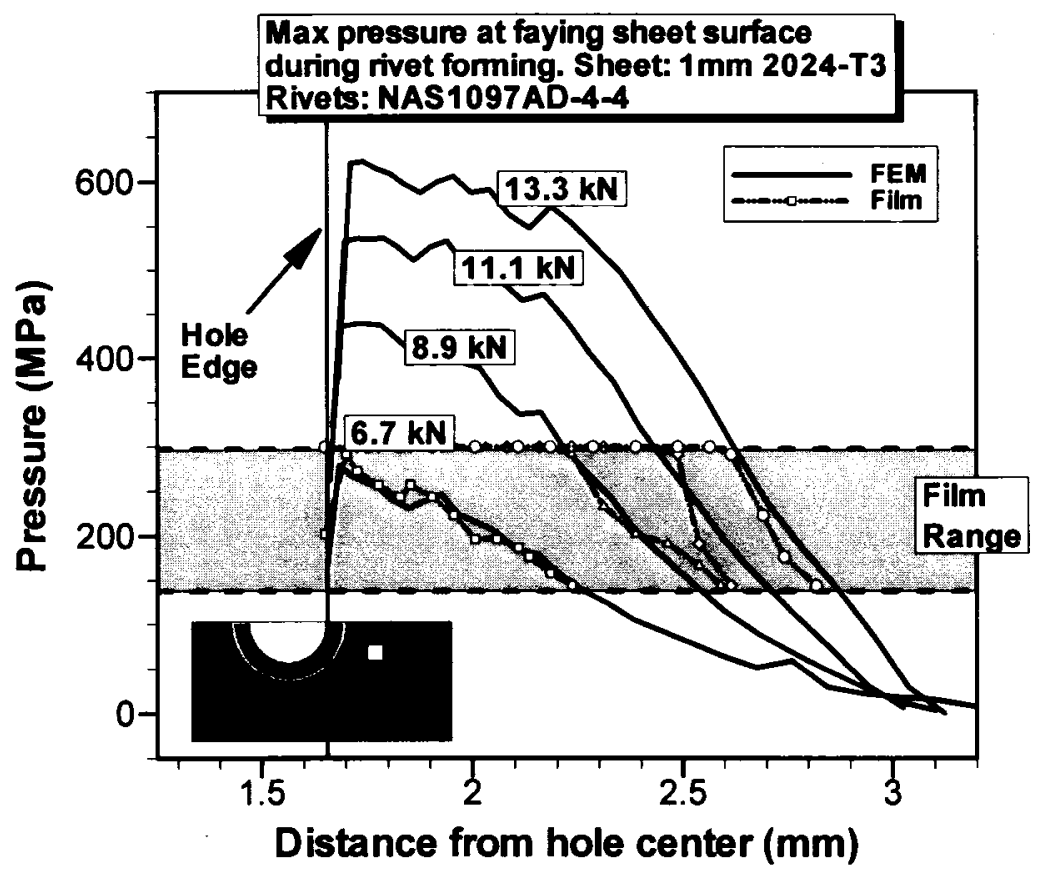

Figure 5.12 Countersunk rivet faying surface forming pressure measurement.

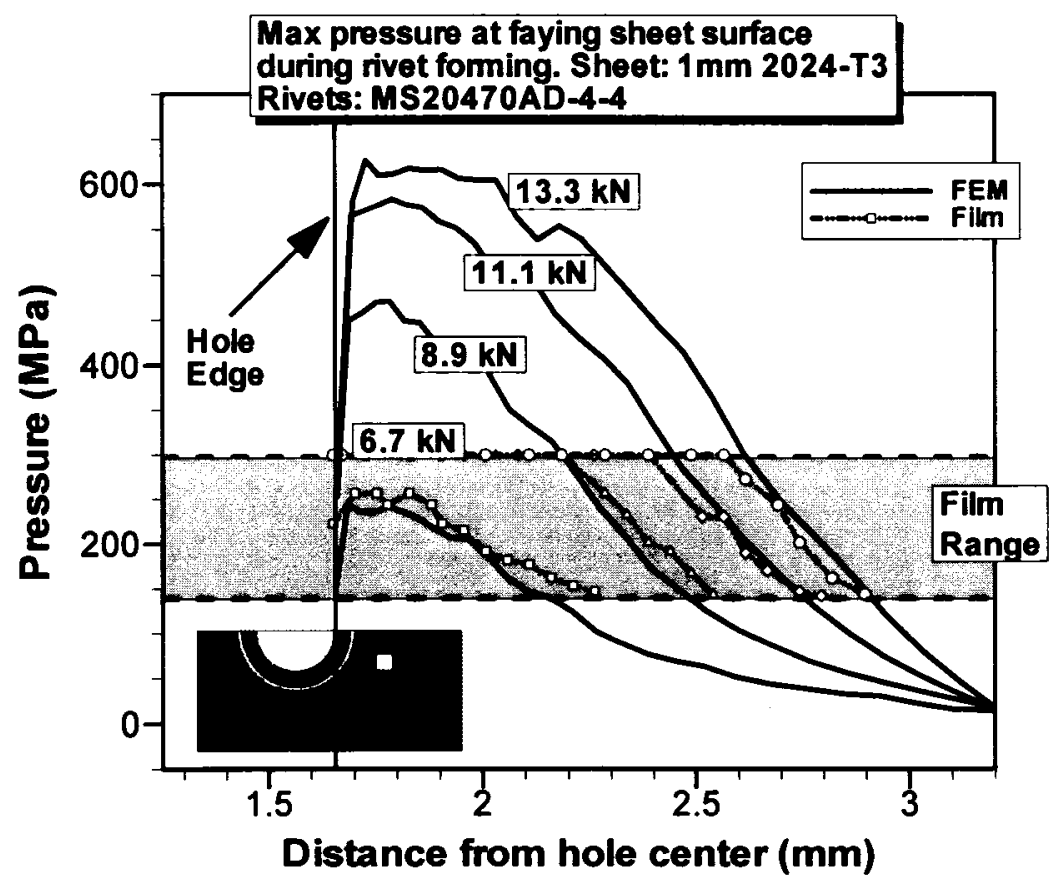

Figure 5.13 Universal rivet faying surface forming pressure measurement. 


\subsubsection{Splice Loading Step - Contact Area}

Verification of the splice loading model was done by a comparison between simulated faying surface contact areas and the fretting scars associated with contact in fatigued coupons. Since the contact area changes during cycling, the FE results for both the loaded and unloaded states are included. The test coupons were cycled until a $1 \mathrm{~mm}$ surface crack had initiated beyond the rivet head, ensuring that any fretting scar would be fully developed.

The comparison is shown for the NAS1097AD-4-4 rivets in Figure 5.14 to Figure 5.17 and for the MS20470AD-4-4 rivets in Figure 5.18 to Figure 5.21. Four different rivet forming loads are presented for each rivet type $(6.7 \mathrm{kN}, 8.9 \mathrm{kN}, 11.1 \mathrm{kN}$, and $13.3 \mathrm{kN})$. The images show typical fretting wear on the faying surface of bare splice coupons with the predicted contact areas on the faying surface of the splice as superimposed boundaries.

In the figures, three general regions of fretting contact can be identified: stick, stick-slip, and slip (identified in Figure 5.15). These regions refer to the behaviour of the contacting asperities in that region and are especially noticeable in the countersunk rivet figures. "Stick" occurs when the clamping force is sufficiently high and no slip happens between the contacting asperities. This can be seen in the figures as the region inside the boundaries where the clamping area does not change during splice loading. On the other extreme, at very low clamping forces the asperities will freely slide and this area is known as "slip". This region is outside the observable contact since this type of contact does not produce any type of scar or damage on the surface. The stick-slip region lies in-between the other two regions, at the edge of contact, and is where the most severe fretting damage will occur. This region is identified by the presence of black oxidized debris. The debris can be observed in the figures as the black material between the contact boundaries of the loaded splice state and the unloaded splice state. It is in the "stick-slip" region that micro-cracks will form and eventually propagate into fatigue cracks. 


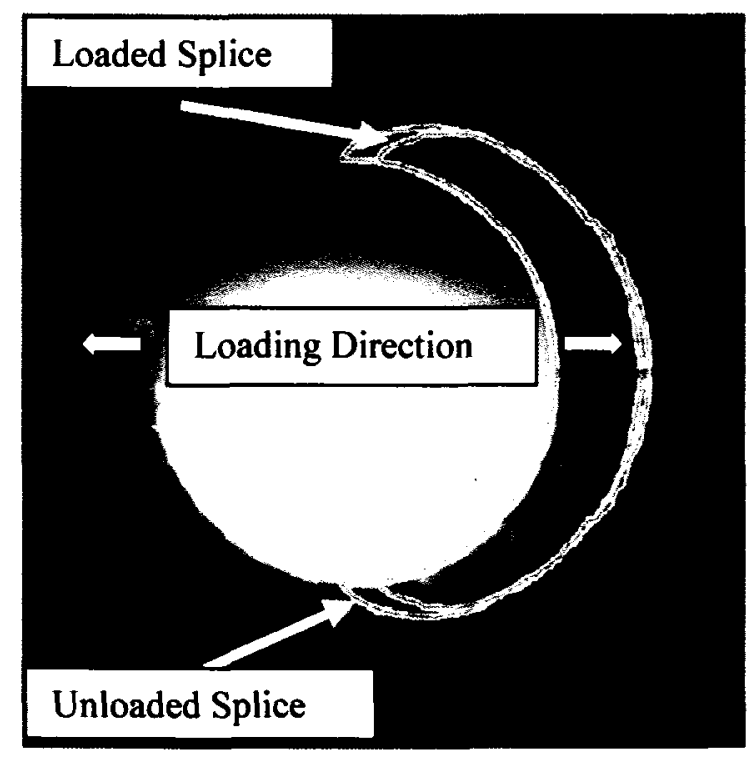

Figure 5.14 FEM predicted contact area outline superimposed onto countersunk fretted coupon hole (6.7 $\mathrm{kN}$ case).

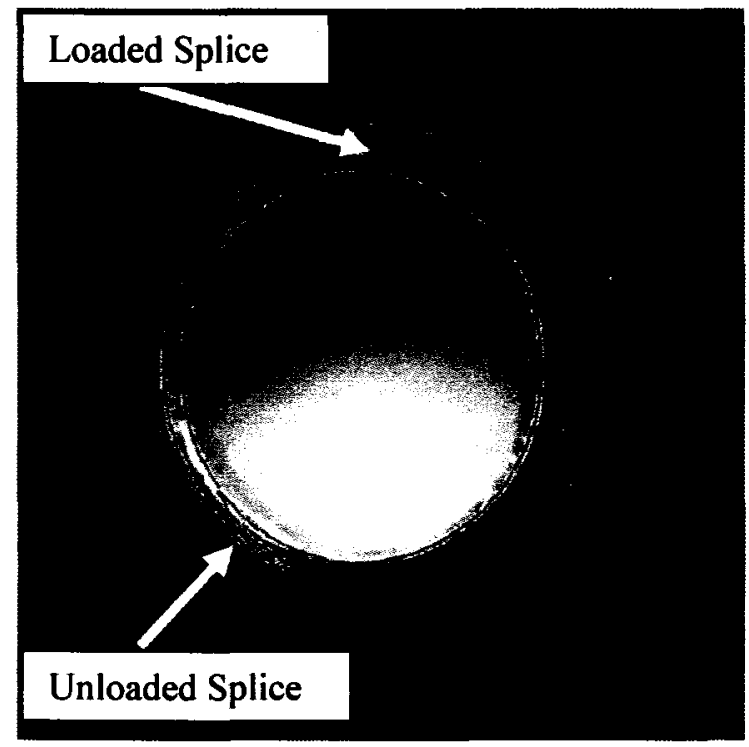

Figure 5.16 FEM predicted contact area outline superimposed onto countersunk fretted coupon hole (11.1 kN case).

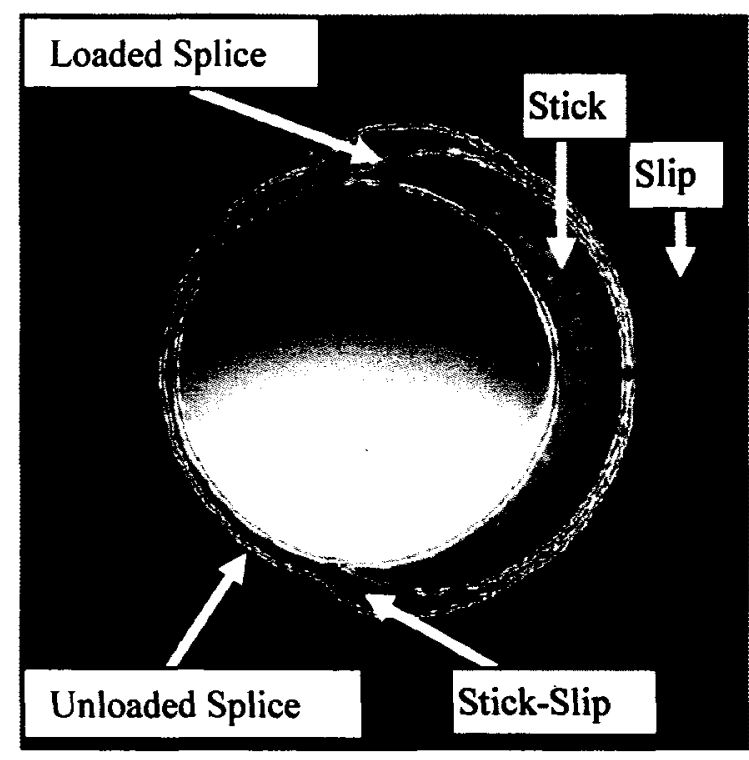

Figure 5.15 FEM predicted contact area outline superimposed onto countersunk fretted coupon hole (8.9 kN case).

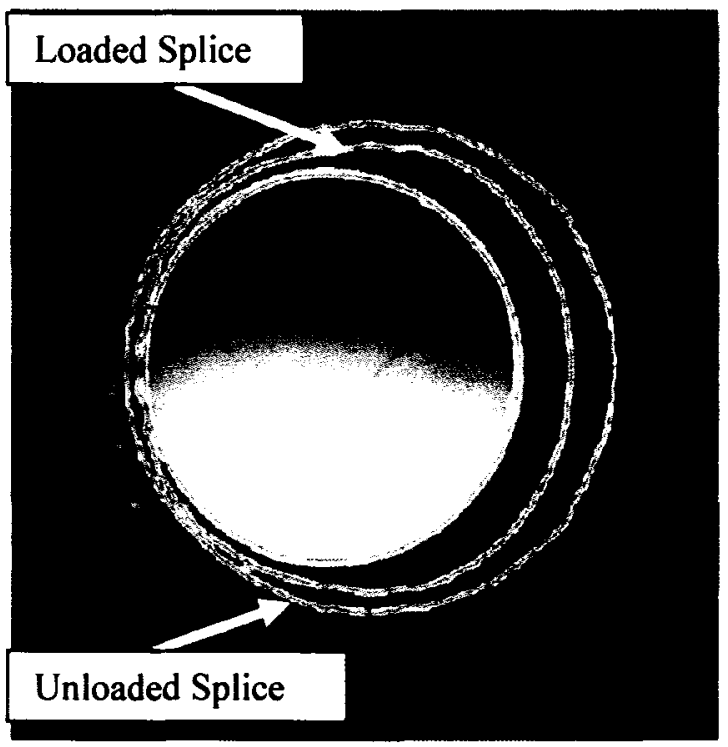

Figure 5.17 FEM predicted contact area outline superimposed onto countersunk fretted coupon hole ( $13.3 \mathrm{kN}$ case). 
It is interesting to observe that the contact area of the countersunk coupons does not always return to the symmetrical distribution created by the rivet forming step upon unloading of the splice. The skewed contact area plays an important role in the region where fretting cracks will nucleate. In the lower rivet squeeze force cases $(6.7 \mathrm{kN}, 8.9 \mathrm{kN})$, the edge of contact coincides more with the net section of the splice at the hole edge. For the high rivet squeeze force cases $(11.1 \mathrm{kN}, 13.3 \mathrm{kN})$, greater clamping is observed and the edge of contact is pushed away from the hole edge.

The figures of the universal rivets (Figure 5.18 to Figure 5.21) show that the predicted contact area does not generally increase until the $13.3 \mathrm{kN}$ case. This prediction agrees with the residual clamping plot for universal rivets presented in Chapter 3. Although the predicted clamping area does not increase, the magnitude of the clamping pressure does. For the low rivet squeeze force cases (Figure 5.18 and Figure 5.19) the fretting damage on the universal rivet coupons is not as severe as on the corresponding machine countersunk rivet coupons (Figure 5.14 and Figure 5.15). This is because, as shown in Chapter 3, universal rivets formed to $6.7 \mathrm{kN}$ and to $8.9 \mathrm{kN}$ have lower residual sheet clamping than the corresponding countersunk rivets. With clamping pressures that are smaller in magnitude $(6.7 \mathrm{kN}$ case $)$ and cover smaller areas $(8.9 \mathrm{kN}$ case), the universal coupons will not produce fretting damage as severe as the countersunk coupons. 


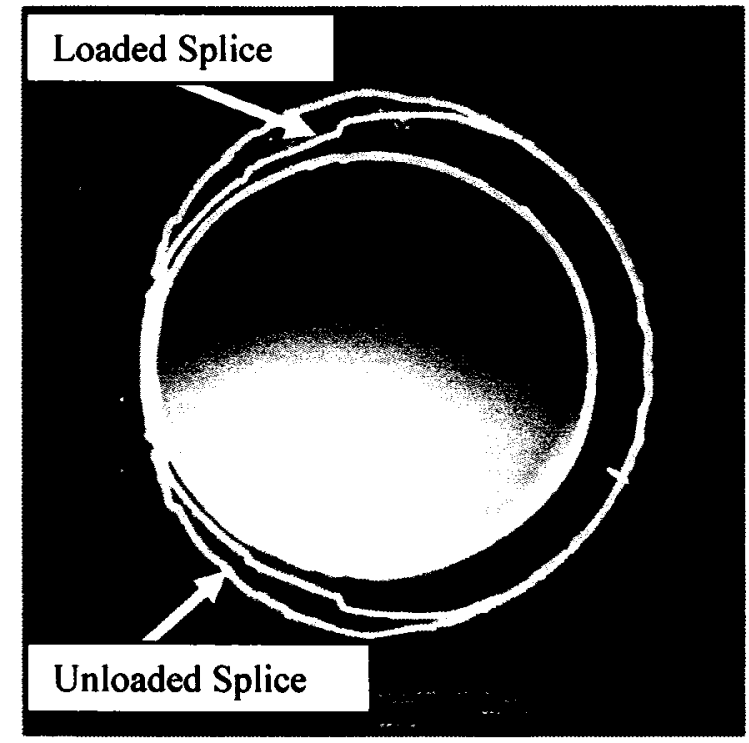

Figure 5.18 FEM predicted contact area outline superimposed onto universal fretted coupon hole (6.7 $\mathrm{kN}$ case).

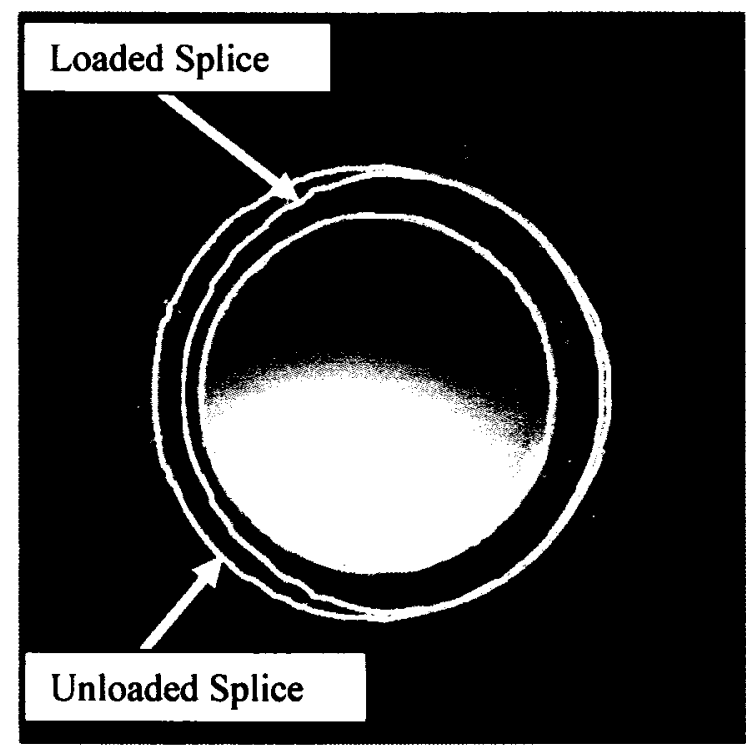

Figure 5.20 FEM predicted contact area outline superimposed onto universal fretted coupon hole (11.1 kN case).

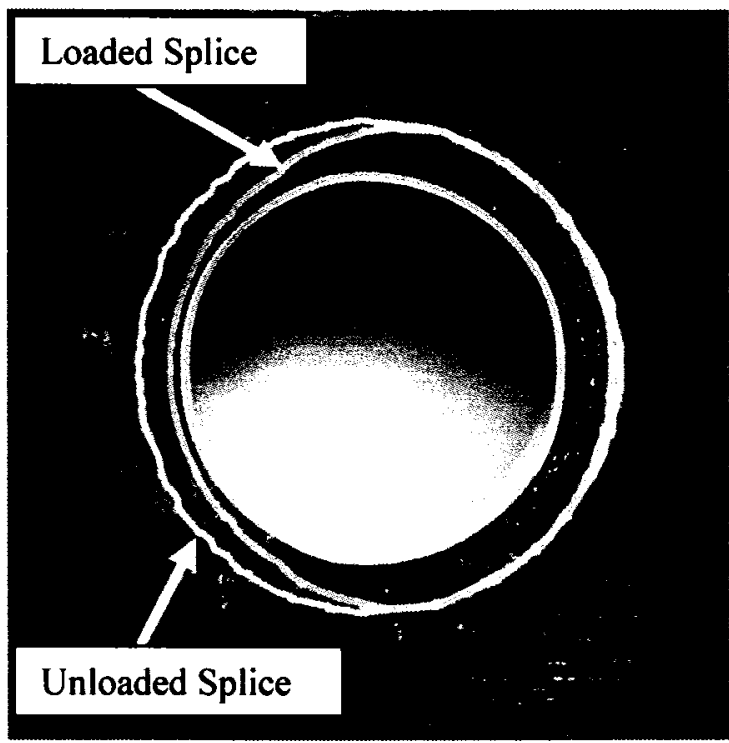

Figure 5.19 FEM predicted contact area outline superimposed onto universal fretted coupon hole (8.9 $\mathrm{kN}$ case).

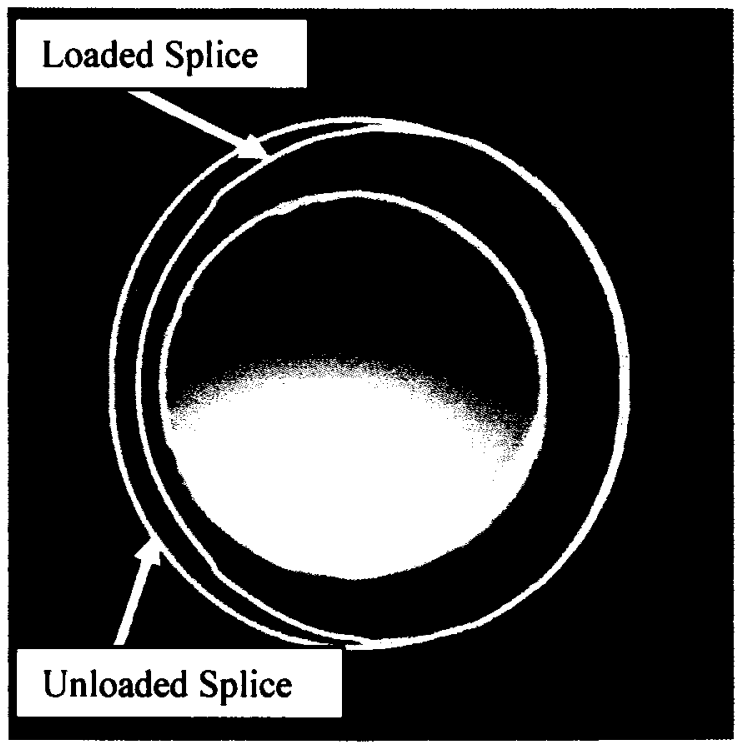

Figure 5.21 FEM predicted contact area outline superimposed onto universal fretted coupon hole (13.3 kN case). 
The previous sections have shown that verification of the splice model was performed using a stress convergence method followed by model validation that included residual strain comparison, pressure measurements, and comparison to test coupons. The stress convergence results showed that, through the use of sub-modelling, stress convergence could be obtained in a large model. The residual strain comparison indirectly validated the modelling technique by simulating similar splice geometry and achieving good results. The pressure sensitive film measurements were an indirect validation of the rivet-forming step as measurements could only be taken for the pressures around the rivet holes at the maximum squeeze force and not the pressures after rivet springback. Good agreement, however, was produced for the maximum forming pressures. Finally, comparison of the predicted faying surface contact area to the fretting wear scars on tested splice coupons showed good agreement with areas that would be expected to show signs of stick, stick-slip, and slip characteristics.

With confidence in the splice FE models, it was then possible to use the stress and strain fields to calculate life predictions described in detail in the next chapter. 


\section{Lap Splice Fretting Fatigue Prediction}

\subsection{Introduction}

To predict crack formation due to fretting fatigue in riveted lap splices, it was necessary to find a predictive method that could lend itself to complex geometries. The summary of predictive methods presented in section 2.4.1 found that the notch analogy method and the asymptotic methods were too restrictive in the geometries to which they apply. Further development of these methods, if possible, would be required for them to be applicable to the complex geometry of a lap splice. The remaining critical plane method for multi-axial fatigue was deemed suitable for complex geometries.

As touched on in Chapter 2, it was suggested by Szolwinski and Farris [12] that a critical plane version of the Smith-Watson-Topper (SWT) strain-life curve could be used to predict the fretting fatigue life of components. This approach originated from a study by Socie [27] who investigated multi-axial fatigue damage models. Szolwinski used the critical plane SWT equation to predict failure in Mindlin-type cylinder-on-flat fretting coupons with good success. Harish and Farris later applied the critical-plane SWT approach to a 2D finite element splice model mentioned in section 2.5.1. Another notable study on the critical plane SWT parameter was performed by Sum et. al. [21] to predict failure lives for titanium gas turbine spline couplings commonly subject to fretting fatigue. 
The benefits of using the critical plane SWT parameter are the versatility and the relative ease of use. The method is versatile because the stress field required for prediction can be found from finite element methods. FEM allows for simulation of almost any complex geometry or loading situation as long as the simulation is well developed and validated. The critical plane SWT predictive method's ease of use stems from it being based on common strain-life constants that are published in open literature.

By using the 3D lap splice model developed in Chapter 5, rivet clamping and secondary bending can be included in the fretting fatigue life prediction as well as residual stresses in the splice sheets due to rivet forming. Being able to model residual stresses in a component this way is essential because, as mentioned by Nowell and Hills [51], "handling of residual stresses remains an important point for the study of fretting fatigue."

This chapter explores the use of the critical-plane SWT parameter in single lap splices to predict where fretting crack nucleation occurs as well as when crack initiation occurs. The difference between crack nucleation and crack initiation being that crack nucleation is a process of degradation and crack initiation is a (arbitrarily) defined crack length for use in analysis. In strict terms a crack will nucleate and propagate to become an initiated crack.

\subsection{Methodology}

\subsubsection{Introduction}

The critical plane Smith-Watson-Topper approach is based on the well-known strain-life equation. The strain-life equation describes the total cyclic strain amplitudes in terms of elastic strain amplitudes (Basquin's equation) and plastic strain amplitudes (Manson-Coffin equation). In this way, both high cycle fatigue (HCF) and low cycle fatigue (LCF) are included. The Basquin and Manson-Coffin equations, shown as equations 6.1 and 6.2 respectively, are given as 


$$
\begin{aligned}
& \left(\frac{\Delta \varepsilon}{2}\right)_{e}=\frac{\sigma_{f}^{\prime}}{E}\left(2 N_{f}\right)^{b} \\
& \left(\frac{\Delta \varepsilon}{2}\right)_{p}=\varepsilon_{f}^{\prime}\left(2 N_{f}\right)^{c}
\end{aligned}
$$

where:

$\begin{array}{ll}\sigma_{\mathrm{f}}^{\prime} & \text { is the tensile fatigue strength coefficient } \\ \varepsilon_{\mathrm{f}}^{\prime} & \text { is the tensile fatigue ductility coefficient } \\ \mathrm{c} & \text { is the fatigue ductility exponent } \\ \mathrm{b} & \text { is the fatigue strength exponent } \\ N_{\mathrm{f}} & \text { is the number of cycles to failure } \\ \mathrm{E} & \text { is the Young's modulus } \\ \Delta \varepsilon & \text { is the strain range }\end{array}$

The total strain amplitude is then the summation of the Basquin and Manson-Coffin equations.

$$
\left(\frac{\Delta \varepsilon}{2}\right)=\frac{\sigma_{f}^{\prime}}{E}\left(2 N_{f}\right)^{b}+\varepsilon_{f}^{\prime}\left(2 N_{f}\right)^{c}
$$

Since this equation does not take into account mean stress effects, Smith et. al. [52] multiplied equation 6.3 by Basquin's equation for maximum stress given below.

$$
\sigma_{\max }=\sigma_{f}^{\prime}\left(2 N_{f}\right)^{b}
$$

The resulting equation is known as the Smith-Watson-Topper strain life equation with the lefthand term referred to as the SWT parameter.

$$
\sigma_{\max }\left(\frac{\Delta \varepsilon}{2}\right)=\frac{\sigma_{f}^{\prime 2}}{E}\left(2 N_{f}\right)^{2 b}+\sigma_{f}^{\prime} \varepsilon_{f}^{\prime}\left(2 N_{f}\right)^{b+c}
$$

Applying equation 6.5 to a critical plane within a material allows for the handling of multi-axial fatigue scenarios. Equation 6.5 is used here with the definition of the critical plane 
SWT parameter as defined by Szolwinski and Farris: the product of the maximum normal stress and the strain amplitude on the critical plane.

\subsection{Critical plane calculations}

Determining the orientation and location of the critical plane in a component as well as the maximum value of the SWT parameter normally requires some type of numerical method. In complex structures the finite element method is required. Once the stress and strain fields are obtained from the FE analysis, a search can be made to find the maximum SWT parameter at each node or integration point.

The search for the critical plane begins by examining the stress state at a particular node.

Figure 6.1 illustrates the normal stresses at such a location. Shear stresses would be present as well but are omitted from the figure for clarity; they are still included in all calculations. The 3D stress state is described by the $3 \times 3$ matrix given in equation 6.6 .

$$
\left[\sigma_{\mathrm{xyz}}\right]=\left[\begin{array}{lll}
\sigma_{\mathrm{xx}} & \sigma_{\mathrm{xy}} & \sigma_{\mathrm{xz}} \\
\sigma_{\mathrm{yx}} & \sigma_{\mathrm{yy}} & \sigma_{\mathrm{yz}} \\
\sigma_{\mathrm{zx}} & \sigma_{\mathrm{zy}} & \sigma_{\mathrm{zz}}
\end{array}\right]
$$

It is convenient to choose one of the normal stresses as a normal vector that will be transformed to find the critical plane. In this case, the $\sigma_{\mathbf{x x}}$ stress was chosen as the normal vector. The stress field can then be transformed (Figure 6.2) using equation 6.7 and 6.8 in incremental steps about angles $\theta$ and $\Phi$ until the normal vector has traced an entire hemisphere. In this study, an increment of 0.017 radians ( $1 \mathrm{deg}$ ) was used.

$$
\left[\sigma_{\mathrm{x} \prime \mathrm{y} \mathrm{z}^{\prime}}\right]=[\mathrm{T}]\left[\sigma_{\mathrm{xyz}}\right][\mathrm{T}]^{\mathrm{T}}=\left[\begin{array}{lll}
\sigma_{\mathrm{xx}}{ }^{\prime} & \sigma_{\mathrm{xy}}{ }^{\prime} & \sigma_{\mathrm{xz}}{ }^{\prime} \\
\sigma_{\mathrm{yx}}{ }^{\prime} & \sigma_{\mathrm{yy}}{ }^{\prime} & \sigma_{\mathrm{yz}} \\
\sigma_{\mathrm{zx}}{ }^{\prime} & \sigma_{\mathrm{zy}}{ }^{\prime} & \sigma_{\mathrm{zz}}{ }^{\prime}
\end{array}\right]
$$




$$
[T]=\left[\begin{array}{ccc}
\cos \theta & \sin \theta & 0 \\
-\sin \theta \cos \Phi & \cos \theta \cos \Phi & \sin \Phi \\
\sin \theta \sin \Phi & -\cos \theta \sin \Phi & \cos \Phi
\end{array}\right]
$$

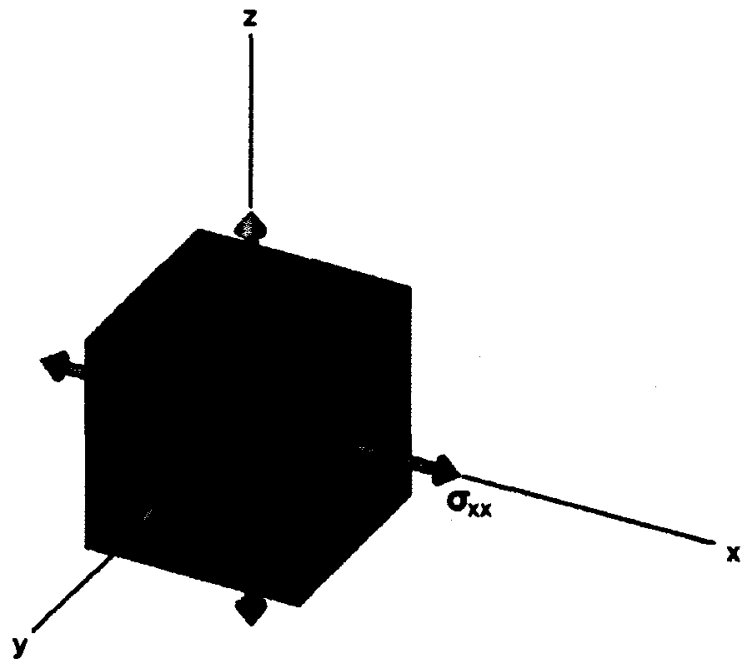

Figure 6.1 Stress state at a node or integration point in an FE model.

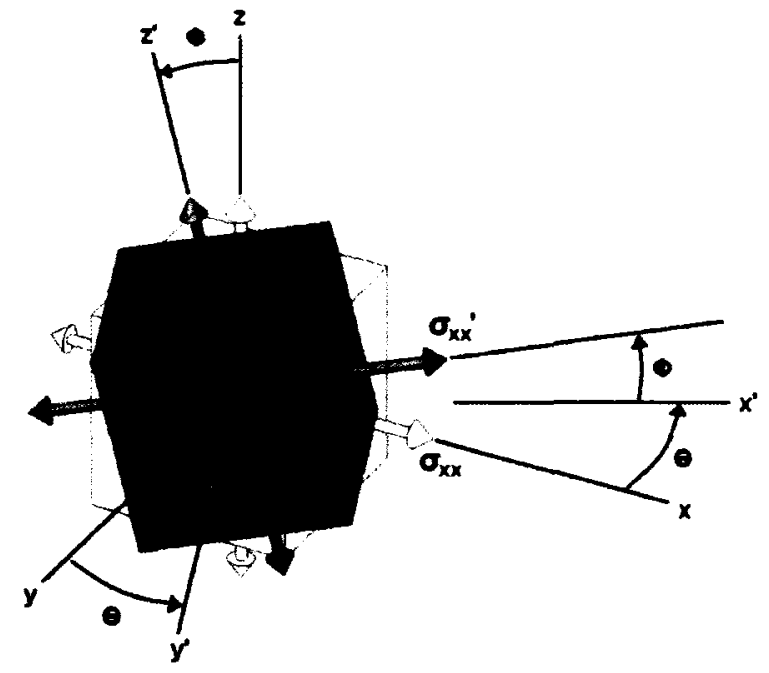

Figure 6.2 Incremental stress transformations to find the maximum SWT parameter on the critical plane.

After each angle increment, the product of the maximum normal stress and the strain amplitude was calculated and compared to the previous increment to find the maximum value for each node. It was then possible to generate a contour plot for the entire component to determine the global maximum.

The above methodology was applied in this study by importing the stress state from each node of a splice simulation into a Matlab program (included in Appendix C). The program then performed calculations to find the maximum SWT parameter on the critical plane. The results were exported to a data file that was used to generate a contour plot. The maximum SWT parameter could then be obtained from the plot and used in equation 6.5 to solve for the fatigue life $\left(2 \mathrm{~N}_{\mathrm{f}}\right)$. The constants used in equation 6.5 are published in open literature for 2024-T3 and are given in Table 6.1. 
Table 6.1 Strain-life constants for 2024-T3 [53].

\begin{tabular}{ll}
\hline$\sigma_{\mathrm{f}}^{\prime}(\mathrm{ksi})$ & 121107 \\
$\varepsilon_{\mathrm{f}}^{\prime}$ & 0.174 \\
$\mathrm{~b}$ & -0.096 \\
$\mathrm{c}$ & -0.644 \\
$\mathrm{E}(\mathrm{ksi})$ & 10500 \\
\hline
\end{tabular}

In addition to life prediction, the contour plot was also used to identify where crack nucleation was likely to occur. The location of the peak critical plane SWT contour, normally corresponding to the edge of contact, is the location where crack nucleation should occur. With the predictions and contour plots available, it was necessary to make a comparison to experimental results.

\subsection{Experiment}

A test matrix was created for bare aluminum single lap splice coupons matching the geometry of the finite element models discussed in Chapter 5. The test coupons consisted of two rows of 3 rivets each as illustrated in Figure 6.3. Both universal (MS20470AD-4-4 rivet) coupons and machine countersunk (NAS1097AD-4-4 rivet) coupons were tested with the same four rivet forming loads used in the $\mathrm{FE}$ simulation $(6.7 \mathrm{kN}, 8.9 \mathrm{kN}, 11.1 \mathrm{kN}$, and $13.3 \mathrm{kN})$ with a load accuracy of $\pm 22 \mathrm{~N}$. For each rivet-forming load, four coupons per geometry were tested to assess the scatter inherent in fatigue tests. Sinusoidal cyclic fatigue testing was performed on a hydraulic test frame with maximum stresses matching the FE simulations (79 $\mathrm{MPa}$ and $100 \mathrm{MPa}$ ) and an $\mathrm{R}$ ratio of 0.1. 


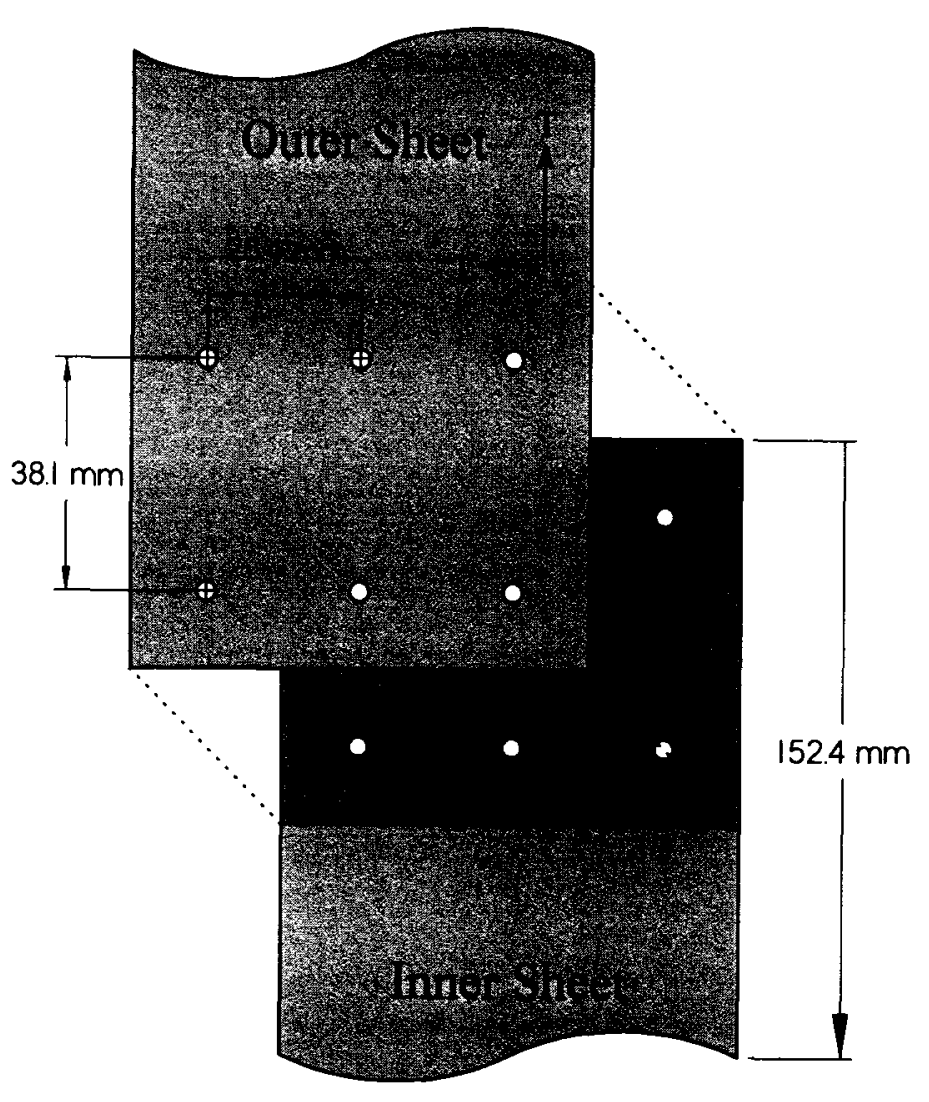

Figure 6.3 Geometry and nomenclature of test coupon splice.

Each sheet of the coupons was $76.20 \pm 0.03 \mathrm{~mm}$ wide by $152.40 \pm 2.50 \mathrm{~mm}$ long and overlapped the adjoining sheet by $63.50 \pm 2.50 \mathrm{~mm}$. Drilling of the holes was performed on a milling machine to ensure that the spacing between the holes was accurate to within $0.01 \mathrm{~mm}$. After hole drilling, the holes were deburred and, if necessary, countersunk using a stop countersinking tool (US industrial tool \#TP61B). Before assembly, the faying surfaces of the sheets were cleaned with alcohol to remove any dirt or oil.

Crack initiation in the splices was defined as the presence of a $1 \mathrm{~mm}$ crack, observed and measured using a travelling microscope, beyond the rivet head. This measurement corresponds to the presence of a $1 \mathrm{~mm}$ through-thickness crack as it breaks the surface of the sheet for splices with high rivet forming loads. In these splices, cracks will nucleate at a location approximately 1 $\mathrm{mm}$ from the hole edge on the faying surface and propagate toward the outer surface of the sheet 
as shown in crack reconstructions performed by Rans [8]. A $1 \mathrm{~mm}$ surface crack is also easily observable with visual inspection and the critical plane SWT predictions are based on stress-life (SN) data to a $1 \mathrm{~mm}$ crack. This is a result of the SWT strain life curve utilizing fatigue constants obtained from experimental testing. The constants used in this study are obtained from standardized fatigue tests based on fatigue lives to the initiation of a $1 \mathrm{~mm}$ crack in the standardized test coupon. Therefore, any time this equation is used, one must realize that these constants do not predict the life to crack nucleation but, rather, initiation of a $1 \mathrm{~mm}$ long crack.

The coupon test matrix is shown in Table 6.2.

Table 6.2 Test matrix for riveted single lap splice coupons.

\begin{tabular}{ccc}
\hline Rivet Type & $\begin{array}{c}\text { Rivet Forming } \\
\text { Load kN (lbf) }\end{array}$ & $\begin{array}{c}\text { Number of } \\
\text { Coupons }\end{array}$ \\
\hline & $6.7(1500)$ & 4 \\
MS20470AD-4-4 & $8.9(2000)$ & 4 \\
& $11.1(2500)$ & 4 \\
& $13.3(3000)$ & 4 \\
\hline & $6.7(1500)$ & 4 \\
NAS1097AD-4-4 & $8.9(2000)$ & 4 \\
& $11.1(2500)$ & 4 \\
& $13.3(3000)$ & 4 \\
\hline
\end{tabular}

\subsection{Results and Discussion}

The results of the critical plane SWT predictions for the machine countersunk and universal riveted splices are compared to test coupon crack initiation lives in Figure 6.4 and Figure 6.5 respectively. Failure in the machine countersunk splices occurred in the top row of the outer sheet in all cases while failure of the universal splices occurred primarily in the bottom row of the inner sheet. Both sets of life predictions showed good agreement to the coupon test data. 
First examining the machine countersunk splice case, the predictions for the crack initiation lives were conservative when compared to the average lives in all cases. Only the 6.7 $\mathrm{kN}$ rivet squeeze force case predicted a life outside the bounds of the $90 \%$ confidence level in the data. The highest scatter and greatest difference between the predicted life and the average coupon life was in the case of the $13.3 \mathrm{kN}$ rivet squeeze force. The increase in scatter reflects how the crack nucleation process becomes more dependent on fretting damage and on the residual stress field in the sheet at high forming loads. High rivet forming loads produce greater compressive residual stresses in the sheet.

Second, the life prediction for the universal coupons, shown in Figure 6.5, also showed good estimates for the test coupon fatigue lives. The best agreement was observed in the $6.7 \mathrm{kN}$ and $13.3 \mathrm{kN}$ rivet forming cases. Unfortunately agreement of the predicted and tested fatigue lives for the $8.9 \mathrm{kN}$ and $11.1 \mathrm{kN}$ cases was not as good as the other two rivet forming loads. The $8.9 \mathrm{kN}$ case over-estimated the fatigue life by $10 \%$ while the $11.1 \mathrm{kN}$ case under-estimated the coupon fatigue life by $12 \%$. Although the middle two rivet forming life predictions were outside the confidence intervals in the test data, the predictions still followed the trend in the data.

Possible reasons for differences between the predicted and actual fatigue lives include sensitivity in the predictive equation to variation in stress levels from the FE models and possible variation in the tested fatigue lives due to manufacturing considerations. In manufacturing splices for testing, factors such as the height of the countersunk rivet head above the sheet, as shown by Rans [8], can have considerable effect on the fatigue life of the joint. 


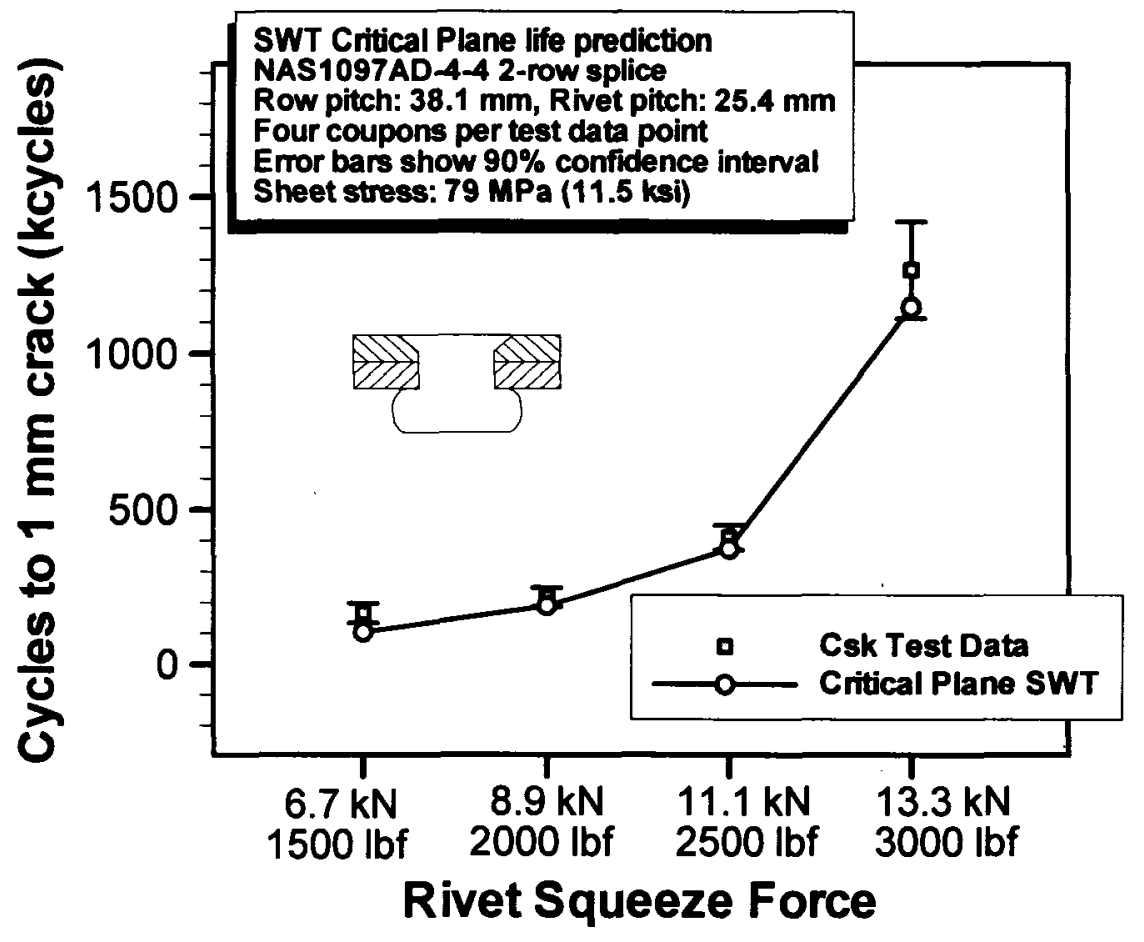

Figure 6.4 Fretting fatigue life prediction for countersunk rivets.

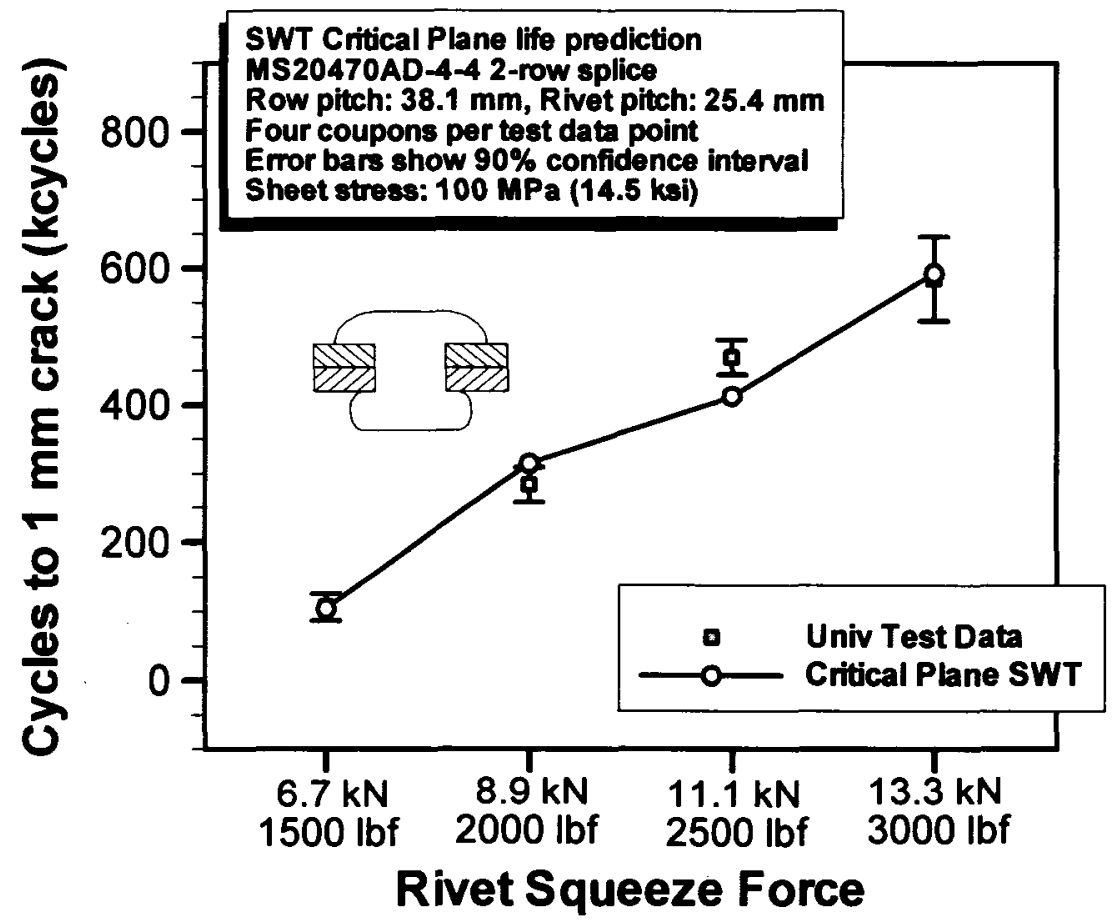

Figure 6.5 Fretting fatigue life prediction for universal rivets. 
Aside from being able to predict the number of cycles to the initiation of a $1 \mathrm{~mm}$ crack, it is important for a predictive method to indicate where cracks will nucleate in a complex structure. Figure 6.6 to Figure 6.13 illustrate the peaks in the critical plane SWT parameter around the rivet holes of the lap splices. The peaks in the SWT parameter are the values used for life prediction and should correlate with the location of crack nucleation at the faying surface edge of contact. Results for the machine countersunk coupons are presented in Figure 6.6 to Figure 6.9 while the results for the universal coupons are presented in Figure 6.10 to Figure 6.13. The figures show a contour plot of the critical plane SWT parameter with a representative failed rivet hole photo. Superimposed on the contour plot are locations of cracks from failed splice test coupons.

In the machine countersunk splice figures, good agreement was observed between the location of the peak critical plane SWT parameter and the location of crack nucleation. In the lower rivet squeeze force cases, crack nucleation occurs close to the net section whereas the high rivet squeeze force cases show crack nucleation and growth tangent to the hole. The change in direction of the cracks near the hole in Figure 6.8 is an indication that the crack nucleated away from the hole edge, and then grew both toward and away from the hole (distinct in universal results as well). This type of behaviour has also been observed in marker-band crack reconstructions performed on the same splice geometry by Rans [8]. 


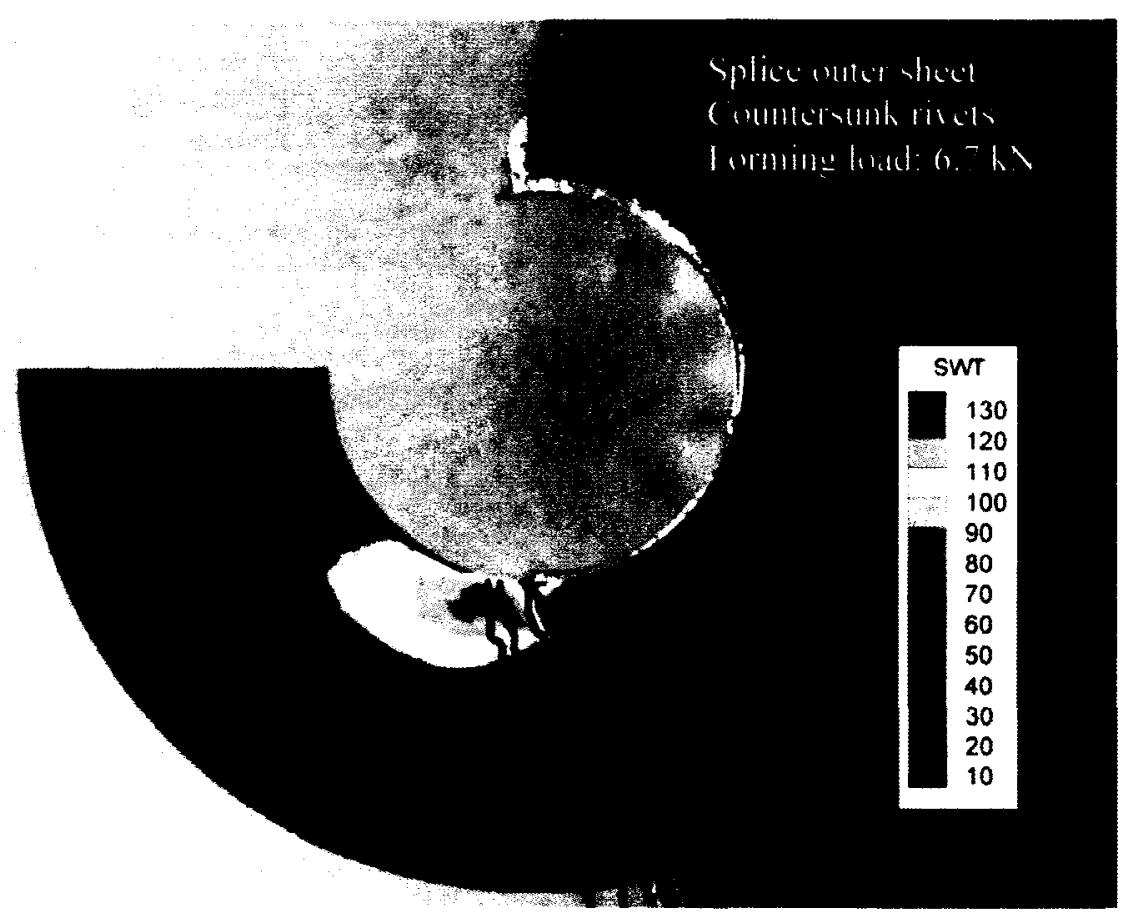

Figure 6.6 Contour plot of SWT parameter with cracks from typical failed countersunk coupons superimposed. $6.7 \mathrm{kN}$ case.

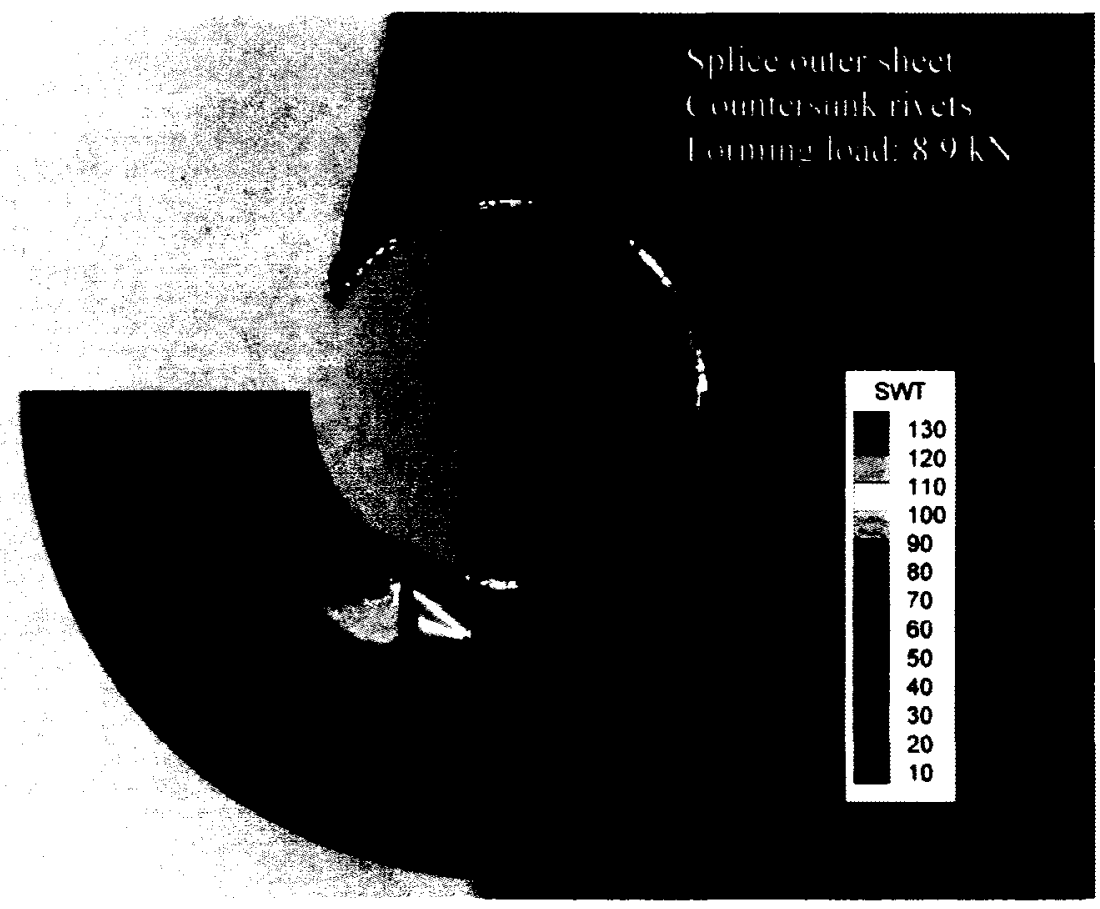

Figure 6.7 Contour plot of SWT parameter with cracks from typical failed countersunk coupons superimposed. $8.9 \mathrm{kN}$ case. 


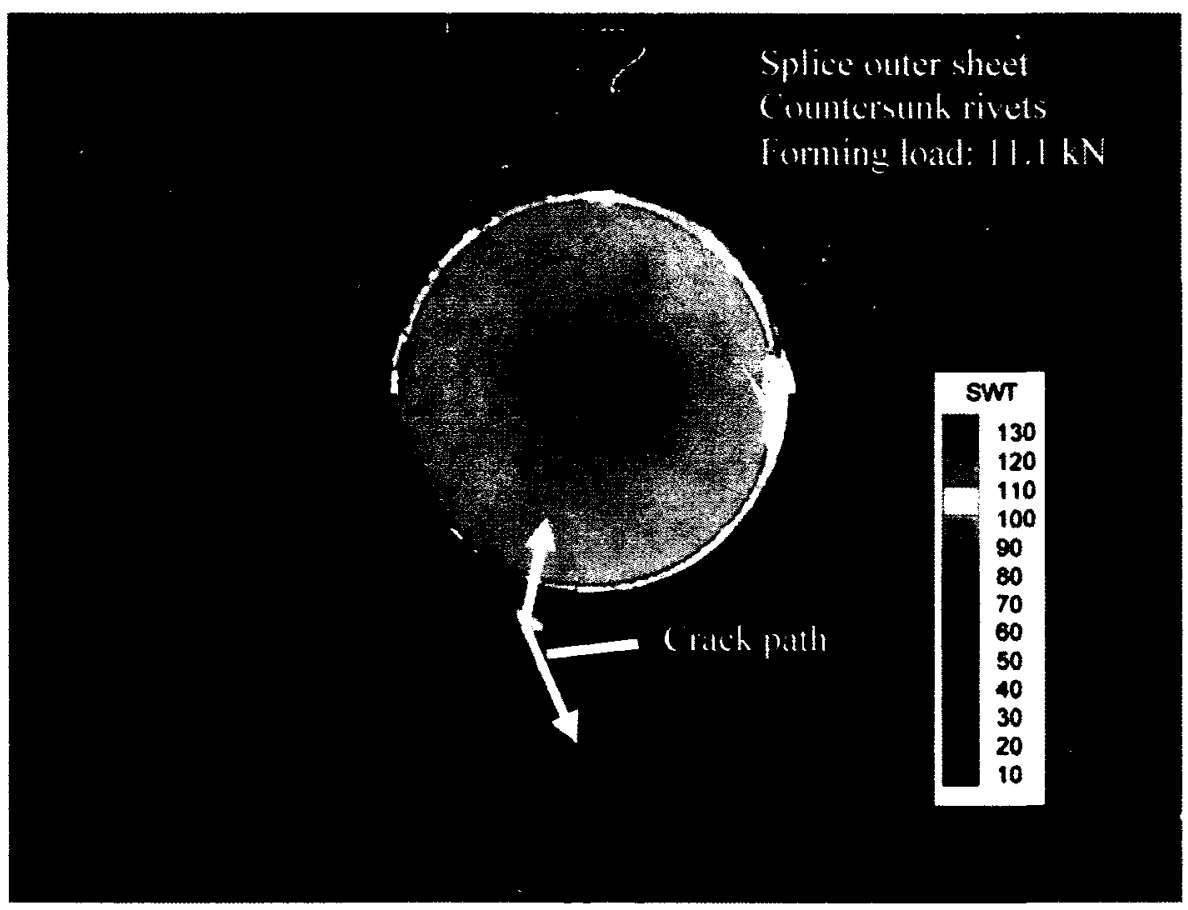

Figure 6.8 Contour plot of SWT parameter with cracks from typical failed countersunk coupons superimposed. $11.1 \mathrm{kN}$ case.

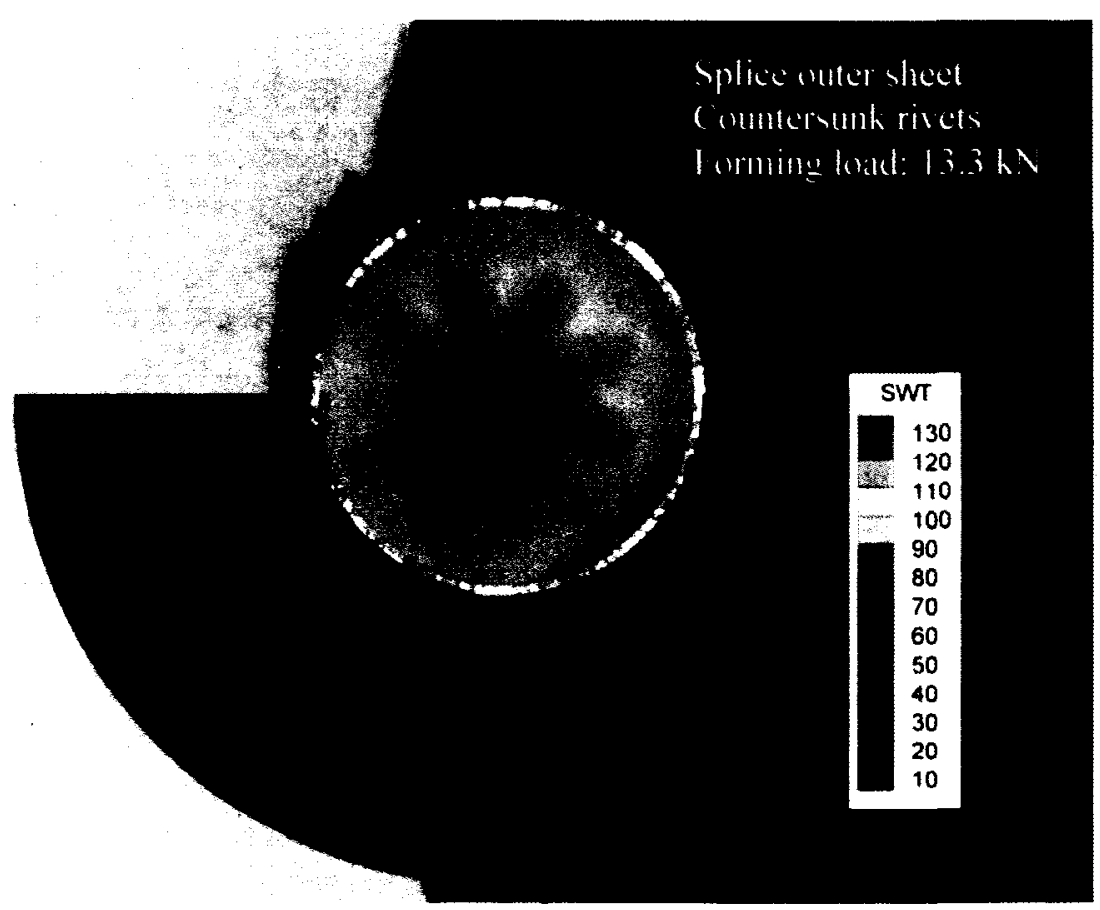

Figure 6.9 Contour plot of SWT parameter with cracks from typical failed countersunk coupons superimposed. $13.3 \mathrm{kN}$ case. 


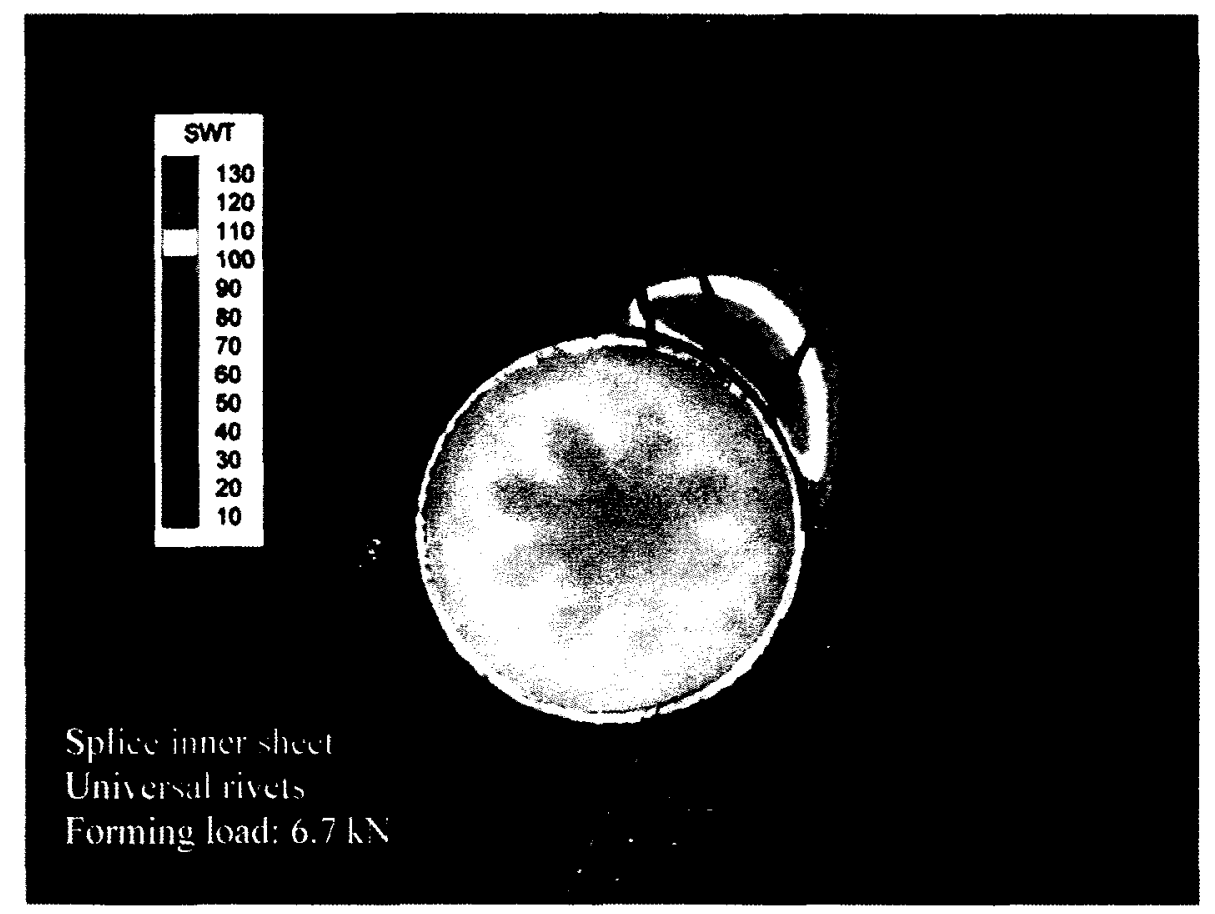

Figure 6.10 Contour plot of SWT parameter with cracks from typical failed universal coupons superimposed. $6.7 \mathrm{kN}$ case.

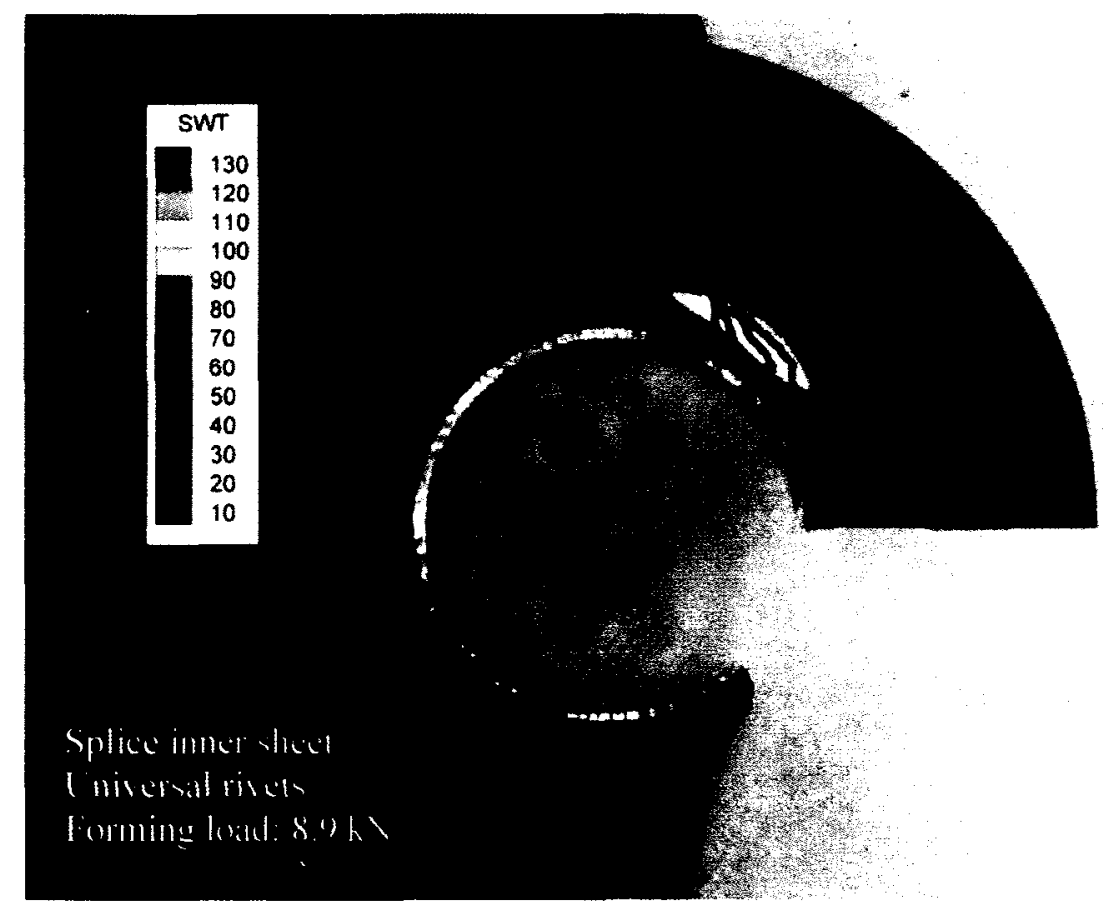

Figure 6.11 Contour plot of SWT parameter with cracks from typical failed universal coupons superimposed. $8.9 \mathrm{kN}$ case. 


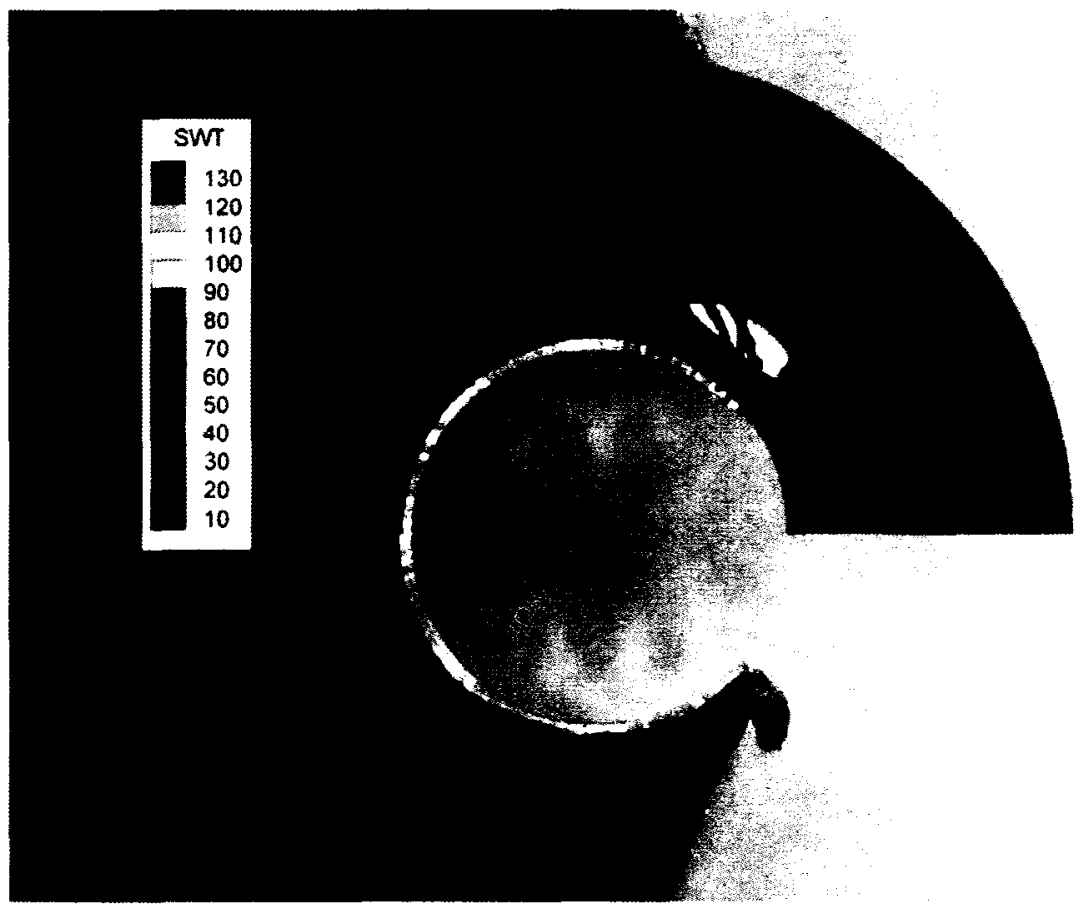

Figure 6.12 Contour plot of SWT parameter with cracks from typical failed universal coupons superimposed. $11.1 \mathrm{kN}$ case.

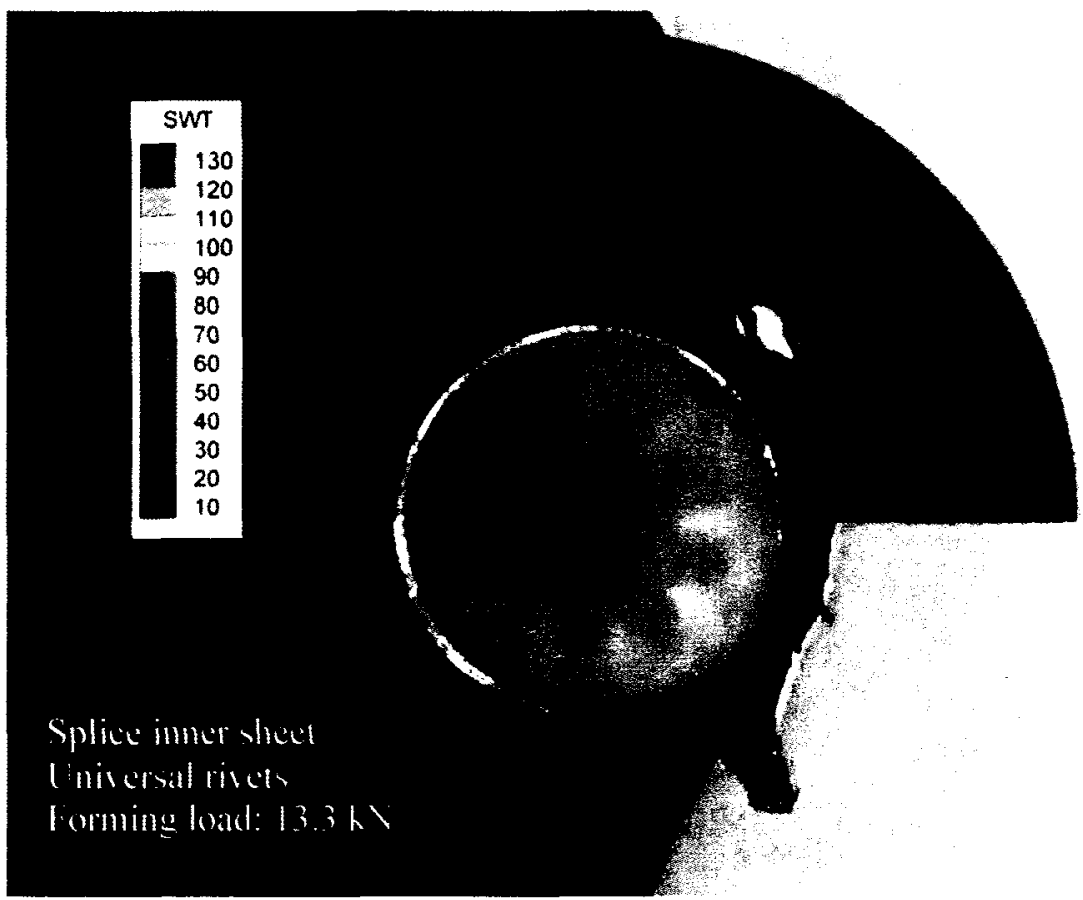

Figure 6.13 Contour plot of SWT parameter with cracks from typical failed universal coupons superimposed. $13.3 \mathrm{kN}$ case. 
For the universal riveted splices, crack paths agreed well with peaks in the critical plane SWT parameter. As expected, the universal SWT contours show peaks further away from the hole edge than the countersunk splice cases. Crack formation further away from the hole edge is due to nucleation favouring the inner sheet in bare universal splices. The formed rivet head provides a constraint on secondary bending that is larger than that provided by the machine countersunk manufactured rivet head. In the universal splices, all but the $6.7 \mathrm{kN}$ rivet squeeze force case show distinct signs of nucleation away from the hole edge and crack propagation both toward and away from the hole. Evidence of this is the sharp turn in the crack path visible in Figure 6.11 and Figure 6.12. Figure 6.13 shows that the compressive residual stresses in the sheet were large enough to prevent the crack from reaching the hole edge at all.

The results showed that, in general, the critical-plane SWT parameter proved to be a versatile tool for estimating the crack initiation life and nucleation location in complex geometries. The versatility of this method comes from the use of finite element methods to generate the stress and strain data.

\subsection{Conclusions}

The critical-plane SWT life prediction was found to agree well with crack initiation lives for splices constructed out of $1 \mathrm{~mm}$ sheet and riveted with both machine countersunk and universal rivets. The location of crack nucleation also agreed with peaks in the critical-plane SWT contour plot at the edge of contact on the faying surface.

The bare 2024-T3 aluminum splices showed failure in the outer sheet at the top rivet row for the machine countersunk coupons and failure in the inner sheet at the bottom rivet row for the universal splice coupons. In each case, the failed splice sheet corresponded to the rivet row with the highest level of secondary bending. 
The critical-plane SWT parameter, in combination with stress and strain data from a validated finite element model, is a good tool to predict fatigue lives for complex structures and components with residual stress fields. 


\section{Effect of Surface Treatment on Fretting Fatigue Life}

\subsection{Introduction}

The previous chapter showed that the critical plane SWT parameter was able to provide a good estimate for the cycles to crack initiation and the location of crack nucleation for bare 2024-T3 sheet. This chapter investigates the effect of surface treatment on the fatigue life of a splice and on the usefulness of the critical plane SWT parameter.

Bare 2024-T3 aluminum sheet is never used in aircraft construction due to its relatively low corrosion resistance. To compensate for the low corrosion resistance, surface treatments are applied. The two most common types of surface treatment are aluminum cladding (alclad) and anodizing. With aluminum cladding, a thin layer of pure aluminum is mechanically bonded through a rolling process to the bare 2024 substrate. The pure aluminum surface of the sheet then protects against surface corrosion. The anodizing process involves the formation of a thin, hard layer of aluminum oxide on the surface of the sheet by passing a current through an electrolyte bath in which the sheet is submerged. The oxide layer then provides greater resistance to corrosion than the bare 2024-T3. Chromic acid anodizing (CAA) remains one of the most common methods of anodizing aerospace components. 
The alclad and the anodizing surface treatments provide different surface characteristics in a fretting fatigue scenario but there is no consensus from manufacturers as to which, if any, type of treatment produces higher fatigue lives. Little effort has been made, to date, to study the effect of surface treatment on fretting fatigue life in lap joints. The lack of interest is because of the belief that crack nucleation most commonly begins at the rivet/hole interface where the bare aluminum is exposed. Tests of thin sheet splices $[8,33]$, however, have shown that crack nucleation occurs on the faying surface and it is, therefore, reasonable to assume that the type of surface treatment will play a role in the formation of fretting damage and crack nucleation. To investigate possible differences between the two most common surface treatments (aluminum cladding and anodizing), two types of fretting fatigue tests were performed.

The first test series, detailed in Section 7.2, used splice coupons intended to replicate the longitudinal fuselage lap joint of a narrow-body aircraft. Testing of complex geometries subject to fretting fatigue is not commonly performed because the geometry and loading conditions are often difficult to duplicate in a laboratory. Fortunately, single lap splice coupon tests are relatively easy to perform in a lab. The benefit of testing the actual geometry is that any results are directly applicable to the problem being studied. The downside is in the potential difficulty in isolating parameters associated with fretting during the fatigue tests.

A second, simultaneous test series was performed, detailed in Section 7.3, in an attempt to reduce the problem of isolating fretting related parameters in the splice tests. The second test series consisted of a simplified contact problem involving rounded pads in contact with a coupon subject to fatigue. Simplified contact geometries are widely used in the study of fretting fatigue as they provide valuable information on the mechanics of the contact being studied. There are a few, select types of test set-ups that the fretting research community uses and they are the closest the 
community has come to standardized tests. The benefit of standardized testing is the ability to compare results to the work of other researchers.

\subsection{Splice Fretting Experiment}

\subsubsection{Experimental Set-up}

The splice fretting experiments were performed on single lap splice coupons with geometry and loading conditions identical to those used in Chapter 6 for the bare splice coupons. Maintaining the same geometry and loading conditions meant that the bare splice series of tests did not have to be repeated. Both machine countersunk (NAS1097AD-4-4 rivets) and universal (MS20470AD-44 rivets) splices were tested.

To make the anodized splices, bare sheet material was anodized using chromic acid anodizing (CAA) at a NADCAP (National Aerospace \& Defense Contractors Accreditation Program) accredited facility. CAA was chosen because it is a common method of anodizing components, including fuselage skin, in the aerospace industry. The alclad sheet material is widely available and was purchased. All of the sheet material had a nominal thickness of $1 \mathrm{~mm}$.

The coupons were tested in hydraulic test frames under sinusoidal loading at a rate of 11 Hz. The machine countersunk coupons were tested at a bulk stress of $79 \mathrm{MPa}(11.5 \mathrm{ksi})$ and the universal coupons were tested at a bulk stress of $100 \mathrm{MPa}(14.5 \mathrm{ksi})$; the same stress levels as those used in the splice tests of Chapter 6 and the FE simulations of Chapter 5.

\subsubsection{Fatigue Life Results}

The results of the countersunk and the universal splice fatigue tests for different surface treatments are presented in Figure 7.1 and Figure 7.2 respectively. 


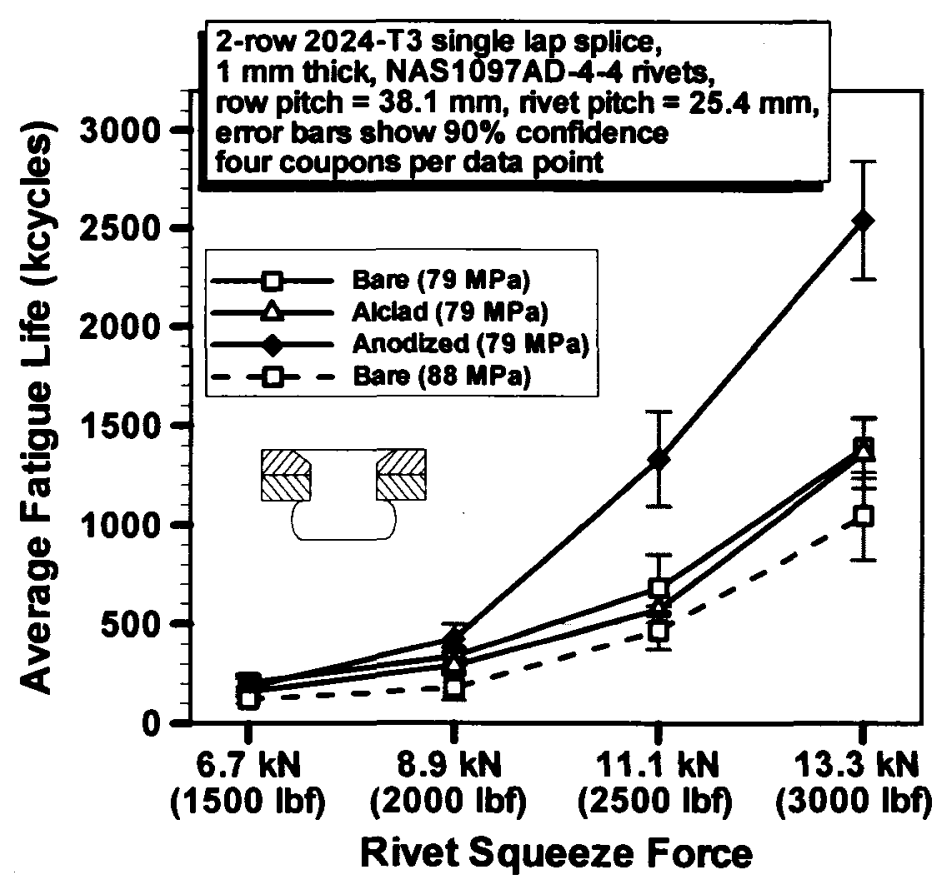

Figure 7.1 Fatigue life of countersunk riveted coupons with different surface treatments.

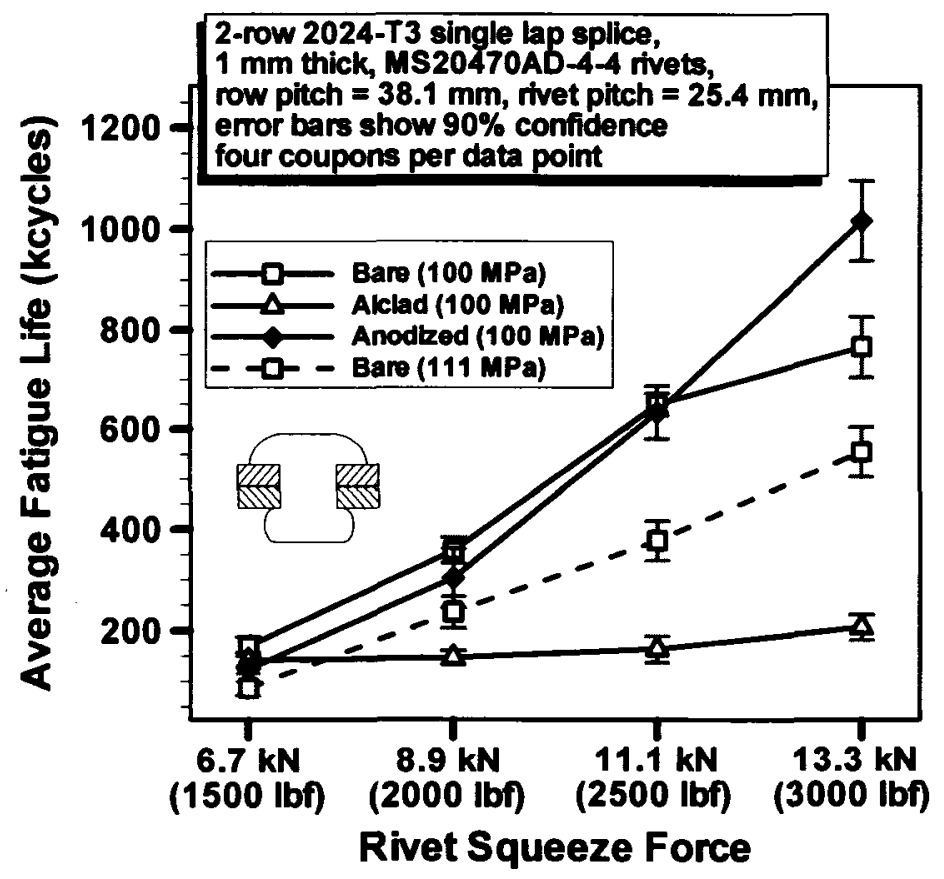

Figure 7.2 Fatigue life of universal riveted coupons with different surface treatments. 
Interesting trends were observed in the fatigue lives of the bare, alclad, and anodized surface treatments for the machine countersunk and universal coupons. For the machine countersunk coupons, very little difference was observed in the fatigue life for the different surface treatments in the $6.7 \mathrm{kN}$ and $8.9 \mathrm{kN}$ rivet forming cases. A significant difference was noted, however, in the fatigue results for the anodized coupons in the $11.1 \mathrm{kN}$ and $13.3 \mathrm{kN}$ rivet forming cases. The anodized coupons produced fatigue lives significantly higher than the bare and alclad coupons, which had effectively the same fatigue life for all rivet forming loads. At the $11.1 \mathrm{kN}$ and $13.3 \mathrm{kN}$ rivet forming loads, the anodized coupons averaged lives $800 \mathrm{kcycles}$ and 1150 kcycles higher than the lives for the bare or alclad coupons respectively. The mode of failure in each case was ultimate failure due to crack nucleation and propagation in the top row of the countersunk sheet from regions of faying surface fretting damage. The outer sheet top row is the location where maximum secondary bending stresses will occur due to the limited bending constraint provided by the countersunk rivet head.

For the universal coupons, there was little difference in fatigue life between the anodized and bare coupons for the lowest three rivet forming loads. There was a difference, however, between the fatigue lives in the bare and anodized coupons at the $13.3 \mathrm{kN}$ rivet squeeze force with the anodized surface treatment providing an average fatigue life $250 \mathrm{kcycles}$ higher than the bare coupons. With the exception of the lowest rivet squeeze force, the alclad universal splice coupons performed remarkably worse than the bare and anodized splices. It was recognized, however, that the presence of an alclad layer on a sheet would reduce the load-carrying crosssectional area of the splice and would affect the fatigue results.

The thickness of the alclad layer on each side of the alclad sheet is approximately 0.05 $\mathrm{mm}(0.002 \mathrm{in})$ and since this pure aluminum layer is less stiff than the substrate, the alclad sheet experiences higher stresses than the other coupon test series. To assess how this may have 
affected the fatigue results, an additional set of tests were performed on bare coupons with the same sheet stress as that experienced by the alclad coupons. The sheet stress for the bare countersunk coupons was $88 \mathrm{MPa}(12.8 \mathrm{ksi})$ while the sheet stress for the universal coupons was $111 \mathrm{MPa}(16.1 \mathrm{ksi})$. The results are included in Figure 7.1 and Figure 7.2 as a dashed line.

As the difference between the bare and alclad fatigue lives for the machine countersunk coupons was small, the higher bulk stress did show a small decrease in life at each rivet forming load. In the case of the bare universal splices tested at $111 \mathrm{MPa}$, the increased stress produced a significant drop in fatigue life but not equal to the fatigue lives of the alclad coupons. This indicated that the surface treatment and secondary bending effects must play a role in the low fatigue lives of the alclad universal splices.

The failure mode for the universal coupons was a mix of inner and outer sheet failures indicating that there is a close competition between secondary bending stresses, residual sheet stresses and surface treatment in the sheets. The predominant failure location in the bare and anodized splices was the inner sheet bottom rivet row while the predominant failure location in the alclad splices was the outer sheet top row. Full details of the splice fatigue data can be found in Appendix D.

\subsubsection{Fretting Damage Results}

The fretting damage on the faying sheet surface for different surface treatments is presented in Figure 7.3 to Figure 7.8 . The figures show damage for only the $11.1 \mathrm{kN}$ rivet forming case as representative coupons. Photo comparisons of the entire range of rivet forming loads can be

found in Appendix E. As shown in the photos, the fretting damage appears most severe in the alclad coupons where the soft cladding was subject to wear. The bare sheet surface demonstrated a moderate amount of wear whereas the hard surface of the anodized sheets showed the least 
amount of wear. The same type of wear behaviour was observed for both the countersunk and universal riveted sheets.

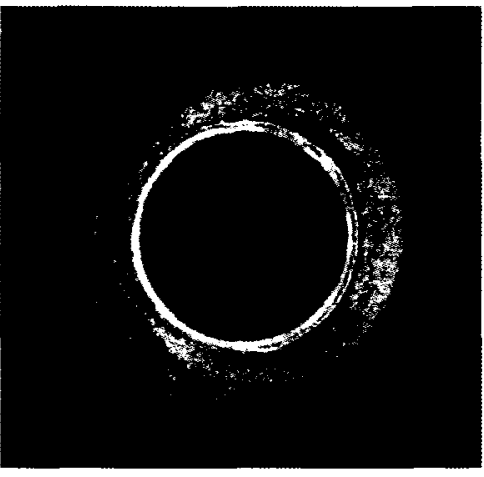

Figure 7.3 Countersunk rivet hole fretting damage. $11.1 \mathrm{kN}$ rivet forming load.

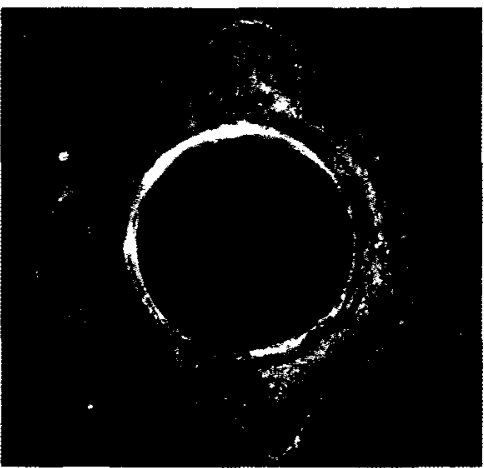

Figure 7.6 Universal rivet hole fretting damage. $11.1 \mathrm{kN}$ rivet forming load.

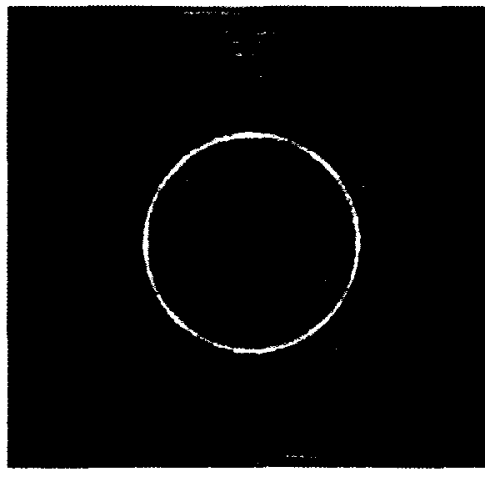

Figure 7.4 Countersunk rivet hole fretting damage. $11.1 \mathrm{kN}$ rivet forming load.

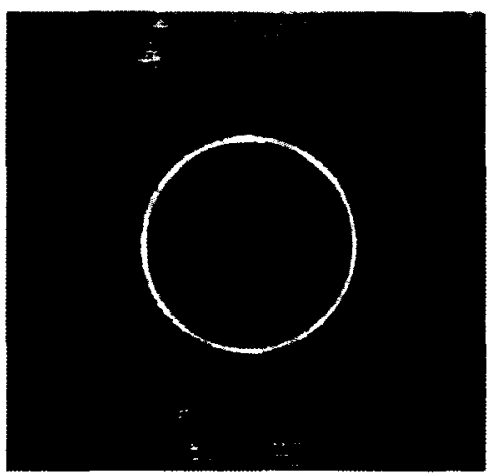

Figure 7.7 Universal rivet hole fretting damage. $11.1 \mathrm{kN}$ rivet forming load.

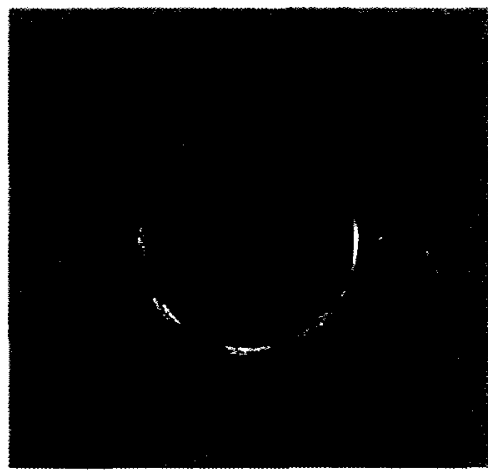

Figure 7.5 Countersunk rivet hole fretting damage. $11.1 \mathrm{kN}$ rivet forming load.

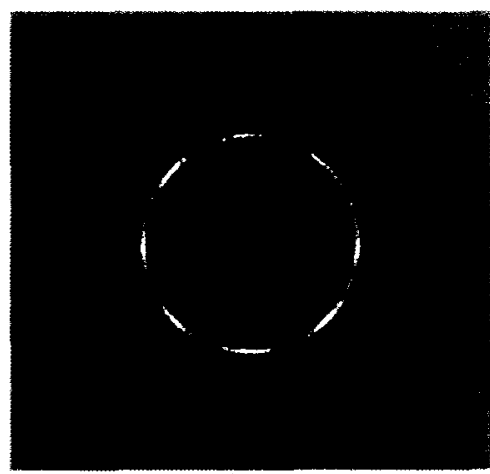

Figure 7.8 Universal rivet hole fretting damage. $11.1 \mathrm{kN}$ rivet forming load.

\subsubsection{Discussion}

The countersunk and universal splice results showed that the anodized coupons performed better in fatigue than the bare and alclad coupons but only at the higher rivet forming loads. It is at the higher rivet forming loads that the faying surface clamping area is larger and the location of maximum fretting damage is moved from the hole edge to the edge of contact. Away from the hole edge, there is less of an impact on the fatigue life due to secondary bending and residual stresses and more of an impact due to surface condition and fretting damage. This can be seen by 
closely examining the contributions of secondary bending and residual stresses to the stress field around the rivet hole.

\subsubsection{Secondary Bending}

Focusing on the secondary bending component of the stress field, an interaction is observed between the fretting contact stresses and the secondary bending stresses. Contour plots for the secondary bending factor (described in Chapter 2) around a rivet hole in a single lap splice were found by Rans [8] and are used here for comparison purposes. The secondary bending factor (SBF) contour plots identify the location of maximum secondary bending factor; effectively the location where secondary bending stresses are highest. The use of the SBF contour plots in this context is illustrated in Figure 7.9 and Figure 7.10.

The figures show example plots for a splice hole with universal rivets formed to $6.7 \mathrm{kN}$. The highest contours are identified in the SBF contour plot and highlighted. The highlighted region is then superimposed onto the critical plane SWT contour plot found in Chapter 6 . The result is a comparison of the locations of peak secondary bending stress and peak critical plane SWT parameter. Representative cracks obtained from experiment are also included in the figures to further highlight the location of crack nucleation. A comparison of this type has been made for each rivet style and rivet forming load. 


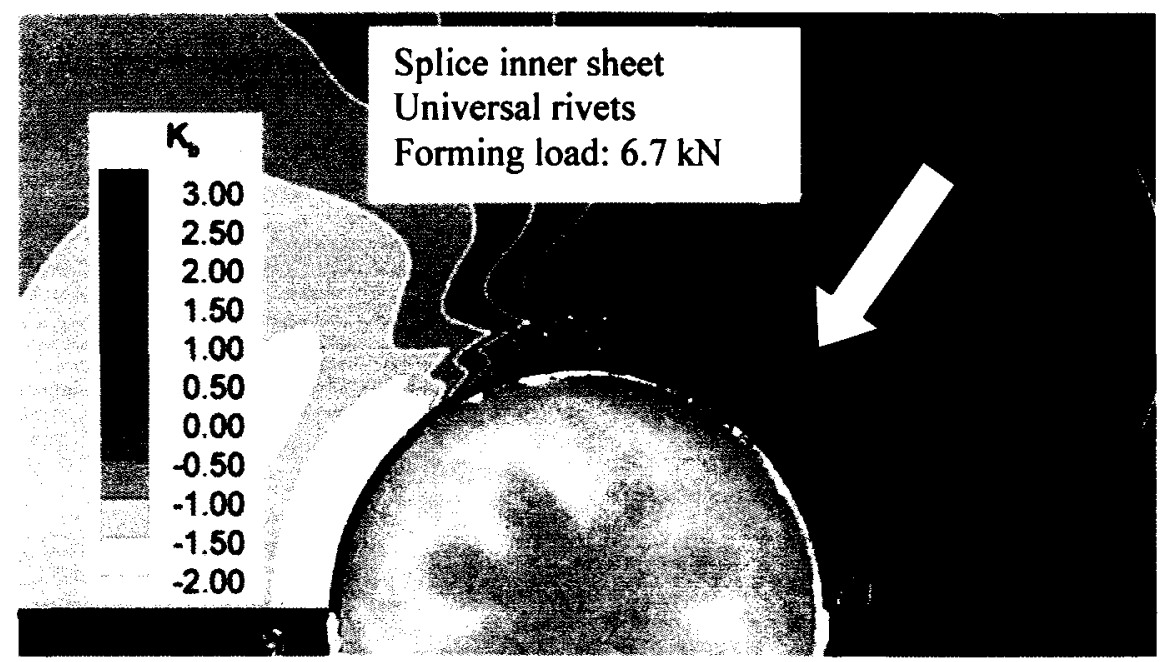

Figure 7.9 Identifying peak secondary bending factor contour [8].

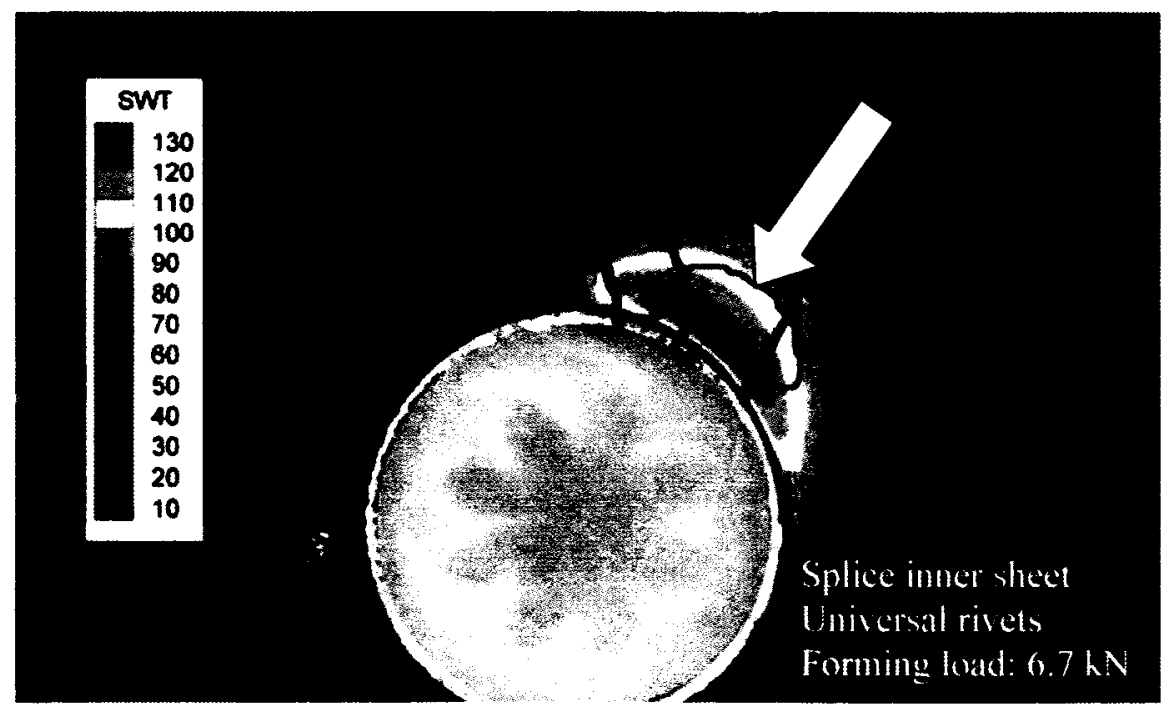

Figure 7.10 Superimposing peak SBF contour and peak critical plane SWT contour.

Figure 7.11 to Figure 7.14 show the comparison of peak secondary bending factor contours and critical plane SWT parameter contours for the machine countersunk splices. 


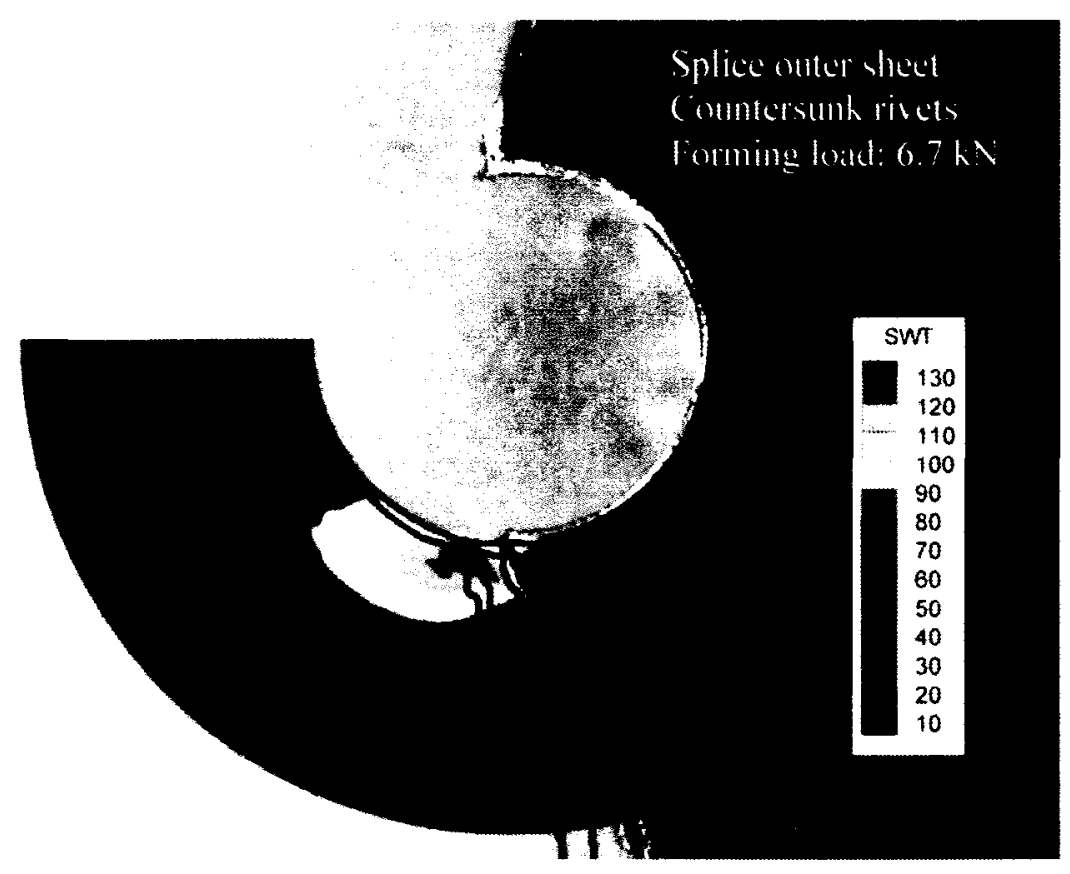

Figure 7.11 Peak SBF contour superimposed on critical plane SWT contour.

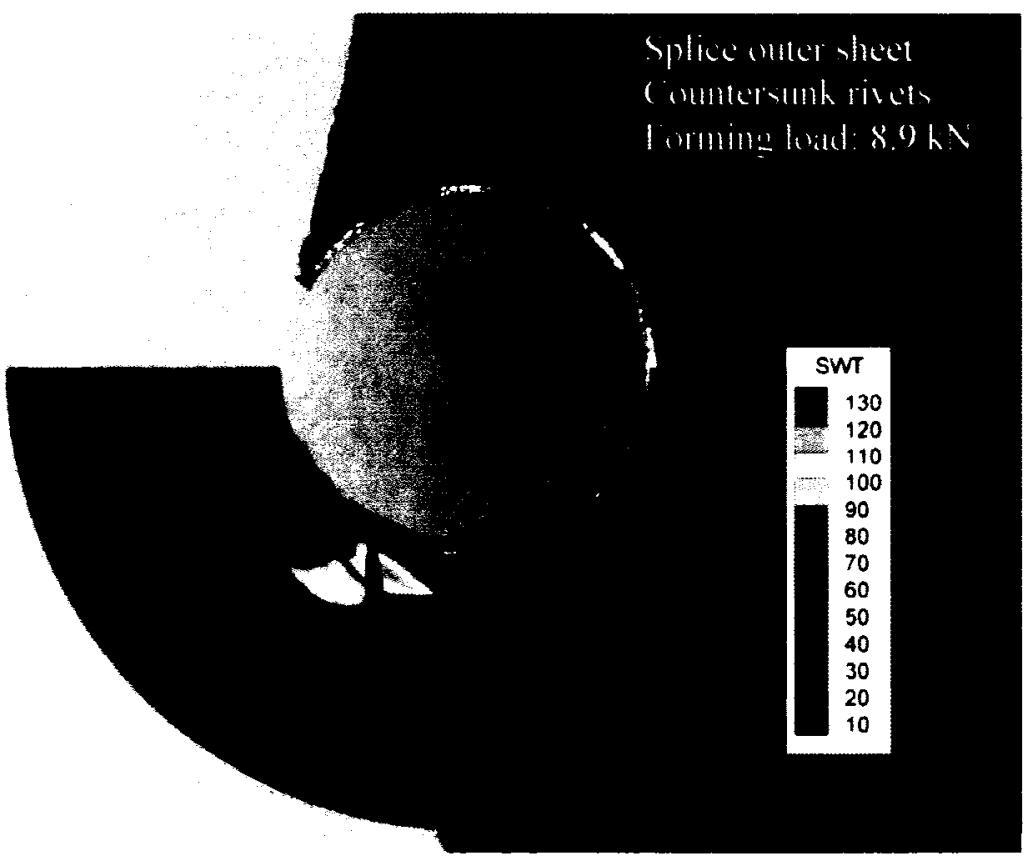

Figure 7.12 Peak SBF contour superimposed on critical plane SWT contour. 


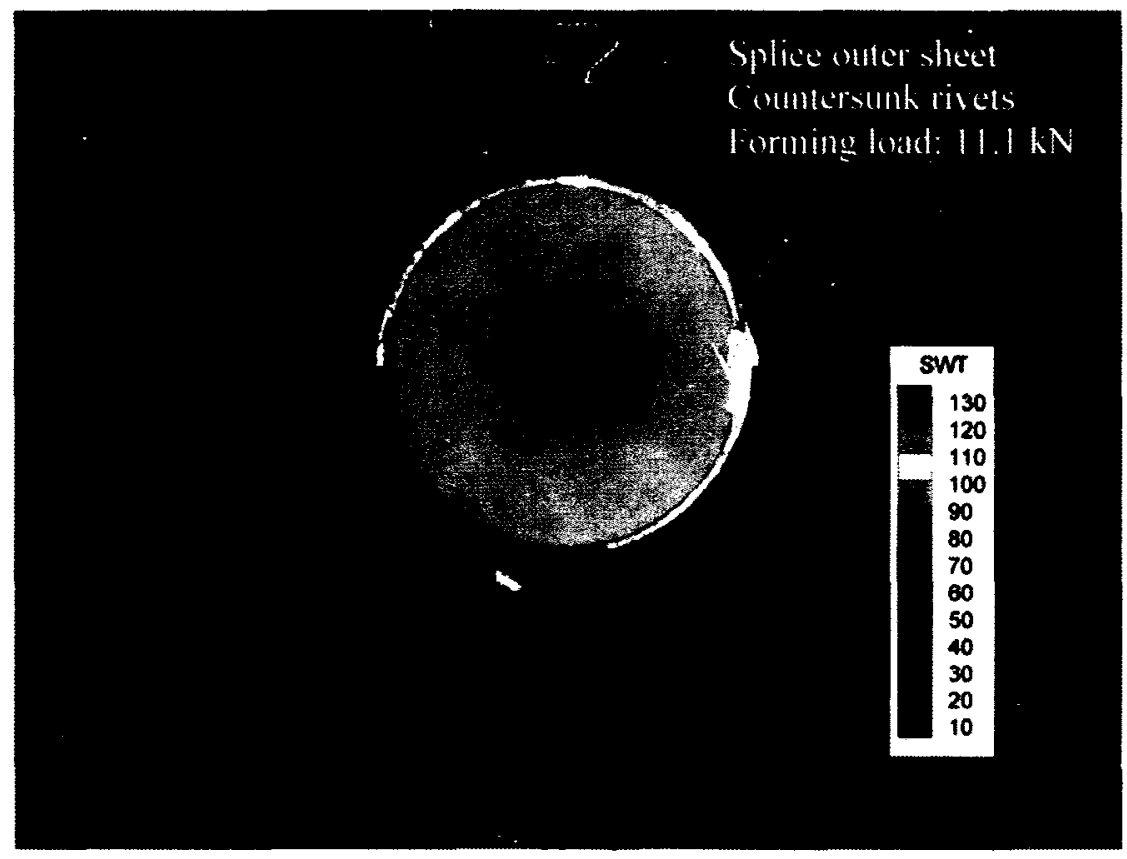

Figure 7.13 Peak SBF contour superimposed on critical plane SWT contour.

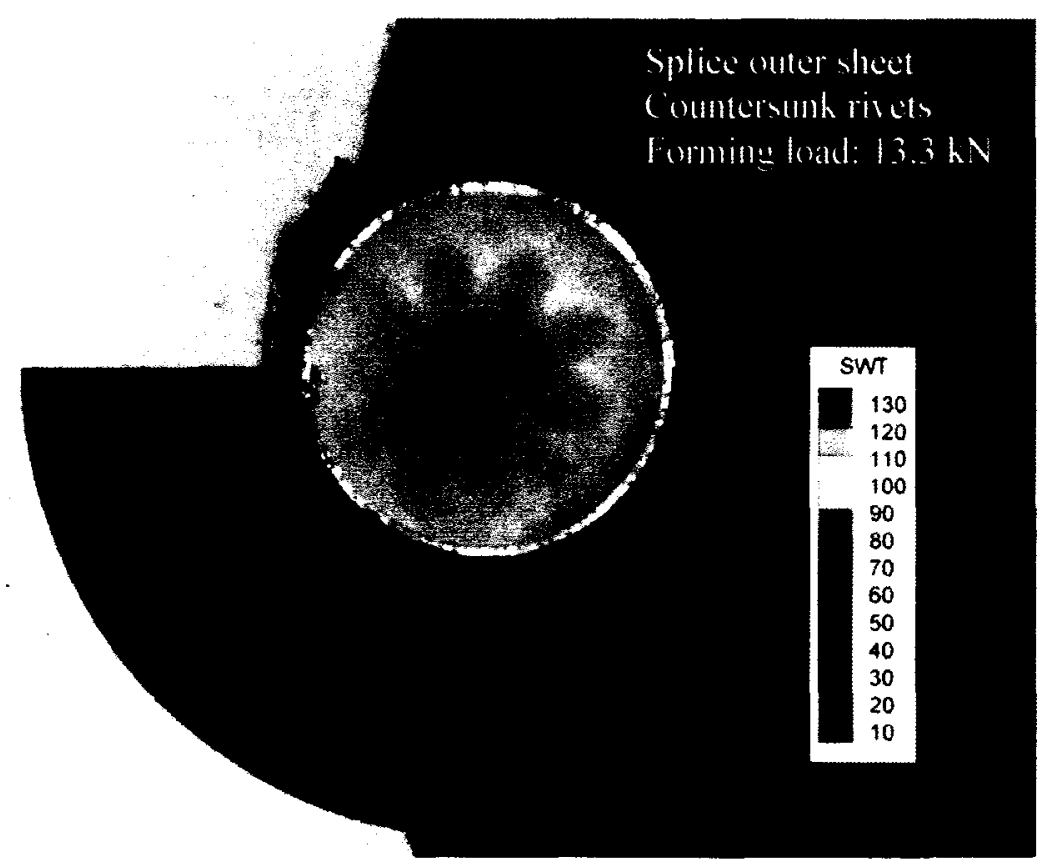

Figure 7.14 Peak SBF contour superimposed on critical plane SWT contour.

For the machine countersunk splices, the peak secondary bending factor contour coincides with the locations of crack nucleation at the lower rivet forming loads $(6.7 \mathrm{kN}$ and 8.9 $\mathrm{kN})$. Corresponding to the increase in fatigue life, the higher rivet forming loads $(11.1 \mathrm{kN}$ and 
$13.3 \mathrm{kN}$ ) show that the peak secondary bending factor contour does not coincide with the predicted location of crack nucleation. In Figure 7.13 the peak SBF contour is shown to be just inside the location of the peak SWT parameter. In a similar manner, the peak SBF contour in Figure 7.14 is shown to be just inside the peak SWT contour and greatly removed from a secondary SWT contour peak at the top of the hole where cracks nucleate (left side in photo).

Figure 7.15 to Figure 7.18 show the comparison of peak secondary bending factor contours and critical plane SWT parameter contours for the universal riveted splices.

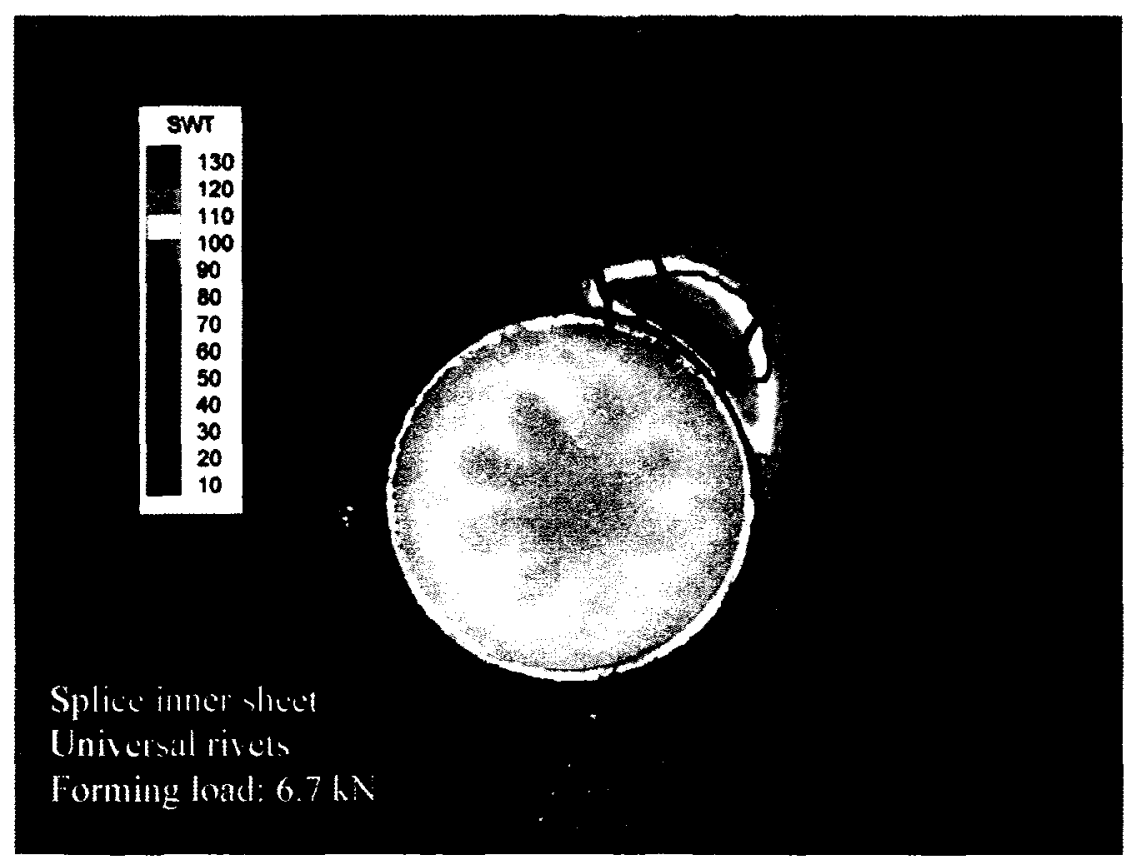

Figure 7.15 Peak SBF contour superimposed on critical plane SWT contour. 


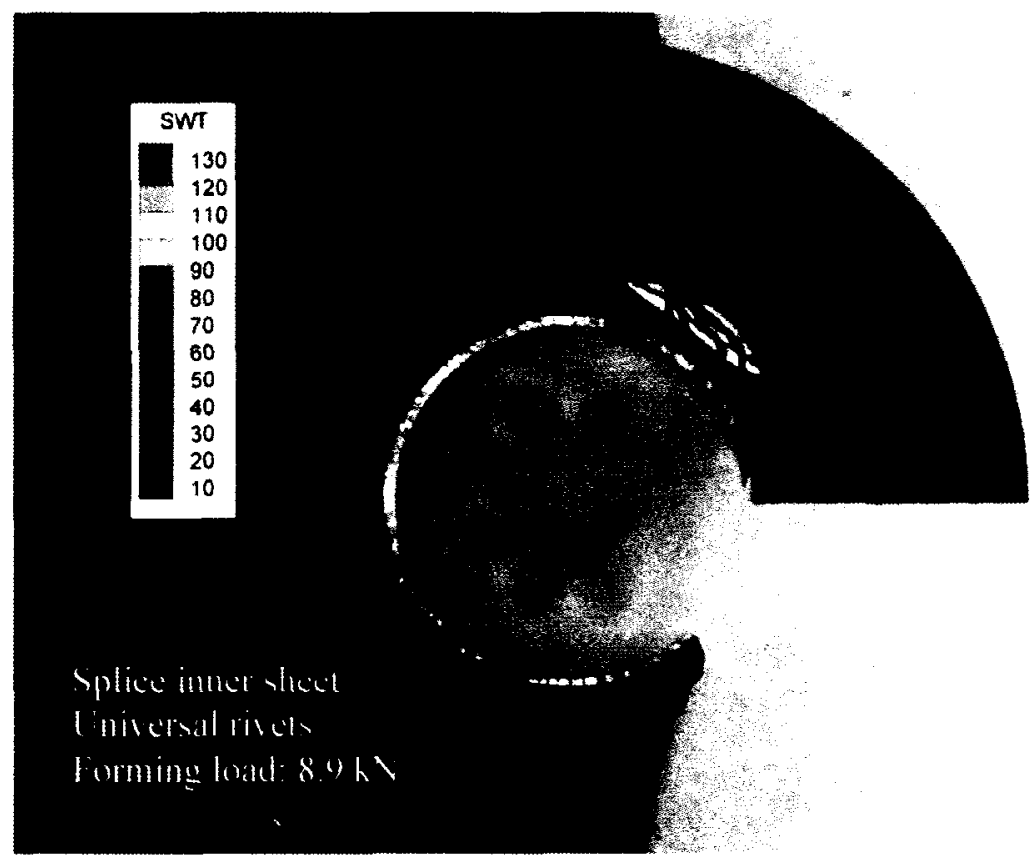

Figure 7.16 Peak SBF contour superimposed on critical plane SWT contour.

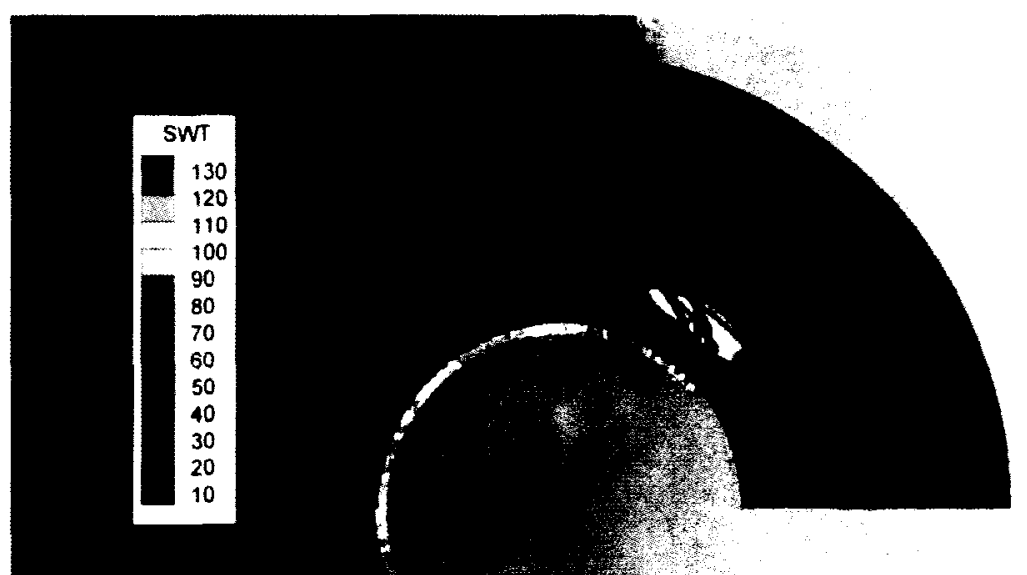

Splice inner stee

Inicusal ricts

forming load: 11.1 h

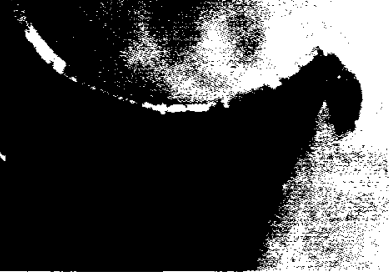

Figure 7.17 Peak SBF contour superimposed on critical plane SWT contour. 


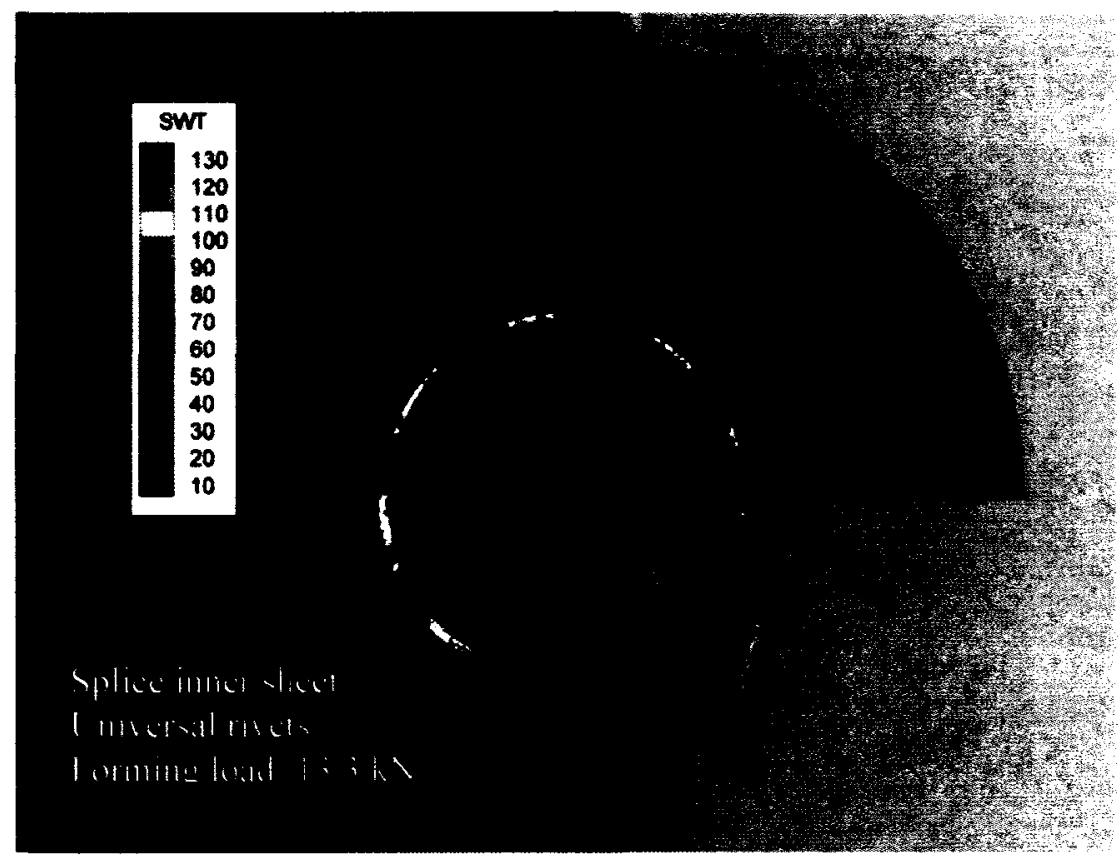

Figure 7.18 Peak SBF contour superimposed on critical plane SWT contour.

A similar trend as that found for the machine countersunk contour plot comparisons is found with the universal plot comparisons. As the rivet forming load increases, the predicted location of crack nucleation moves further away from the peak secondary bending factor. Low fatigue lives are, therefore, partially a result of the coincidence of areas of micro-cracks due to fretting damage and high stress fields due to secondary bending. High fatigue lives are partially a result of the high stress fields due to secondary bending being removed away from the locations of micro-cracks caused by fretting.

In the universal splices, the location of the peak secondary bending factor on the inner sheet moves away from the hole edge with increasing rivet forming load because the size of the formed rivet head is increasing and providing more bending constraint. In the countersunk splices, there is no movement of the location of the peak secondary bending factor because the countersunk head provides the same amount of bending constraint in the outer sheet regardless of the rivet forming load. 


\subsubsection{Residual Stresses}

The residual stresses around a rivet hole, as determined from the finite element simulations in Chapter 3, are limited in magnitude as the distance from the hole edge increases. The benefit of the faying surface compressive residual sheet stresses is dramatically reduced at approximately $0.65 \mathrm{~mm}$ beyond the hole edge. This is where the edge of contact on the faying surface is located for the higher rivet forming loads and where fretting damage will occur. The reduction in beneficial compressive residual stresses at the location of maximum fretting damage is highlighted for the machine countersunk and universal splices in Figure 7.19 and Figure 7.20 respectively. Only the hoop stress distributions for the different rivet forming loads are presented because the hoop stresses are known to have the greatest impact on crack retardation. Cracks forming away from the hole edge are more likely to propagate into the substrate and are more likely to be dependent on fretting damage because of the reduction in beneficial compressive residual stresses.

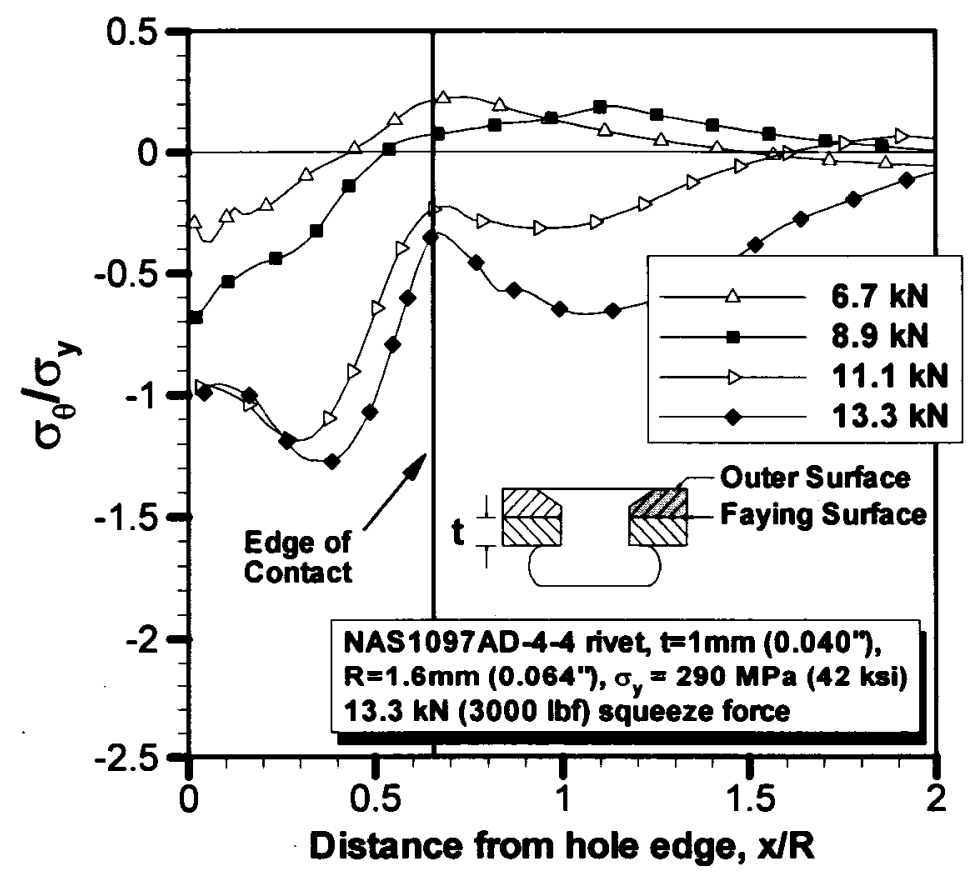

Figure 7.19 Residual hoop stress distribution on the faying surface of a countersunk sheet. 


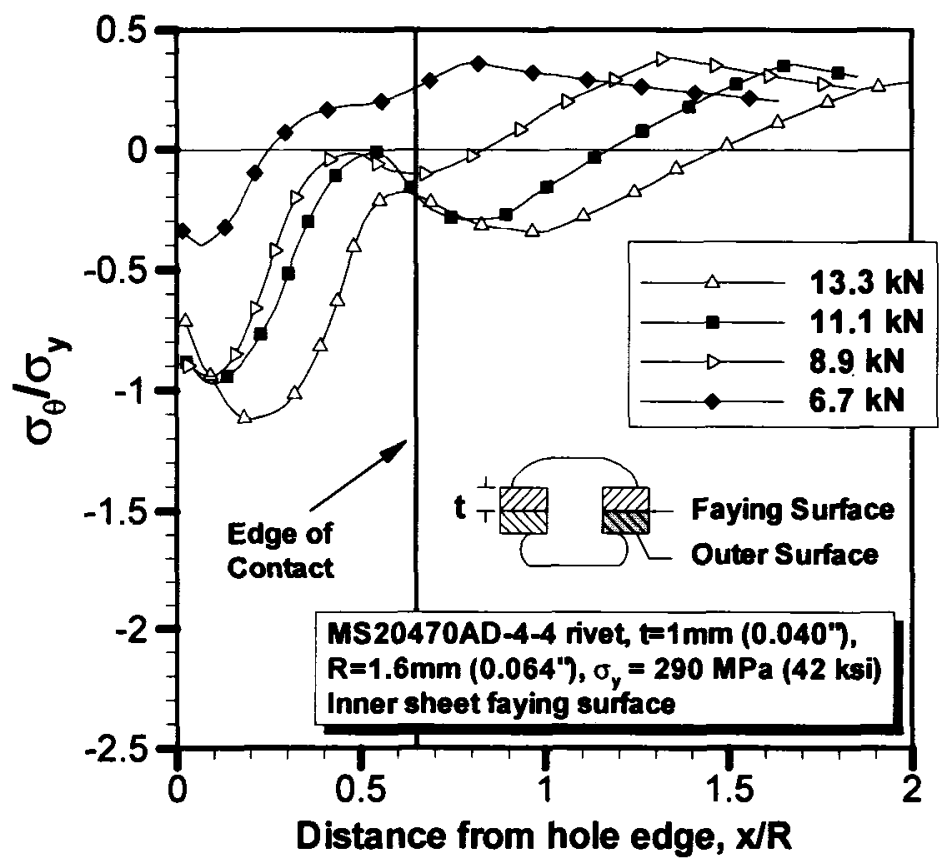

Figure 7.20 Residual hoop stress distribution on the faying surface of a universal sheet.

This chapter has shown that at high rivet forming loads, the type of treatment applied to the faying surface of a splice affects the fatigue performance. Greater fretting damage, as a result of the surface condition, produces significantly lower fatigue lives.

\subsection{Simplified Geometry Fretting Experiment}

\subsubsection{Introduction}

To confirm results observed in the splice coupon fatigue tests a set of fretting fatigue tests was performed simultaneously. These tests used a simplified geometry with controlled fretting conditions. In this way, a more general investigation can be made on the effect that common splice surface treatments have on fretting fatigue life. The first step in this task was to decide on a test configuration as there is currently no standardized test method for fretting fatigue tests in North America and Europe. 
The two most common simplified contact fretting tests are bridge-type tests and Mindlintype tests. Both types of tests involve pads in contact with a test coupon. With bridge-types tests (Figure 7.21), two distinct contacts are used and relative motion is achieved between the bridge and the specimen through differences in compliance when a cyclic load is applied. The bridge pads are placed in contact with a coupon undergoing cyclic axial loading and the strain developed in the test coupon causes a difference in displacement between the contact points of the pads. Tailoring the compliance of the bridge pads provides the desired slip amplitudes at the contact. The normal load is often applied to the test specimen by attaching the pads to a proving ring. A proving ring is a ring of material whose stiffness is used to apply a load through elongation of the ring. A benefit of this type of fretting configuration is that the pads are fixed only to the test coupon and, therefore, it is possible to use this configuration on a rotating-bending fatigue apparatus. Achieving an equal contact condition at all of the interfaces is often difficult and for that reason this type of test is losing popularity in the research community. It is now more common to see Mindlin-type tests.

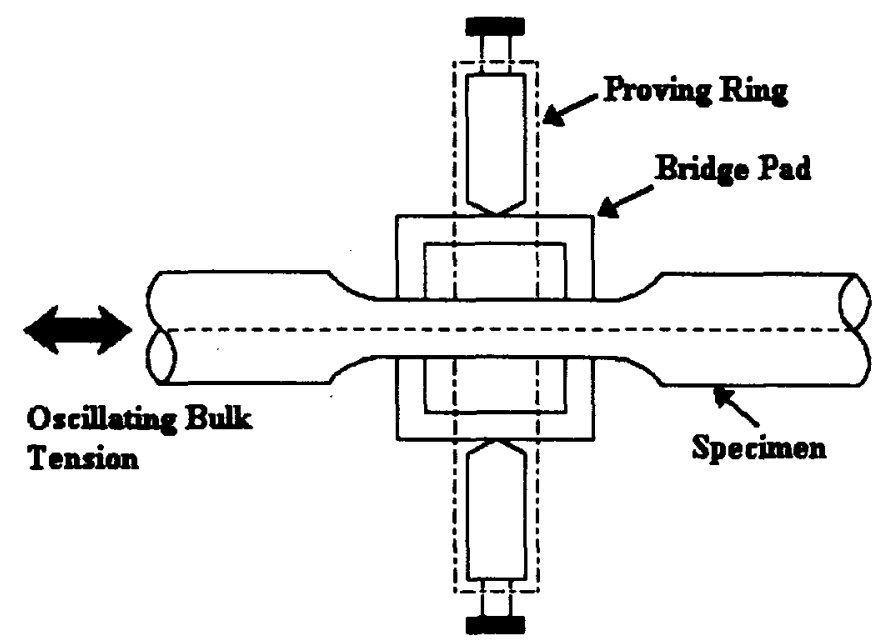

Figure 7.21 Schematic of fretting test set-up using bridge-type pads [23].

Mindlin-type tests use rounded pads that are placed in contact with a test specimen. This method also relies on the strain developed in a loaded specimen to achieve relative slip between 
the contacting bodies. A schematic of a Mindlin type test is shown in Figure 7.22. The implementation of the Mindlin-type fretting test set-up is normally designed around axial load frames with single or double actuators. The single actuator design is the most common since test frames with two actuators are not available in many test facilities.

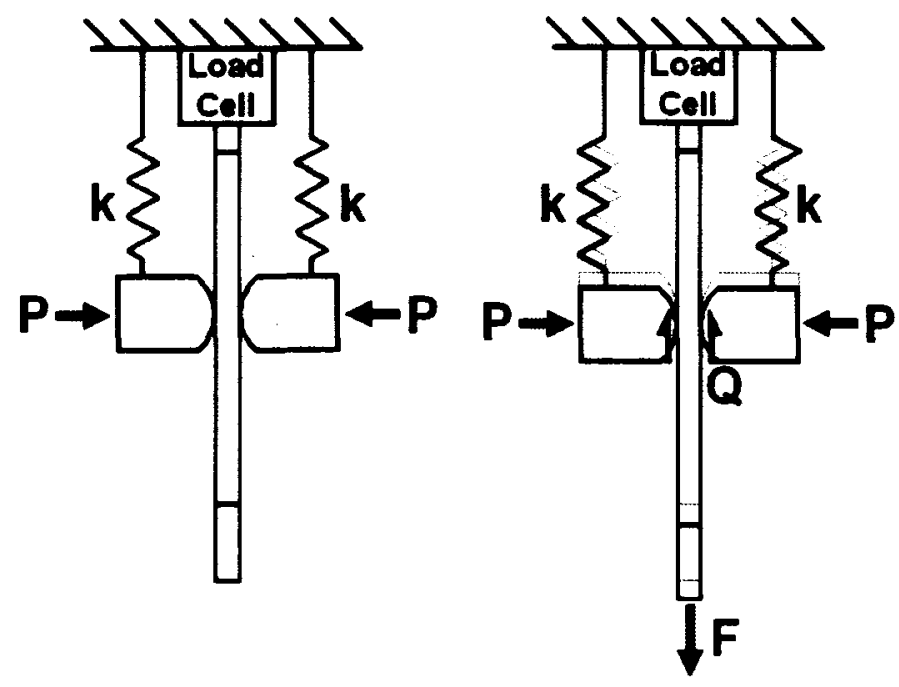

Figure 7.22 Schematic of Mindlin-type fretting fatigue test.

The concept behind using a load frame is that a fretting carriage applies a normal load to a specimen that is installed in the grips of the frame. This fretting carriage is then attached to the frame through a component with a defined stiffness represented in Figure 7.22 as a spring with a spring constant ' $k$ '. As the coupon is cycled in fatigue, displacement of the fretting carriage associated with strain in the coupon is resisted by the stiff spring-like component causing a shear traction, Q, to be applied to the coupon at the point of pad contact. This means that the bulk load in the coupon, $\mathrm{F}$, is in phase with the shear traction applied to the contacting surfaces. In order to change the phase of the bulk load with respect to the shear traction, a double actuator setup is required that allows the 'load cell' portion of the schematic in Figure 7.22 to move as well. 


\subsubsection{Design of Fretting Test Fixture}

Physical realization of the Mindlin-type fretting test fixture has been achieved in many ways as researchers come up with their own designs for implementing the concept described in the previous section. A description of the fretting fatigue test fixture designed and built for this test program is presented in the following paragraphs with detailed design information provided in Appendix F.

The fretting test fixture consists of three major components: rigid upright posts attached to a hydraulic load frame, two simply supported beams (with mounted strain gauges), and a fretting carriage to apply the normal load to the specimen. A solid model of the fixture design is presented in Figure 7.23 with the three major components identified. Physical realization of the solid model is shown in Figure 7.24.

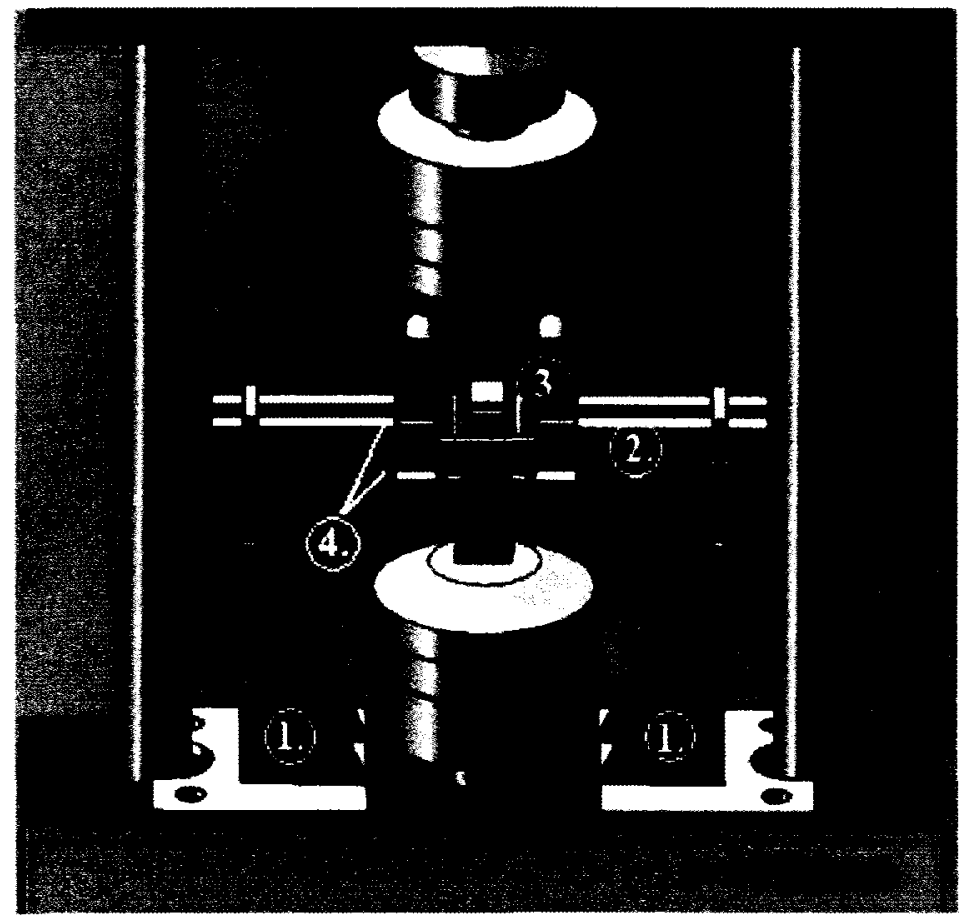

Figure 7.23 Solid model representation of fretting test fixture. 

1. Rigid upright posts
3. Fretting carriage
2. Simply supported beams
4. Strain gauge locations

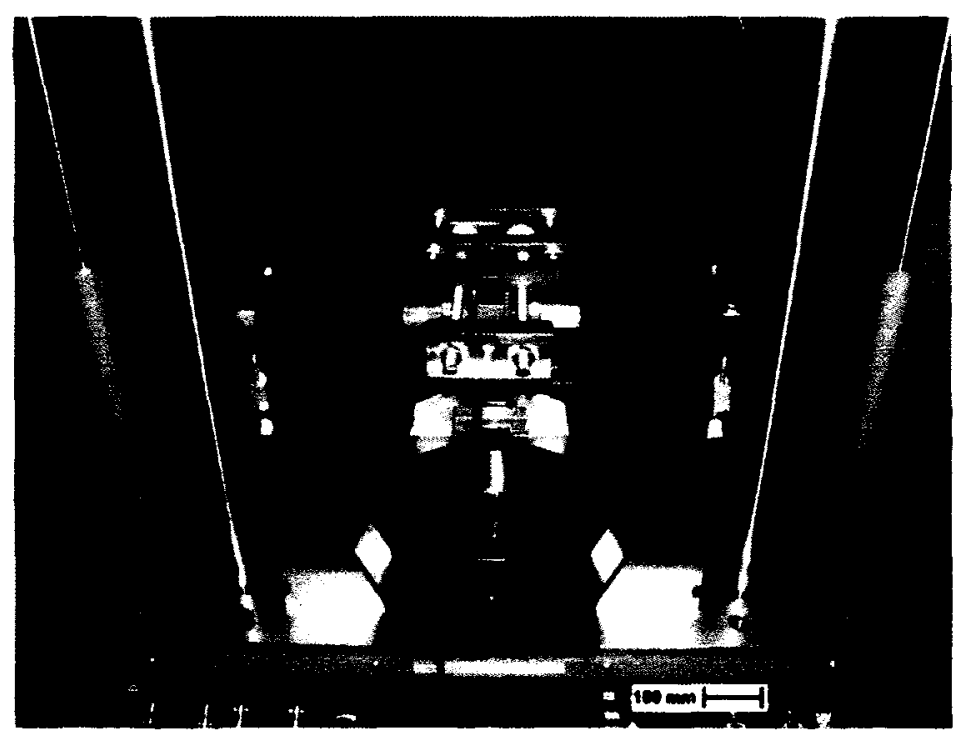

Figure 7.24 Physical realization of fretting test fixture.

The rigid upright posts of the fretting test fixture are manufactured from $12.7 \mathrm{~mm}$ thick 6061-T6 aluminum and are bolted to the base of a $100 \mathrm{kN}$ MTS 810 hydraulic load frame. The top of each rigid post is machined to a knife edge. The knife edges align with small grooves machined into the two $25.4 \mathrm{~mm}$ by $50.8 \mathrm{~mm}$ cross section simply supported steel beams. Clamped to the centre of the simply supported beams is a fretting carriage that applies the normal load to the coupon.

The fretting carriage was carefully designed to reduce the possibility of misalignment of the fretting pads with respect to the coupon and to each other. Misalignment is a common difficulty with fretting fatigue test fixtures and can either be in the form of skewed pad misalignment (Figure 7.25) or tilted pad misalignment (Figure 7.26). Elimination of tilted misalignment is the more important of the two as the tilt will alter the pressure distribution over 
the surface of the contact. Skew misalignment values are normally small enough to not be of concern.

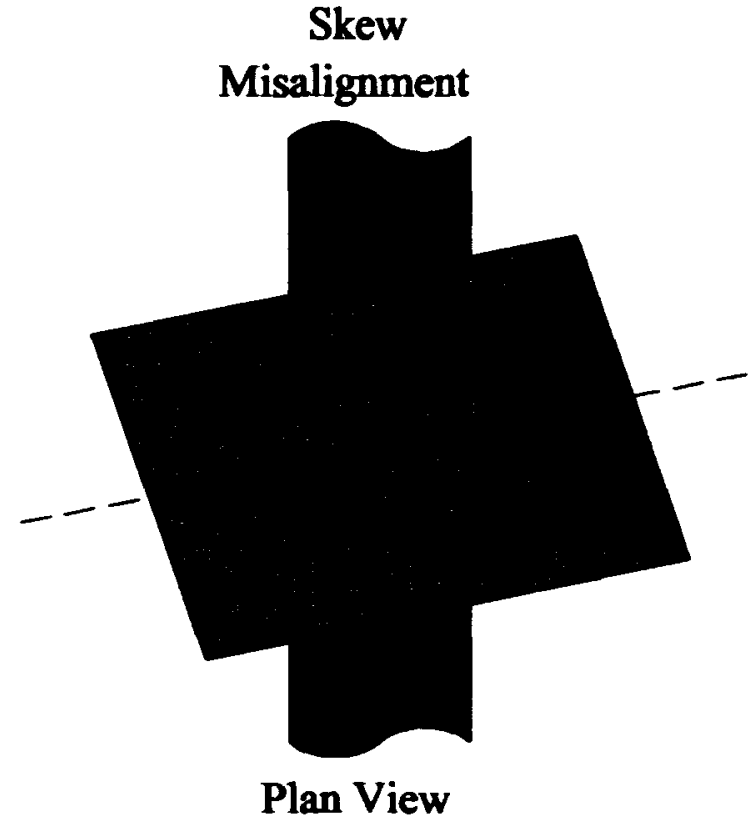

Figure 7.25 Illustration of a skew misalignment between a fretting pad and coupon.

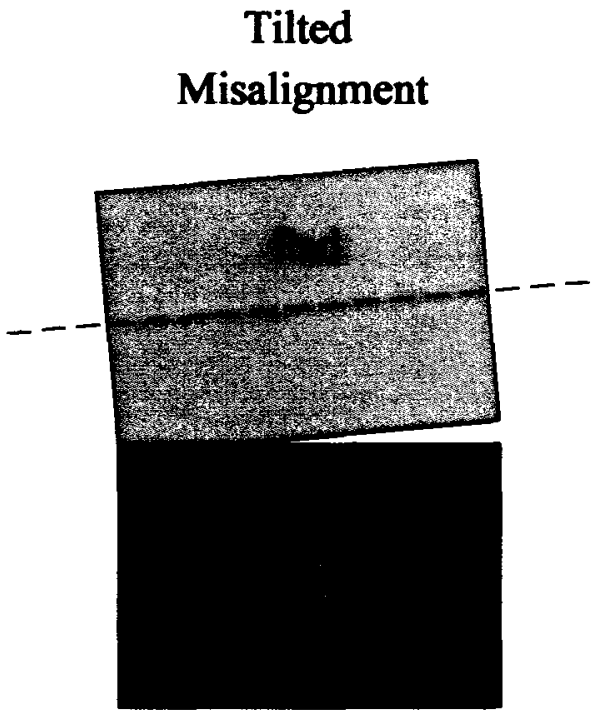

End View

Figure 7.26 Illustration of a tilted misalignment between a fretting pad and coupon.

To reduce the possibility of tilted misalignment, the fretting carriage was designed around a central ground parallel block that slides on aligned, precisely ground rods supported by two external parallel blocks (Figure 7.27). For sliding to work properly, the rods, and the faces of the members, had to be parallel to within $0.05 \mathrm{~mm}$. By mounting the fretting pads on the opposing faces of the parallel blocks in the carriage assembly, a uniform contact distribution could be ensured. Sliding of the central parallel block also allows for easy adjustment to various thicknesses of test coupons. The normal loading is applied to the coupon by tightening nuts on a threaded stud attached to the load cell and to threaded drawbars attached to the sliding member of the carriage. To add compliance to the load train, springs were placed between the threaded drawbars and the sliding member. 


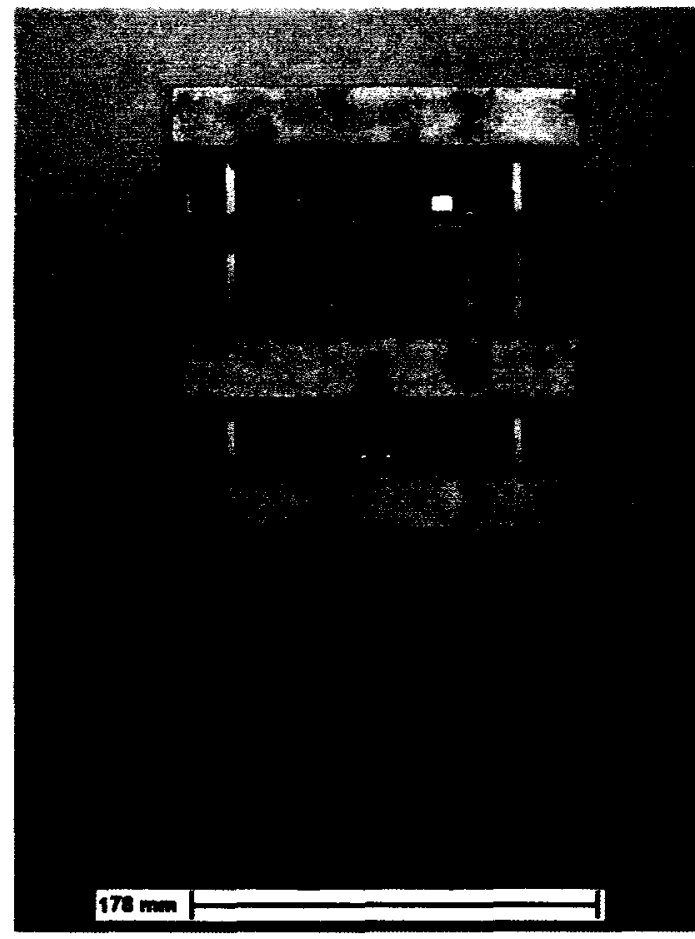

\author{
1. Ground Rods \\ 2. Ground parallel blocks \\ 3. Load Cell \\ 4. Threaded drawbars \\ 5. Compliance springs \\ 6. Bottom plate
}

7. Threaded stud

8. Fretting pads

Figure 7.27 Carriage used to apply normal load to coupons in fretting test fixture.

The amount of deflection in the simply supported beams of the fretting test fixture was used to calculate the shear load provided by the pads on the coupon. The shear load was monitored through a Wheatstone bridge of strain gauges mounted on the simply supported beams. As a check of the shear output values from the simply supported beam strain gauges, gauges were also applied to the coupons, below the pad contact. By doing so, the shear load can be calculated as the difference between the readings from the test frame load cell and the load indicated by the coupon strain gauge. Readings from the coupon strain gauges were calibrated by gripping the coupons in the hydraulic test frame and generating a voltage output curve for known applied loads. Accuracy of the readings was within $\pm 22 \mathrm{~N}$. The voltage output curve was then used in a data acquisition system.

Data acquisition for the tests was performed using both the software for the MTS controller and the software LabVIEW. The MTS Station Manager was used to monitor and 
control the bulk load applied to the coupons as well as the frequency and type of signal being used. LabVIEW v.8 was used to monitor both the normal and the shear loads applied to the test coupon. The signals from the strain gauges on both the simply supported beams and on the coupons were fed into Vishay P-3500 strain indicator boxes where the voltage signals were amplified and output to the LabVIEW input card in a conventional PC. Figure 7.28 and Figure 7.29 shows the virtual instrumentation panel that was created in LabVIEW and the MTS Station Manager respectively.

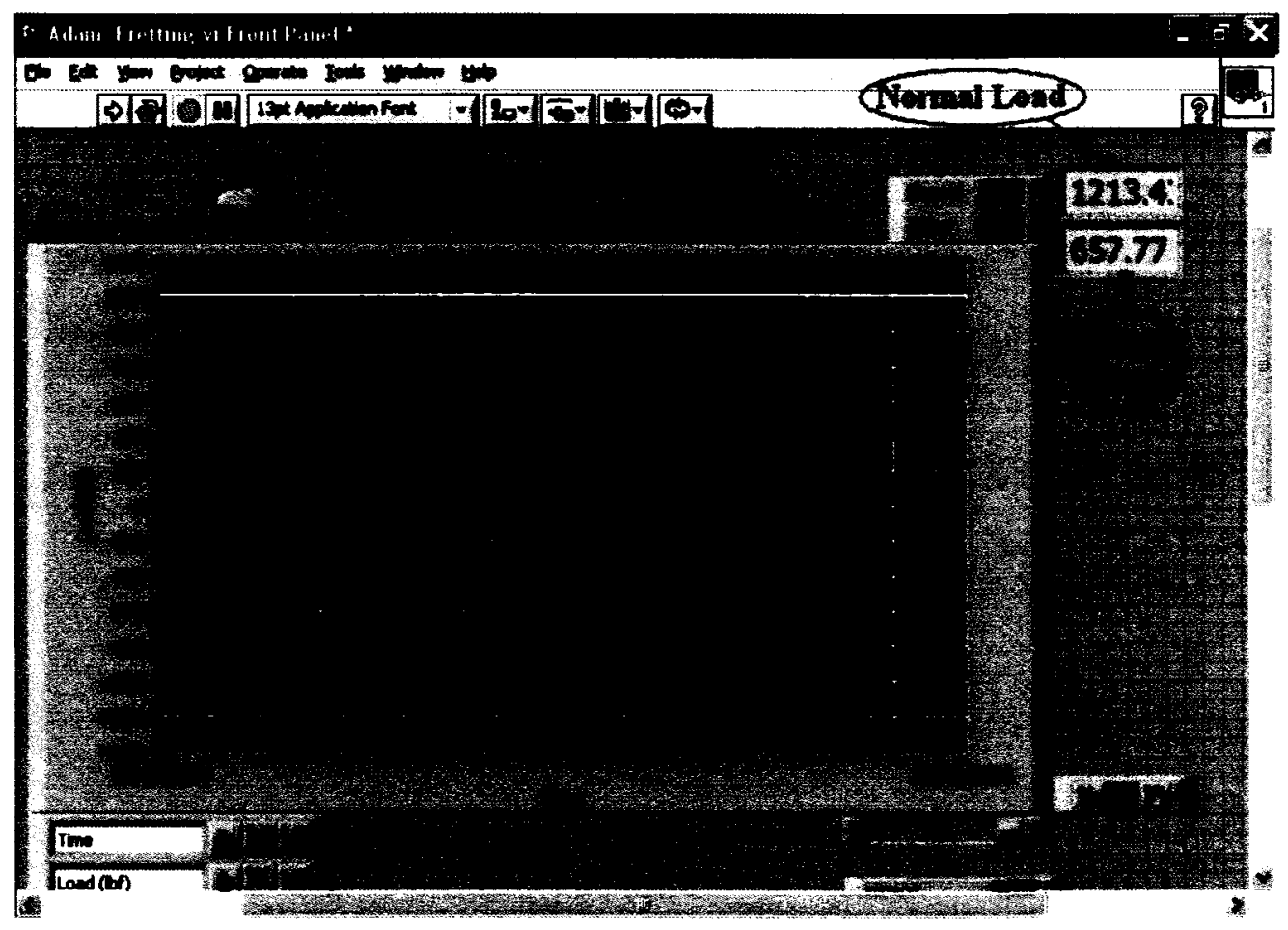

Figure 7.28 LabVIEW front panel used to monitor the normal and shear loads on the Mindlin-type coupons. 


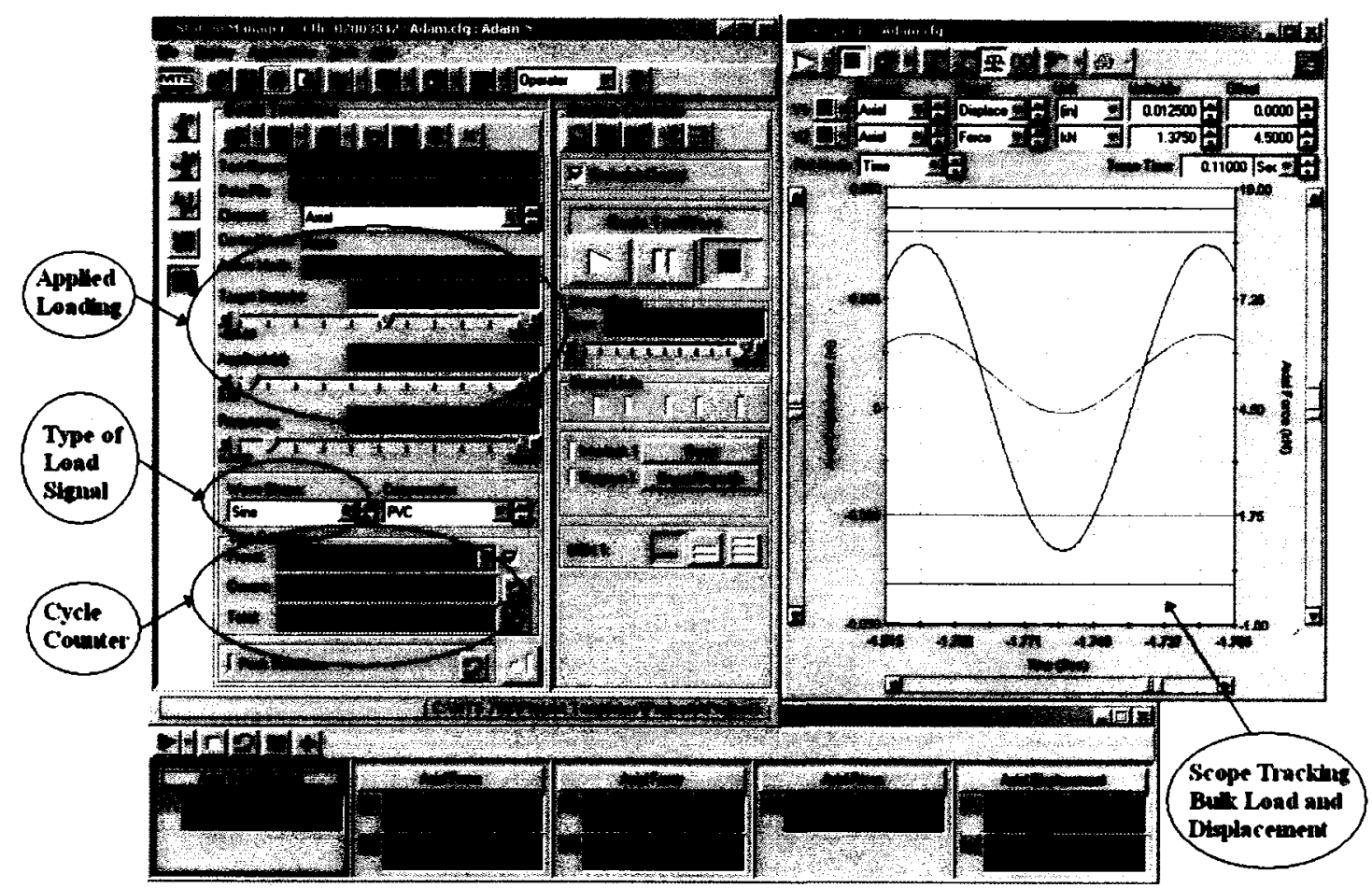

Figure 7.29 MTS Station Manager used to operate hydraulic test frame and monitor bulk loads in the Mindlin-type coupons.

\subsubsection{Test Coupons}

The fretting test coupons had dogbone geometry (Figure 7.30) with a width of $12.7 \mathrm{~mm}(0.5$ inches) and a thickness of $4.8 \mathrm{~mm}$ ( 0.190 inches). The thickness was chosen based on the need to test different common surface treatments. A $4.8 \mathrm{~mm}$ thickness is the greatest thickness for commercially available alclad sheet.

All of the cylindrical pads were NC machined out of $12.7 \mathrm{~mm} \mathrm{2024-T351} \mathrm{plate} \mathrm{to} \mathrm{the}$ specified geometry (Figure 7.30). After the pads were machined, the surface of the pad showed slight machining marks and a slight concavity across the width due to the release of residual stresses during the machining process. To create a smooth, uniform surface finish, each pad was progressively sanded on $240,320,400$, and 600 grit sanding blocks. Concavity was checked for by placing the pads against a precision parallel bar. Once the sanding was complete, some of the pads went on to be anodized. Bare 2024 pads were used for both the alclad and bare test series. It 
was not possible to use alclad pads because aluminum cladding is a rolling process that creates a mechanical bond between the alclad layer and the substrate; this process could not be performed with the complex geometry of the pads. The impact of using bare pads with the alclad coupons was that the fretting damage on the alclad coupons may not have been as severe as it would be with both surfaces having an alclad surface treatment. The bare pad also does not conform under normal loading as an alclad pad would; providing a slightly smaller contact area. For simplicity, in the remainder of this work the configuration of bare pads in contact with alclad coupons will be referred to as the alclad tests.

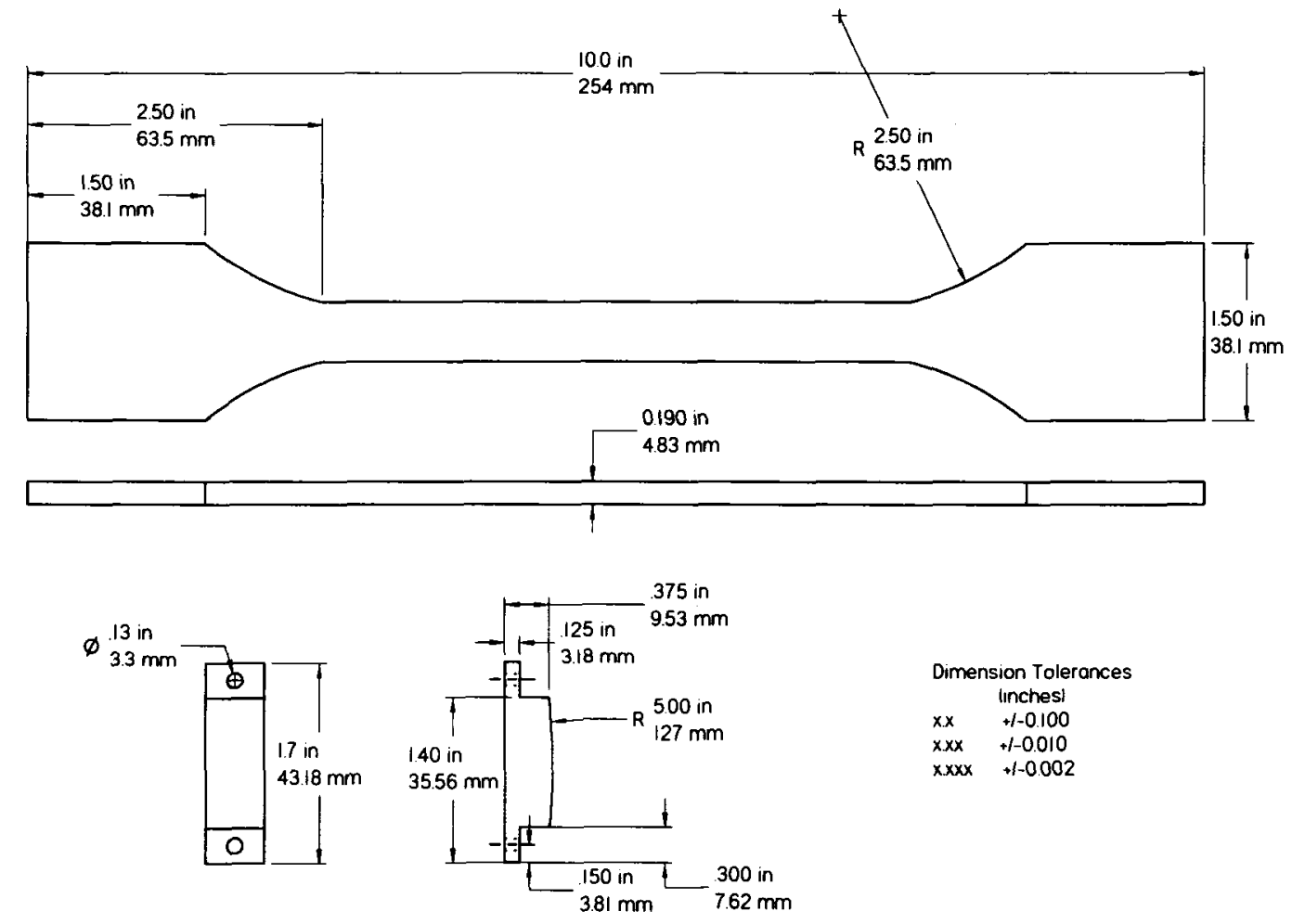

Figure 7.30 Fretting fatigue coupon and pad geometry.

\subsubsection{Procedure}

The first step in the testing procedure was to clean all surfaces with alcohol to remove any oil or dirt on the surface of the coupons or pads. With the coupons and pads clean and prepared, the 
pads were fastened to the ground parallel blocks by screws. The test coupon was then inserted between the pads and clamped in the grips of the hydraulic test frame. Guides fixed to the grips were used to align the coupons in the same position and alignment for each test. Before the test began, Pressurex 'Super-high' pressure sensitive film with a range of $141 \mathrm{MPa}-300 \mathrm{MPa}$ was used to ensure that the contact between the pads and the test coupon was uniform across the width. After uniform contact was confirmed, the normal load was re-applied to the coupon and the test commenced. Pressure film used to ensure contact in one of the tests is shown in Figure 7.31 and the pad surface with fretting damage is shown in Figure 7.32.
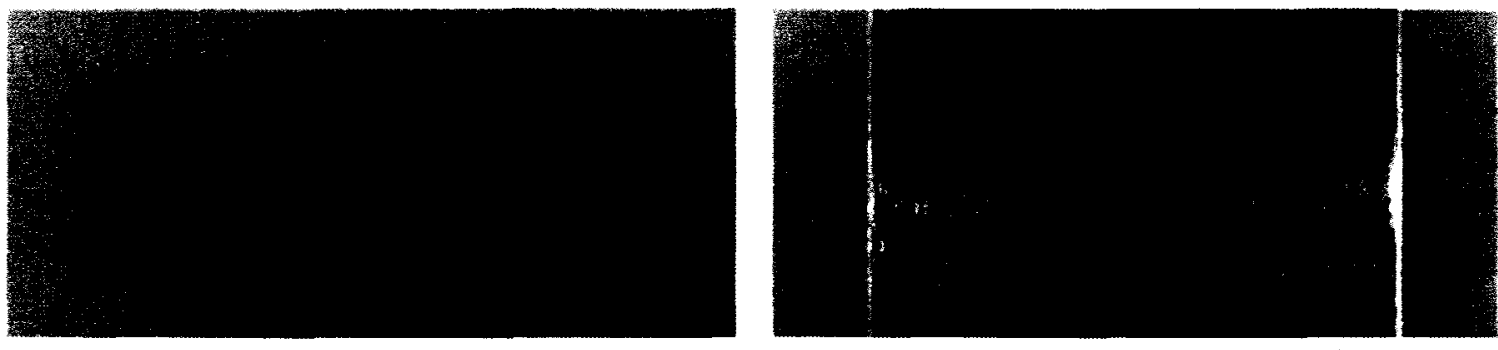

Figure 7.31 Pressure film impression for Figure 7.32 Fretting damage at edge of contact Pad/coupon contact. on pad after fretting test.

Two series of tests were performed with the fretting fatigue coupons. The first series compared bare, anodized, and alclad surface treatments at a low bulk force, and hence, shear force. The second series tested the different surface treatments at a high bulk and shear force. The test parameters are presented in Table 7. 1. Note that the normal load remained the same for all test series.

Table 7. 1 Parameters for fretting test series.

\begin{tabular}{|c|c|c|}
\hline Test Series & $\begin{array}{c}\text { Normal Force } \\
\mathbf{k N}(\mathbf{l b f})\end{array}$ & $\begin{array}{c}\text { Bulk Force } \\
\mathbf{k N}(\mathbf{l b f})\end{array}$ \\
\hline Low Bulk Force Series & $5.3(1200)$ & $\pm 3.6(800)$ \\
\hline High Bulk Force Series & $5.3(1200)$ & $\pm 5.3(1200)$ \\
\hline
\end{tabular}




\subsubsection{Results}

The results of the simplified geometry fretting fatigue tests are presented in Figure 7.33 and show life to ultimate failure of the coupons. In these fretting fatigue tests, as in the case of the splice fatigue tests, coupons treated with the anodized surface treatment provided the best fatigue lives for the low bulk load case. The low bulk load case best simulates the loading situation as seen by the splices in the high rivet forming load situations. The splices with high rivet forming loads have lower sheet stresses due to the presence of compressive residual stresses.

The high bulk load fretting fatigue tests showed no difference between the three different surface treatments. This loading scenario simulates the situation as seen by the splices with low rivet forming loads where sheet stresses would be higher.

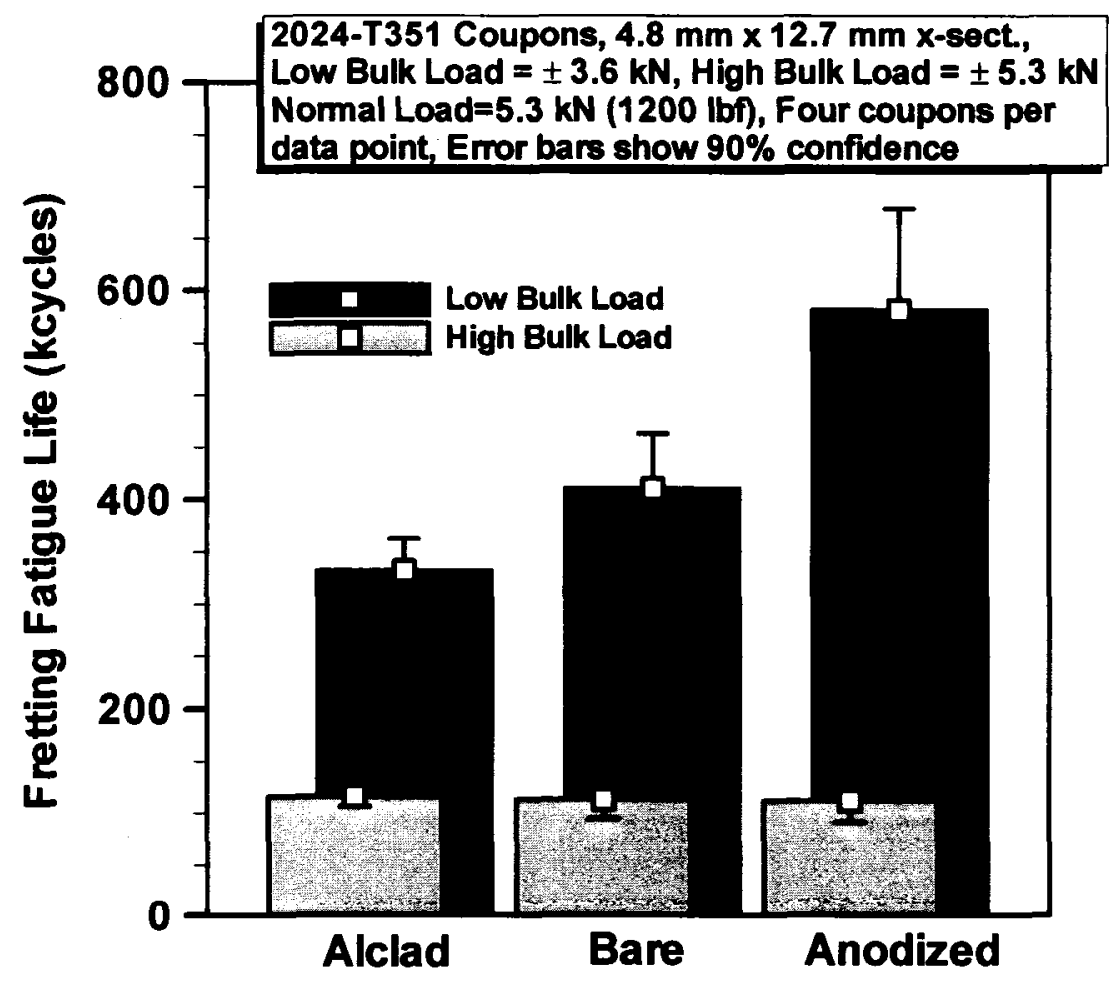

Figure 7.33 Results of fretting fatigue tests for three different surface treatments. 
Representative fretting damage on pad surfaces for each type of surface treatment is presented in Figure 7.34 to Figure 7.39. Fretting damage on the pad surfaces can be seen as the black line of oxidized fretting debris. This line is located at the edge of contact between the pads and the coupons. It should be noted that the pads displayed in Figure 7.34 and Figure 7.37 show the fretting scar for bare pads that were in contact with alclad coupons. Below the black oxidized line, scratches can be observed on the bare and anodized test pad surfaces. These scratches are due to the failed coupon separating at the edge of contact (failure location) and sliding away from the pads that were still applying a normal load to the coupon.

The fretting scars on the pads showed a wide scar for the pad in contact with the alclad coupon and progressively less fretting damage on the bare and anodized pads respectively. Rounding of the fretting scars at the edges of each pad is due to a reduction in contact pressure associated with edge effects. At the edge of the pads, there is no material to restrain expansion in the width direction thereby allowing smaller contact pressures.

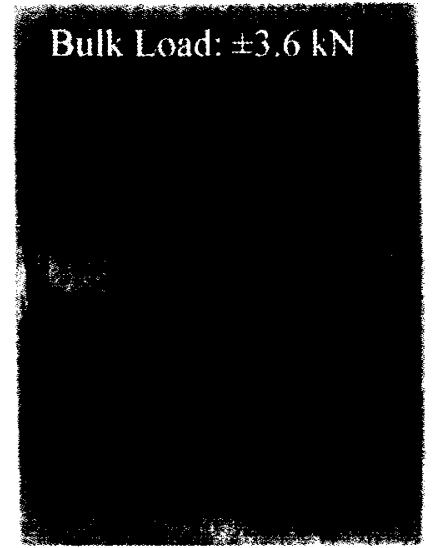

Figure 7.34 Fretting damage on pad from alclad coupon tests.

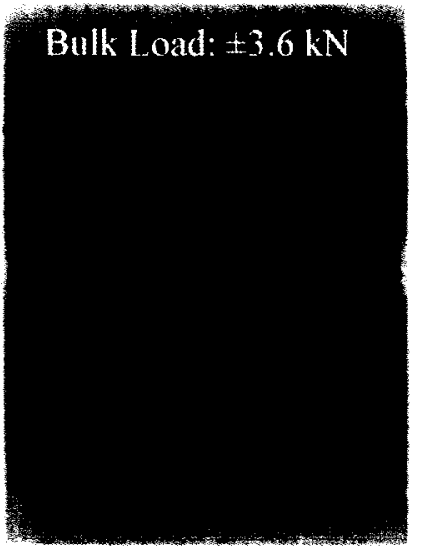

Figure 7.35 Fretting damage on pad from bare coupon tests.

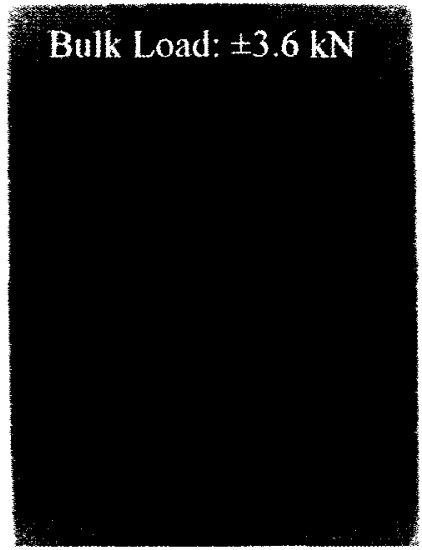

Figure 7.36 Fretting damage on pad from anodized coupon tests. 


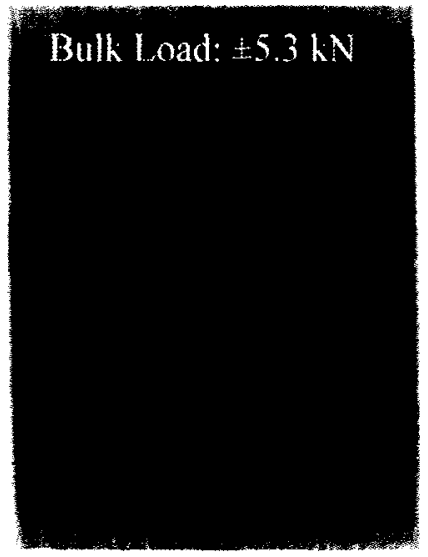

Figure 7.37 Fretting damage on pad from alclad coupon tests.

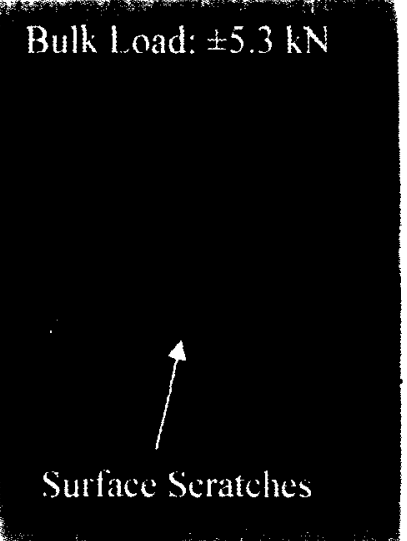

Figure 7.38 Fretting damage on pad from bare coupon tests.

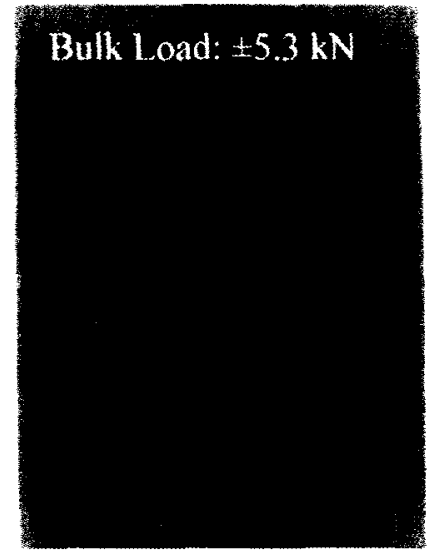

Figure 7.39 Fretting damage on pad from anodized coupon tests.

\subsubsection{Discussion}

The purpose of the simplified fretting fatigue tests was to isolate parameters associated with fretting damage: normal load, shear load, bulk load, and surface condition. The tests were able to examine the effects of common splice surface treatments while excluding effects of secondary bending in the splice. The tests were also able to exclude the variability associated with rivet forming and joint assembly. It is recognized that new but different variability was introduced in the set-up of each fretting test.

With the fretting fatigue parameters isolated, the results of the simplified fretting coupon tests were in agreement with the results of the splice fatigue coupon tests. The high bulk load tests of Figure 7.33 showed that there is no difference in the fatigue lives for the different surface treatments. This corresponds to the low rivet forming load $(6.7 \mathrm{kN}$ and $8.9 \mathrm{kN})$ results of the splice coupon tests presented in Figure 7.1 and Figure 7.2 that have high stress states around the rivet holes.

Conversely, the low bulk load tests of Figure 7.33 showed an increase in fatigue life as the surface treatment was changed from alclad to bare to anodized. This agreed with the high 
rivet forming load $(11.1 \mathrm{kN}$ and $13.3 \mathrm{kN})$ results of the splice coupon tests that have low stress states around the rivet holes.

The faying surface of the fretting fatigue pads, illustrated in Figure 7.34 to Figure 7.39, showed a decrease in the width of the fretting scar when moving from the alclad, to the bare, to the anodized tests. This type of scarring agrees with the results observed around the holes in the failed splice coupons of section 7.2.3. Compliance of the soft alclad layer of the coupon in contact with the pad of Figure 7.37 resulted in a larger fretting scar than the bare and anodized pads. The hardened aluminum oxide surface of the anodized pad in Figure 7.39 demonstrated the least fretting damage of the three surface treatments tested.

Because the results from the splice fatigue tests and the simplified geometry fretting fatigue tests showed great differences in fatigue lives for the three tested surface conditions, the usefulness of the critical plane SWT predictive model will be affected. The idealized bare surface treatment of the finite element model will not be able to predict fretting fatigue lives of splices with alclad or anodized surface treatments at high rivet forming loads. It may be necessary to include the surface condition in a finite element model to obtain accurate predictions for treated splices. Including the surface condition may be in the form of wear models (for the alclad surface treatments) or correction factors on the predicted fatigue life.

\subsection{Conclusions}

The results of the splice fatigue tests have shown that, at (desirable) high rivet squeeze forces, the surface treatment of a splice impacts the crack nucleation life with anodized coupons performing better than bare and alclad coupons. At low rivet squeeze forces, the surface treatment of a splice has little or no impact on the life to crack nucleation. 
The dependence of fatigue life on surface treatment and fretting damage under the high rivet forming loads is due to the edge of contact and location of fretting damage being removed away from the hole edge. At high rivet forming loads the crack nucleation location does not coincide with the location of maximum secondary bending stress and is outside the zone of greatest beneficial compressive residual stresses.

Fretting scars on the surface of the Mindlin test pads and on the faying surface of the lap splices both showed varying degrees of surface damage for the three surface treatments. The soft surface of the alclad surface treatment allowed for greater damage as the alclad layer conformed under normal load. The bare surface treatment showed less damage than the alclad and the hard surface of the anodized treatment showed the least amount of fretting damage.

The difference in fretting fatigue results between the three types of common surface treatment means that the usefulness of the SWT predictive parameter is limited. To use the SWT predictive parameter on splices with surface treatments, corrections to the FE model or to the fatigue life will have to be made. 


\section{General Discussion}

This chapter provides an overall discussion of the results presented in the previous chapters. The discussion is broken into four sections. The first three sections discuss the objectives defined in Chapter 1 while the fourth section discusses splice faying surface fretting in general. The objectives defined in Chapter 1, related to faying surface fretting in single lap splices, are repeated here as:

1. Finding a methodology to predict faying surface fretting fatigue in lap splices

2. Exploring the role of rivet forming load on splice faying surface fretting damage

3. Exploring the role of faying surface treatment on the fatigue life of lap splices.

\subsection{Predicting Faying Surface Fretting Fatigue in Lap Splices}

The chosen predictive method for this study was the critical plane version of the Smith-WatsonTopper (SWT) strain life curve. The key benefit of the critical plane SWT method over other methods discussed in Chapter 2 is the versatility in the geometry that can be studied. This versatility, based on the use of finite element models, means that it should be possible to use the approach on other types of splices in an aircraft. General application of the methodology for any components subject to fretting fatigue, however, has yet to be proven. 


\subsubsection{Explicit Simulation of Fretting Contact}

When modelling fretting contact stresses, it is best to use strict contact formulations such as the Lagrange Multiplier method so that exact nodal stick and slip can be simulated. Not all situations, however, lend themselves to this type of contact formulation. Large models and models with large displacements or plastic strains near the fretting region render implicit simulations and the Lagrange Multiplier method ineffective due to the problem size or due to non-linearity. For these types of problems an explicit simulation is often preferred or required. Unfortunately, contact formulations are limited with explicit simulations. If the size of a model is not too large, it may be possible to perform a simulation that uses an explicit solver to calculate a residual stress field and then switches to an implicit solver to apply the fretting-related loads. This was not practical in a single lap splice model as secondary bending caused significant out-of-plane displacement in the sheets.

Sub-modelling was shown in this study to be an effective method of obtaining fine mesh densities for fretting contact problems. The sub-modelling approach allows for the investigation of a specific area subject to fretting without having to generate a fine mesh for the entire structure. It is also possible to use sub-modelling with shell elements of very large structures. A larger global shell model can be simulated, such as an aircraft fuselage, and then 3D sub-models can be developed in an area of interest to be driven by the shell element displacements from the global model. Without sub-modelling, obtaining a fine mesh density in large models would produce high numbers of elements requiring prohibitively long solution times.

A key benefit to using explicit finite element simulations is the ability to simulate cold working and the introduction of plastic strains in the simulation inexpensively. This allows for modelling of residual stress fields in the regions where fretting damage may occur. Modelling of residual stress fields could include surface stresses developed through high temperature surface 
treatment processes being developed to reduce fretting damage. These types of residual surface stress fields remain a difficulty for those developing analytical solutions to fretting contact situations.

Analytical solutions to fretting contact problems can be preferable to numerical solutions but unfortunately the complexity of most fretting problems excludes the use of analytical solutions. The closest to modelling fretting contact in a complex geometry that analytical solutions have come is the dovetail joint (described in Chapter 2). The contact between the blade root and the rotor disk has the geometry of a flat pad with rounded edges in contact with a flat plane. As this geometry is relatively simple and the fretting problem quite common, many researchers are working on the development of analytical solutions to the problem. Outside simple contacts, however, numerical methods are necessary.

\subsubsection{SWT Critical Plane Predictive Method}

The critical plane SWT predictive method was shown to be useful in the prediction of crack initiation life and nucleation location for bare splice coupons. Key to the successful application of the predictive method is detailed modelling of the stress field in the area of interest. Modelling details normally overlooked in an idealized finite element model may have to be included to achieve good results. For the single lap splice, this meant modelling rivet details such as the crown of material on the top of a NAS1097 rivet that could normally be overlooked in an idealized rivet model. Another detail of importance was the height of the formed countersunk rivet above the sheet, shown by Rans [8] to be critical in estimating the residual stress distribution in the sheet.

Careful modelling of the stress field is required, especially in high cycle fatigue situations $\left(>10^{6}\right.$ cycles) as it was found that there is sensitivity in the SWT parameter to small changes in the stress level at high fatigue lives. The reason for the sensitivity is best explained with the 
example of a standard S-N curve (Figure 8.1). A stress-life (or S-N) curve illustrates how small changes in the stress at low stress levels result in large changes in fatigue lives.

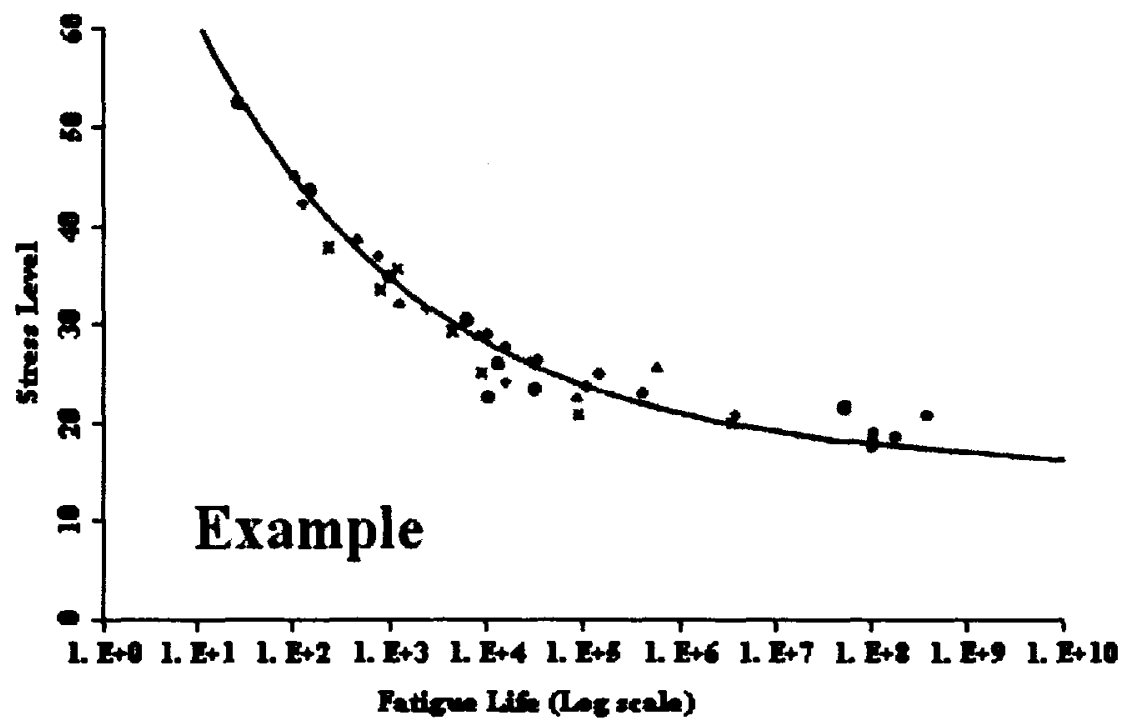

Figure 8.1 Example S-N curve showing fatigue trend in metals. Modified from [38].

A further benefit of the critical plane SWT predictive method is that it relies on strain life parameters for the life prediction. Since the strain life method has been in use for some time, the parameters are published in open literature for many types of metals. Unfortunately, if the material being studied is non-standard and not available in the open literature, testing will have to be performed to obtain the strain life parameters.

One drawback of the critical plane SWT predictive method is the significant time commitments that may be required to find accurate solutions. The time commitments required include the time to set-up and validate a finite element model, the solution time (which can be significant), and the time required to run the code developed (Appendix C) to search for the critical plane of each node or integration point. 


\subsection{Effect of Rivet Forming Load on Fretting}

In fretting fatigue, the edge of contact is of key importance. The edge of contact between mating bodies is the location where maximum surface stresses and the most severe fretting damage will occur. In riveted lap splices manufactured from thin sheet, the rivet forming load defines where the edge of contact will be on the faying surface and the magnitude of the residual clamping pressure. It was shown in this study that at high rivet forming loads, the edge of contact and location of fretting damage is located away from the hole edge. The higher the rivet forming load, the further from the hole is the edge of contact. It is reasonable to assume that this trend should hold for thicker sheet material and larger fasteners as well. As the size of the sheet material is scaled up, so must the fastener size, the rivet forming load, and the clamped area on the faying surface.

It was shown in Chapter 5 that the initial clamping area developed from the rivet forming process does not remain after the first splice loading cycle is applied. Loading of the splice produces an unsymmetrical contact area around the hole due to bending in the joint and upon release of the load an unsymmetrical contact area remains. It would normally be expected that the contact area would return to the original distribution upon unloading but this was not so. The change in contact area after the initial rivet forming step has been observed in the universal and machine countersunk splice simulations as well as in fretting wear on test coupons. The discovery of unsymmetrical contact areas will affect future assumptions by researchers when crack nucleation around rivet holes is being studied. The unsymmetrical pressure distribution, favouring one side of the rivet hole, defines where fretting damage will occur at the edge of contact.

Interactions exist between rivet forming load, faying surface contact area, the formation of residual stress fields, and secondary bending stresses. It must, therefore, be recognized that fretting damage is not the only parameter affecting the fatigue life of a splice for a particular rivet 
forming load. Higher rivet forming loads will create greater hole expansion and larger residual stress fields around the rivet hole. At the same time, larger diameters of the formed rivet head produce larger faying surface clamping areas and greater restraint to secondary bending in the sheet. It is important to note that, within this complex interaction, fretting is the phenomenon that contributes to crack nucleation. Therefore, at high rivet forming loads, faying surface crack nucleation makes the surface treatment an important factor.

\subsection{Effect of Splice Surface Treatment}

The splice fatigue tests as well as the simplified geometry fretting fatigue tests showed a distinct increase in the fatigue lives of components under low stress (high rivet forming loads) when changing from alclad to bare to anodized surface treatments.

Since different surface treatments produce different fatigue lives at high rivet forming loads, a correction is required for any lifing model used for splices. The critical plane SWT parameter, as presented in this study, was dependent on the results of a finite element analysis. As such, the effect of surface treatment would have to be included in a splice model to achieve reasonable fatigue life estimates for splices with surface treatments. Including surface treatments in a model may prove difficult, especially for the alclad surface treatment, as wear may have to be included in the simulation. One way of including wear may be through application of a methodology proposed by Ding et. al. [28]. The methodology couples a finite element simulation with a wear simulation, based on the Archard equation for sliding wear, that updates the nodal geometry according to the number of wear cycles. Including wear in the finite element simulations will, however, increase the time requirement and cost of using this method. An alternative to wear calculations may be the development of correction factors on fatigue lives for different surface treatments. 
The failure location for the anodized and bare universal coupons was a mix of inner and outer sheet failures with the majority occurring in the inner sheet. In contrast, most failures in the alclad sheets occurred in the outer sheet. This variation in failure location indicates that there is a close competition between secondary bending stresses, residual sheet stresses and surface treatment in the splices. This competition is described with the following points:

- The smaller size of the formed rivet head, in comparison to the manufactured rivet head, provides less constraint to secondary bending favouring crack nucleation in the inner sheet

- The inner sheet, however, contains larger beneficial compressive residual stresses than the outer sheet favouring crack nucleation in the outer sheet

- The degree of wear on the faying sheet surfaces also contributes to crack nucleation.

The importance of the failure location is in the practical aspect of inspection. Crack nucleation on the inner sheet of a splice is not desirable because access to the inside of the fuselage skin would be required. It is possible that, in coupons that tend to fail in the inner sheet, the failure location could be moved to the critical row of the outer sheet by changing the geometry of the splice.

The results of this study have brought into question the use of alclad sheet in fuselage construction because the fatigue performance is so poor in comparison to anodized sheet. The alclad layer provides corrosion resistance only and in a nominally $1 \mathrm{~mm}$ thick sheet, only $90 \%$ of the thickness carries the structural loads. There is, therefore, a weight penalty to using the alclad surface treatment for corrosion resistance. Further study is also required on the benefits of anodized surface treatments as the aluminum oxide surface of the anodized sheets may be more susceptible to brittle cracking over time.

This study has only looked at bare, alclad, and anodized surface treatments in 2024-T3 aluminum. Based on the results of this study, however, it is possible that alternate surface 
treatments exist that could out-perform the anodized splices. Effectively eliminating fretting damage around a rivet on the faying surface of lap splices could further increase fatigue lives at high rivet forming loads.

\subsection{Faying Surface Fretting in Single Lap Splices}

The work by Müller and other researchers $[2,36,50]$ on rivet forming showed the benefit of using load controlled riveting and high rivet squeeze forces to create greater fatigue lives in lap splices. Using greater rivet squeeze forces in thin sheet material, however, results in crack nucleation on the faying surface rather than the rivet/hole interface. This change in crack nucleation location places greater importance on faying surface fretting damage and the surface treatment. It was especially important here, to investigate differences between common surface treatments already applied to the faying surface of lap splices. With common surface treatments, changing from one type to another can be easily done if the result is higher fatigue lives of the joint.

This work showed that, in the case of commonly used sheet surface treatments, choosing an anodized treatment over an alclad treatment can produce greater fatigue lives in the joint. Changes to the splice geometry may have to be made, as mentioned in the previous section, to move the location of critical failure to the easily inspected outer sheet in the case of the universal riveted splices.

The results of the surface treatment study have also provided insight for designers using fasteners with high clamping loads; such as certain titanium bolts. It would be reasonable to assume that the type of faying surface treatment could play a role in the fatigue life of those joints as well. Although this work was performed on the single lap splice, the results found here should lend themselves to other geometries with secondary bending such as the single butt splice. 


\section{Conclusions and Contribution Statement}

The research detailed in the previous chapters examined the impact of fretting damage on the faying surface of single lap splices. A combination of numerical and experimental methods has been followed to produce the results from which the following conclusions have been drawn:

\section{Chapter 3:}

3.1 It is clear from the residual stress plots presented in Figure 3.3 to Figure 3.10 that the variation in the residual stress field of a riveted sheet requires a 3D representation of a riveted single lap splice. The need for a 3D finite element lap splice is compounded by the presence of high secondary bending stresses at the outer rivet rows of a splice.

3.2 The residual faying surface pressure distribution for the machine countersunk rivets was found to be smaller in magnitude than for the universal rivets with the exception of the $6.7 \mathrm{kN}$ rivet forming case. The extent of the pressure distribution, however, was larger with the countersunk rivets having greater clamping radii.

3.3 A limit on peak clamping pressure existed for the machine countersunk rivets due to the lower constraint provided by the manufactured rivet head. No such limit was observed for the universal rivets.

3.4 The manufactured rivet head style also plays a role in the sheet clamping at the hole edge. The machine countersunk rivets create a wedging effect that provides high clamping 
pressures up to the hole edge for all rivet forming loads. The universal rivets produce a gap in the contact between the manufactured rivet head and the outer sheet at the hole edge. The presence of the gap causes much smaller clamping pressures at the hole edge compared to the countersunk rivets.

3.5 Determining the amount of clamping on the faying sheet surface after rivet springback is important in illustrating where peaks in stress may occur at the edge of contact during splice loading. This does not, however, provide the complete picture as the clamping area will change during splice loading due to secondary bending. To observe the changes in contact during joint loading, a full splice simulation is required.

\section{Chapter 4:}

4.1 Modelling of shear tractions with 3D explicit simulations did not produce results comparable to those of 2D implicit simulations. Normal tractions and surface stresses in the $\mathrm{x}$ direction, however, did show good agreement for the 2D, 3D and analytical solutions. As most predictive fretting fatigue life methodologies use the surface stresses rather than shear tractions, 3D solutions were found to be satisfactory for a predictive life model.

4.2 Convergence of the $3 \mathrm{D}$ explicit finite element stress results was shown through two different methods: comparison to the analytical solution and comparison to the previous solution for each mesh refinement level. In this way, it was shown that the comparison to the previous mesh refinement results was a reasonable way to show convergence in an FE study where analytical or experimental results are not available.

\section{Chapter 6:}

6.1 The critical-plane SWT life prediction was found to agree well with crack initiation lives for splices constructed out of $1 \mathrm{~mm}$ sheet and riveted with both machine countersunk and 
universal rivets. The location of crack nucleation also agreed with peaks in the criticalplane SWT contour plot at the edge of contact on the faying surface.

6.2 The bare 2024-T3 aluminum splices showed failure in the outer sheet at the top rivet row for the machine countersunk coupons and failure in the inner sheet at the bottom rivet row for the universal splice coupons. In each case, the failed splice sheet corresponded to the rivet row with the greatest secondary bending.

6.3 The critical-plane SWT parameter, in combination with stress and strain data from a validated finite element model, is a good tool to predict fatigue lives for complex structures and components with residual stress fields.

\section{Chapter 7:}

7.1 The results of the splice fatigue tests have shown that, at (desirable) high rivet squeeze forces, the surface treatment of a splice impacts the crack nucleation life with anodized coupons performing better than bare and alclad coupons. At low rivet squeeze forces, the surface treatment of a splice has little or no impact on the life to crack initiation.

7.2 The dependence of fatigue life on surface treatment and fretting damage in the high rivet forming loads cases is due to the edge of contact and location of fretting damage being removed away from the hole edge. At high rivet forming loads the crack nucleation location does not coincide with the location of maximum secondary bending stress and is outside the zone of greatest beneficial compressive residual stresses.

7.3 Mindlin-type simplified geometry fretting tests confirmed the results of the splice tests by showing differences in fatigue lives at low bulk and shear loads and no difference in fatigue life at high bulk and shear loads.

7.4 Fretting scars on the surface of the Mindlin test pads and on the faying surface of the lap splices both showed varying degrees of surface damage for the three surface treatments. 
The soft surface of the alclad surface treatment allowed for greater damage as the alclad layer conformed under normal load. The bare surface treatment showed less damage than the alclad and the hard surface of the anodized treatment showed the least amount of fretting damage.

7.5 The difference in fretting fatigue results between the three types of common surface treatment means that the usefulness of the SWT predictive parameter is limited. To use the SWT predictive parameter on splices with surface treatments, corrections to the FE model or to the fatigue life will have to be made.

\subsection{Statement of Contribution}

For the purpose of summarizing this work and its contribution to the body of knowledge in aerospace research a contribution statement was developed. The statement follows as:

The work presented here has shown, through a predictive life model, as well as splice and fretting fatigue tests, that increasing the rivet forming load in thin sheet material moves fatigue crack nucleation from the hole edge to the edge of contact on the faying surface. It was shown that at the hole edge secondary bending and stress concentrations dominate crack nucleation whereas away from the hole edge, fretting damage dominates crack nucleation and the faying surface treatment can affect the fatigue life.

The critical-plane SWT parameter was shown to be a versatile tool in predicting the cycles to crack initiation and the location of crack nucleation in complex geometries with residual stress fields. In addition, it was shown that when using load-controlled riveting and high rivet squeeze forces in thin sheet splices, changing the surface treatment to reduce fretting damage results in increased fatigue lives. 


\section{Future Work}

The results of the splice and the Mindlin-style tests showed that the surface treatment plays a significant role in the fretting fatigue life of a coupon. This impacts the usefulness of the critical plane SWT parameter to predict fretting fatigue life. For the SWT parameter to be of use it is necessary for any finite element simulation to properly reflect the surface conditions of the component being modelled. Future work in this area could be the development of finite element models that incorporate an anodized or alclad surface treatment. This may require the inclusion of wear models to the simulation; especially with softer surfaces such as the alclad surface treatment. Wear models have been developed that work in concert with finite element simulations such as the one by Ding et. al. [28] mentioned in section 8.3 .

With potential changes to the surface treatment on faying surfaces of lap splices, an investigation into dimpling as a method of countersinking splices is a potential offshoot of this work. In dimpled splices, as described in section 2.2 .4 .2 , the load transfer mechanism is no longer constrained to rivet bearing on the sheet and a small amount of faying surface friction. Nesting of the dimple cones could actually allow for load transfer between the sheets without the presence of rivets as long as the sheets remained together. Naturally, the sheets would be held together with rivets. This difference in load transfer allows for the application of many different types of faying surface treatments; including treatments that greatly reduce the interfacial friction coefficient. Reducing the interfacial coefficient of friction would normally be detrimental to the fatigue life of 
a splice but, as shown in preliminary research results in section 2.2 .4 .2 , lubricating the faying surface of a modified dimple splice brought about a three fold increase in fatigue life over conventional countersunk riveted splices.

Further potential research exists in the exploration of new types of faying surface treatment to eliminate fretting damage. It is possible that the elimination of fretting damage on splice faying surfaces could lead to further increases in fatigue life. 


\section{References}

[1] T. N. Farris, M. P. Szolwinski, and G. Harish, "Fretting in Aerospace Structures and Materials," in Fretting Fatigue: Current Technology and Practices, West Conshohocken, PA, 2000.

[2] R. P. G. Müller, An experimental and analytical investigation on the fatigue behaviour of fuselage riveted lap joints: the significance of the rivet squeeze force and a comparison of 2024-T3 and Glare 3, Ph.D. dissertation, Delft University of Technology, Delft, 1995.

[3] M. R. Urban, "Analysis of the fatigue life of riveted sheet metal helicopter airframe joints," International Journal of Fatigue, vol. 25, pp. 1013-1026, 2003.

[4] N. Bonacci, Aircraft Sheet Metal. Casper, WY: IAP, Inc., 1992.

[5] C. D. Rans and P. V. Straznicky, "Avoiding knife-edge countersinks in GLARE through dimpling," Fatigue and Fracture of Engineering Materials and Structures, vol. 28, pp. 633-640, 2005.

[6] R. L. Templin and J. W. Fogwell, "Design of tools for press-countersinking or dimpling 0.040-inch-thick 24S-T sheet," National Advisory Committee for Aeronautics, Technical Notes, No. 854, 1942.

[7] A. M. Brown, and P. V. Straznicky, "Dimple tool modification for press-countersinking GLARE," in COM 2006, Montreal, Canada, 2006.

[8] C. D. Rans, The Role of Rivet Installation on the Fatigue Performance of Riveted Lap Joints, Ph.D. dissertation, Carleton University, Ottawa, 2007.

[9] J. Schijve and. A. Hartman, "The effect of secondary bending on the fatigue strength of 2024-T3 Alclad riveted joints," National Aerospace Laboratory NLR 1969.

[10] S. A. Fawaz, Fatigue Crack Growth in Riveted Joints, Ph.D. dissertation, Delft University of Technology, Delft, 1997.

[11] G. Li and G. Shi, "Effect of the riveting process on the residual stress in fuselage lap joints," CASI, vol. 50, pp. 91-105, 2004.

[12] M. P. Szolwinski, The mechanics and tribology of fretting fatigue with application to riveted lap joints, Ph.D. dissertation, Purdue University, West Lafayette, 1998.

[13] M. P. Szolwinski and T. N. Farris, "Linking riveting process parameters to the fatigue performance of riveted aircraft structures," Journal of Aircraft, vol. 37, pp. 130-137, 2000. 
[14] J. H. Park and S. N. Alturi, "Fatigue growth of multiple-cracks near a row of fastenerholes in a fuselage lap-joint," Computational Mechanics, vol. 13, pp. 189-203, 1993.

[15] G. A. Tomlinson, "The rusting of steel surfaces in contact," Proc. Roy. Soc., vol. Series A, pp. 472-483, 1927.

[16] E. J. Warlow-Davies, "Fretting corrosion and fatigue strength: brief results of preliminary experiments," Proc. I.Mech.E., vol. 146, pp. 33-38, 1941.

[17] McDowell, "Fretting corrosion tendencies of several combinations of materials," in Symposium on Fretting Corrosion, Philadelphia, 1953.

[18] R. B. Waterhouse, Fretting Corrosion. Oxford: Pergamon, 1972.

[19] R. B. Waterhouse, Fretting Fatigue. London: Applied Science Publishers, 1981.

[20] M. P. Szolwinski, and T. N. Farris, "Mechanics of fretting fatigue crack formation," Wear, vol. 198, pp. 93-107, 1996.

[21] W. S. Sum, E. J. Williams, and S. B. Leen, "Finite element, critical-plane, fatigue life prediction of simple and complex contact configurations," International Journal of Fatigue, vol. 27, pp. 403-416, 2005.

[22] A. Vadiraj and M. Kamaraj, "Fretting fatigue studies of surface modified biomedical titanium alloys," Materials Science Forum, vol. 539-543, pp. 681-686, 2007.

[23] D. A. Hills and D. Nowell, Mechanics of Fretting Fatigue vol. 30. Dordrecht: Kluwer Academic Publishers, 1994.

[24] D. Nowell, D. Dini, and D.A. Hills, "Recent developments in the understanding of fretting fatigue," Engineering Fracture Mechanics, vol. 73, pp. 207-222, 2005.

[25] A. E. Giannakopoulos, T. C. Lindley and S. Suresh, "Aspects of equivalence between contact mechanics and fracture mechanics: theoretical connections and a life-prediction methodology for fretting-fatigue," Acta Materialia, vol. 46, pp. 2955-2968, 1998.

[26] A. E. Giannakopoulos, T. C. Lindley and S. Suresh, "Similarities of stress concentrations in contact at round punches and fatigue at notches: implications to fretting fatigue crack initiation," Fatigue and Fracture of Engineering Materials and Structures, vol. 23, pp. 561-571, 2000.

[27] D. Socie, "Multiaxial Fatigue Damage Models," Journal of Engineering Materials and Technology, vol. 109, pp. 293-298, 1987.

[28] J. Ding, S. B. Leen, and I. R. McColl, "The effect of slip regime on fretting wear-induced stress evolution," international Journal of Fatigue, vol. 26, pp. 521-531, 2004.

[29] C. D. Lykins, S. Mall, and V. Jain, "An evaluation of parameters for predicting fretting fatigue crack initiation," International Journal of Fatigue, vol. 22, pp. 703-716, 2000.

[30] H. Proudhon, S. Fouvry, and J.-Y. Buffiere, "A fretting crack initiation prediction taking into account the surface roughness and the crack nucleation process volume," International Journal of Fatigue, vol. 27, pp. 569-579, 2005.

[31] G. Harish and T. N. Farris, "Shell modeling of fretting in riveted lap joints," $A L A A$ Journal, vol. 36, pp. 1087-1093, 1998. 
[32] G. Harish and T. N. Farris, "An integrated approach for prediction of fretting crack nucleation in riveted lap joints.," in ALAA/ASME/ASCE/AHS/ASC 40th Structures, Structural Dynamics, and Materials Conference St. Louis, MO: AIAA, 1999.

[33] A. M. Brown and P. V. Straznicky, "Modelling fretting contact stresses in a single lap splice," in International Symposium on Fretting Fatigue 5, Montreal, Canada, 2007.

[34] M. Liao, G. Shi, and Y. Xiong, "Analytical methodology for predicting fatigue life distribution of fuselage splices," International Journal of Fatigue, vol. 23, pp. S177S185, 2001.

[35] K. Iyer, P. C. Bastias, C. A. Rubin, and G. T. Hahn, "Influence of interference and clamping on fretting fatigue in single rivet-row lap joints," Journal of Tribology, vol. 123, pp. 686-698, 2001.

[36] C. D. Rans, R. C. Alderliesten, and P. V. Straznicky, "Riveting process induced residual stresses around solid rivets in mechanically fastened joints," Journal of Aircraft, vol. 44, pp. 323-329, 2007.

[37] L. Ryan and J. Monaghan, "Failure Mechanisms of riveted joint in fibre-metal laminates," Journal of Materials Processing Technology, vol. 103, pp. 36-43, 2000.

[38] MIL-HDBK-5H, Metallic Materials and Elements for Aerospace Vehicle Structures: U.S. Department of Defense, 1998.

[39] R. D. Mindlin, "Compliance of elastic bodies in contact," Jnl. Appl. Mech., vol. 16, pp. 259-268, 1949.

[40] C. Cattaneo, "Sul contatto di due corpi elastici: distribuzion locale degli sforzi," Reconditi dell Accademia nazionale dei Lincei, vol. 27, pp. 342-348, 434-436, 474-478, 1938.

[41] K. L. Johnson, Contact Mechanics. Cambridge: Cambridge University Press, 1985.

[42] Westergaard.

[43] C. T. Tsai, and S. Mall, "Elasto-plastic finite element analysis of fretting stresses in prestressed strip in contact with cylindrical pad," Finite Elements in Analysis and Design, vol. 36, pp. 171-187, 2000.

[44] M. Tur, J. Fuenmayor, J. J. Rodenas, E. Giner, "3D analysis of the influence of specimen dimensions on fretting stresses," Finite Elements in Analysis and Design, vol. 39, pp. 933-949, 2003.

[45] O. Jin, and S. Mall, "Effects of slip on fretting behavior: experiments and analyses," Wear, vol. 256, pp. 671-684, 2004.

[46] H. S. Kim, S. Mall, "Investigation into three-dimensional effects of finite contact width on fretting fatigue," Finite Elements in Analysis and Design, vol. 41, pp. 1140-1159, 2005.

[47] ABAQUS, User's and Theory Manuals Version 6.6. Pawtucket: Rhode Island: HKS, 2006.

[48] G. Eastaugh, Multiple site fatigue damage in fuselage skin splices, Master's thesis, Carleton University, 1993.

[49] I. R. McColl, J. Ding, and S. B. Leen, "Finite element simulation and experimental validation of fretting wear," Wear, vol. 256, pp. 1114-1127, 2004. 
[50] G. Li, G. Shi, and N. Bellinger, "Study of the Residual Strain in Lap Joints," Journal of Aircraft, vol. 43, pp. 1145-1151, 2006.

[51] D. Nowell, D. Dini, and D. A. Hills, "Recent developments in the understanding of fretting fatigue," Engineering Fracture Mechanics, vol. 73, pp. 207-222, 2006.

[52] K. N. Smith, P. Watson, and T. H. Topper, "A stress-strain function for the fatigue of metals," J. Mater., vol. 5, pp. 767-778, 1970.

[53] C. Boller and T. Seeger, Materials data for cyclic loading, Part D: Aluminium and Titanium alloys. Amsterdam: Elsevier, 1987. 


\section{Appendix A - Splice Through-thickness Residual Stress}

The full set of plots for residual stresses through the thickness discussed in Chapter 3 is presented here. All of the plots have been obtained from refined axi-symmetric rivet forming simulations of machine countersunk and universal rivet styles. The first set of data is for the NAS1097AD-4-4 rivets in $1 \mathrm{~mm}$ sheet whereas the second set of data is for the MS20470AD-4-4 rivets in $1 \mathrm{~mm}$ sheet. For both cases, four rivet forming loads were simulated $(6.7 \mathrm{kN}, 8.9 \mathrm{kN}, 11.1 \mathrm{kN}$, and 13.3 $\mathrm{kN})$.

The residual stress values were taken from trace lines along the faying, middle, and outer cross sections of the sheets. Data plotted from the trace lines provides a clearer picture of the residual stress values around the formed rivet head. It can be seen in the plots that the amount of compressive residual stresses increases with increasing rivet forming load and that there is a distinct variation in the residual stresses through the sheet thickness. 


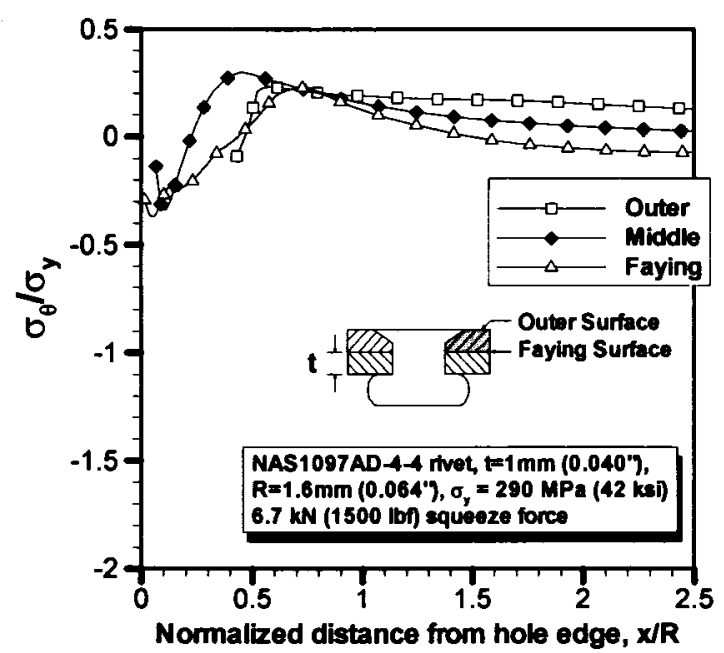

Figure A - 1 Outer sheet residual hoop stress (through thickness). Rivets formed to $6.7 \mathrm{kN}$.

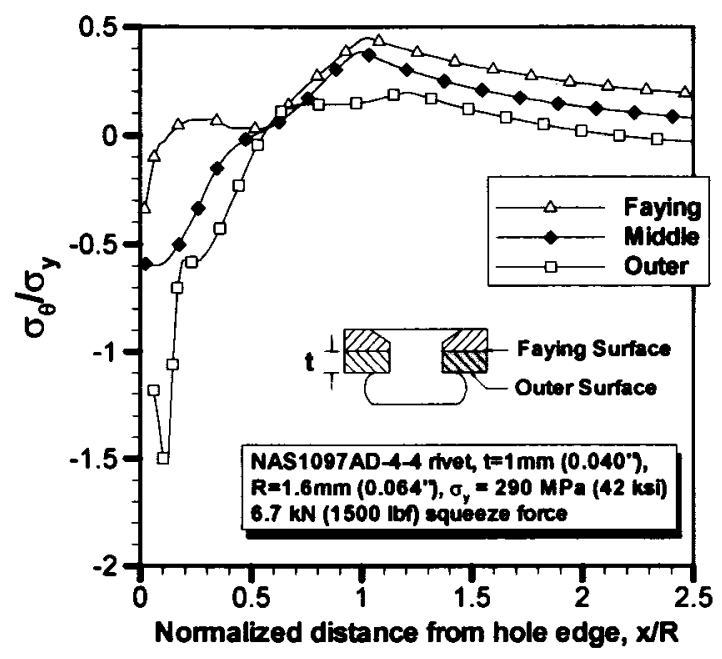

Figure A - 3 Inner sheet residual hoop stress (through thickness). Rivets formed to $6.7 \mathrm{kN}$.

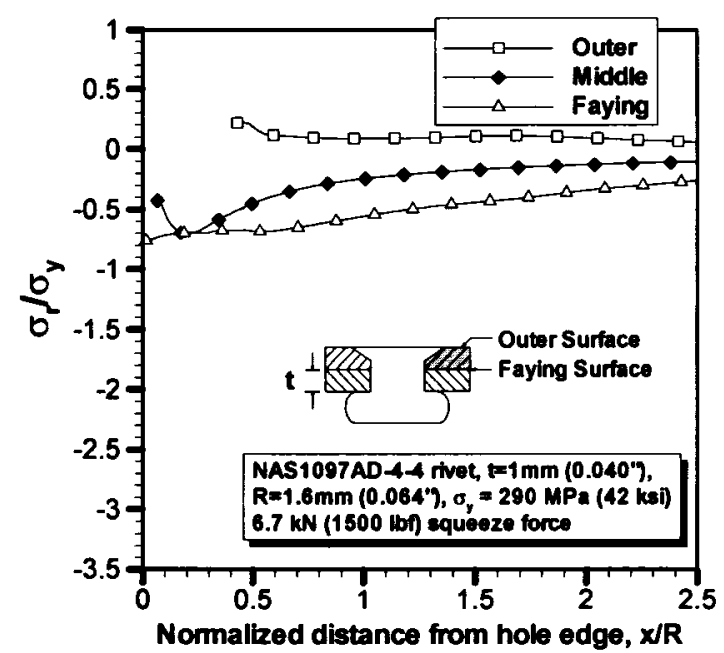

Figure A - 2 Outer sheet residual radial stress (through thickness). Rivets formed to $6.7 \mathrm{kN}$.

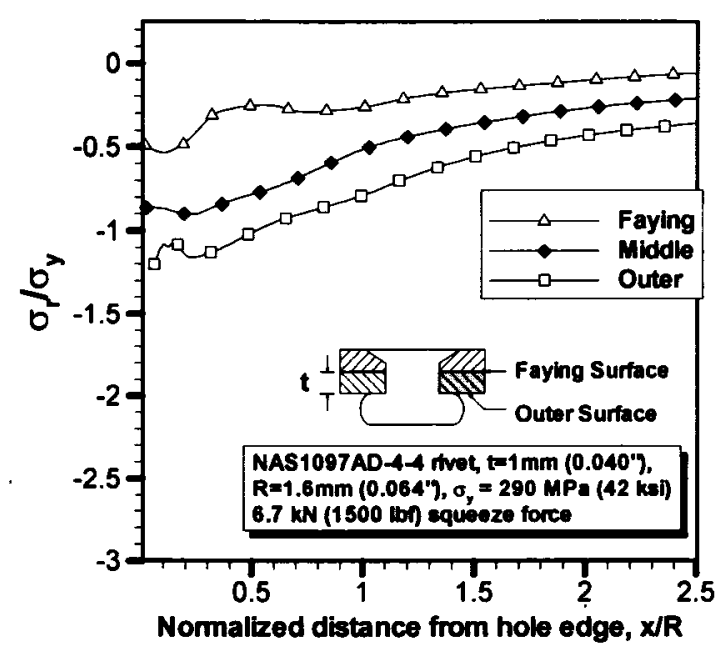

Figure A - 4 Inner sheet residual radial stress (through thickness). Rivets formed to $6.7 \mathrm{kN}$. 


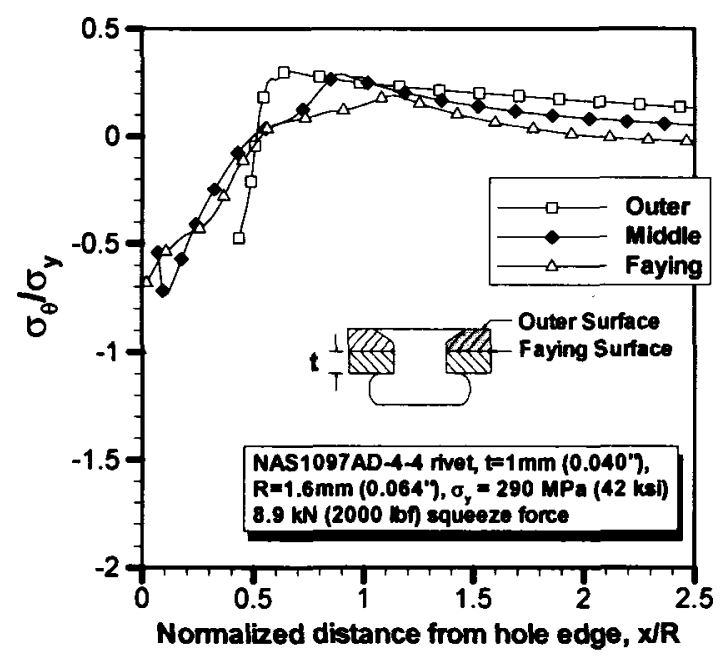

Figure A - 5 Outer sheet residual hoop stress (through thickness). Rivets formed to $8.9 \mathrm{kN}$.

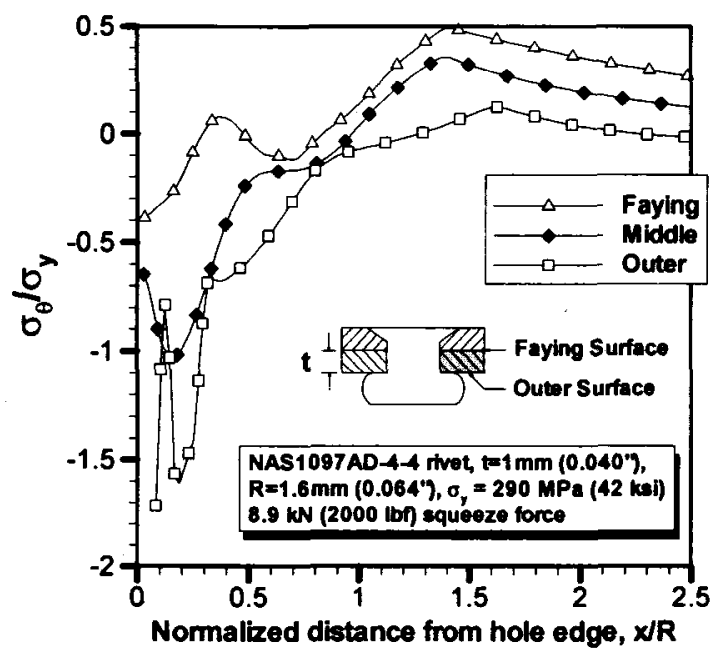

Figure A - 7 Inner sheet residual hoop stress (through thickness). Rivets formed to $8.9 \mathrm{kN}$.

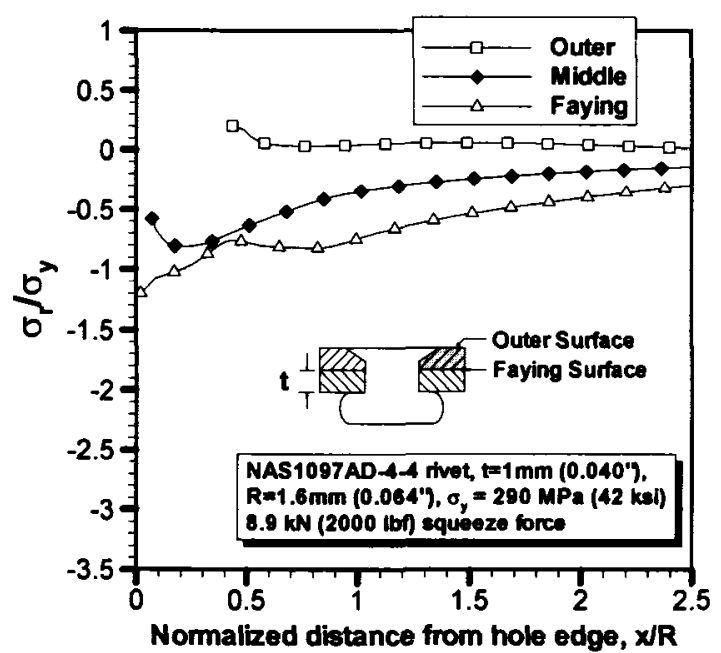

Figure A - 6 Outer sheet residual radial stress (through thickness). Rivets formed to $8.9 \mathrm{kN}$.

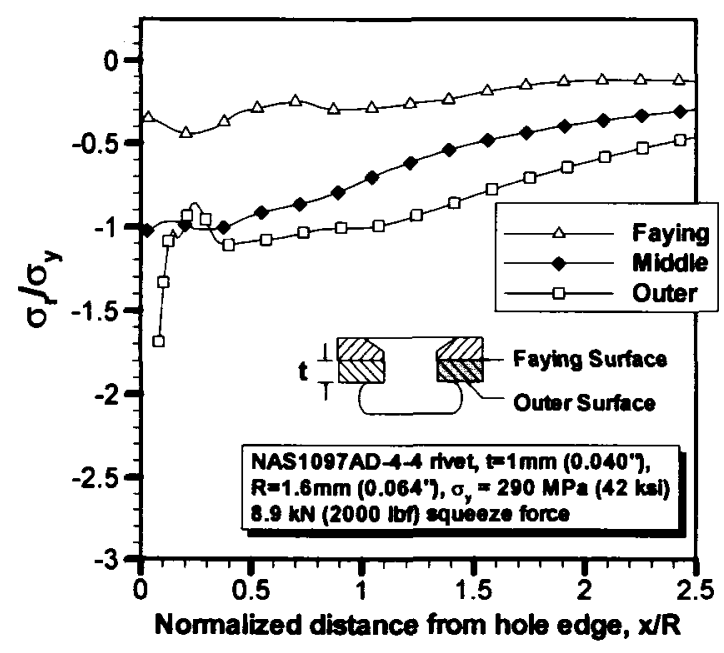

Figure A - 8 Inner sheet residual radial stress (through thickness). Rivets formed to $8.9 \mathrm{kN}$. 


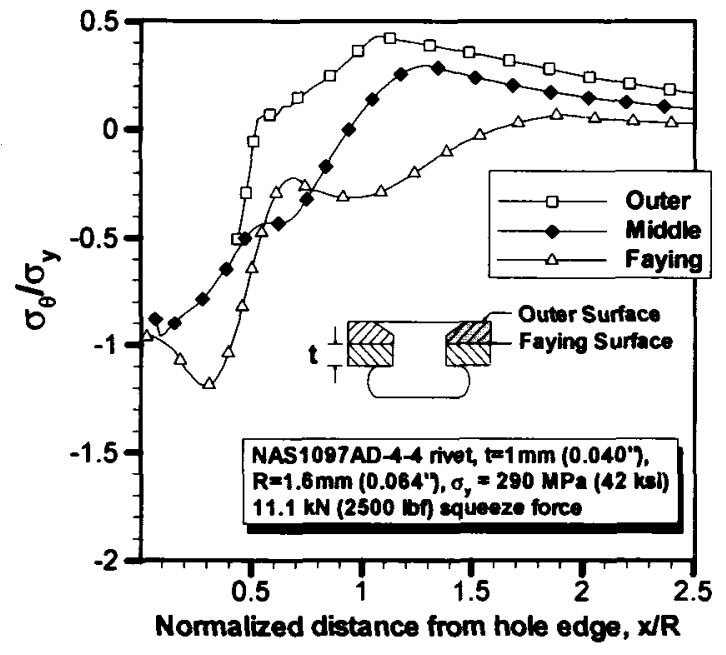

Figure A - 9 Outer sheet residual hoop stress (through thickness). Rivets formed to $11.1 \mathrm{kN}$.

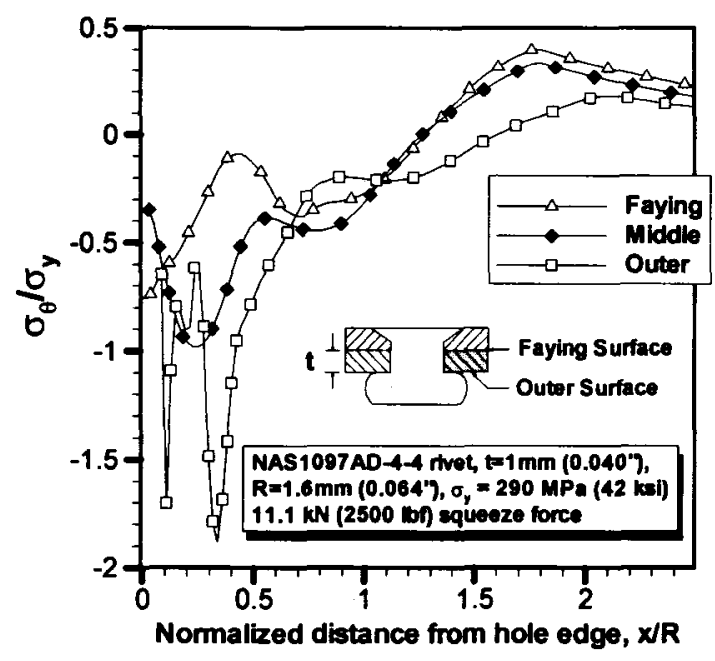

Figure A - 11 Inner sheet residual hoop stress (through thickness). Rivets formed to $11.1 \mathrm{kN}$.

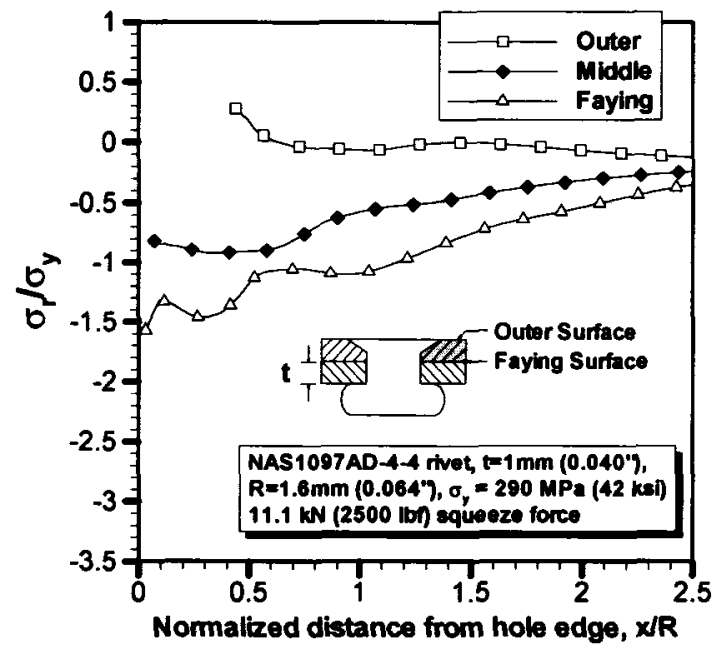

Figure A - 10 Outer sheet residual radial stress (through thickness). Rivets formed to $11.1 \mathrm{kN}$.

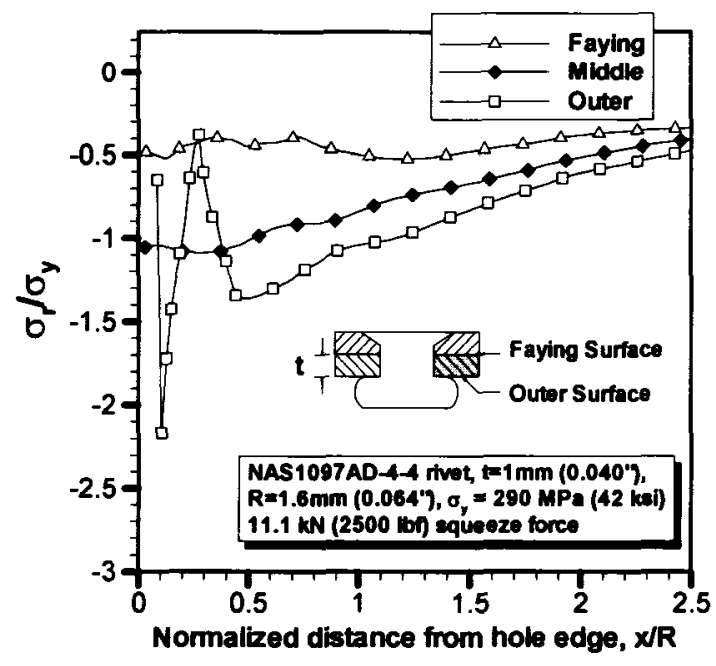

Figure A - 12 Inner sheet residual radial stress (through thickness). Rivets formed to $11.1 \mathrm{kN}$. 


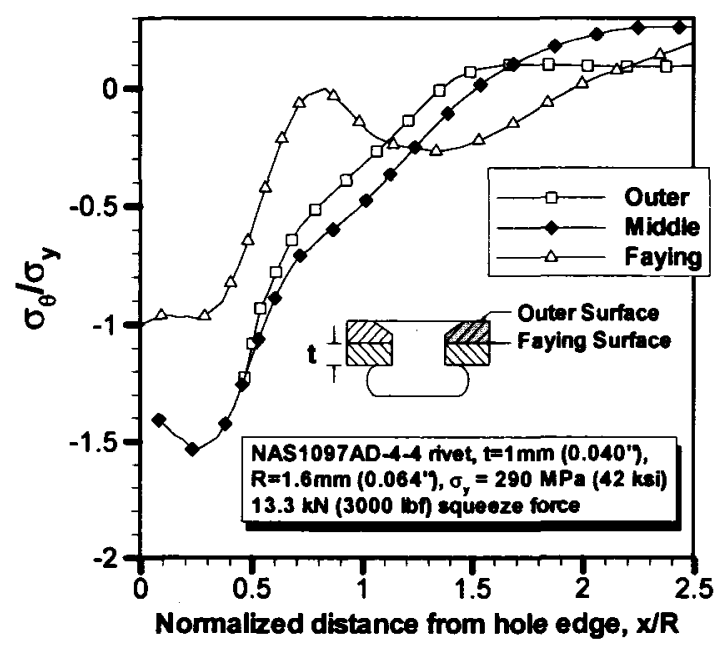

Figure A - 13 Outer sheet residual hoop stress (through thickness). Rivets formed to $13.3 \mathrm{kN}$.

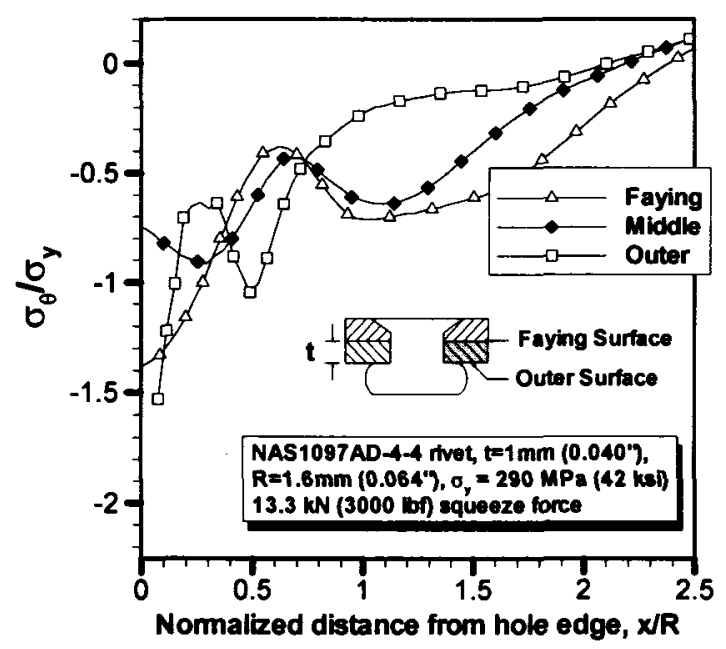

Figure A - 15 Inner sheet residual hoop stress (through thickness). Rivets formed to $13.3 \mathrm{kN}$.

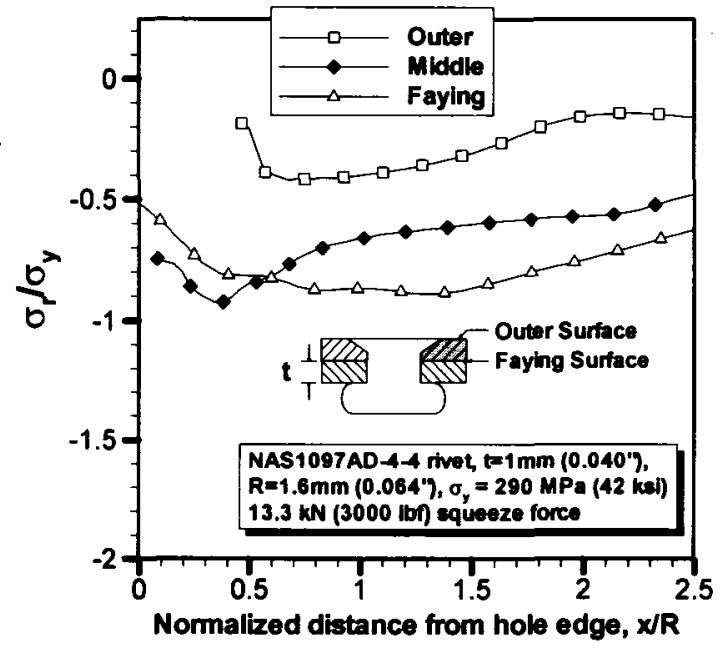

Figure A - 14 Outer sheet residual radial stress (through thickness). Rivets formed to $13.3 \mathrm{kN}$.

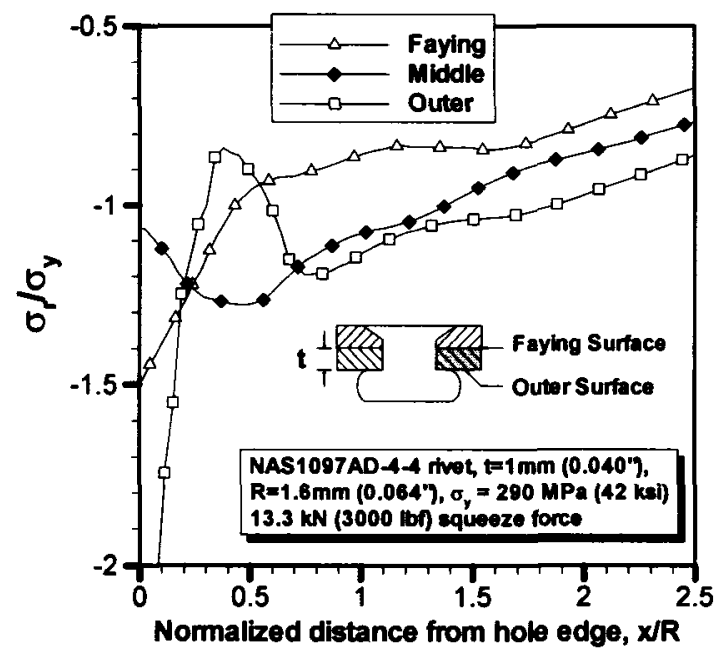

Figure A - 16 Inner sheet residual radial stress (through thickness). Rivets formed to $13.3 \mathrm{kN}$. 


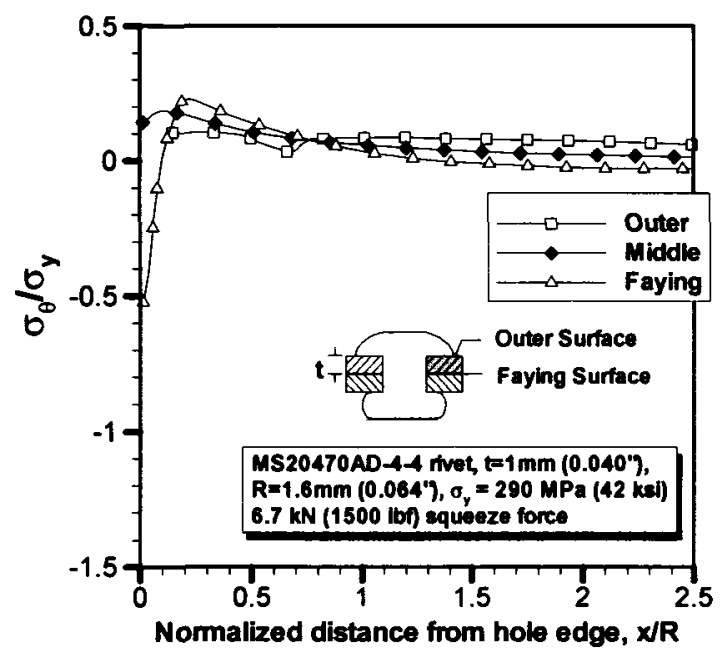

Figure A - 17 Outer sheet residual hoop stress (through thickness). Rivets formed to $6.7 \mathrm{kN}$.

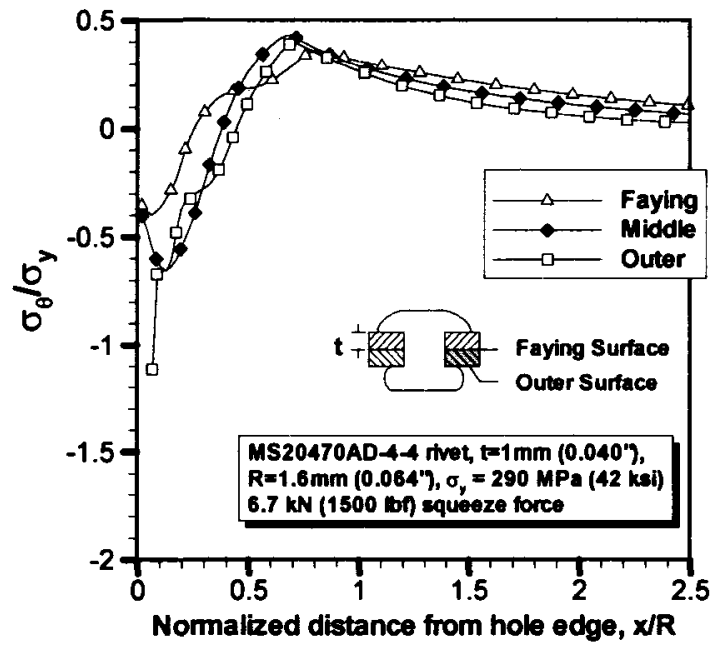

Figure A - 19 Inner sheet residual hoop stress (through thickness). Rivets formed to $6.7 \mathrm{kN}$.

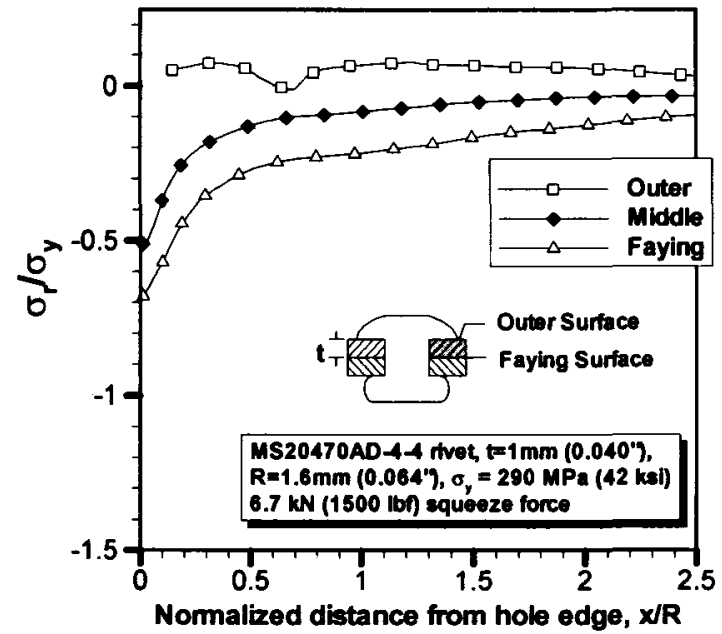

Figure A - 18 Outer sheet residual radial stress (through thickness). Rivets formed to $6.7 \mathrm{kN}$.

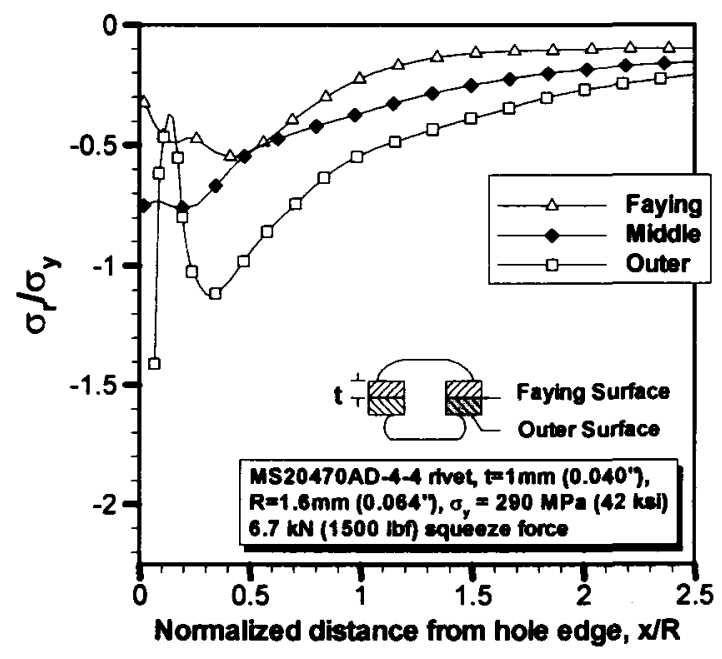

Figure A - 20 Inner sheet residual radial stress (through thickness). Rivets formed to $6.7 \mathrm{kN}$. 


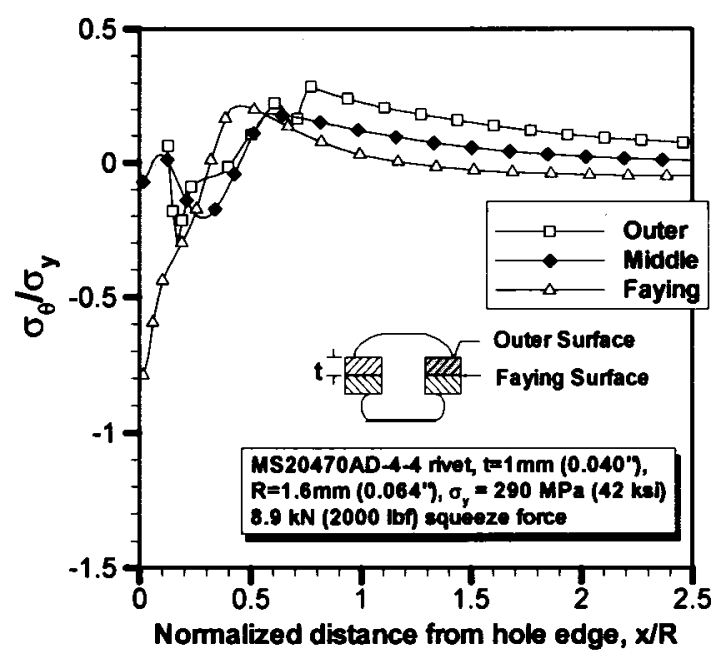

Figure A - 21 Outer sheet residual hoop stress (through thickness). Rivets formed to $8.9 \mathrm{kN}$.

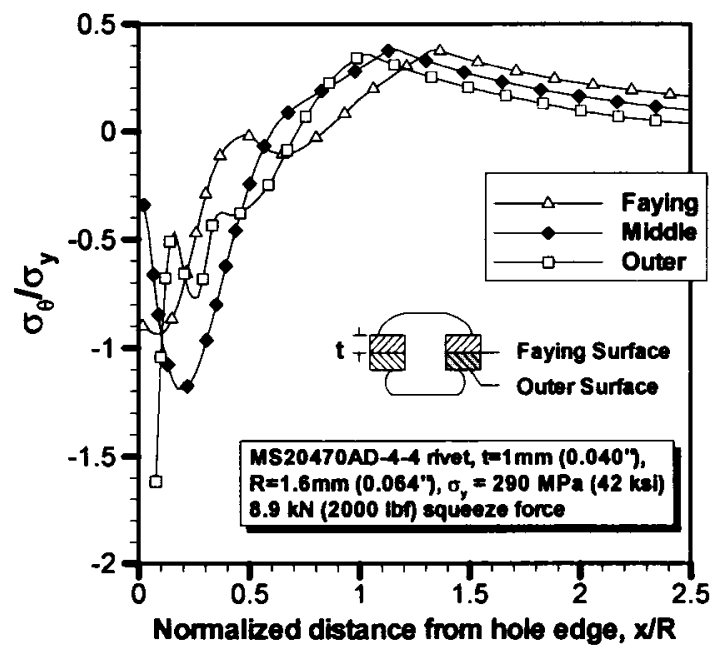

Figure A - 23 Inner sheet residual hoop stress (through thickness). Rivets formed to $8.9 \mathrm{kN}$.

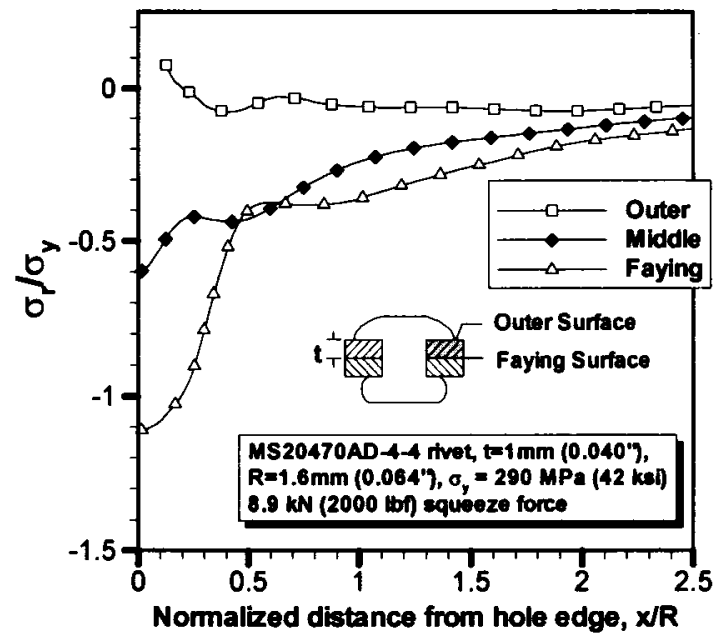

Figure A - 22 Outer sheet residual radial stress (through thickness). Rivets formed to $8.9 \mathrm{kN}$.

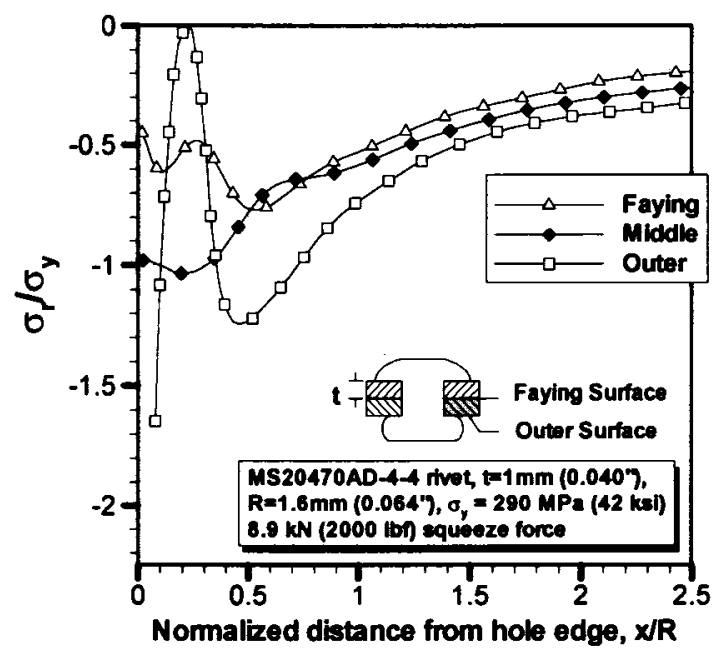

Figure A - 24 Inner sheet residual radial stress (through thickness). Rivets formed to $8.9 \mathrm{kN}$. 


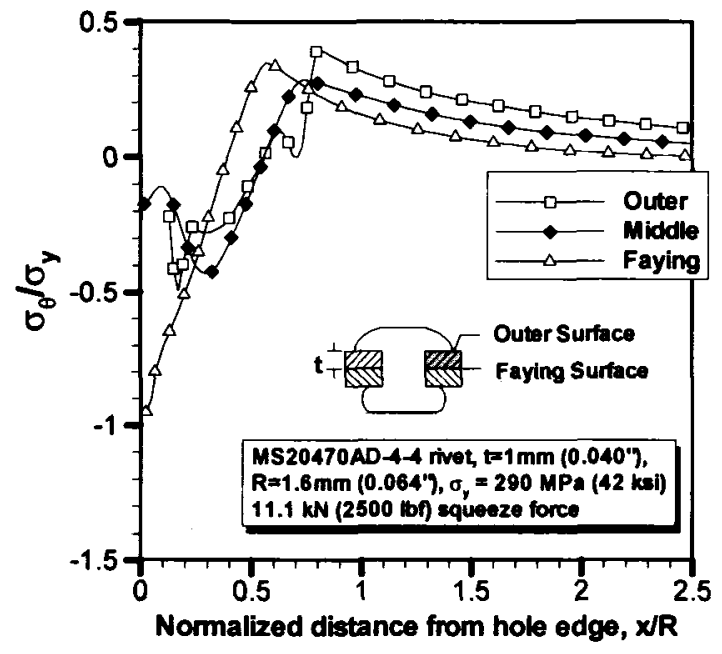

Figure A - 25 Outer sheet residual hoop stress (through thickness). Rivets formed to $11.1 \mathrm{kN}$.

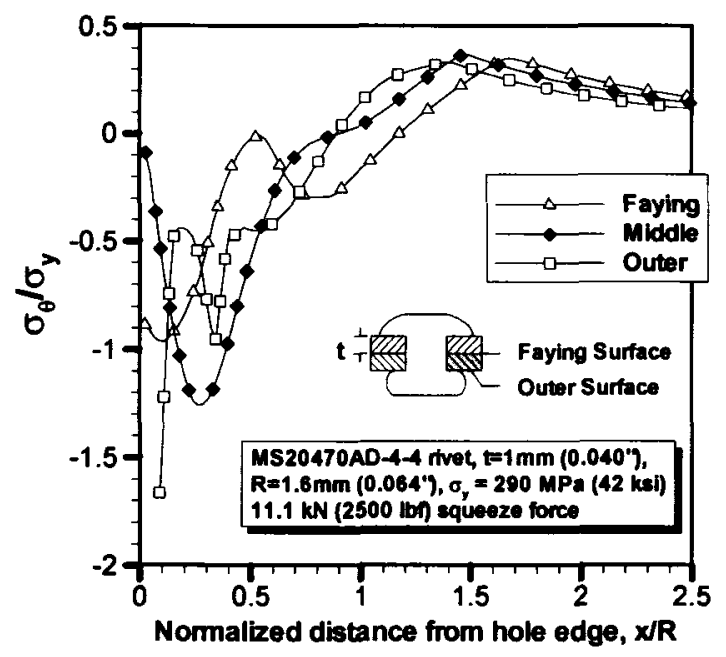

Figure A - 27 Inner sheet residual hoop stress (through thickness). Rivets formed to $11.1 \mathrm{kN}$.

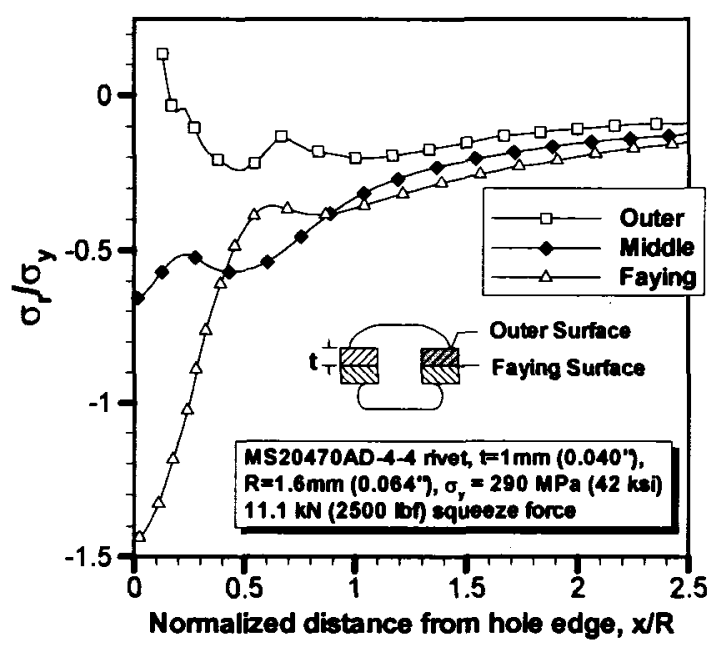

Figure A - 26 Outer sheet residual radial stress (through thickness). Rivets formed to $11.1 \mathrm{kN}$.

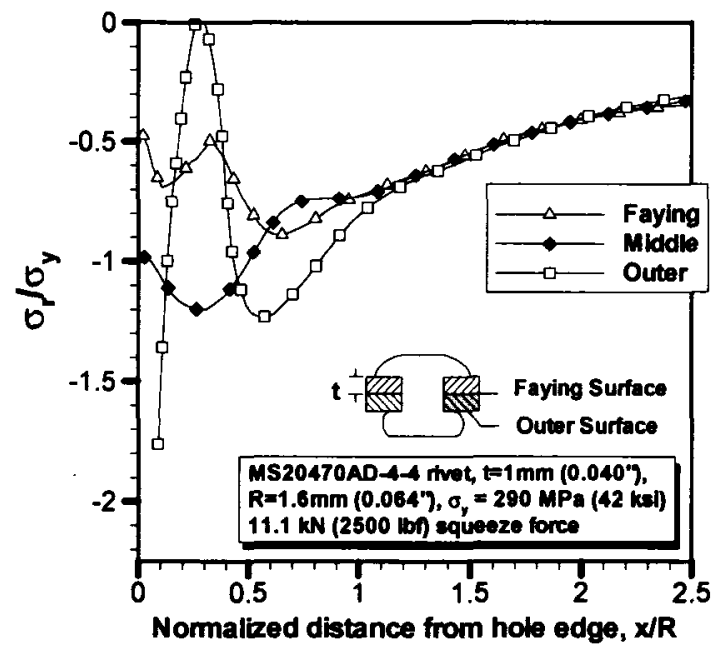

Figure A - 28 Inner sheet residual radial stress (through thickness). Rivets formed to $11.1 \mathrm{kN}$. 


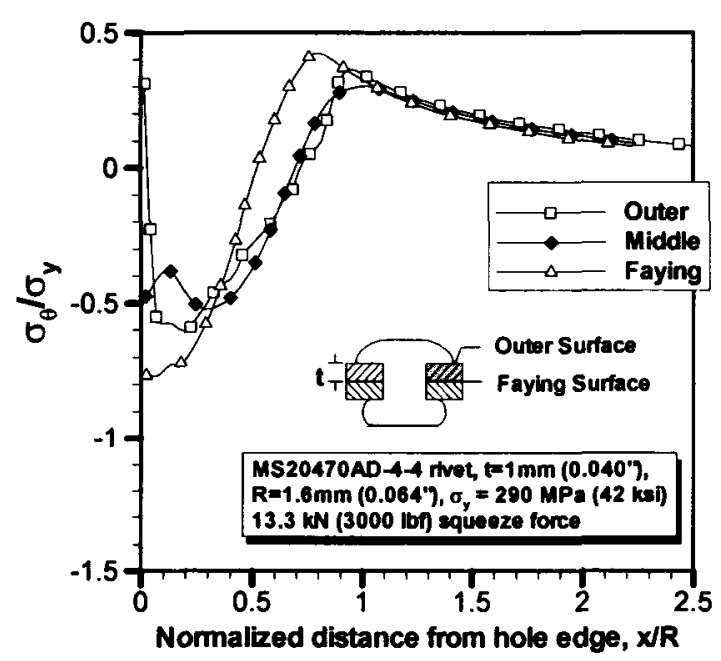

Figure A - 29 Outer sheet residual hoop stress (through thickness). Rivets formed to $13.3 \mathrm{kN}$.

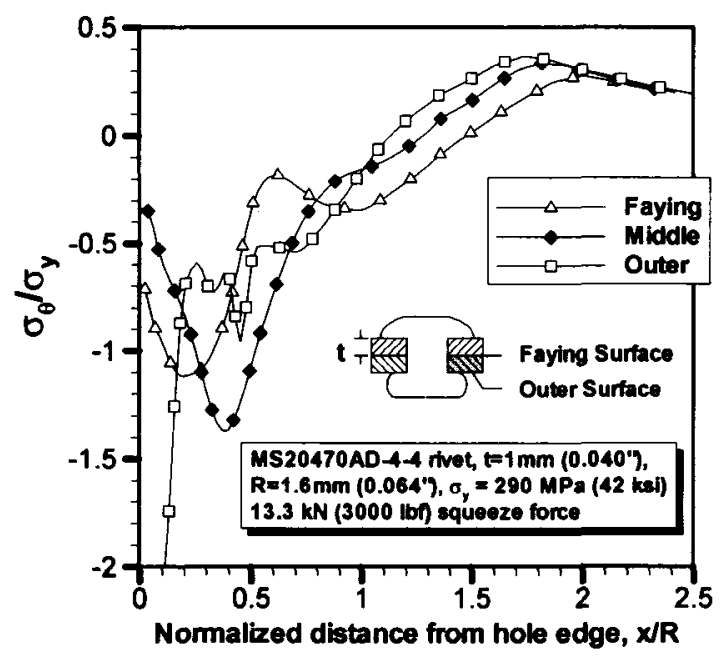

Figure A - 31 Inner sheet residual hoop stress (through thickness). Rivets formed to $13.3 \mathrm{kN}$.

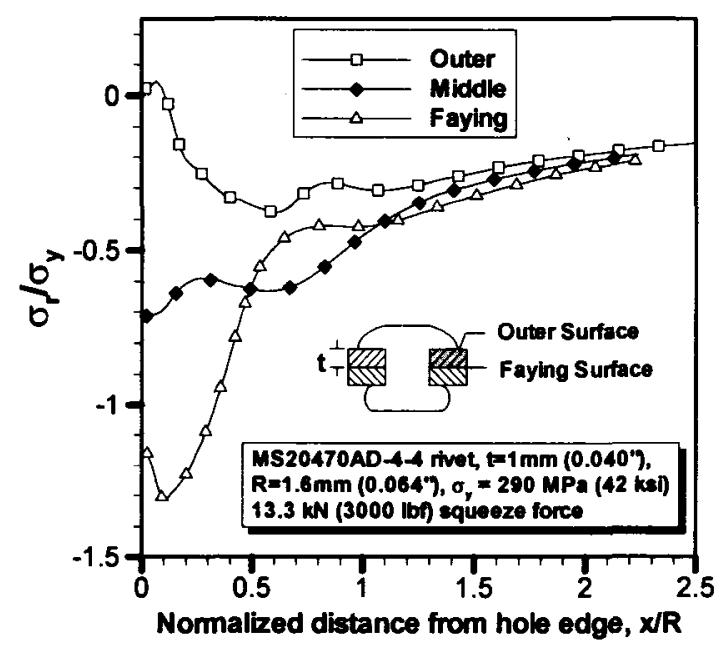

Figure A - 30 Outer sheet residual radial stress (through thickness). Rivets formed to $13.3 \mathrm{kN}$.

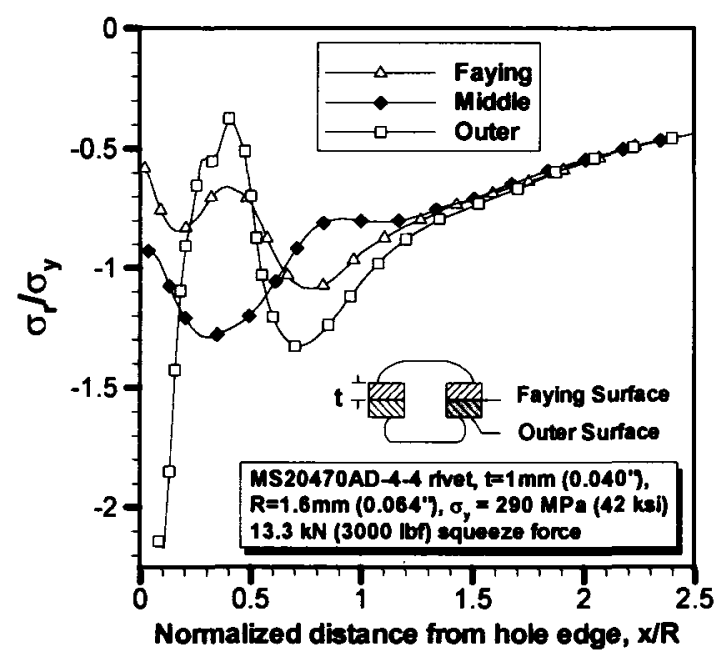

Figure A - 32 Inner sheet residual radial stress (through thickness). Rivets formed to $13.3 \mathrm{kN}$. 


\section{Appendix B - Neutron Diffraction Measurements}

Neutron diffraction measurements of the residual stress field around formed solid rivets were obtained by the National Research Council of Canada. The data was made available as a validation method of the modelling techniques used in this study. It is an indirect validation because the measurements were performed on sheets twice the thickness of the ones used in this work. MS20426AD-8-9 rivets were examined in $2 \mathrm{~mm}$ thick 2024-T3 sheet. The comparisons validate the modelling methodology and parameters used in the $1 \mathrm{~mm}$ thick 2024-T3 splice simulations.

Quarter symmetry 3D solid rivet forming models were created to match the geometry of the test coupons. Two different rivet forming loads $(44.5 \mathrm{kN}, 53.4 \mathrm{kN})$ were simulated and the model results were compared to other FE simulations $[8,50]$ as well as the measurement data. The data from this study is presented as the 3D Abaqus results. Other data is from 3D LS-DYNA simulations performed by Rans [8] and 2D axi-symmetric MSC Marc simulations performed at the National Research Council of Canada [50]. It should be noted that some of the discrepancies in the result comparisons may be due to averaging of the measurements which are taken over a gauge volume of approximately $1 \mathrm{~mm}^{3}$. 


\section{Radial Strains:}

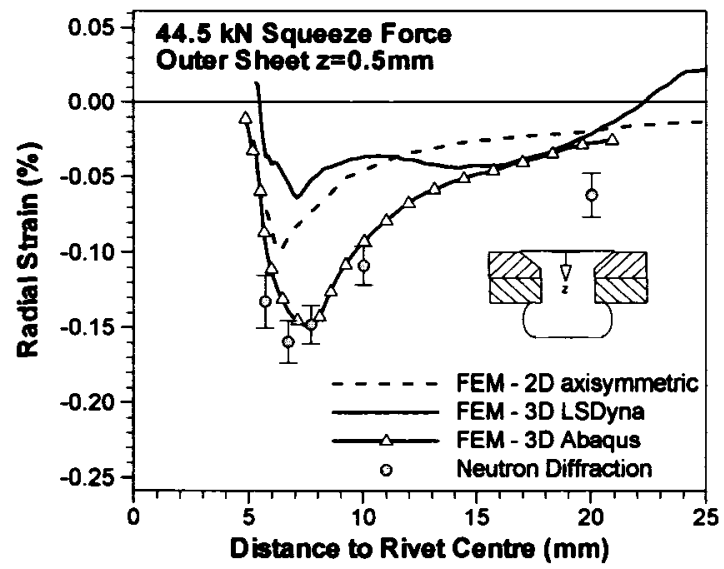

Figure B - 1 Outer sheet residual radial strains. Rivet forming load: $\mathbf{4 4 . 5} \mathrm{kN}$.

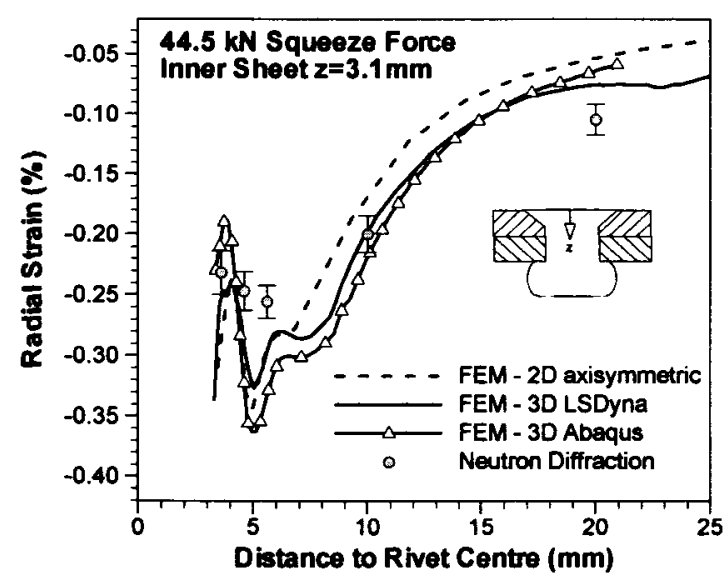

Figure B - 3 Inner sheet residual radial strains. Rivet forming load: $\mathbf{4 4 . 5} \mathrm{kN}$.

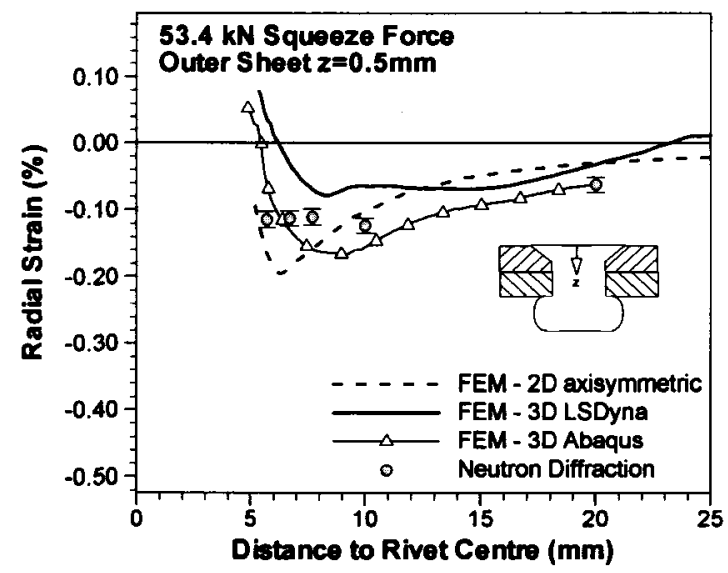

Figure B - 2 Outer sheet residual radial strains. Rivet forming load: $53.4 \mathrm{kN}$.

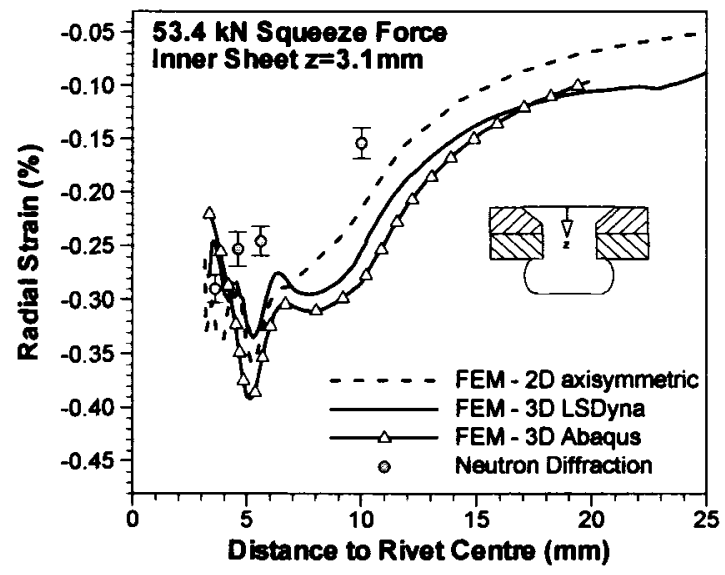

Figure B - 4 Inner sheet residual radial strains. Rivet forming load: $53.4 \mathrm{kN}$. 
Hoop Strains:

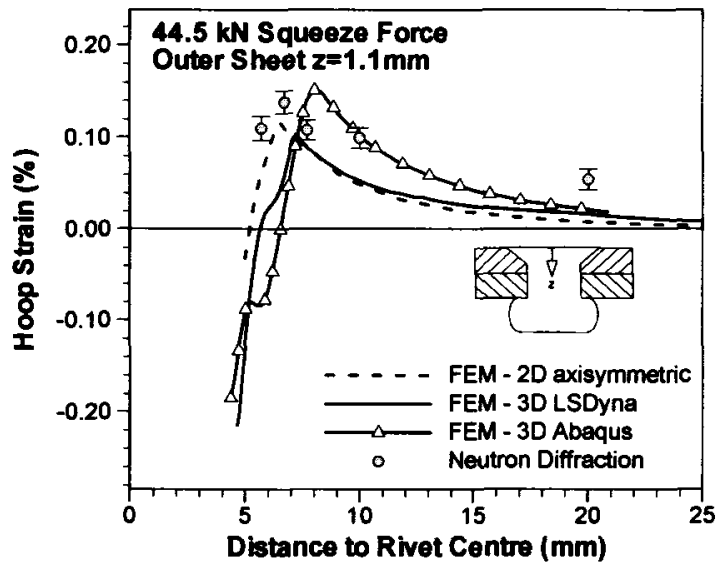

Figure B - 5 Outer sheet residual hoop strains. Rivet forming load: $44.5 \mathrm{kN}$.

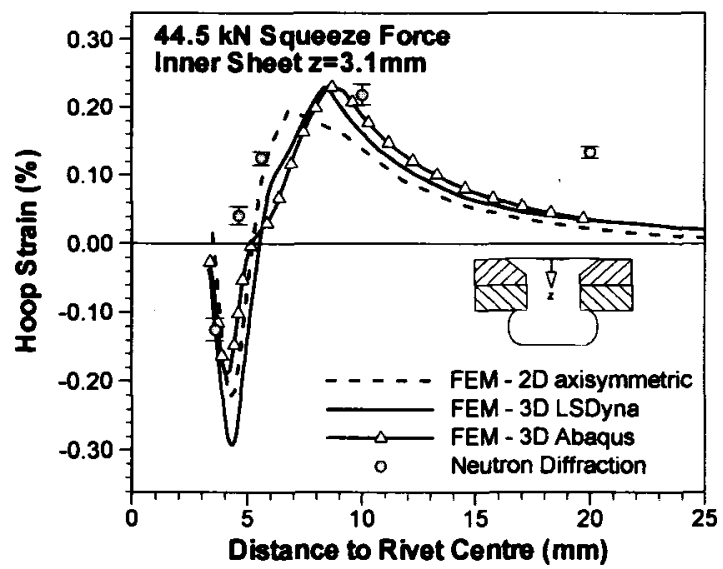

Figure B - 7 Inner sheet residual hoop strains. Rivet forming load: $\mathbf{4 4 . 5} \mathbf{~ k N}$.

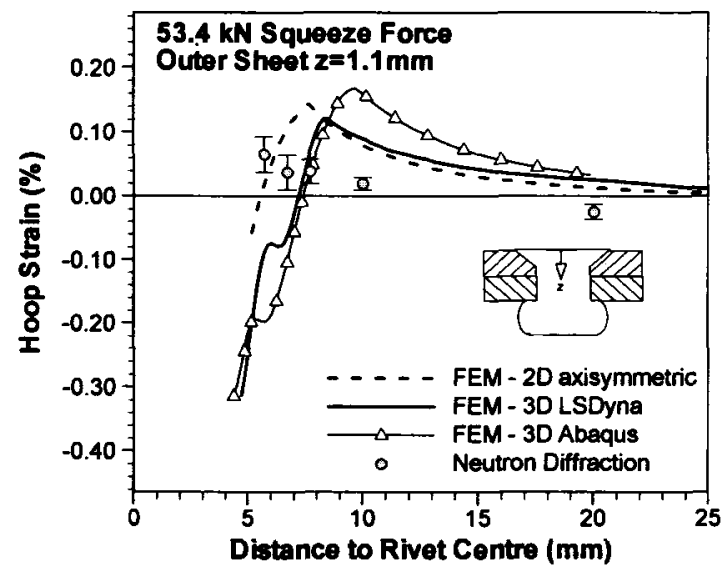

Figure B - 6 Outer sheet residual hoop strains. Rivet forming load: 53.4 kN.

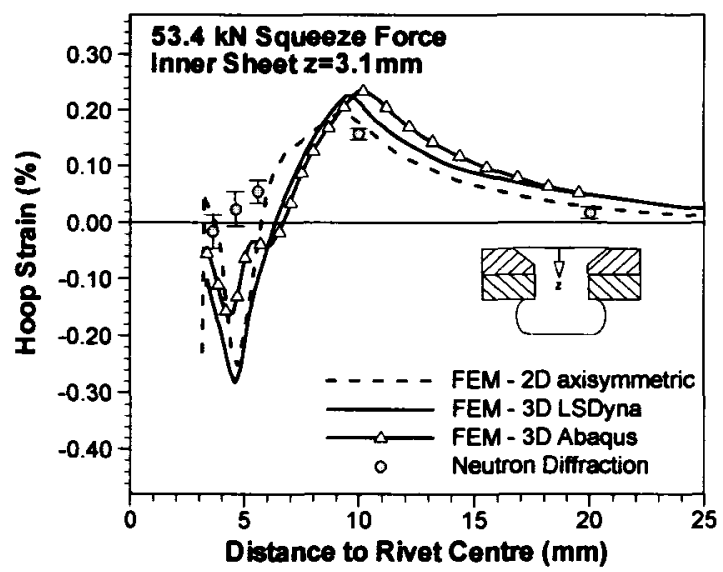

Figure B - 8 Inner sheet residual hoop strains. Rivet forming load: $53.4 \mathrm{kN}$. 
Clamping Strains:

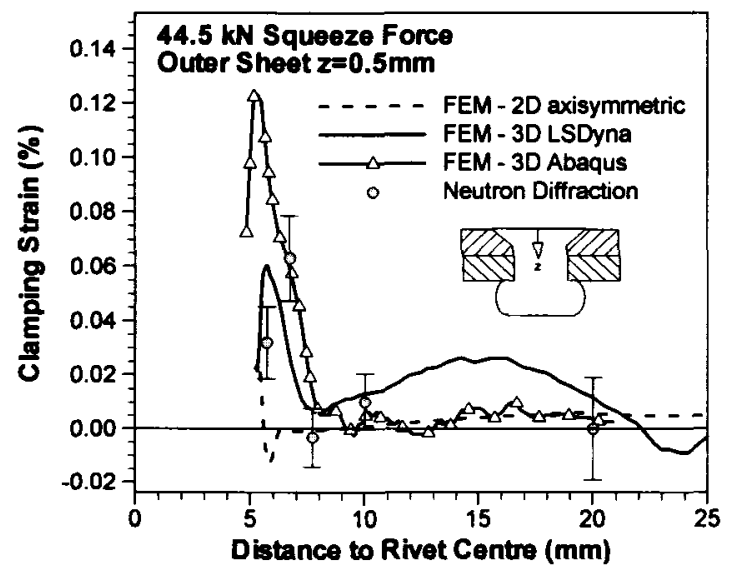

Figure B - 9 Outer sheet residual clamping strains. Rivet forming load: $44.5 \mathrm{kN}$.

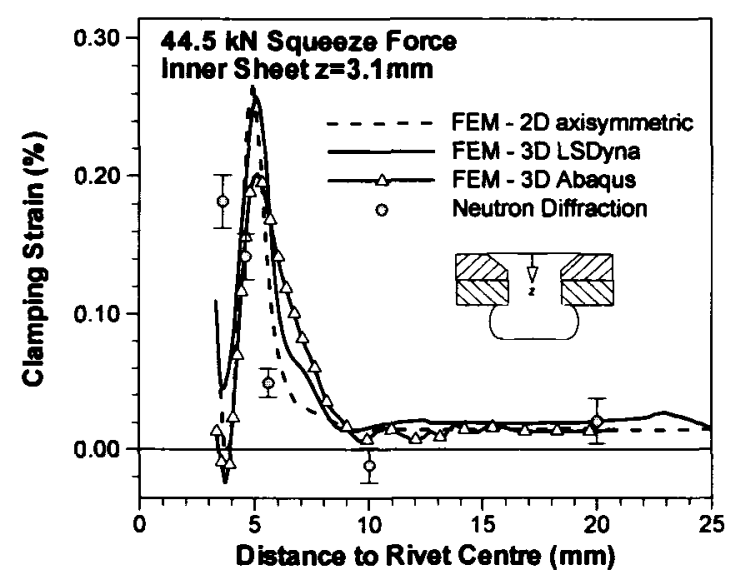

Figure B - 11 Inner sheet residual clamping strains. Rivet forming load: $\mathbf{4 4 . 5} \mathbf{~ k N}$.

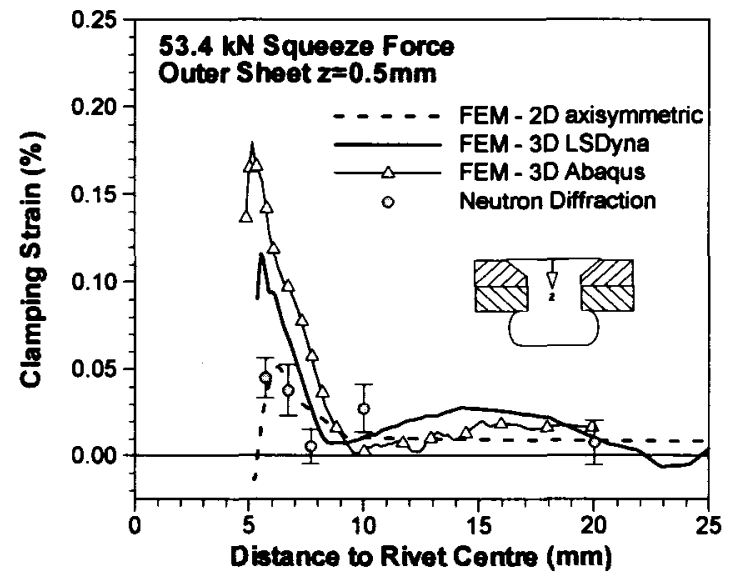

Figure B - 10 Outer sheet residual clamping strains. Rivet forming load: 53.4 kN.

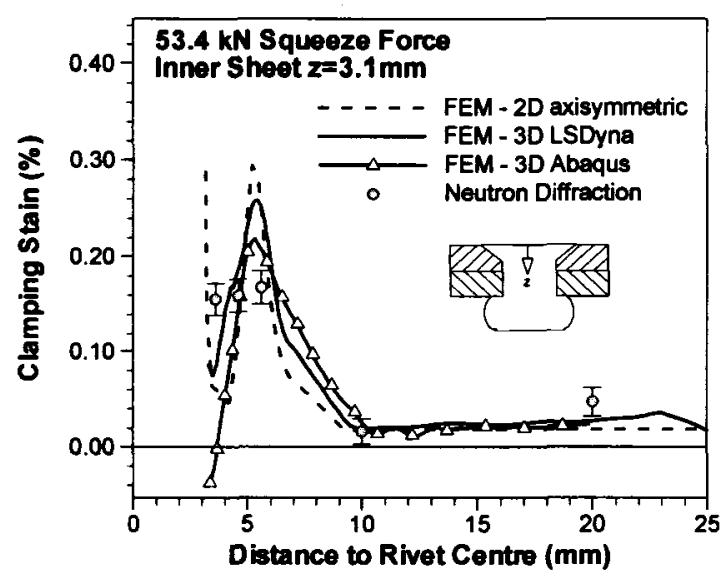

Figure B - 12 Inner sheet residual clamping strains. Rivet forming load: 53.4 kN. 


\section{Appendix C - Matlab Program for Critical Plane SWT Calculations}

Use of the critical plane SWT life prediction parameter involves repetitive calculations to find the critical plane in the material. These calculations must be performed for every node within a finite element simulation to find the global maximum SWT parameter. The Matlab program presented here was written to input stress values from the finite element simulations of Chapter 5 and perform the necessary calculations to find the critical plane SWT parameter at each node. The results from the calculations are then output to a data file that can be used to generate contour plots of the critical plane SWT parameter. The global maximum SWT parameter is then used for the life prediction analysis.

The 3D stress state at each node is input as a matrix and the stress in $\mathrm{x}$-direction is chosen as a normal vector. The matrix is then transformed in increments about the $\mathrm{y}$ and $\mathrm{z}$ axes until the normal vector has traced an entire hemisphere. For each increment, a comparison is made to see if the product of the normal stress and the strain amplitude is larger than the previous increment. In the end, the largest value is kept and the orientation of the plane recorded. 


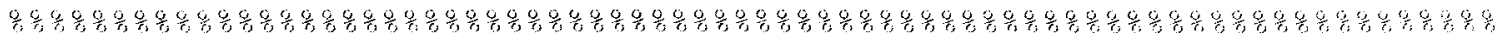
PROGRAM TO CALCULATE CRITICAL PLANE SWT (GAMMA) PARAMETER FOR FEM MODELS

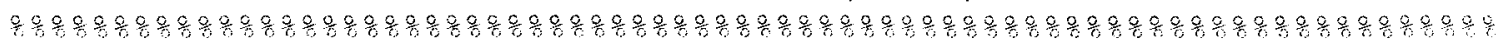
Using the $x$-axis as a normal vector, the program searches a hemisphere for the maximum normal stress multiplied by the strain amplitude. This value, gamma, provides the critical plane on which a crack should nucleate.

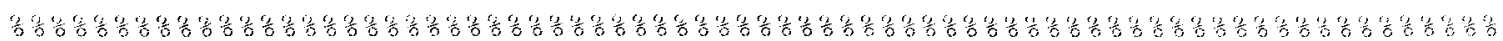
实

UALL ANGLES MUST BE GIVEN IN RADIANS

clear slear memory of previous data

clc

format long

output=fopen ('Gamma Output', 'w');

load b.rpt tmust rename input stress data as "b.rpt" Imports data as one large matrix with the same

load c.rpt name as file name (without the extension).

zinit stress: grust rename input stress data as "c.rpt"

thet $a=0$;

initializing values

phi=0;

sxx_max=0;

$E=10500000 ; \quad$ Foung's modulus for the aluminum $\mathrm{mu}=0.33$; gPoisson's ratio for the aluminum

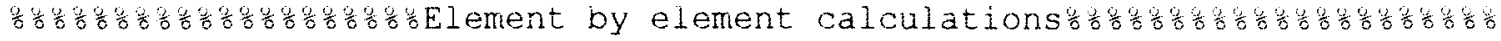
$\mathrm{n}=$ input ( How many lines do the matrices have? -> ")

for $m=1: 1: n$

to $(1,1) \quad(1,2)(1,3)(1,4)(1,5)(1,6)(1,7)$

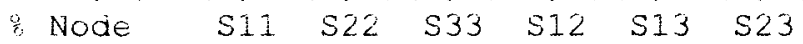

$$
\begin{aligned}
& \mathrm{s}=[\mathrm{b}(\mathrm{m}, 2) \quad b(\mathrm{~m}, 5) \quad b(\mathrm{~m}, 6) ; \quad \text { (11 } 1213 \\
& \mathrm{b}(\mathrm{m}, 5) \quad \mathrm{b}(\mathrm{m}, 3) \mathrm{b}(\mathrm{m}, 7) ; \quad \text { z } 212223 \\
& \mathrm{~b}(\mathrm{~m}, 6) \mathrm{b}(\mathrm{m}, 7) \mathrm{b}(\mathrm{m}, 4)] ; \text {; } 313233)
\end{aligned}
$$

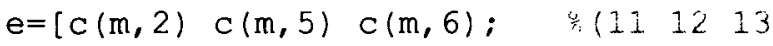

$$
\begin{aligned}
& c(m, 5) \quad c(m, 3) \quad c(m, 7) ; \quad 212223 \\
& c(m, 6) \quad c(m, 7) c(m, 4)] ; \quad 3132 \quad 33)
\end{aligned}
$$

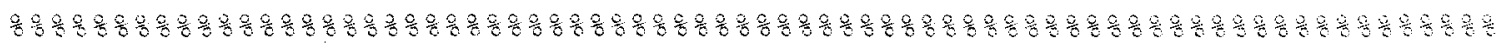

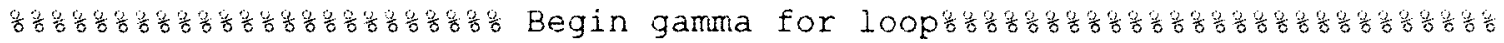

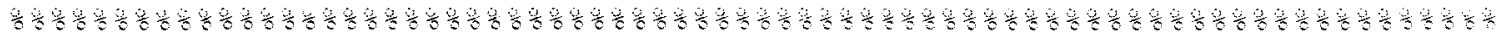
gamma $=0$;

thet a $\max =0$;

phi_max=0;

for phi=0:0.01745:3.14\%Begin calculation for all theta and phi of single elem

for theta $=0.0: 0.01745: 3.14$ SIncrement in RADIANS 
trotation about $y$-axis

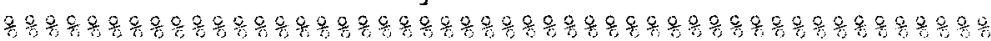

$\mathrm{T} y=\left[\begin{array}{lll}\cos (\text { theta) } & 0 & -\sin (\text { theta); }\end{array}\right.$

$0 \quad 1 \quad 0 ;$

$\sin ($ theta) $0 \quad \cos ($ theta) ] ;

Rotation about z-axis

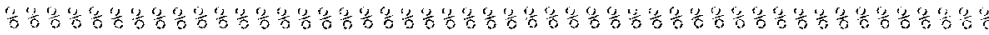

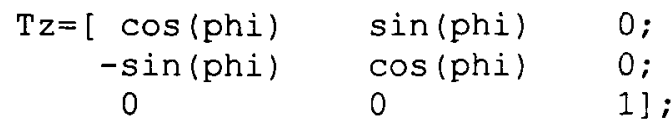

$\mathrm{T}=\mathrm{Ty} \mathrm{T}^{*} \mathrm{~T} ; \quad$ ETransformation matrix

$S l=T^{*} S^{*} T^{\prime} ; \quad$ Calculate the stresses in the new coordinate system

$e l=T^{\star} e^{\star} T^{\prime} ; \quad$ calculate the initial stresses in the new coord system

e init $=\left(1 / E^{\star}\left(e 1(1,1)-m u^{\star} e 1(2,2)-m u^{\star} e 1(3,3)\right)\right) ;$ Calculate the strain from the stresses in the new coordinate system

$\operatorname{exx}=\left(1 / E^{\star}\left(s 1(1,1)-\mathrm{mu}^{\star} s 1(2,2)-\mathrm{mu}^{\star} \mathrm{s} 1(3,3)\right)\right) ;$ falculate the stxain from the stresses in the new coordinate systern

e_amp=exx-e_init;

gamma $1=($ abs $($ e_amp $) / 2) * s 1(1,1)$;

if gammal>gamma skeep track of the largest value for gamma gamma=gamma 1;

theta $\max =$ theta;

end phi $\max =$ phi;

end

end

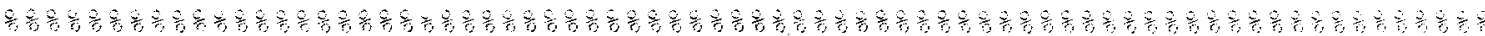

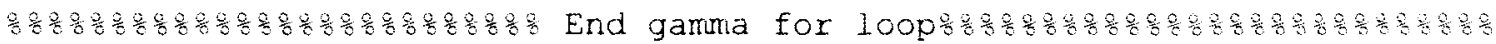

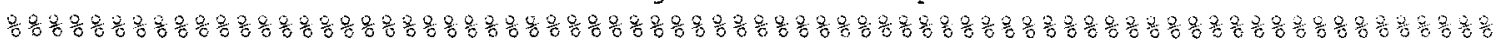
fprintf ('s $\backslash \mathrm{g} \backslash \mathrm{r}, \mathrm{m})$;

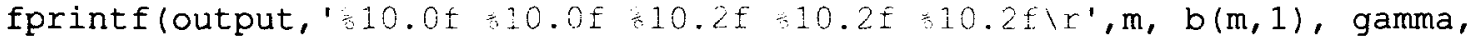
theta_max, phi_max);

Ángles are ir radians

end

fclose (output); 


\section{Appendix D - Fretting Fatigue Data}

The details of the fatigue life data presented in Chapter 5 and Chapter 6 are presented here. Lap splice crack nucleation data, used in Chapter 5, is presented first for bare countersunk and universal splices. Following the splice crack nucleation data is the splice ultimate fatigue life data presented in Chapter 6. The splice data includes the coupon name, cycles to failure, in which sheet failure occurred, and the statistical confidence in the results. Finally, details of the simplified geometry fretting fatigue tests are presented. 


\section{Splice Crack Initiation Data}

\begin{tabular}{|c|c|c|c|c|}
\hline \multicolumn{3}{|c|}{ Machine Countersunk Bare } & \multicolumn{2}{|c|}{79 MPa (11.5 ksi) } \\
\hline Coupon Name & $\begin{array}{l}\text { Cycles to } \\
\text { Initiation }\end{array}$ & $\begin{array}{c}\text { Initiation } \\
\text { Average }\end{array}$ & Std. Dev. & $90 \%$ Conf. $( \pm)$ \\
\hline NAS_Bare_15_1 & 200000 & \multirow{4}{*}{166250} & \multirow{4}{*}{26887} & \multirow{4}{*}{31638} \\
\hline NAS_Bare_15_2 & 170000 & & & \\
\hline NAS_Bare_15_3 & 160000 & & & \\
\hline NAS_Bare_15_4 & 135000 & & & \\
\hline NAS_Bare_20_1 & 185000 & \multirow{4}{*}{217500} & \multirow{4}{*}{25981} & \multirow{4}{*}{30571} \\
\hline NAS_Bare_20_2 & 230000 & & & \\
\hline NAS_Bare_20_3 & 245000 & & & \\
\hline NAS_Bare_20_4 & 210000 & & & \\
\hline NAS_Bare_25_1 & 370000 & \multirow{4}{*}{410000} & \multirow{4}{*}{33665} & \multirow{4}{*}{39613} \\
\hline NAS_Bare_25_2 & 420000 & & & \\
\hline NAS_Bare_25_3 & 450000 & & & \\
\hline NAS_Bare_25_4 & 400000 & & & \\
\hline NAS_Bare_30_1 & 1420000 & \multirow{4}{*}{1267500} & \multirow{4}{*}{130735} & \multirow{4}{*}{153834} \\
\hline NAS_Bare_30_3 & 1110000 & & & \\
\hline NAS_Bare_30_4 & 1230000 & & & \\
\hline NAS_Bare_30_5 & 1310000 & & & \\
\hline \multicolumn{3}{|l|}{ Universal Bare } & \multicolumn{2}{|c|}{$100 \mathrm{MPa}(14.5 \mathrm{ksi})$} \\
\hline & Cycles to & Initiation & & \\
\hline Coupon Name & Initiation & Average & Std. Dev. & $90 \%$ Conf. $( \pm)$ \\
\hline Univ_Bare_15_1 & 120000 & \multirow{4}{*}{106250} & \multirow{4}{*}{22867} & \multirow{4}{*}{26908} \\
\hline Univ_Bare_15_2 & 80000 & & & \\
\hline Univ_Bare_15_3 & 130000 & & & \\
\hline Univ_Bare_15_4 & 95000 & & & \\
\hline Univ_Bare_20_1 & 245000 & \multirow{4}{*}{283750} & \multirow{4}{*}{30923} & \multirow{4}{*}{36387} \\
\hline Univ_Bare_20_2 & 290000 & & & \\
\hline Univ_Bare_20_3 & 320000 & & & \\
\hline Univ_Bare_20_4 & 280000 & & & \\
\hline
\end{tabular}


Univ_Bare_25_1

Univ_Bare_25_2

Univ_Bare_25_3

Univ_Bare_25_4

Univ_Bare_30_1

Univ_Bare_30_2

Univ_Bare_30_3

Univ_Bare_30_4
480000

470000

440000

470000

21602

25419

490000

660000

600000

560000

$585000 \quad 59722$

70273

\section{Splice Fatigue Data}

\begin{tabular}{|c|c|c|c|c|c|}
\hline \multicolumn{3}{|c|}{ Machine Countersunk Bare } & \multicolumn{3}{|c|}{79 MPa (11.5 ksi) } \\
\hline & Cycles to & \multirow{2}{*}{$\begin{array}{c}\text { Sheet } \\
\text { Failure }\end{array}$} & \multirow{2}{*}{$\begin{array}{c}\text { Splice } \\
\text { Average }\end{array}$} & \multirow[b]{2}{*}{ Std. Dev. } & \multirow[b]{2}{*}{$90 \%$ Conf. $( \pm)$} \\
\hline Coupon Name & Coupon Failure & & & & \\
\hline NAS_Bare_15_1 & 253347 & Outer & \multirow{4}{*}{205171} & \multirow{4}{*}{35296} & \multirow{4}{*}{41532} \\
\hline NAS_Bare_15_2 & 202322 & Outer & & & \\
\hline NAS_Bare_15_3 & 196313 & Outer & & & \\
\hline NAS_Bare_15_4 & 168703 & Outer & & & \\
\hline NAS_Bare_20_1 & 293620 & Outer & \multirow{4}{*}{338254} & \multirow{4}{*}{38962} & \multirow{4}{*}{45846} \\
\hline NAS_Bare_20_2 & 340146 & Outer & & & \\
\hline NAS_Bare_20_3 & 388303 & Outer & & & \\
\hline NAS_Bare_20_4 & 330948 & Outer & & & \\
\hline NAS_Bare_25_1 & 482298 & Outer & \multirow{4}{*}{537232} & \multirow{4}{*}{41477} & \multirow{4}{*}{48806} \\
\hline NAS_Bare_25_2 & 545576 & Outer & & & \\
\hline NAS_Bare_25_3 & 582758 & Outer & & & \\
\hline NAS_Bare_25_4 & 538294 & Outer & & & \\
\hline NAS_Bare_30_1 & 1541571 & Outer & \multirow{4}{*}{1389684} & \multirow{4}{*}{130585} & \multirow{4}{*}{153657} \\
\hline NAS_Bare_30_2 & 1234224 & Outer & & & \\
\hline NAS_Bare_30_3 & 1347235 & Outer & & & \\
\hline NAS_Bare_30_4 & 1435707 & Outer & & & \\
\hline
\end{tabular}




\begin{tabular}{|c|c|c|c|c|c|}
\hline \multicolumn{3}{|c|}{ Machine Countersunk Alclad } & \multicolumn{3}{|c|}{$79 \mathrm{MPa}$ (11.5 ksi) } \\
\hline & Cycles to & Sheet & Splice & Std Dav & $00 \%$ Conf $(+)$ \\
\hline Coupon Name & Coupon railure & Failure & & Sta. Dev. & $90 \%$ Coni. ( $( \pm)$ \\
\hline NAS_Clad_15_1 & 143454 & Outer & & & \\
\hline NAS_Clad_15_2 & 187820 & Outer & 150471 & 20103 & 23760 \\
\hline NAS_Clad_15_3 & 146711 & Outer & 10841 & 20170 & 25100 \\
\hline NAS_Clad_15_4 & 159900 & Outer & & & \\
\hline NAS_Clad_20_1 & 320772 & Outer & & & \\
\hline NAS_Clad_20_2 & 255109 & Outer & 280712 & 20057 & 24100 \\
\hline NAS_Clad_20_3 & 277983 & Outer & 209712 & 29007 & 34170 \\
\hline NAS_Clad_20_4 & 304983 & Outer & & & \\
\hline NAS_Clad_25_1 & 572592 & Outer & & & \\
\hline NAS_Clad_25_2 & 541436 & Outer & 572570 & 27273 & 32092 \\
\hline NAS_Clad_25_3 & 568399 & Outer & & & \\
\hline NAS_Clad_25_4 & 607851 & Outer & & & \\
\hline NAS_Clad_30_1 & 1344027 & Outer & & & \\
\hline NAS_Clad_30_2 & 1247120 & Inner & 1362556 & 147741 & 173844 \\
\hline NAS_Clad_30_3 & 1575894 & Inner & & & \\
\hline NAS_Clad_30_4 & 1283184 & Inner & & & \\
\hline
\end{tabular}

Machine Countersunk Anod Cycles to Sheet Splice

Coupon Name Coupon Failure Failure Average Std. Dev. 90\% Conf. $( \pm)$

\begin{tabular}{|c|c|c|c|c|c|}
\hline NAS_Anod_15_1 & 231892 & Outer & \multirow{4}{*}{182945} & \multirow{4}{*}{40260} & \multirow{4}{*}{47374} \\
\hline NAS_Anod_15_2 & 147423 & Outer & & & \\
\hline NAS_Anod_15_3 & 199843 & Outer & & & \\
\hline NAS_Anod_15_4 & 152621 & Outer & & & \\
\hline NAS_Anod_20_1 & 393938 & Outer & \multirow{4}{*}{426357} & \multirow{4}{*}{59837} & \multirow{4}{*}{70409} \\
\hline NAS_Anod_20_2 & 376095 & Outer & & & \\
\hline NAS_Anod_20_3 & 424419 & Outer & & & \\
\hline NAS_Anod_20_4 & 510975 & Outer & & & \\
\hline NAS_Anod_25_1 & 1616595 & Outer & \multirow{2}{*}{1334310} & \multirow{2}{*}{203164} & \multirow{2}{*}{239060} \\
\hline NAS_Anod_25_2 & 1265482 & Outer & & & \\
\hline
\end{tabular}




$\begin{array}{llllll}\text { NAS_Anod_25_3 } & 1136414 & \text { Outer } & & \\ \text { NAS_Anod_25_4 } & 1318747 & \text { Outer } & & \\ & & & & \\ \text { NAS_Anod_30_1 } & 2721725 & \text { Outer } & & \\ \text { NAS_Anod_30_2 } & 2381704 & \text { Outer } & 2539118 & 254823 & 299845 \\ \text { NAS_Anod_30_3 } & 2265407 & \text { Outer } & & \\ \text { NAS_Anod_30_4 } & 2787637 & \text { Outer } & & & \end{array}$

\section{Machine Countersunk Bare}

Cycles to

Coupon Name Coupon Failure
$88 \mathrm{MPa}$ (12.8 ksi)

Sheet Splice

Failure Average Std Dev $90 \%$ Conf. ( \pm )

\begin{tabular}{|c|c|c|c|c|c|}
\hline NAS_Bare_15_1H & 102854 & Outer & \multirow{4}{*}{121036} & \multirow{4}{*}{17563} & \multirow{4}{*}{20667} \\
\hline NAS_Bare_15_2H & 139080 & Outer & & & \\
\hline NAS_Bare_15_3H & 109503 & Outer & & & \\
\hline NAS_Bare_15_4H & 132708 & Outer & & & \\
\hline NAS_Bare_20_1H & 246931 & Outer & \multirow{4}{*}{177898} & \multirow{4}{*}{54236} & \multirow{4}{*}{63818} \\
\hline NAS_Bare_20_2H & 121196 & Outer & & & \\
\hline NAS_Bare_20_3H & 152138 & Outer & & & \\
\hline NAS_Bare_20_4H & 191326 & Outer & & & \\
\hline NAS_Bare_25_1H & 524417 & Outer & \multirow{4}{*}{467846} & \multirow{4}{*}{81222} & \multirow{4}{*}{95572} \\
\hline NAS_Bare_25_2H & 544608 & Outer & & & \\
\hline NAS_Bare_25_3H & 431257 & Outer & & & \\
\hline NAS_Bare_25_4H & 371101 & Outer & & & \\
\hline NAS_Bare_30_1H & 1182129 & Outer & \multirow{4}{*}{1047954} & \multirow{4}{*}{187874} & \multirow{4}{*}{221068} \\
\hline NAS_Bare_30_2H & 863698 & Outer & & & \\
\hline NAS_Bare_30_3H & 910694 & Outer & & & \\
\hline NAS_Bare_30_4H & 1235295 & Outer & & & \\
\hline
\end{tabular}

\begin{tabular}{|c|c|c|c|c|c|}
\hline \multirow{2}{*}{$\begin{array}{c}\text { Universal Bare } \\
\text { Coupon Name } \\
\end{array}$} & \multirow[b]{2}{*}{$\begin{array}{c}\text { Cycles to } \\
\text { Coupon Failure }\end{array}$} & \multirow[b]{2}{*}{$\begin{array}{l}\text { Sheet } \\
\text { Failure }\end{array}$} & \multicolumn{2}{|c|}{$100 \mathrm{MPa}(14.5 \mathrm{ksi})$} & \multirow[b]{2}{*}{$90 \%$ Conf. $( \pm)$} \\
\hline & & & $\begin{array}{c}\text { Splice } \\
\text { Average }\end{array}$ & Std. Dev. & \\
\hline Univ_Bare_15_1 & 176678 & Inner & & & \\
\hline Univ_Bare_15_2 & 149497 & Inner & 169216 & 16214 & 19079 \\
\hline Univ_Bare_15_3 & 186943 & Outer & & & \\
\hline
\end{tabular}




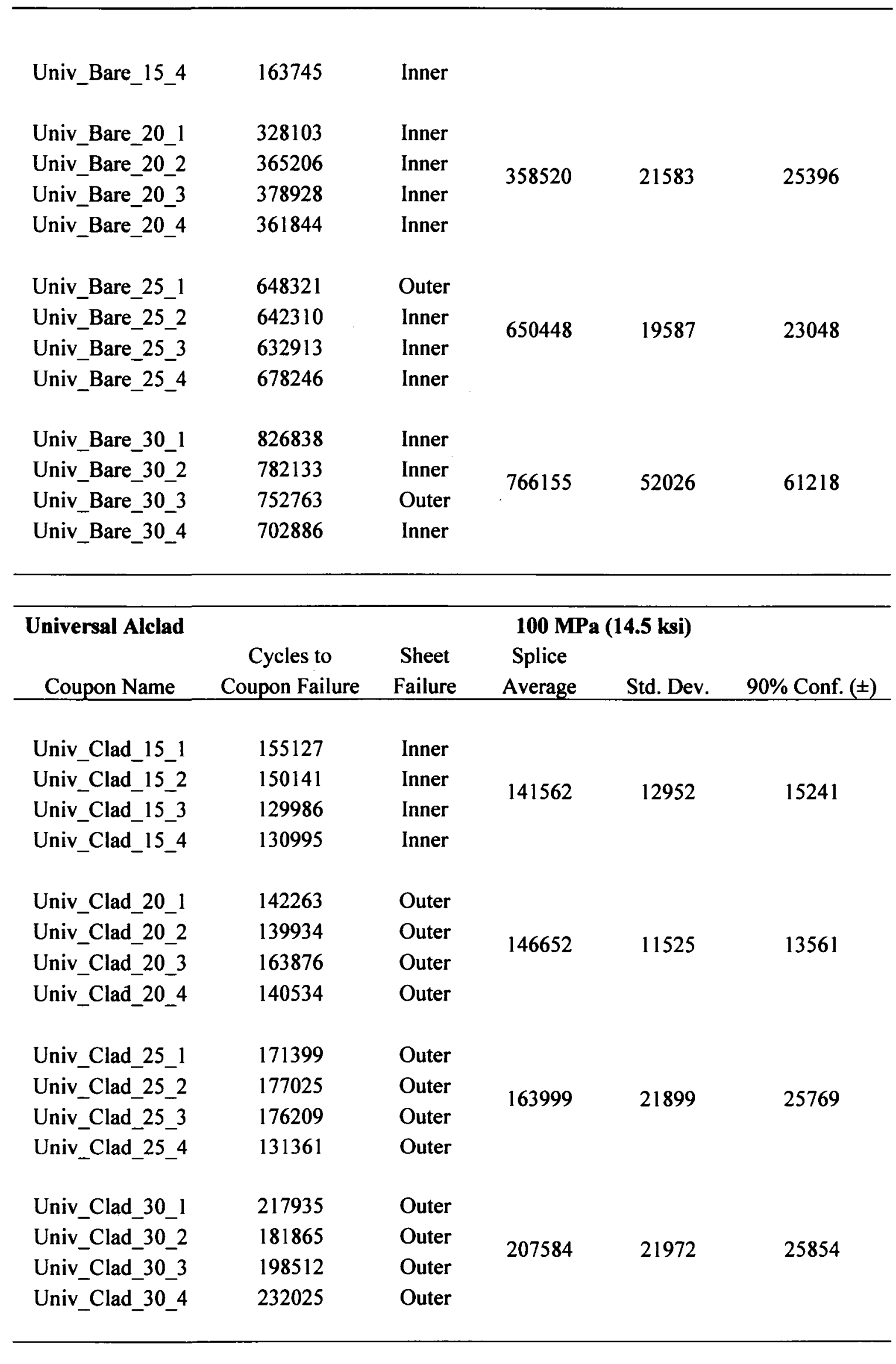




\begin{tabular}{|c|c|c|c|c|c|}
\hline \multicolumn{3}{|l|}{ Universal Anodized } & \multicolumn{3}{|c|}{$100 \mathrm{MPa}(14.5 \mathrm{ksi})$} \\
\hline Coupon Name & $\begin{array}{c}\text { Cycles to } \\
\text { Coupon Failure }\end{array}$ & $\begin{array}{c}\text { Sheet } \\
\text { Failure }\end{array}$ & $\begin{array}{c}\text { Splice } \\
\text { Average }\end{array}$ & Std. Dev. & $90 \%$ Conf. $( \pm)$ \\
\hline Univ_Anod_15_1 & 114095 & Inner & & & \\
\hline Univ_Anod_15_2 & 126770 & Inner & 124248 & 7528 & 8858 \\
\hline Univ_Anod_15_3 & 132028 & Inner & 124240 & 1020 & 0000 \\
\hline Univ_Anod_15_4 & 124099 & Inner & & & \\
\hline Univ_Anod_20_1 & 357697 & Outer & & & \\
\hline Univ_Anod_20_2 & 259825 & Inner & 307223 & 41084 & 48343 \\
\hline Univ_Anod_20_3 & 294179 & Inner & & & \\
\hline Univ_Anod_20_4 & 317192 & Inner & & & \\
\hline Univ_Anod_25_1 & 673657 & Inner & & & \\
\hline Univ_Anod_25_2 & 570700 & Inner & 634487 & 44653 & 52542 \\
\hline Univ_Anod_25_3 & 652942 & Outer & & & \\
\hline Univ_Anod_25_4 & 640650 & Inner & & & \\
\hline Univ_Anod_30_1 & 1038662 & Inner & & & \\
\hline Univ_Anod_30_2 & 964767 & Inner & 1017484 & 67228 & 79106 \\
\hline Univ_Anod_30_3 & 1103374 & Outer & 1011404 & 01220 & 17100 \\
\hline Univ_Anod_30_4 & 963132 & Inner & & & \\
\hline Universal Bare & & & $111 \mathrm{MP}$ & $6.1 \mathrm{ksi})$ & \\
\hline & Cycles to & Sheet & Splice & & \\
\hline Coupon Name & Coupon Failure & Failure & Average & Std. Dev. & $90 \%$ Conf. $( \pm)$ \\
\hline Univ_Bare_15_1H & 91247 & ${ }^{*}$ Rivet & & & \\
\hline Univ_Bare_15_2H & 67563 & ${ }^{*}$ Rivet & 86548 & 12038 & 15223 \\
\hline Univ_Bare_15_3H & 90727 & ${ }^{*}$ Rivet & & 12900 & 15223 \\
\hline Univ_Bare_15_4H & 96656 & ${ }^{*}$ Rivet & & & \\
\hline Univ_Bare_20_1H & 217719 & Inner & & & \\
\hline Univ_Bare_20_2H & 209719 & Inner & 236467 & 26812 & 31550 \\
\hline Univ_Bare_20_3H & 253974 & Inner & & & \\
\hline Univ_Bare_20_4H & 264454 & Inner & & & \\
\hline Univ_Bare_25_1H & 388921 & Outer & 378048 & 33115 & 38966 \\
\hline Univ_Bare_25_2H & 393683 & Inner & 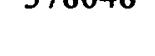 & נודונד & 3030 \\
\hline
\end{tabular}




$\begin{array}{llllll}\text { Univ_Bare_25_3H } & 328907 & \text { Inner } & & \\ \text { Univ_Bare_25_4H } & 400681 & \text { Inner } & & \\ & & & & \\ \text { Univ_Bare_30_1H } & 575638 & \text { Inner } & & \\ \text { Univ_Bare_30_2H } & 554765 & \text { Inner } & 555610 & 42165 & 49615 \\ \text { Univ_Bare_30_3H } & 497295 & \text { Inner } & & \\ \text { Univ_Bare_30_4H } & 594740 & \text { Inner } & & \\ & & & & \end{array}$

\section{Mindlin-type Fretting Fatigue Data}

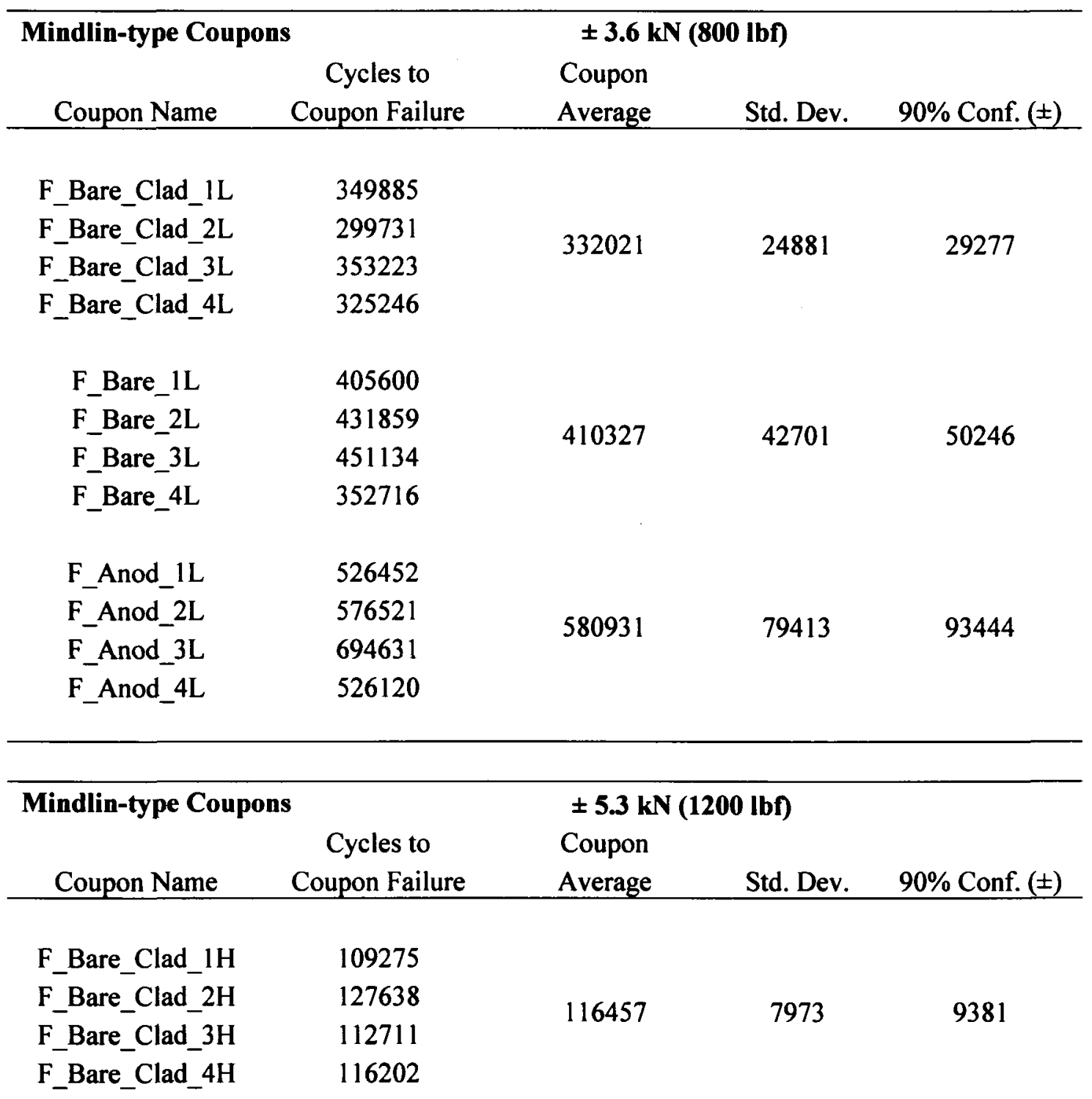




$\begin{array}{lcccc}\text { F_Bare_1H } & 120626 & & & \\ \text { F_Bare_2H } & 90939 & 113447 & 15028 & 17684 \\ \text { F_Bare_3H } & 122099 & & \\ \text { F_Bare_4H } & 120122 & & & \\ & & & & \\ \text { F_Anod_1H } & 127800 & & & \\ \text { F_Anod_2H } & 105813 & 112264 & 16538 & \\ \text { F_Anod_3H } & 91968 & & & \\ \text { F_Anod_4H } & 123473 & & & \end{array}$




\section{Appendix E - Fretting Fatigue Coupon Photos}

The following photos show representative faying surface fretting damage around rivet holes in single lap splices manufactured with $1 \mathrm{~mm}$ 2024-T3 sheet. The splices were riveted with both universal MS20470AD-4-4 and machine countersunk NAS1097AD-4-4 rivets to four rivet forming loads $(6.7 \mathrm{kN}, 8.9 \mathrm{kN}, 11.1 \mathrm{kN}$, and $13.3 \mathrm{kN})$. The photos show, in order, fretting scars on sheets with alclad, bare, and anodized surface treatments. Images for the countersunk splices are presented first, followed by the universal splice images.

The degree of fretting damage is shown to increase with rivet forming load and the sheet clamping that accompanies those loads. The fretting damage was found to be most severe in the alclad coupons where the surface treatment is soft and least severe in the anodized coupons where the surface treatment is hard. Damage to the bare coupons was similar or slightly more than the anodized coupons. 


\section{Countersunk Splice Faying Surface Photos:}

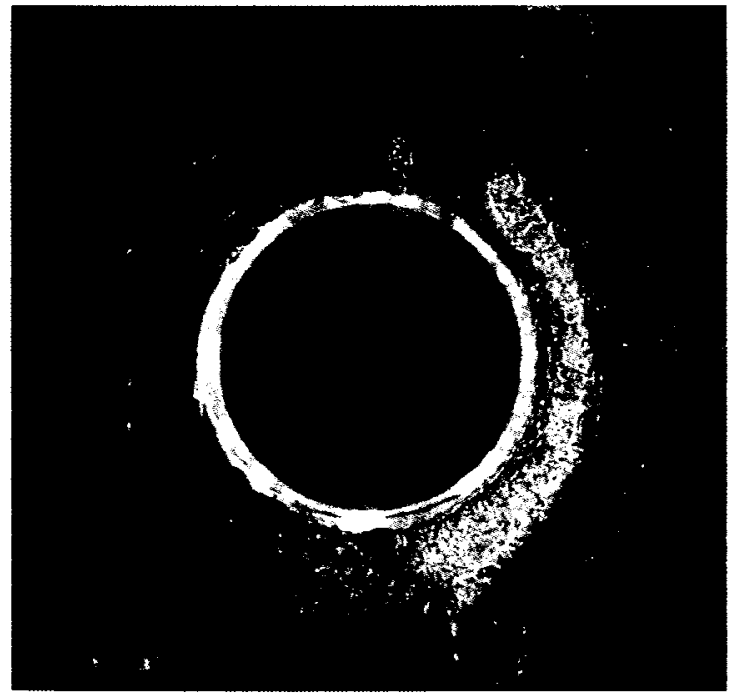

Figure E - 1 Fretting damage on faying surface of alclad countersunk splice $(6.7 \mathrm{kN})$.

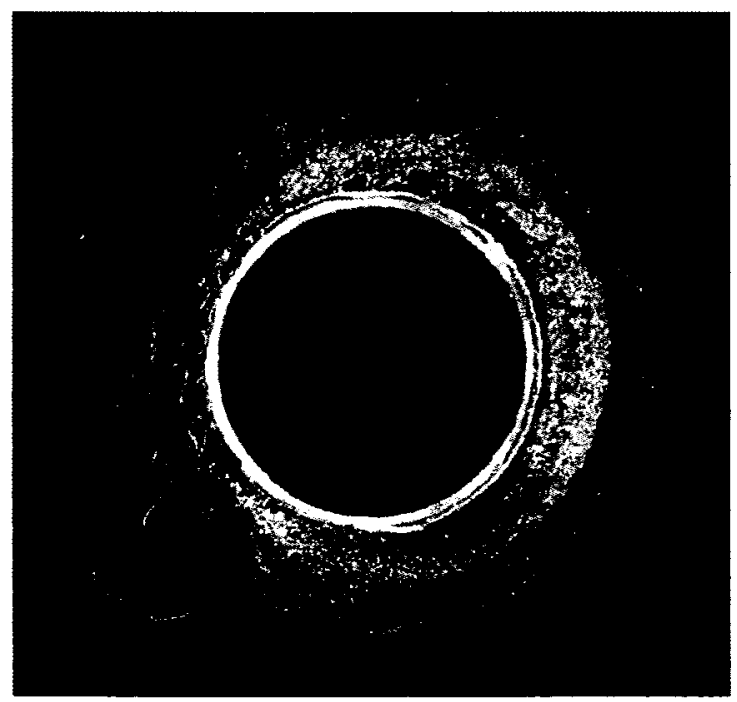

Figure E - 3 Fretting damage on faying surface of alclad countersunk splice (11.1 kN).

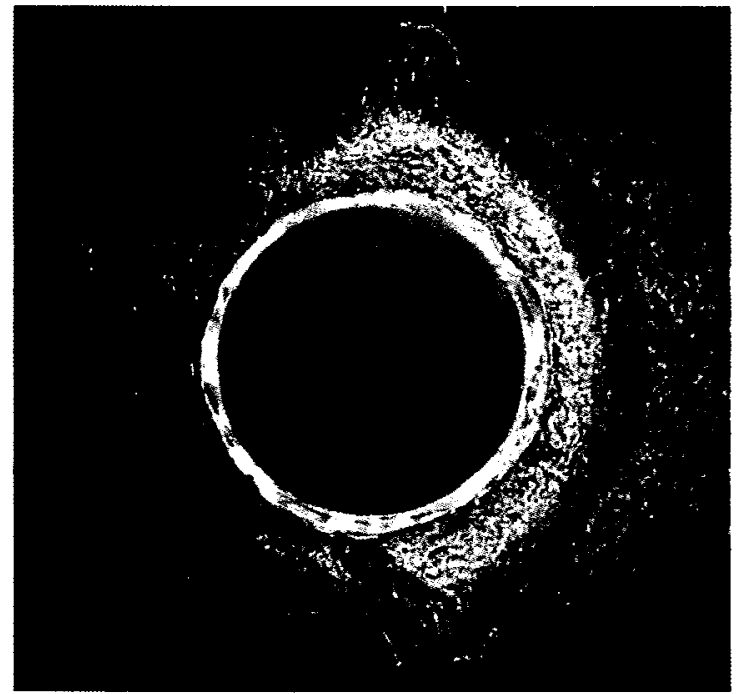

Figure E - 2 Fretting damage on faying surface of alclad countersunk splice $(8.9 \mathrm{kN})$.

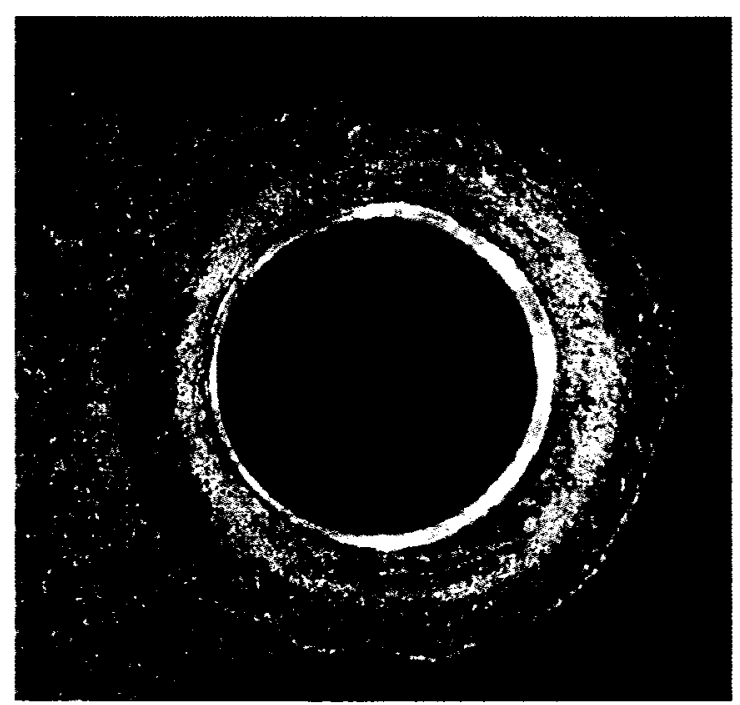

Figure $E$ - 4 Fretting damage on faying surface of alclad countersunk splice $(13.3 \mathrm{kN})$. 


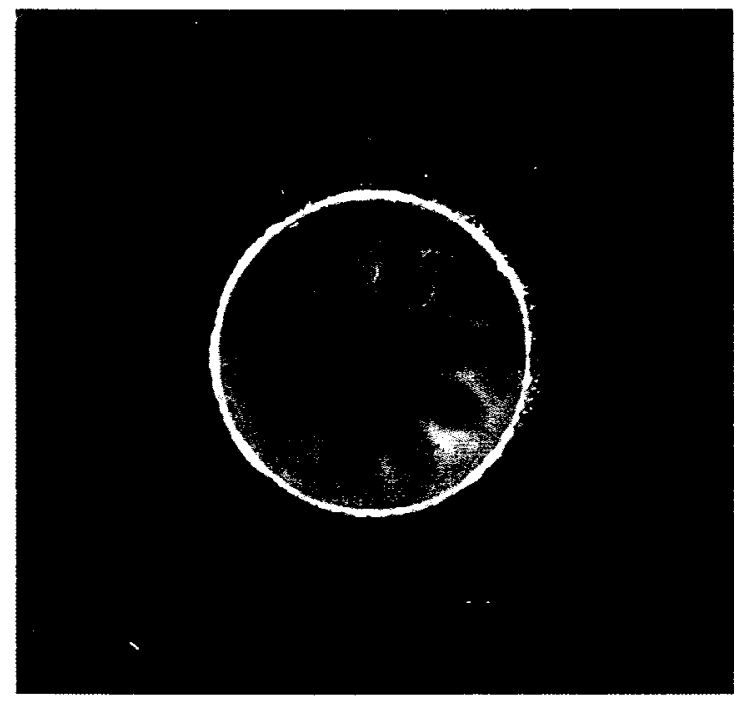

Figure E - 5 Fretting damage on faying surface of bare countersunk splice $(6.7 \mathrm{kN})$.

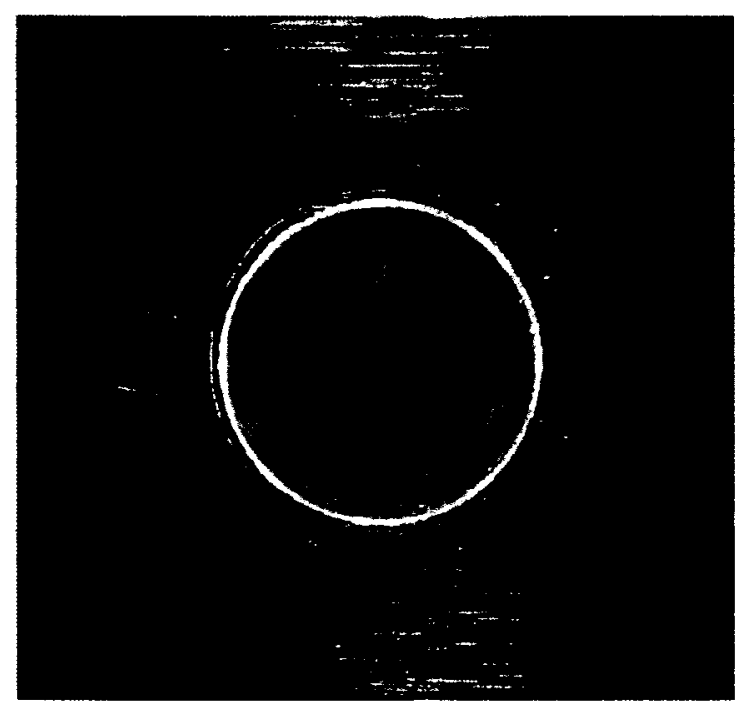

Figure E - 7 Fretting damage on faying surface of bare countersunk splice (11.1 kN).

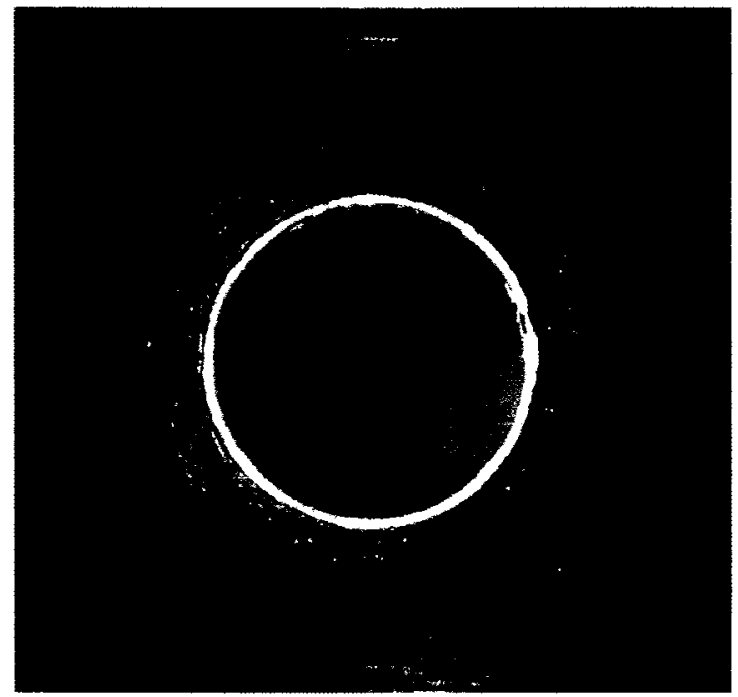

Figure E - 6 Fretting damage on faying surface of bare countersunk splice $(8.9 \mathrm{kN})$.

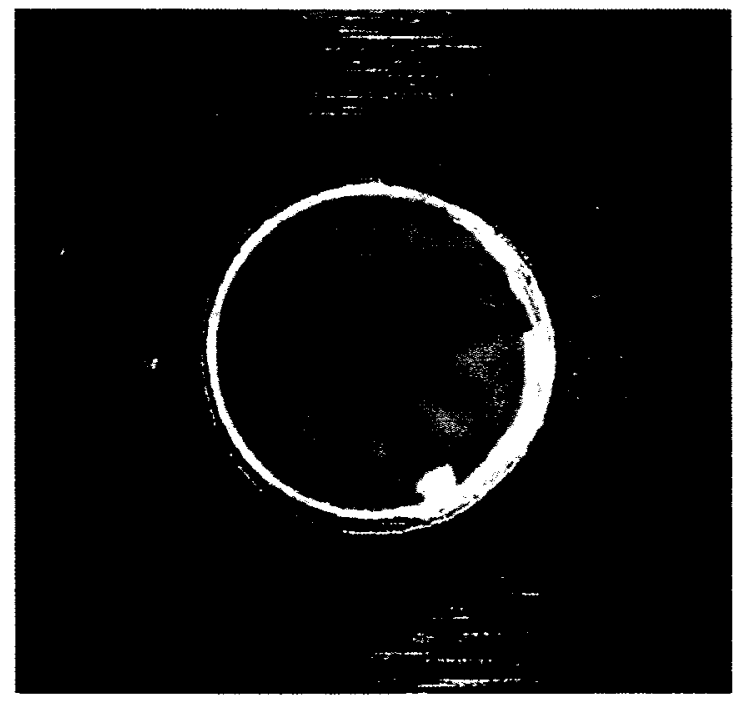

Figure E - 8 Fretting damage on faying surface of bare countersunk splice (13.3 kN). 


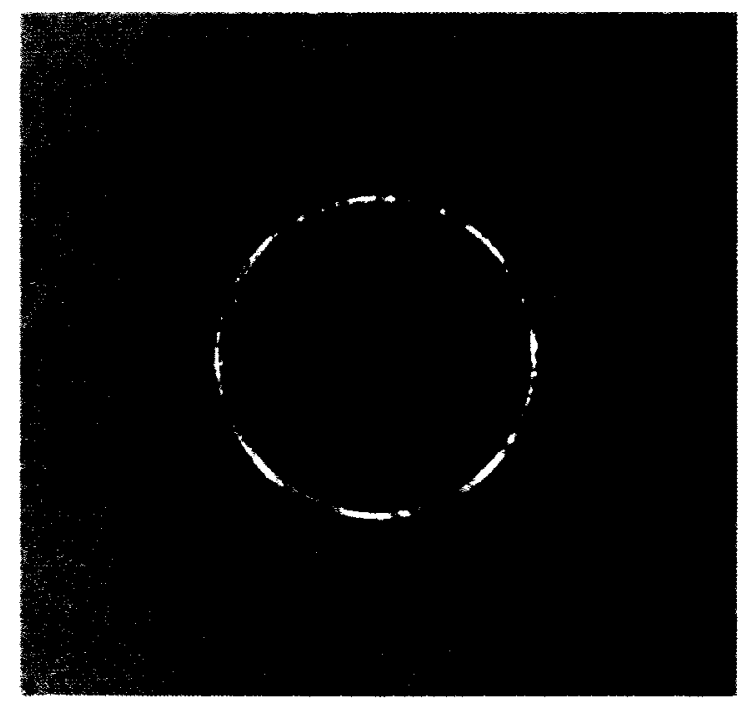

Figure E - 9 Fretting damage on faying surface of anodized countersunk splice $(6.7 \mathrm{kN})$.

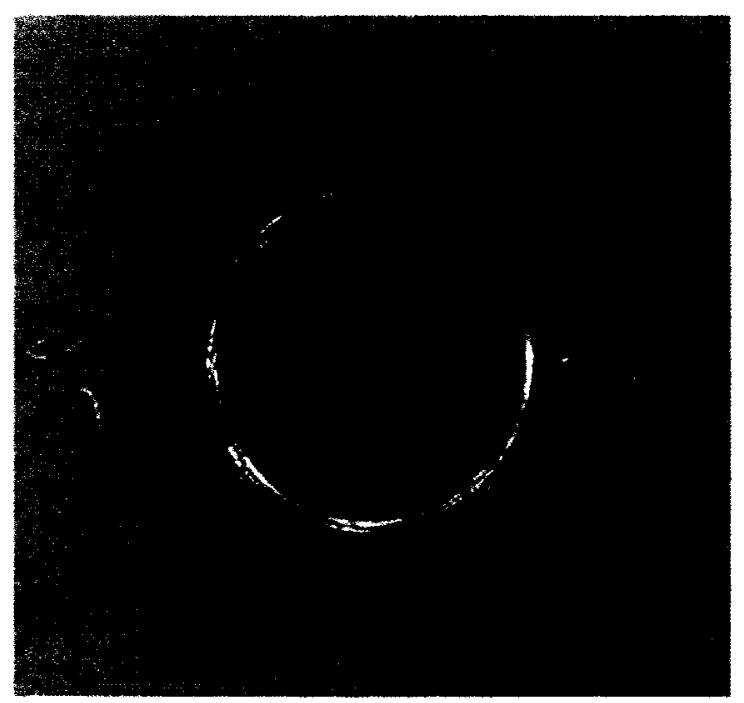

Figure E - 11 Fretting damage on faying surface of anodized countersunk splice (11.1 kN).

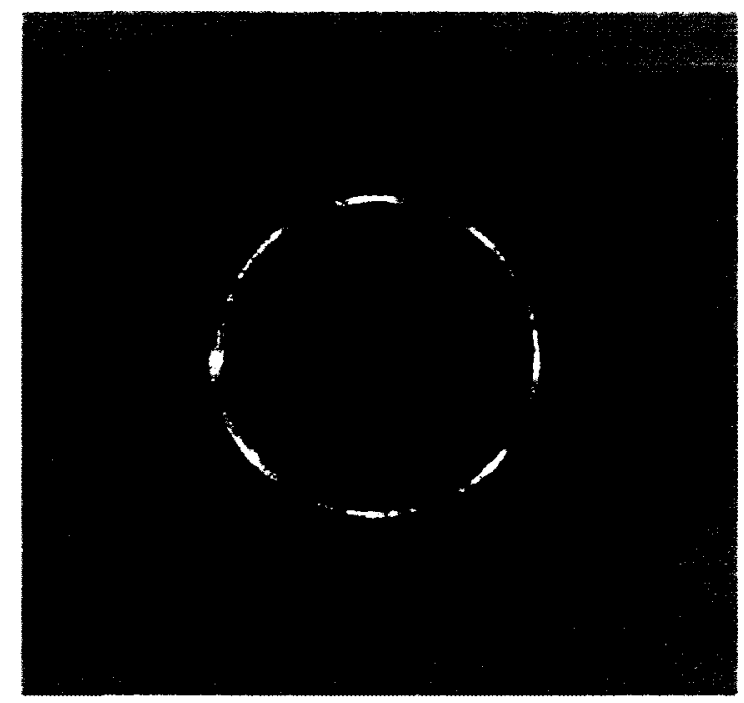

Figure E - 10 Fretting damage on faying surface of anodized countersunk splice (8.9 kN).

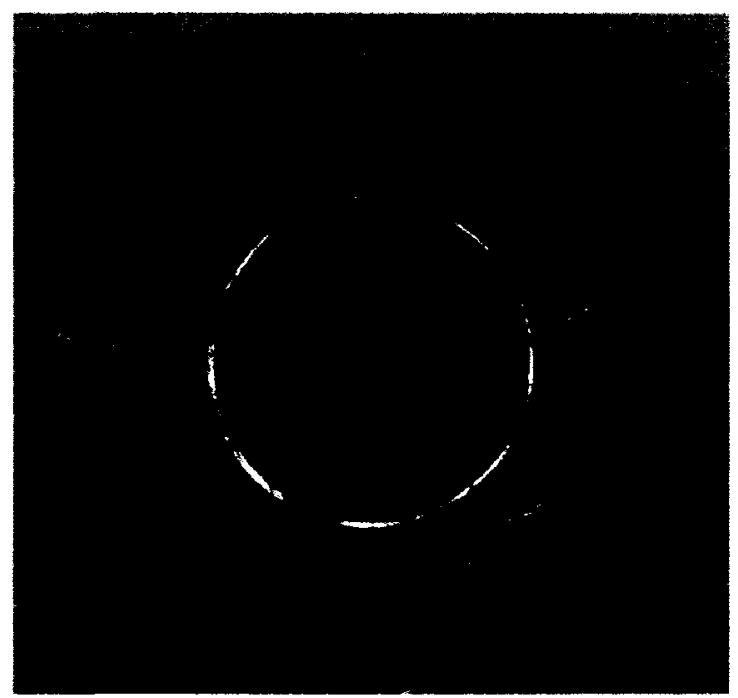

Figure E - 12 Fretting damage on faying surface of anodized countersunk splice $(13.3 \mathrm{kN})$. 
Universal Splice Faying Surface Photos:

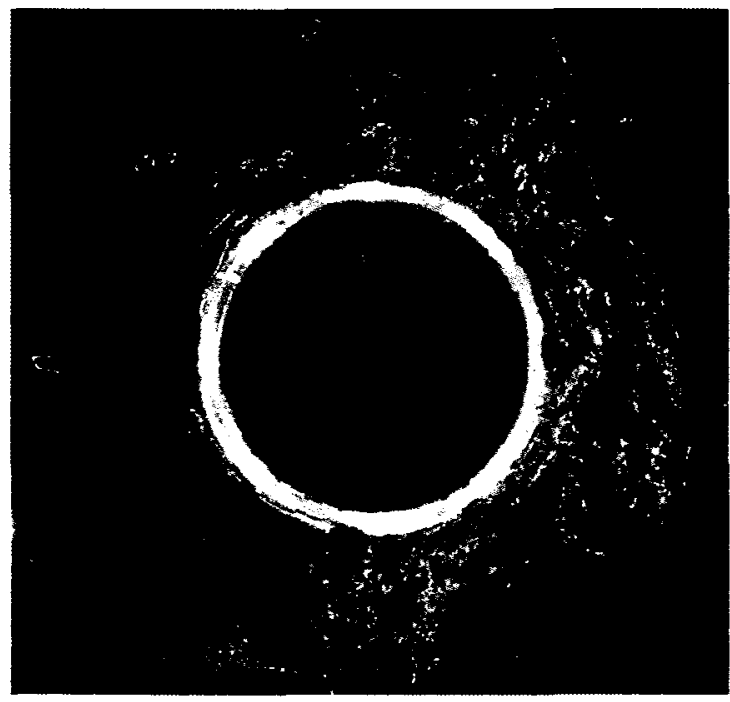

Figure E - 13 Fretting damage on faying surface of alclad universal splice $(6.7 \mathrm{kN})$.

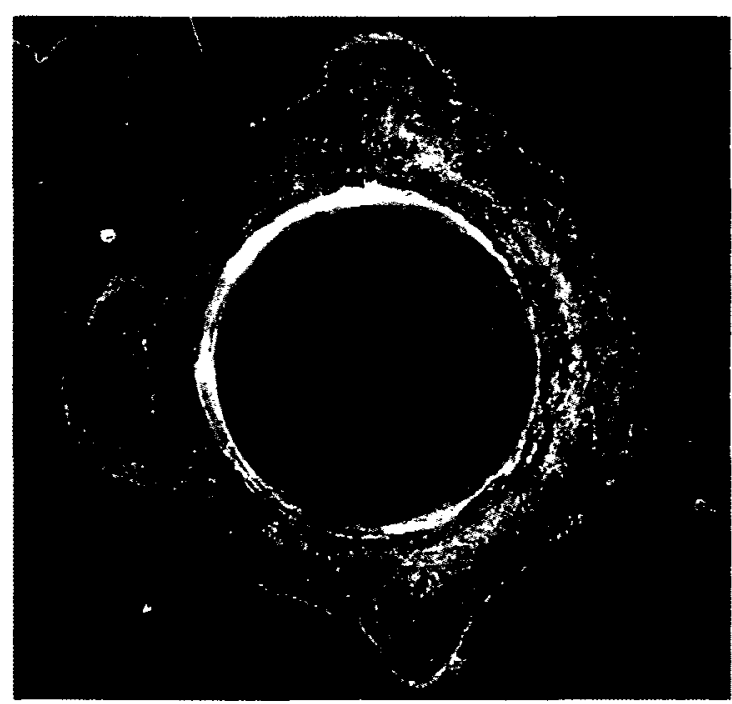

Figure E - 15 Fretting damage on faying surface of alclad universal splice $(11.1 \mathrm{kN})$.

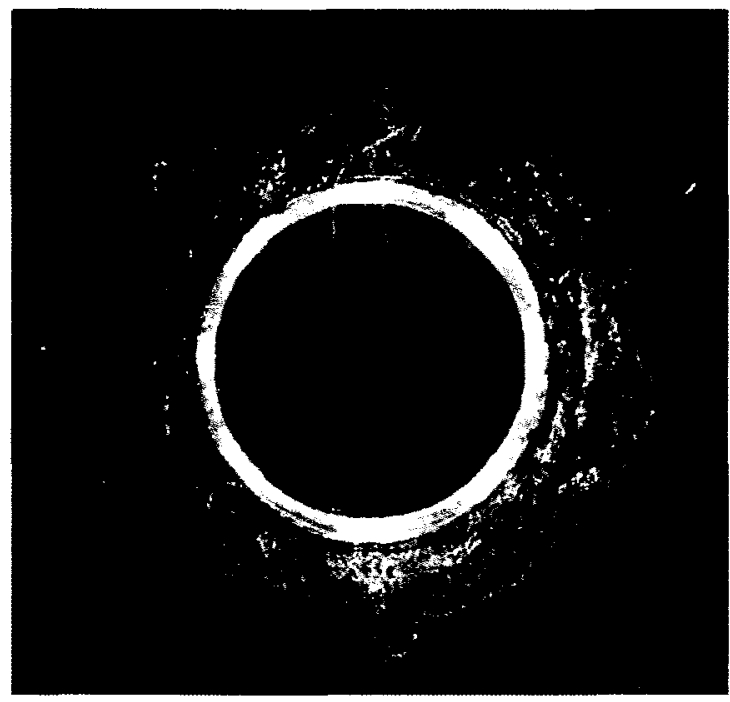

Figure E - 14 Fretting damage on faying surface of alclad universal splice $(8.9 \mathrm{kN})$.

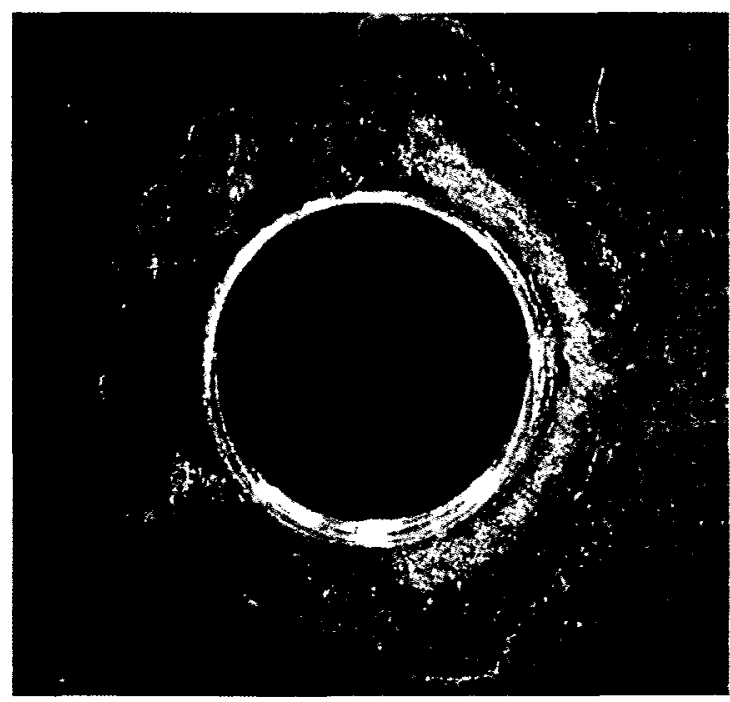

Figure E - 16 Fretting damage on faying surface of alclad universal splice $(13.3 \mathrm{kN})$. 


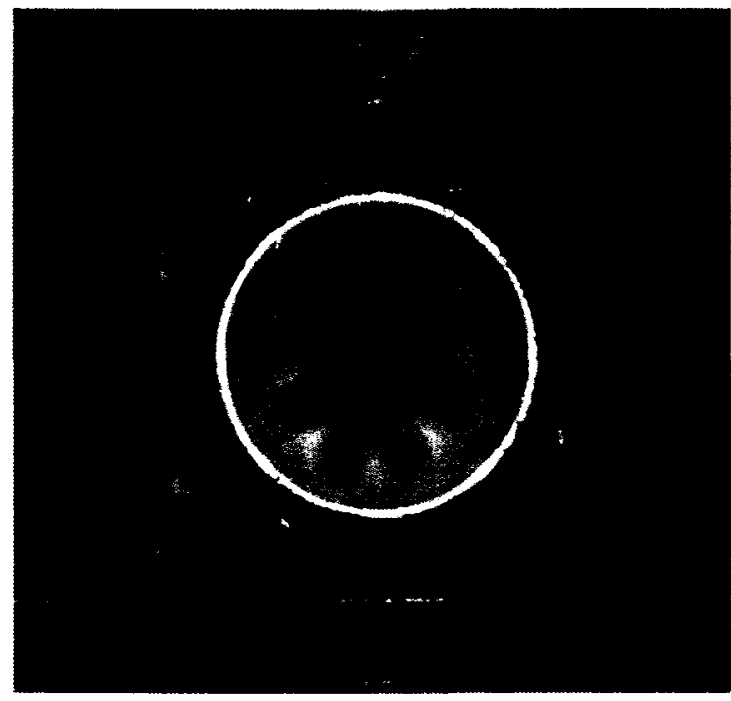

Figure E - 17 Fretting damage on faying surface of bare universal splice $(6.7 \mathrm{kN})$.

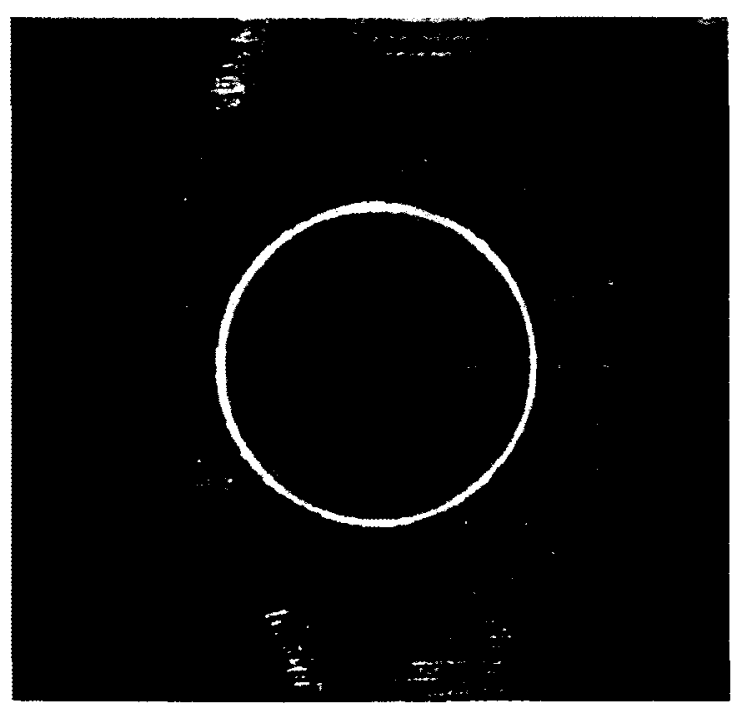

Figure E - 19 Fretting damage on faying surface of bare universal splice (11.1 kN).

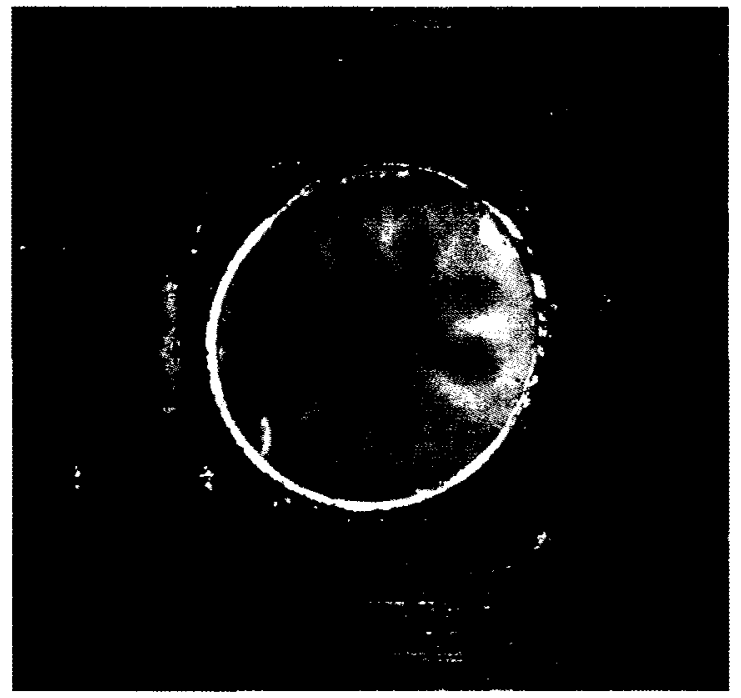

Figure E - 18 Fretting damage on faying surface of bare universal splice $(8.9 \mathrm{kN})$.

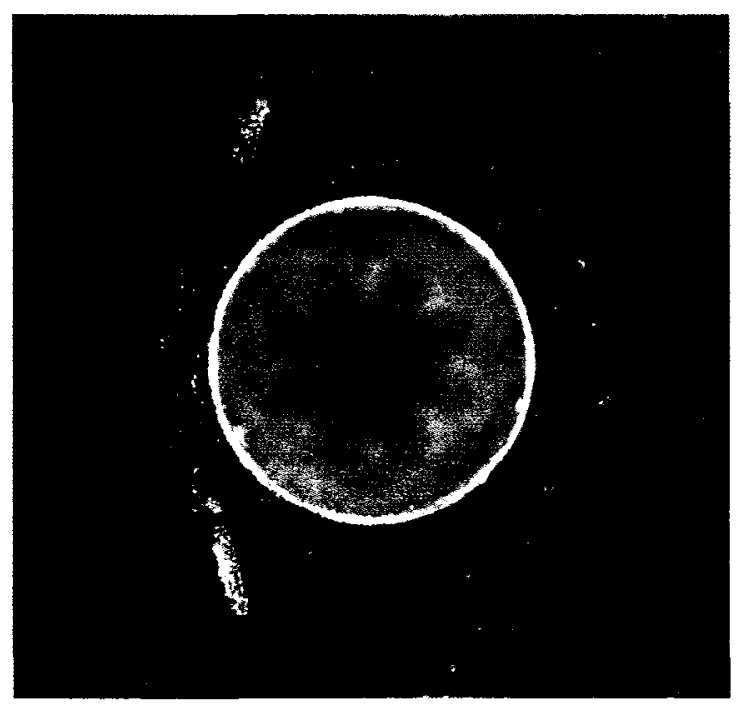

Figure E - 20 Fretting damage on faying surface of bare universal splice $(13.3 \mathrm{kN})$. 


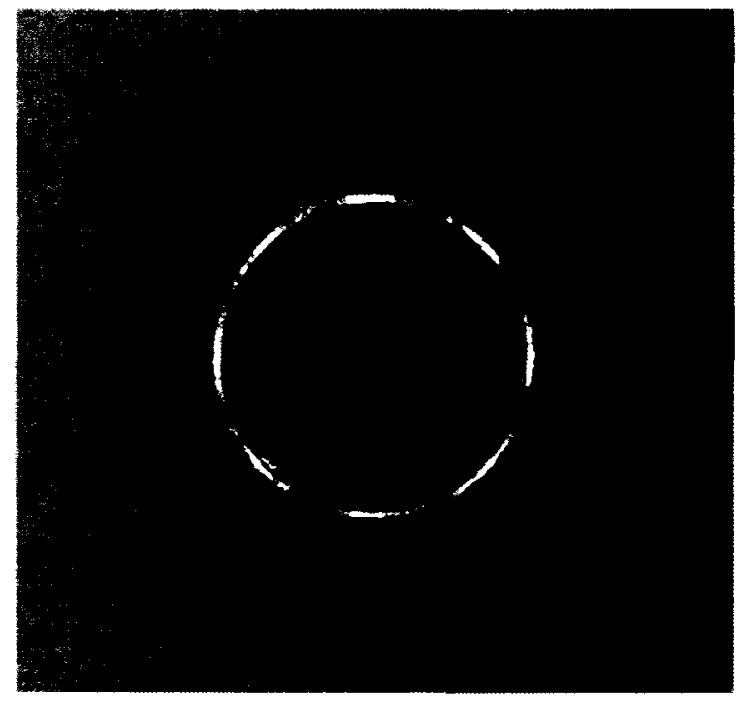

Figure E - 21 Fretting damage on faying surface of anodized universal splice $(6.7 \mathrm{kN})$.

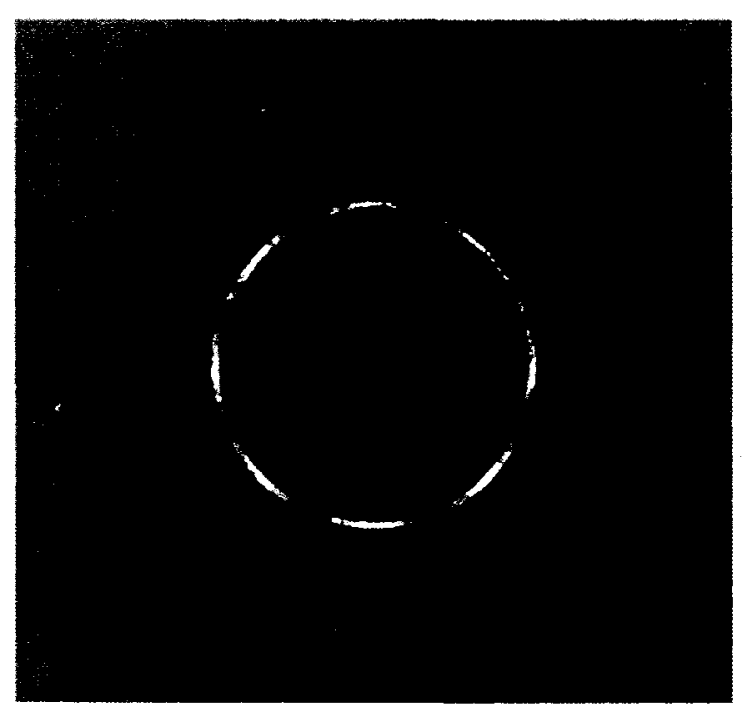

Figure E - 23 Fretting damage on faying surface of anodized universal splice (11.1 kN).

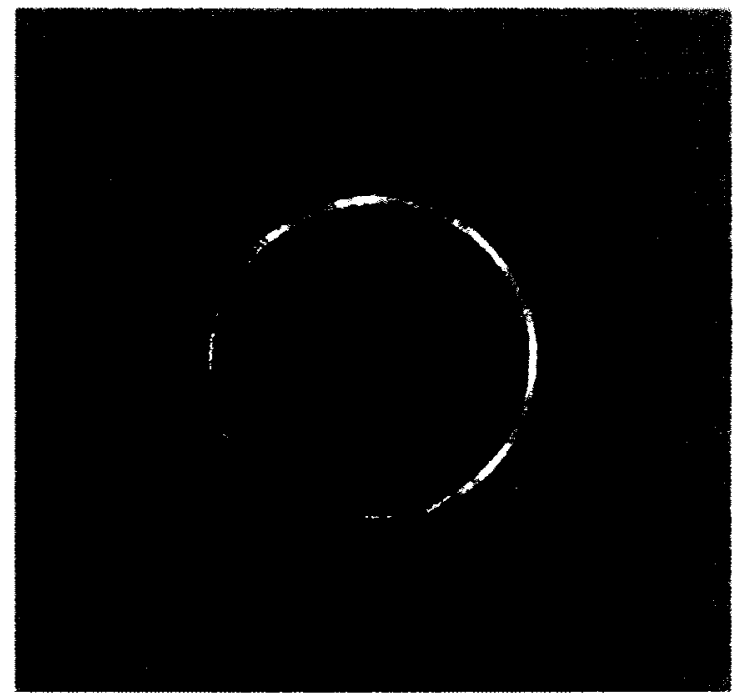

Figure E - 22 Fretting damage on faying surface of anodized universal splice $(8.9 \mathrm{kN})$.

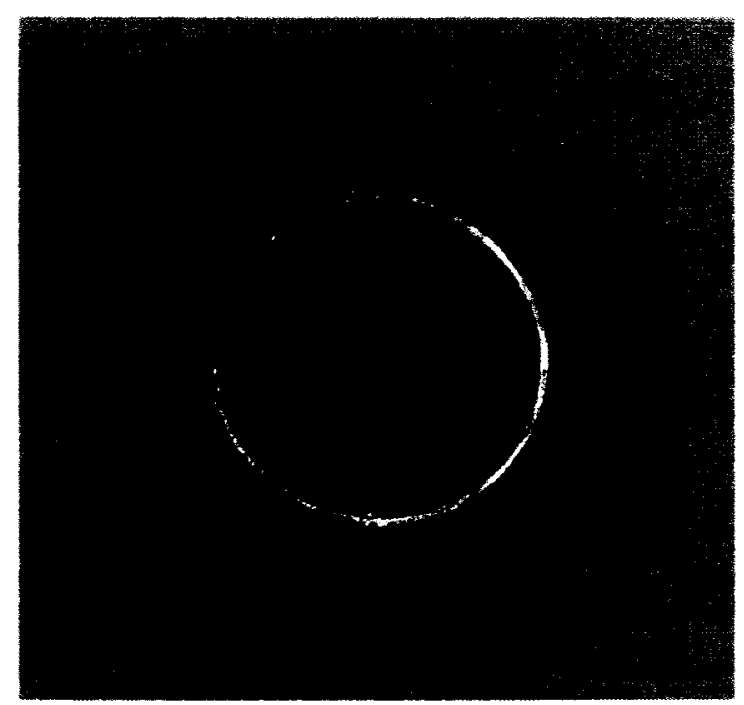

Figure E - 24 Fretting damage on faying surface of anodized universal splice $(13.3 \mathrm{kN})$. 


\section{Appendix F - Fretting Test Rig Design}

Design drawings of components for the fretting fatigue test fixture built for this study are presented here. Some components used on the rig and shown in assembly figures were purchased from outside sources. The engineering drawings that follow are, therefore, only of parts that were manufactured at Carleton University.

The drawings are presented in order of parts manufactured for the base of the fixture, connectors, and then the fretting carriage. Assembly drawings and exploded views of the fixture components are included to help clarify the design of the rig for the reader. 


\section{Fretting Test Fixture Base and Connectors}

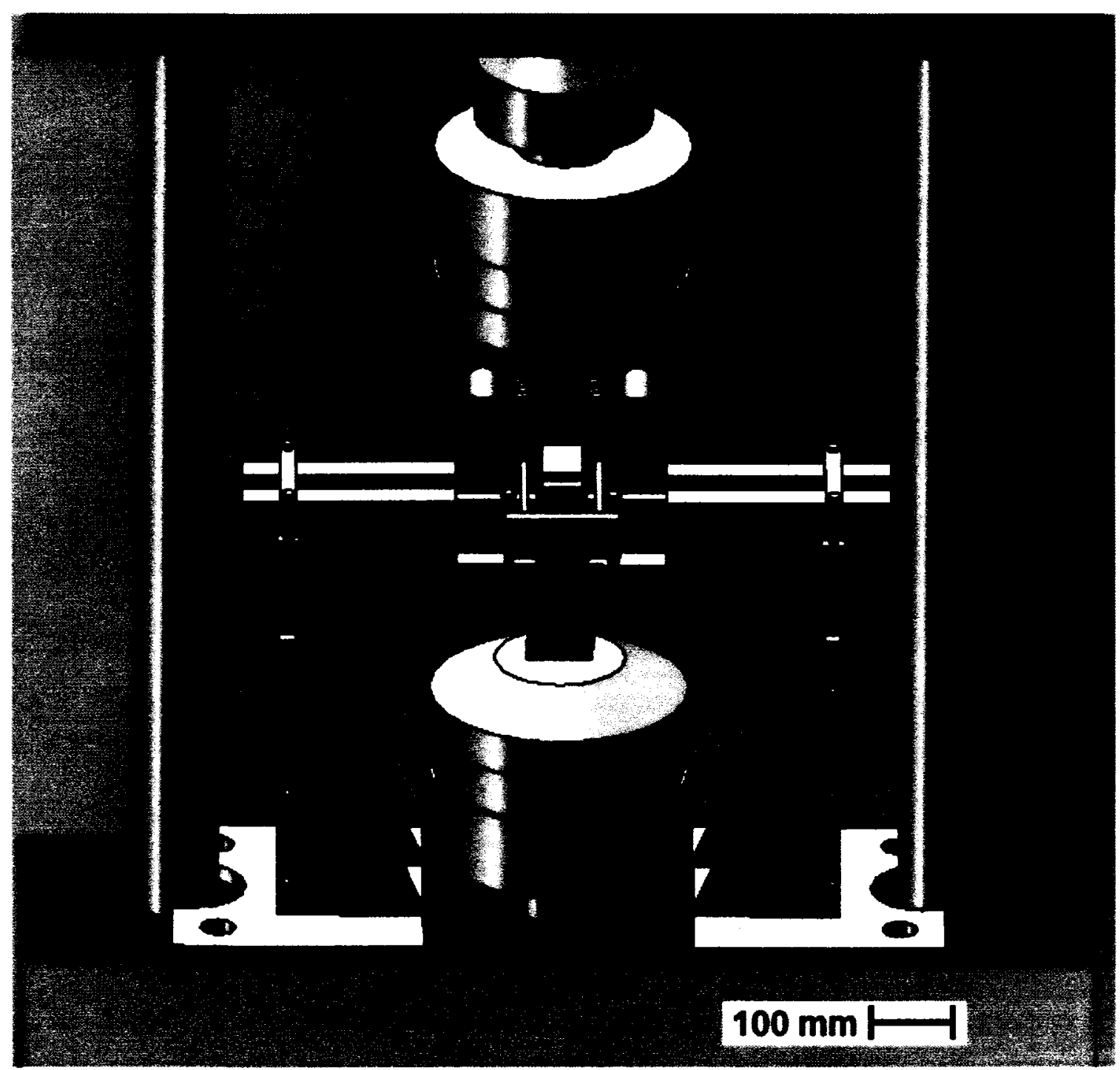

Figure F- 1 Overview of fretting test fixture on hydraulic test frame. 


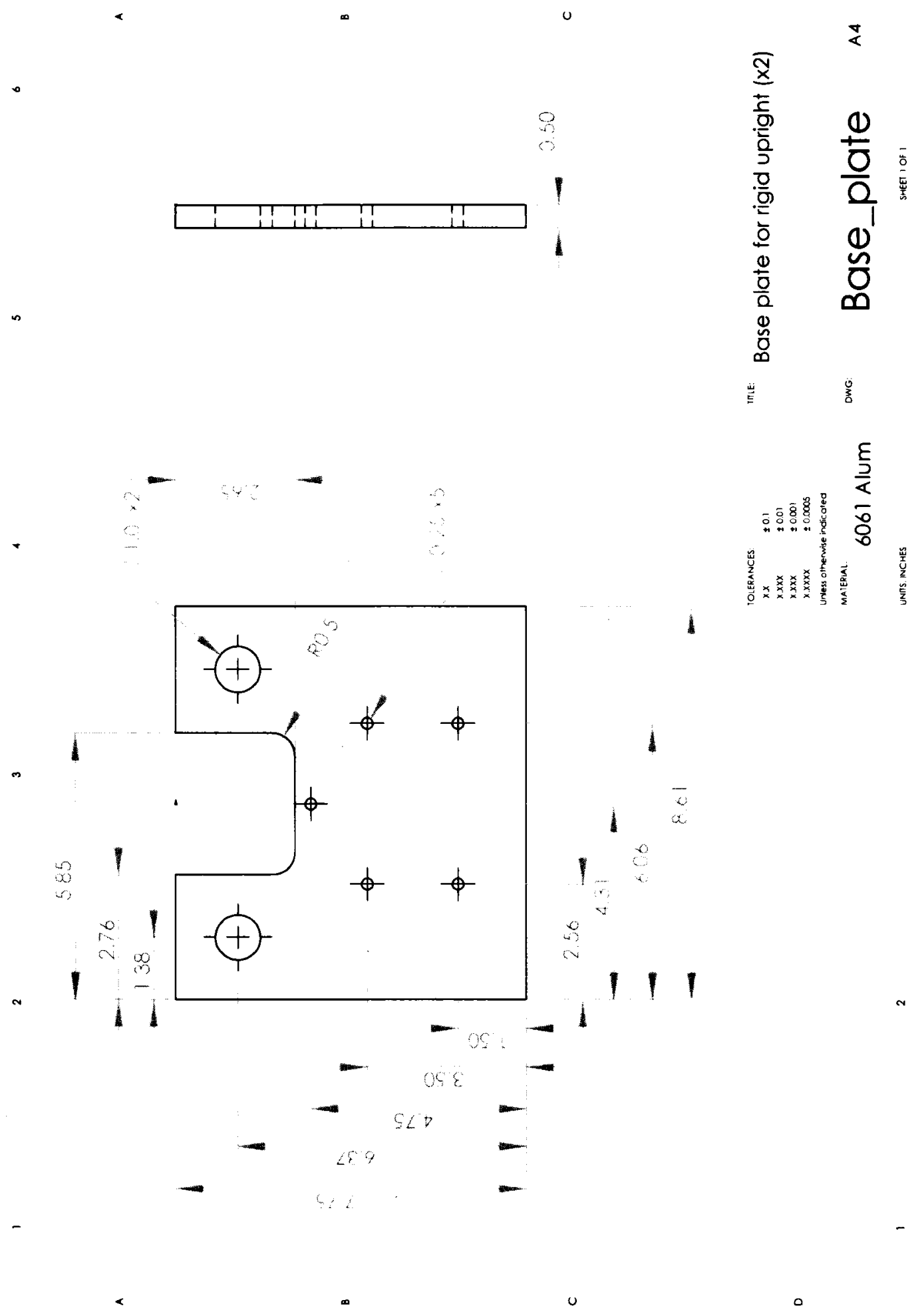



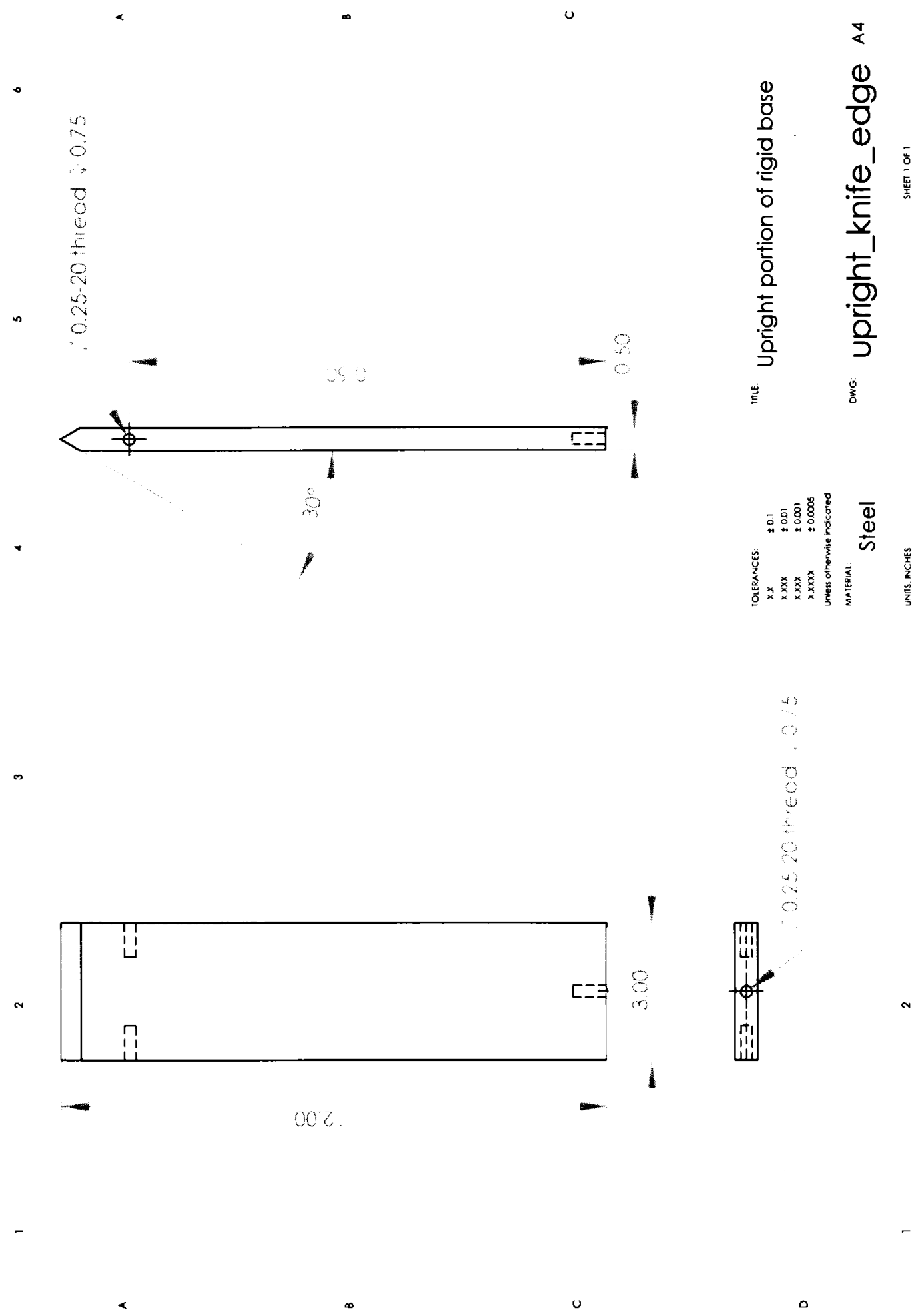


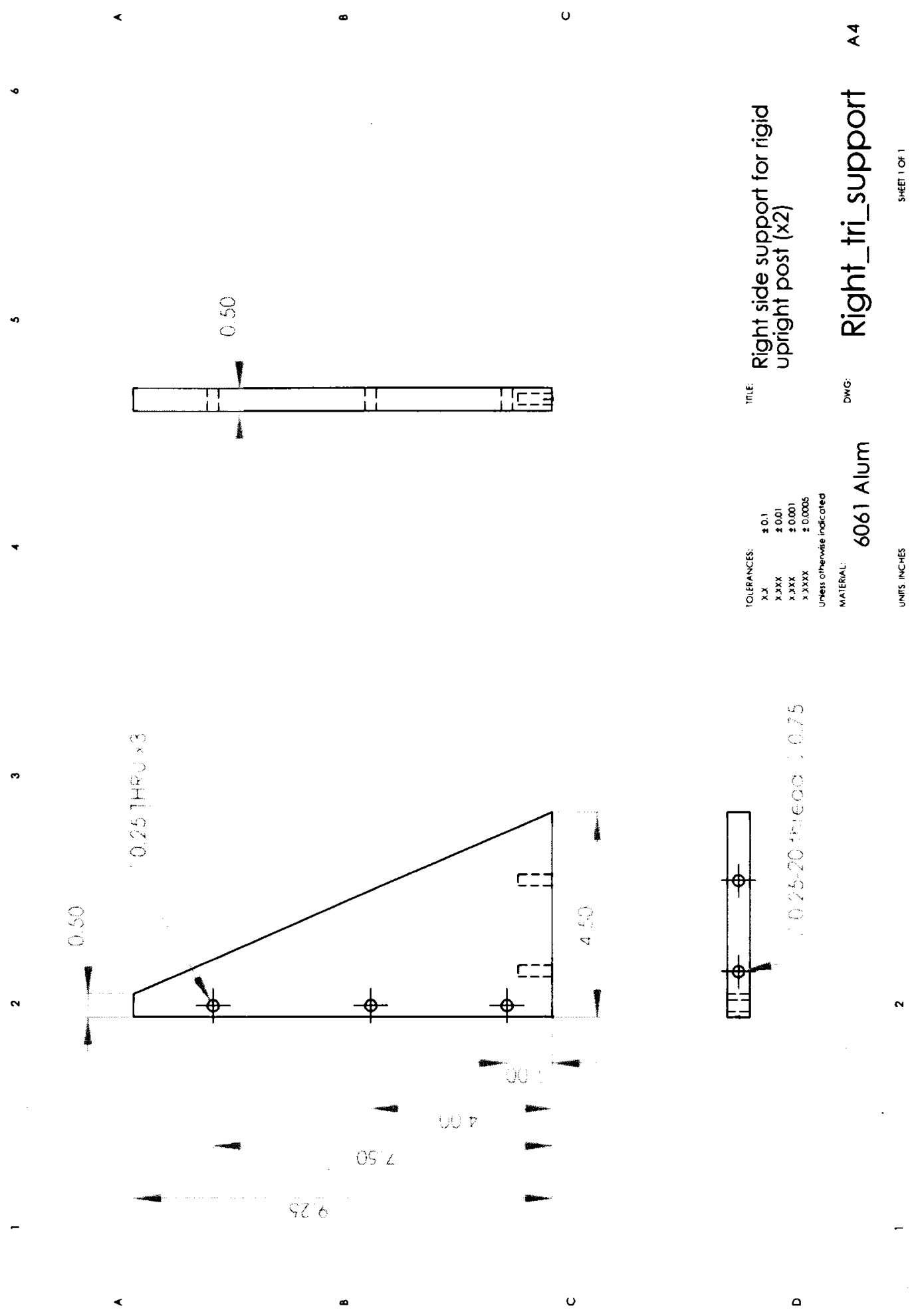




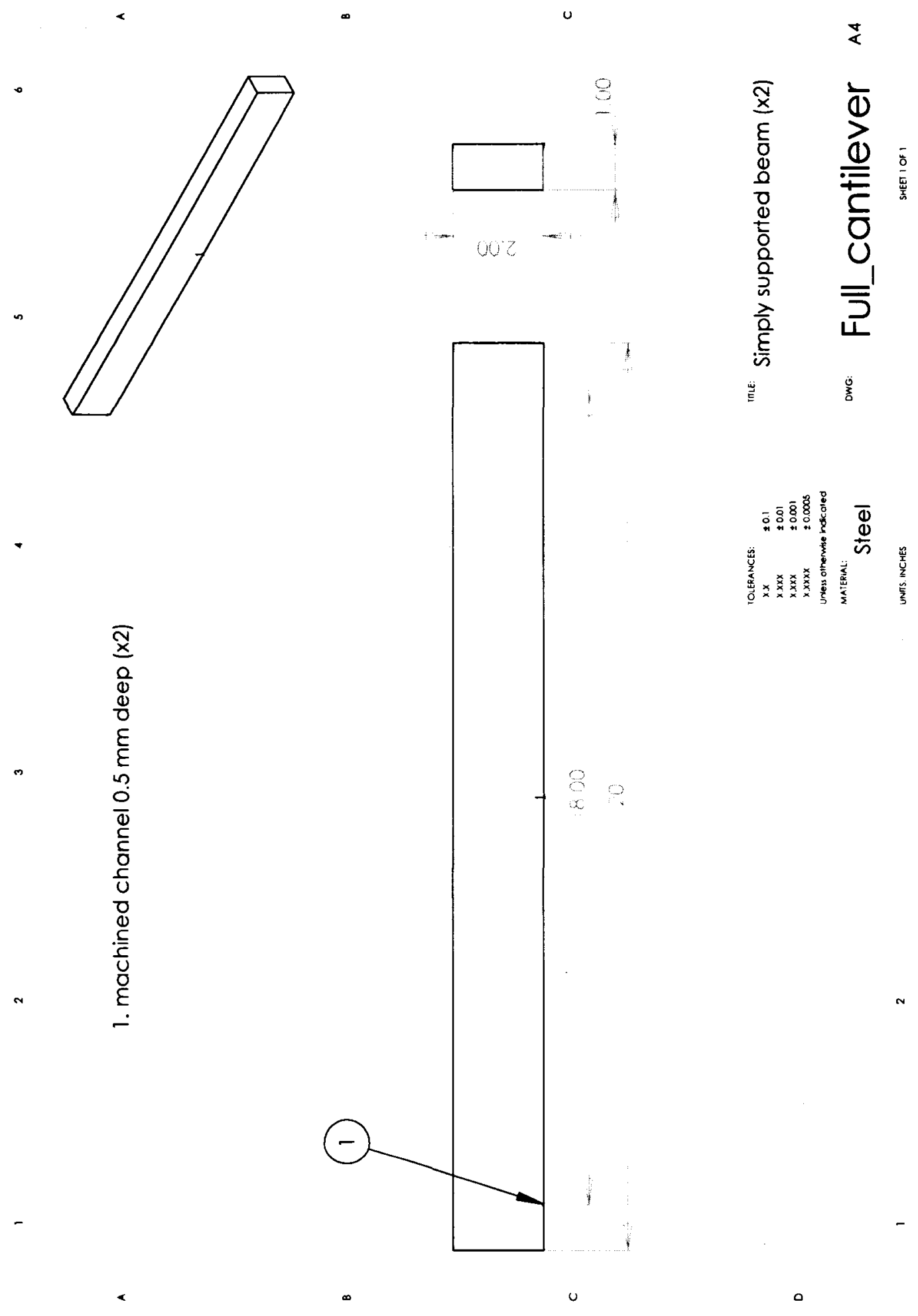




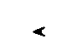

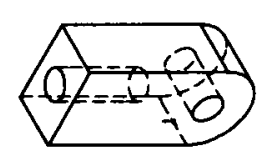

n

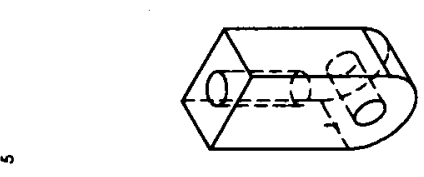

m

N

$\infty$

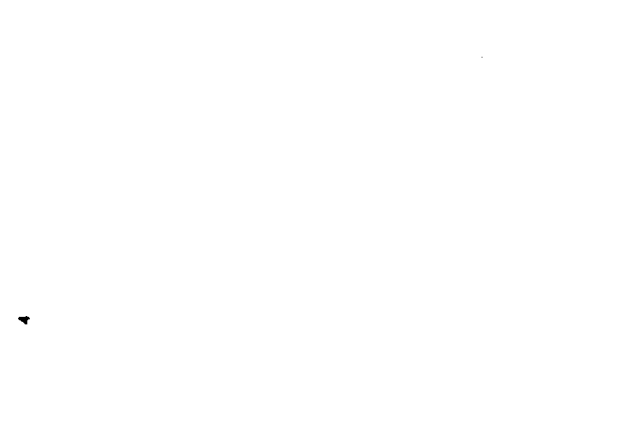

$\pm$
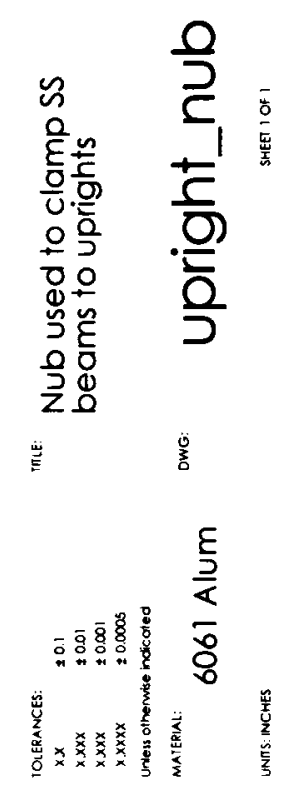

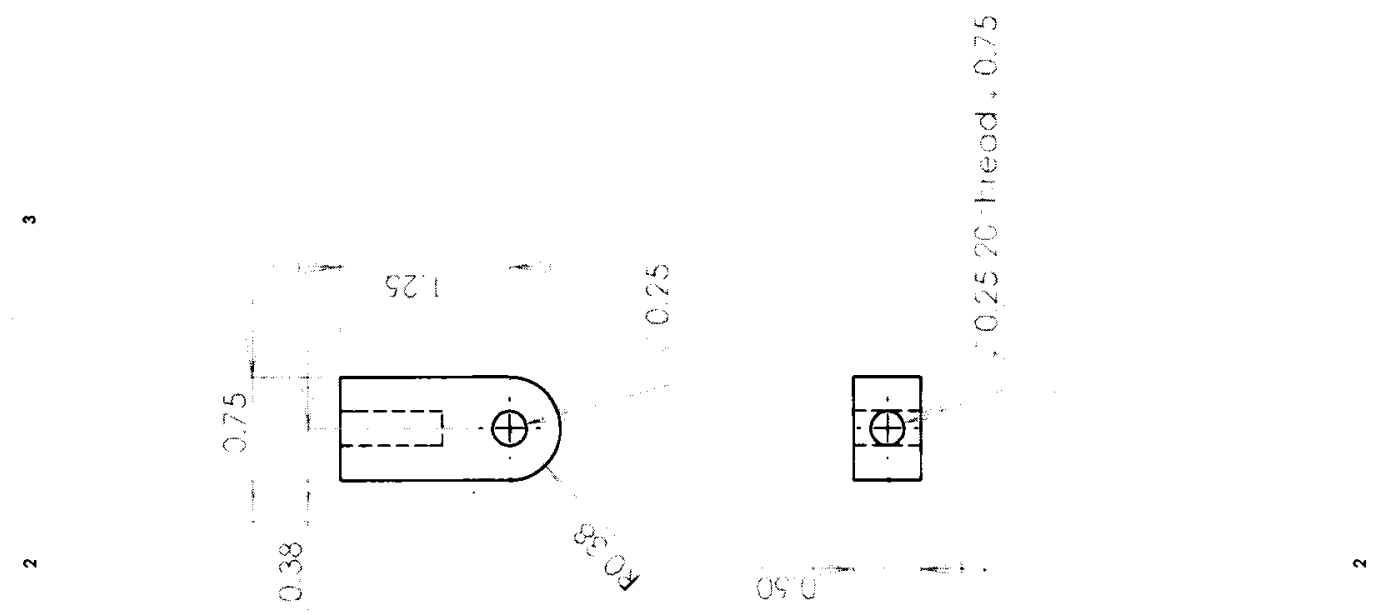

$<$

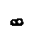

u

o 

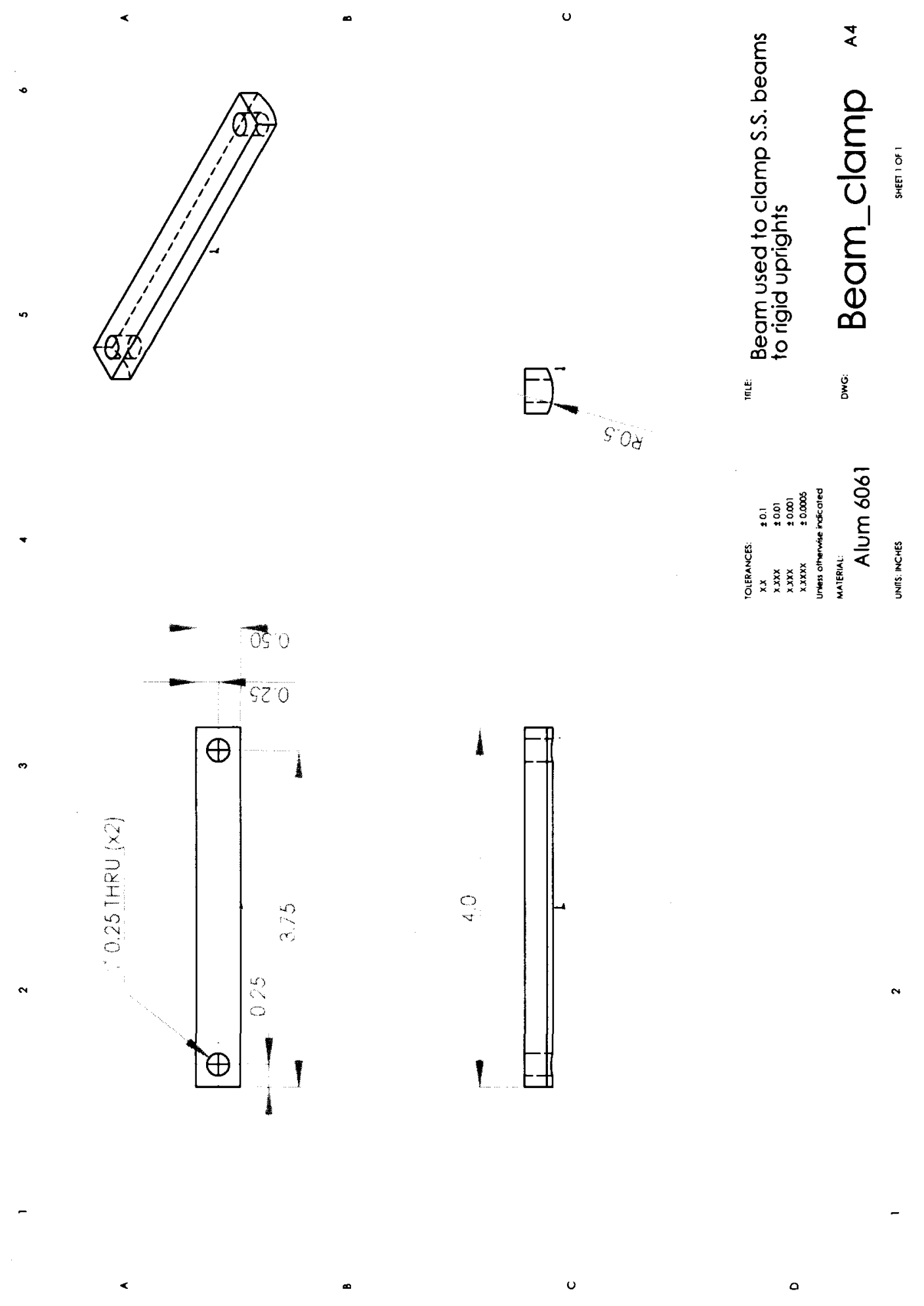


\section{Fretting Carriage}

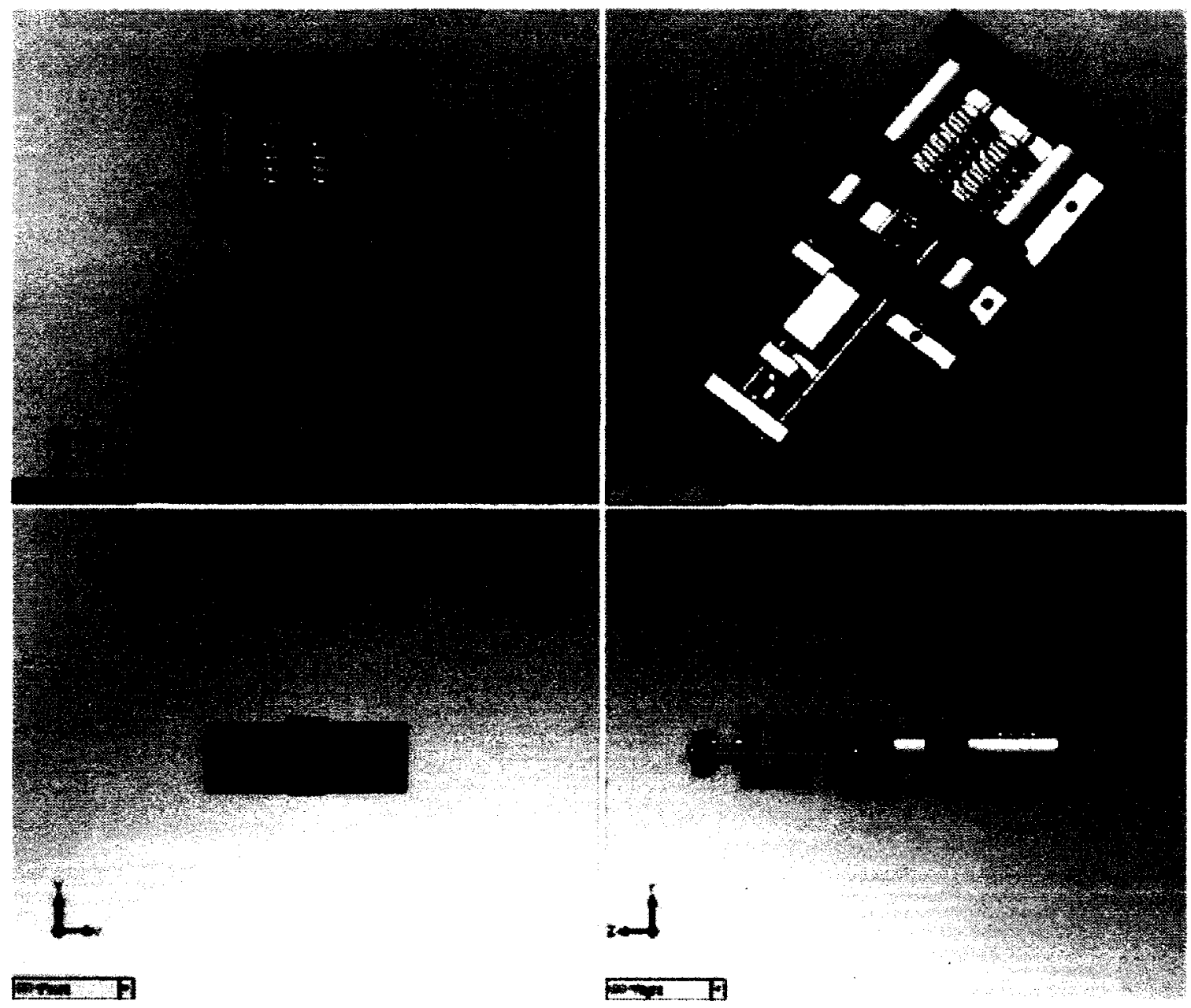

Figure F- 2 4-view picture of assembled fretting carriage. 


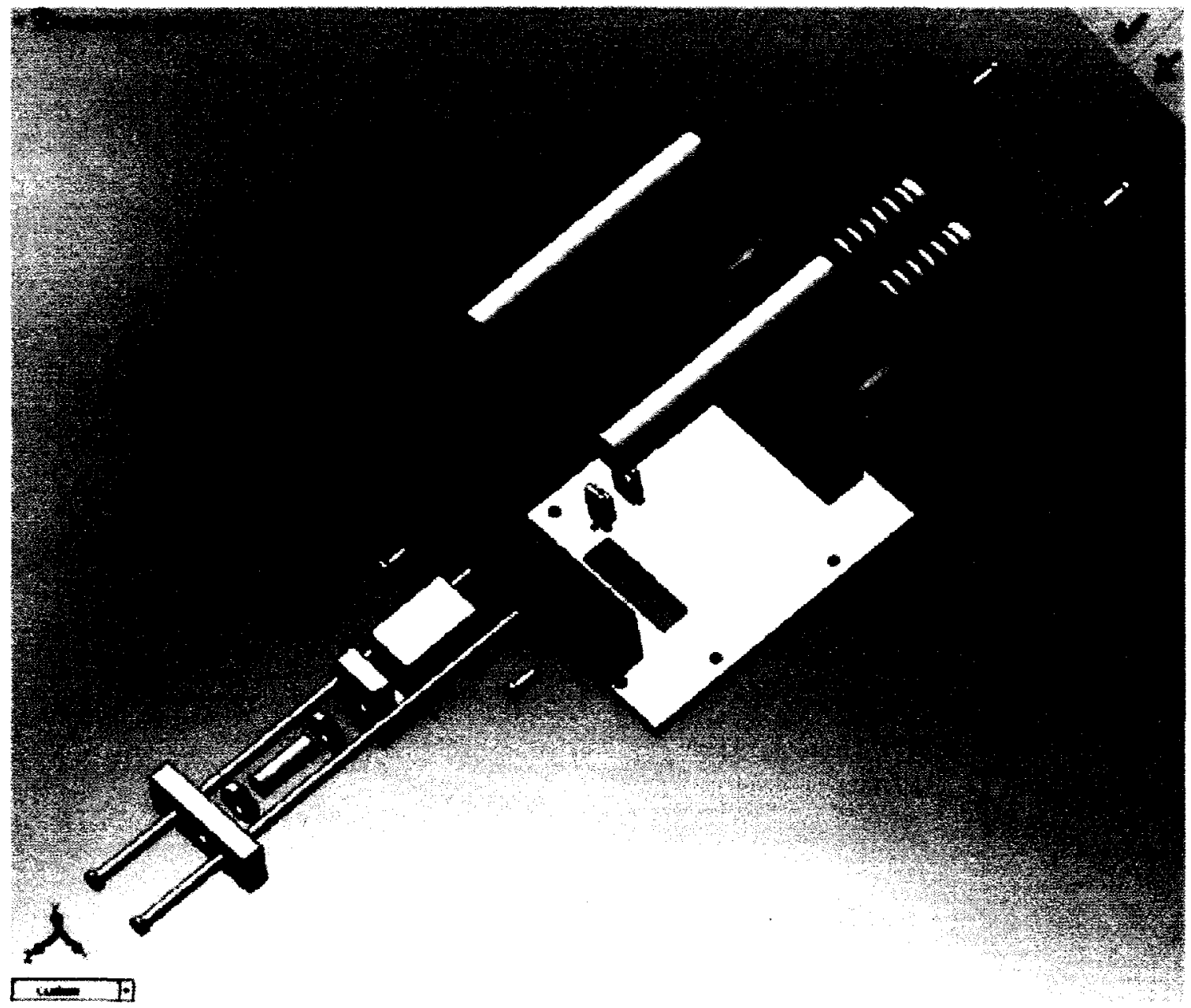

Figure F- 3 Exploded view of assembled fretting carriage.

Table F- 1 Part list of components purchased for fretting carriage.

\begin{tabular}{lll}
\hline Component & Supplier & Part Number \\
\hline Ground rods (x 2) & Reid Supply Company & TPC-760-X-7 \\
Bushings (x 2) & Reid Supply Company & LBB-06-07 \\
Load cell & Omega & LCCA-3k \\
Compliance springs $(\times 2)$ & Diamond Wire & EH125-200 \\
\hline
\end{tabular}




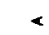

$\infty$

。

is

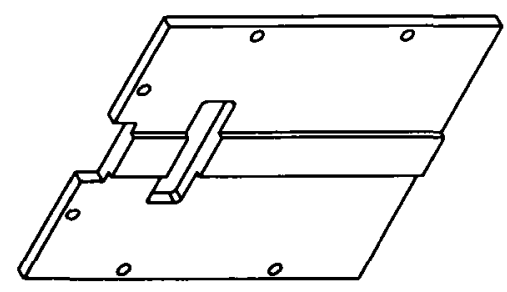

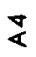

$\frac{\frac{0}{0}}{\frac{0}{0}^{\frac{5}{0}}}$

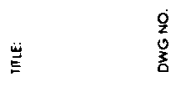

$\underset{\Phi}{\Phi}$

1

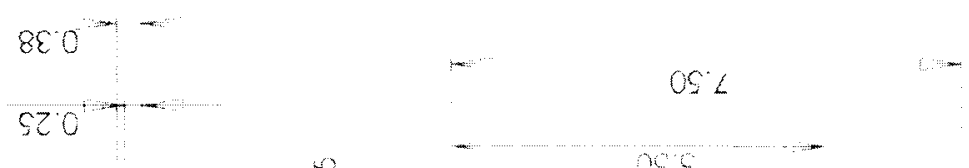

$\infty$

$\sim$

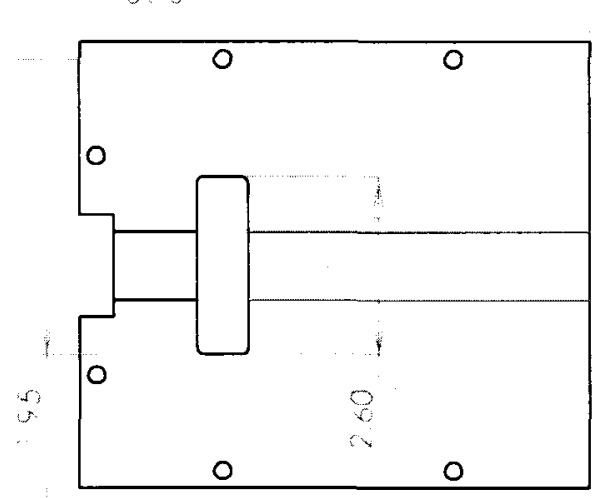

-

$<$
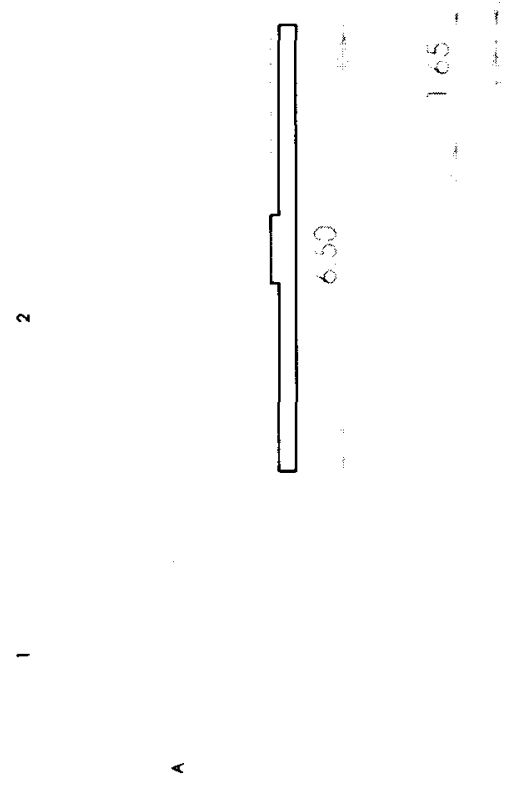

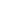

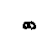

u

o 


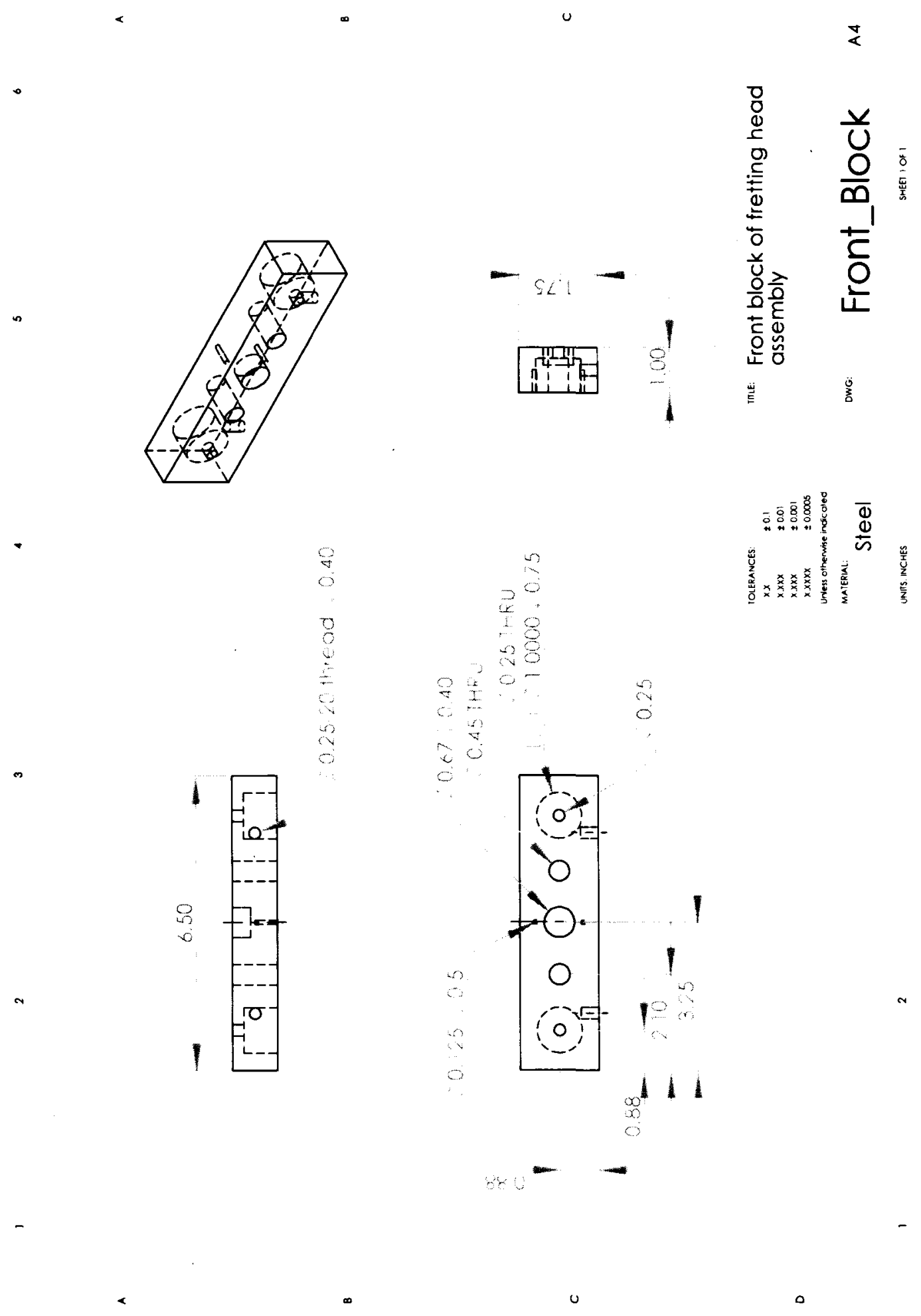




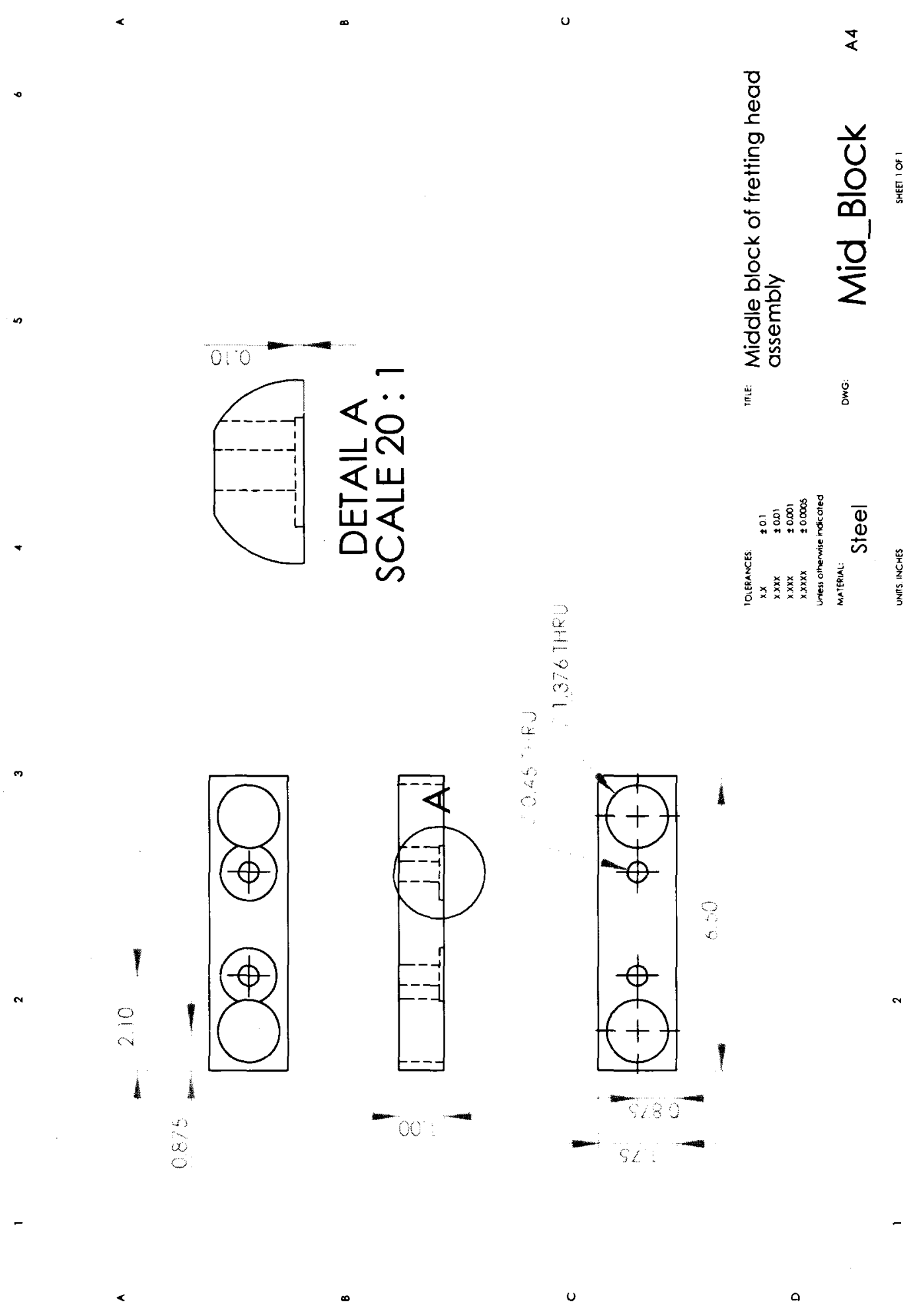




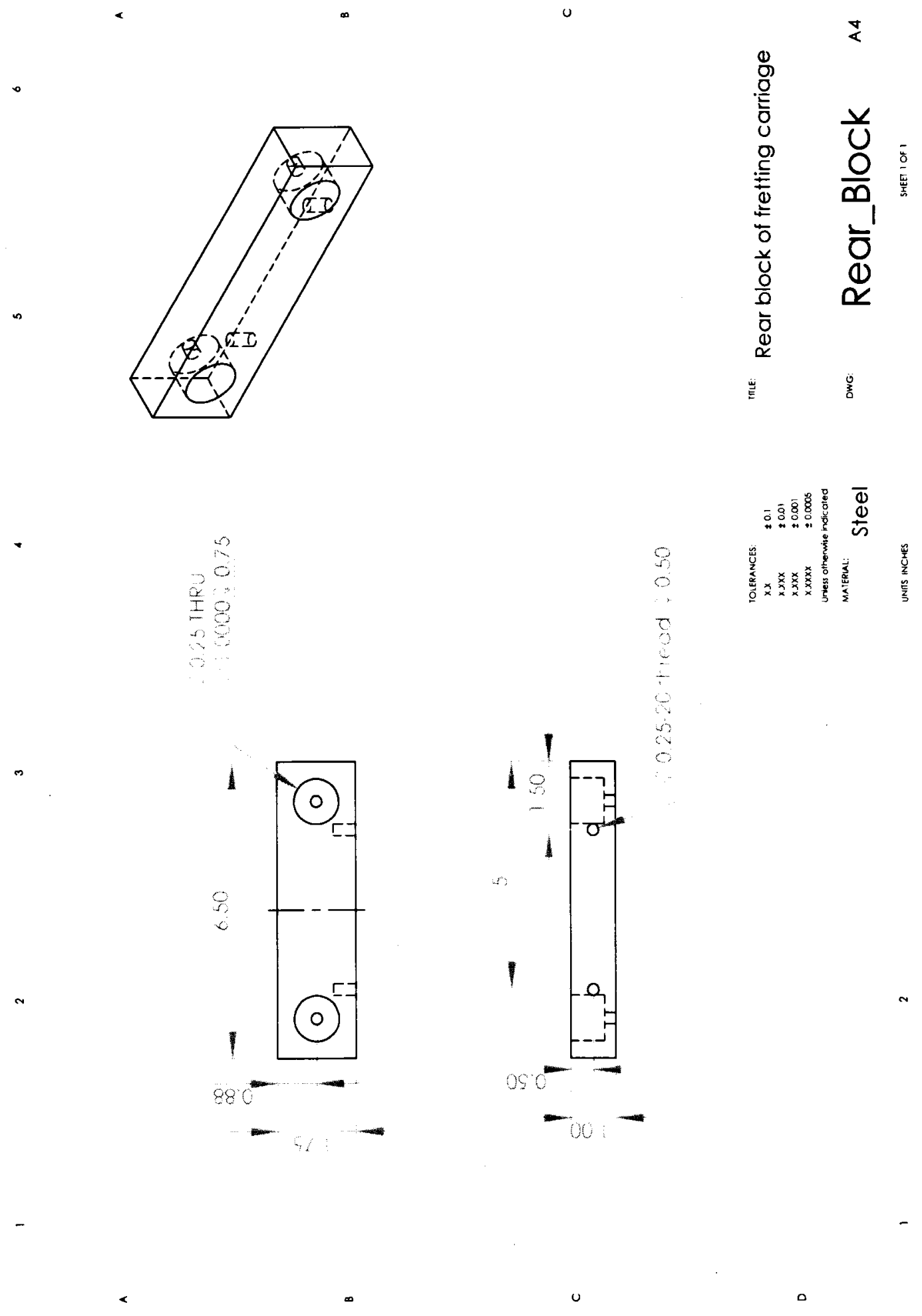




\section{Appendix G - List of Publications}

Brown, A.M. and P.V. Straznicky, "Simulating fretting contact in single lap splices," Accepted for publication in International Journal of Fatigue, July 2008.

Brown, A.M., C.D. Rans and P.V. Straznicky, "On achieving optimal riveted lap joint design for fibre metal laminates," presented at CANCOM, Winnipeg, Manitoba, August 2007.

Brown, A.M., and P.V. Straznicky, "Modelling fretting contact stresses in a single lap splice," presented at ISFF5, Montreal, Quebec, April 2007.

Brown, A.M., and P.V. Straznicky, "Dimple tool modification for press-countersinking GLARE," presented at COM, Montreal, Quebec, October 2006. 